\title{
TWO EMPIRICAL ANALYSES OF THE MINIMUM WAGE IMPACTS ON EMPLOYMENT
}

\author{
A Thesis presented to \\ the Faculty of the Graduate School \\ at the University of Missouri
}

In Partial Fulfillment

of the Requirements for the Degree

Doctor of Philosophy

by

YANDI LIU

Dr. Peter Mueser, Thesis Supervisor

May 2015 
l' Copyright by Yandi Liu 2015

All Rights Reserved 
The undersigned, appointed by the Dean of the Graduate School, have examined the dissertation entitled:

\section{TWO EMPIRICAL ANALYSES OF THE MINIMUM WAGE IMPACTS ON EMPLOYMENT}

presented by Yandi Liu

a candidate for the degree of Doctor of Philosophy

and hereby certify that, in their opinion, it is worthy of acceptance.

Dr. Peter Mueser

Dr. Shawn Ni

Dr. Michael Podgursky

Dr. Cory Koedel

Dr. Rajeev Darolia 


\section{DEDICATION}

I dedicate my dissertation work to my family and many friends. A special gratitude for my husband, Yonghui Li, the most important supporter of my academic life and soul mate of my life, for taking care of everything. Without your love, support and encouragement, I would never have had the strength to accomplish such a major life goal. Thank you for always making me your priority. This dissertation is also

dedicated to my mother, Guilan Li and my father, Xiaoxian Liu. Their words of encouragement and push are very important to me throughout my life. 


\section{ACKNOWLEDGMENTS}

I am most grateful to my advisor, Dr. Peter Mueser for introducing me to the field of labor economics. He led me down the correct path to accomplish this personal and professional goal. He gave me so many valuable advice since beginning and helped me to start from both theoretical and empirical aspects. In addition, the essential methodologies for research that I learnt from him will go on benefit me in my future career. I greatly appreciate his patience, encouragement and countless hours of help throughout the entire journey.

I would like to thank the members of my committee, Dr. Shawn Ni, Dr. Cory Koedel, Dr. Michael Podgursky, and Dr. Rajeev Darolia for their time, encouragement, and expertise. Their thoughtful comments and recommendations are of great help. Special thanks to Dr. Ni, my instructor in research workshop for two years, for his introductions and suggestions of academic research and presentation skills. I also would like to thank Dr. Xinghe Wang, director of graduate studies, for all his kind helps and advice even before I came to Mizzou.

Next, I must thank Chinese Scholarship Council and Nankai University for sponsoring my study in United States. Without this opportunity, I would not have the chance to study abroad.

I would like to thank my fellow graduate students, Ting Wang, So Hyun Joo, Nguyen Doan and Rebecca Whitworth. I will always remember the time that we five girls studied together and encouraged each other. Thanks to Jiaxi Li, Peng Xiang for the discussions regarding the empirical methodologies.

I also want to give special thanks to my friends: Chao Wu, Xue Li, Tianyu Liu, Kuo-Hsuan Chin, Weiwei Wu, Xiang Li, Jiong Zhang, Ka Shen, Yiyao Chen, Yuan Wang. I must also thank Hao Cheng for being my roommate and a close friend. The friendship I have made in Mizzou are long lasting. 


\section{Contents}

ACKNOWLEDGMENTS ................. ii

LIST OF FIGURES ....................

LIST OF TABLES $\ldots \ldots \ldots \ldots \ldots \ldots \ldots \ldots \ldots \ldots \ldots \ldots$

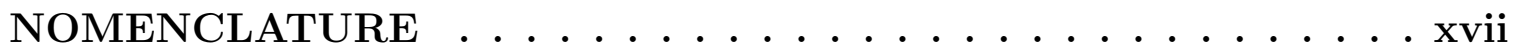

ABSTRACT .................. xix

\section{CHAPTER}

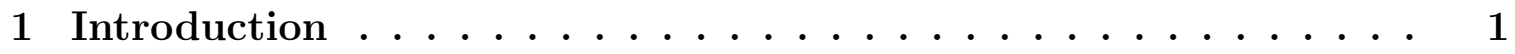

2 Literature Review . . . . . . . . . . . . . . 9

2.1 Background . . . . . . . . . . . . . . . . . . . 9

2.2 Theoretical Framework . . . . . . . . . . . . . . . . . . . . . . . 12

2.2.1 Perfectly Competitive Labor Market Model . . . . . . . . . 12

$2.2 .2 \quad$ Labor Mobility . . . . . . . . . . . . . . . . . . . . 14

2.2 .3 Monopsony Model . . . . . . . . . . . . . . . . . . . . . . 16

2.2.3.1 Static Monopsony Model . . . . . . . . . . . . . . 16

2.2.3.2 Dynamic Monopsony Model with Search Friction (Imperfect Information) $\ldots \ldots \ldots \ldots$ 
2.2.4 Channels of Adjustments . . . . . . . . . . . . . . . 20

2.2.4.1 Substitution Effects__Employment Composition . 20

2.2.4.2 Short-Run vs. Long-Run . . . . . . . . . . . . 20

2.2.4.3 Hours Effects . . . . . . . . . . . . . . . . 21

2.2.4.4 Price Effects . . . . . . . . . . . . . 21

2.2.4.5 Reduction in Non-Wage Benefits . . . . . . . . . 22

2.2.4.6 Wage Distribution . . . . . . . . . . . 22

2.2.4.7 Other Possible Channels of Adjustment . . . . . . . 22

2.3 Empirical Research Methodologies . . . . . . . . . . . . . 23

2.3.1 Natural Experiment — Difference-In-Differences Method . . 23

2.3.1.1 Work by Card and Krueger (1995) . . . . . . . . 23

2.3.1.2 Brief Review of The Methodology . . . . . . . . 26

2.3.1.3 Results of Case Studies . . . . . . . . . . . . 27

2.3.1.4 Difference-In-Differences-In-Differences . . . . . . . . 28

2.3.1.5 Statistical Problems of DID Estimators . . . . . . . 30

2.3.2 Panel Data Analysis . . . . . . . . . . . . . . . 30

2.3.2.1 Earlier Research (1946 to 1992) — Time Series Anal-

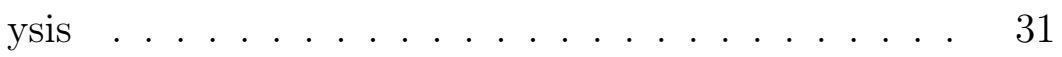

2.3.2.2 Brief Introduction of Panel Data Analysis after 199231 
2.3.2.3 CPS-Based Papers . . . . . . . . . . . . . . . 32

2.3.2.4 Concerns in the Panel Data Analysis . . . . . . . . 34

2.3.3 Common Issues and Other Strategies . . . . . . . . . . 38

2.3.3.1 Binding Minimum Wages . . . . . . . . . . 38

2.3.3.2 Endogeneity . . . . . . . . . . . . . . . 39

2.3.3.3 Lagged and Anticipation Effects . . . . . . . . . . 40

2.3.3.4 Individual-Level Analysis _ . . . . . . . . . . . 41

2.3.3.5 Other Research Strategies . . . . . . . . . . . . 42

2.4 Missouri State Minimum Wage . . . . . . . . . . . . . . 43

3 A Panel Data Analysis Using More Recent CPS Monthly Data • 45

3.1 Concerns in My Study . . . . . . . . . . . . . . . . . . 45

3.2 Model Specification Strategies . . . . . . . . . . . . . 50

3.3 Data . . . . . . . . . . . . . . . . . . . . . . 51

3.3 .1 Data Description . . . . . . . . . . . . . . . 51

3.3.2 Variation in State Minimum Wages . . . . . . . . . . . 53

3.3.3 Data Discrepancy . . . . . . . . . . . . . . . . . . . . 54

3.4 Empirical Results . . . . . . . . . . . . . . . . 56

3.4.1 The Minimum Wage Effect on Teenage Wage Rate . . . . . 56 
3.4.2 Teenage Employment Effect _. . . . . . . . . . . . 57

3.4.3 The Appropriateness of Including Year Effects . . . . . . . . . 59

3.4.4 Lagged Minimum Wage Effects on Employment . . . . . . . 60

3.4.5 Minimum Wage Effects for More Recent Years _. . . . . . . 61

3.4.6 Alternative Macroeconomic Controls . . . . . . . . . . . 62

3.4.7 Corrections for Autocorrelation and Heteroskedasticity . . . . 62

3.4.8 Heterogeneity in Regional Level . . . . . . . . . . . . . . . . 63

3.4.9 Heterogeneity in State Level Time Trends . . . . . . . . . . 64

3.4 .10 Indexation of Minimum Wages . . . . . . . . . . . . . . 64

3.4.11 Interaction with Unemployment Rate . . . . . . . . . . 65

3.5 Summary of the Study . . . . . . . . . . . . . . 66

4 Employment Effects of Missouri State Minimum wage . . . . . 82

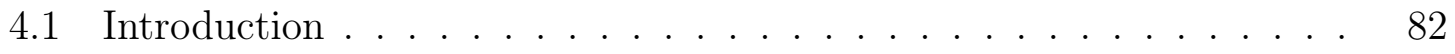

4.2 Missouri Minimum Wage . . . . . . . . . . . . . . . 83

4.3 Data . . . . . . . . . . . . . . . . . . . . 84

4.3.1 Advantages and Limitations of Data . . . . . . . . . . 85

$4.3 .2 \quad$ Data Issues . . . . . . . . . . . . . . . . . . . . . . 86

4.3.3 Missouri Minimum Wage Exemption . . . . . . . . . 88 
4.3.4 Data Description . . . . . . . . . . . . . . . . . . 89

4.3.5 Employment Levels . . . . . . . . . . . . . . . . . . . . . . 92

4.4 Single Wave Difference-in-Differences Employment Estimation . . . . 93

4.5 Firm-Level Regression Analysis of the Employment Effects . . . . . 101

4.5.1 Regression Model Specifications . . . . . . . . . . . . . . 101

$4.5 .2 \quad$ Estimation Results . . . . . . . . . . . . . . . . . . . . 104

4.5 .3 Interpretation of Results . . . . . . . . . . . . . . 108

4.5.4 Robustness Check . . . . . . . . . . . . . . . . . . . . 110

4.6 Individual-Level Regression Analysis . . . . . . . . . . . . . 111

4.6.1 Description of Earnings _ . . . . . . . . . . . . . . 111

4.6 .2 Regression Model . . . . . . . . . . . . . . . . . . . . . . . 114

4.6 .3 Estimation Results . . . . . . . . . . . . . . . . . . 116

4.6.4 Results Summary and Discussion _ . . . . . . . . . . 118

4.7 Regression Analysis Regarding Labor Mobility . . . . . . . . . . 120

4.7.1 Regression Model . . . . . . . . . . . . . . . . . 120

4.7 .2 Estimation Results . . . . . . . . . . . . . . . . . . . . 123

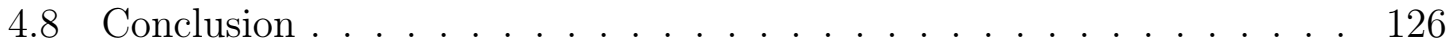

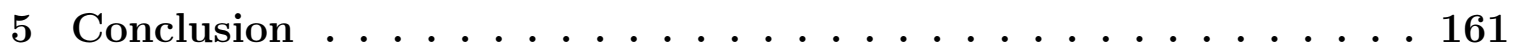




\section{APPENDIX}

A Geographic Codes ..................... 170

A.1 Missouri . . . . . . . . . . . . . . . . . 170

A.1.1 Invalid Codes . . . . . . . . . . . . . . . . . 170

A.1.2 Multiple "County" Codes for One Employer ID . . . . . . . . . 171

A.2 Kansas . . . . . . . . . . . . . . . . . . . . . . . . 172

A.2.1 Multiple FIPS Codes for One Employer ID . . . . . . . . . . 172

A.2.2 Difference in DATA Construction . . . . . . . . . . . . 173

B Industry Codes . . . . . . . . . . . . . . . . 174

B.1 Missouri — NAICS code . . . . . . . . . . . . . . . . . 174

B.2 Kansas — SIC code . . . . . . . . . . . . . . . . . . . 174

B.2.1 Missing SIC Code . . . . . . . . . . . . . . . . . . 174

B.2.2 Converting SIC to NAICS . . . . . . . . . . . . . 175

B.2.2.1 Matching Problems . . . . . . . . . . . . . 175

B.2.2.2 Logic of Consistency Check . . . . . . . . . . 177

B.2.2.3 Revision Procedures . . . . . . . . . . . . 178

B.2.2.4 SIC-NAICS Revision Details . . . . . . . . . . . 179

C Missouri Payroll-to-Revenue Ratio . . . . . . . . . . . . . 181 
D Discontinuous Records . . . . . . . . . . . . . 182

E Restrictions Based on Missing Counties and Industry Codes Conversion for Firm-Level Analysis $\ldots \ldots \ldots \ldots \ldots$

F Bumps in Kansas Border Employment Level Plot $\ldots \ldots$. . . 189

G Procedures to Construct Data for DID Analysis . . . . . . . . . 192

G.1 Missouri Part . . . . . . . . . . . . . . . . . . . . . . . . . . . . 192

G.2 Kansas Part . . . . . . . . . . . . . . . . . . . . . . . . . . 194

G.3 Another Set of DID Results . . . . . . . . . . . . . . . . . 194

H Estimation Results for the DID Robustness Check . . . . . . 195

I Procedures to Construct Multi-Period and Multi-Group FirmLevel Panel Data . . . . . . . . . . . . . . . . 201

I.1 Missouri Part . . . . . . . . . . . . . . . . . . . . . . . . . . . 201

I.2 Kansas Part . . . . . . . . . . . . . . . . . . . . . . . . . . . . 202

I.3 Final Data Set . . . . . . . . . . . . . . . . . . . . . . . . 202

J Regression Results When D4 Group is Omitted . . . . . . . . 203

K Procedures to Construct Multi-Period and Multi-Group IndividualLevel Panel Data . . . . . . . . . . . . . . 210

Bibliography . . . . . . . . . . . . . . . . 213

VITA ......................... 219 


\section{List of Figures}

Figure

2.1 A Binding Minimum Wage in a Perfectly Competitive Market . . . . 13

2.2 Substitution Effect and Scale Effect _. . . . . . . . . . . 13

2.3 Determination of the Optimal Quantity Level . . . . . . . . . . . 13

2.4 Labor Mobility . . . . . . . . . . . . . . . . . . . . 15

2.5 Monopsony Model . . . . . . . . . . . . . . . . . . . . 17

2.6 Monopsony Model with Minimum Wage . . . . . . . . . . 17

3.1 Number of States with Higher Minimum Wages _ . . . . . . . 68

3.2 Average Percentage Difference Relative to Federal Minimum Wages for the States with Higher Minimum Wages _. . . . . . . . 68

3.3 Average Teenage Employment to Population Ratio in Regional Level 80

4.1 Missouri and Kansas Employment Level Plot _ . . . . . . . . . . 129

4.2 Plot of Employment Level for Missouri and Kansas Border Firms after Selecting, with the Corresponding Minimum Wage Changes _. . . 132

4.3 Summary of DID Estimators - Comparisons for Two Sequential Quar-

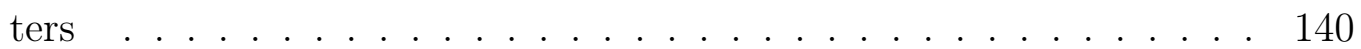

4.4 Summary of DID Estimators - Comparisons of Same Quarters in Two Sequential Years . . . . . . . . . . . . . . . . . . . . . 141

4.5 Employment Level Plot of Four Firm Size Groups . . . . . . . . . . 142 
4.6 Estimation Results Summary for the Firm-Level Analysis . . . . . . 149

4.7 Distribution of Estimated Hourly Wage Rate (Trimmed at \$100) . 151

4.8 Distribution Plots of Initial Estimated Hourly Wages in 2006 Q3 in Relevant Industries . . . . . . . . . . . . . . . . . . . . . . . . . . 152

4.9 Hourly Wage Patterns for Five Earning Groups . . . . . . . . . . . . 153

4.10 Estimation Results Summary for the Individual-Level Analysis . . 156

4.11 Employment Possibility Illustration . . . . . . . . . . . . . . . 157

B.1 Illustration of the SIC-NAICS Consistency Check . . . . . . . . . . . 177

F.1 Employment Level Plot of Johnson and Wyandotte in Kansas . . . . 190

F.2 Employment Level Plot of Leavenworth, Miami, Linn and Franklin 190

F.3 Employment Level Plot of Johnson and Wyandotte after Limiting to No-Multi Location Firms _. . . . . . . . . . . . . . . . . . 191 


\section{List of Tables}

Table $\quad$ Page

3.1 State Minimum Wages that are Higher than the Federal Minimum Wages from 1995 to 2011 on January 1 . . . . . . . . . . . . . . . . 69

3.2 State Minimum Wages are Higher than the Federal Minimum Wages from 1995 to 2011 on January 1 (continued) . . . . . . . . . . . . . . 70

3.3 Description of the Variables Used in the Study . . . . . . . . . . . . . 71

3.4 Minimum Wage Effect on Teenage Wage Rate . . . . . . . . . . . . . 72

3.5 Minimum Wage Effect on the Ratio of Teenage Employment to Teenage Population (January 1979 to December 1997) . . . . . . . . . . . . 73

3.6 Minimum Wage Effect on the Ratio of Teenage Employment to Teenage Population (January 1979 to December 2011) . . . . . . . . . . . . . 74

3.7 One Year Lagged Minimum Wage Effects on the ratio of Teenage Employment to Teenage Population (January 1980 - December 1997) . . 75

3.8 One Year Lagged Minimum Wage Effects on the Ratio of Teenage Employment to Teenage Population (January 1980 - December 2011) 76

3.9 Minimum Wage Effect on Teenage Employment (January 1997 to December 2011) . . . . . . . . . . . . . . . . . . . . . 77

3.10 Employment Effect with Alternative Microeconomic Controls (from January 1979 to December 2011) . . . . . . . . . . . . . . . . . 78 
3.11 Minimum Wage Effect on Teenage Employment after Correction for State-level Autocorrelation and Heteroskedasticity(January 1979 to De-

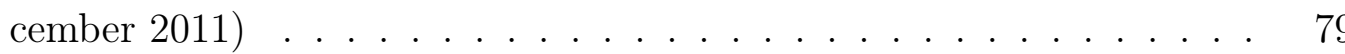

3.12 Minimum Wage Effect on the Teenage Employment Ratio with Year Dummies and Division Specific Year Dummies, from January 1979 to December $2011 \ldots \ldots \ldots$. . . . . . . . . . . . . . . . 80

3.13 Minimum Wage Effect on the Teenage Employment Ratio with Time Trends, from January 1979 to December 2011 . . . . . . . . . . . . . 80

3.14 States with Indexation . . . . . . . . . . . . . . . . 81

3.15 Minimum Wage Effect on the Teenage Employment Ratio with Indexation, from January 1979 to December 2011 . . . . . . . . . . . . . . 81

3.16 Minimum Wage Effect on the Teenage Employment Ratio with Unemployment Interaction, from January 1979 to December 2011 . . . . . 81

4.1 Minimum Wage History in Missouri and Kansas from 2006 to 2012 129

4.2 List of Relevant Terms . . . . . . . . . . . . . . . . . . . . 130

4.3 Descriptions for Border Counties in Missouri and Kansas from 2006 Q3 to 2012 Q1 . . . . . . . . . . . . . . . . 131

4.4 Frequency Check of NAICS Industry Structure . . . . . . . . . . . 133

4.5 Single Wave DID Estimations for the Entire Panel Sample . . . . . . 134

4.6 Single Wave DID Estimations for the Food and Accommodation Industry with 1 to 50 Employees . . . . . . . . . . . . . 135

4.7 Single Wave DID Estimations for the Retail Trade Industry with 1 to 50 Employees ......................... 136

4.8 Single Wave DID Estimations for the Construction Industry with 1 to 50 Employees ......................... 137

4.9 Single Wave DID Estimations for the Manufacturing Industry with 1 to 100 Employees . . . . . . . . . . . . . . . . . . . 138 
4.10 Single Wave DID Estimations for the "Selected Industries Combined" category (Finance, Information and Other Service) with 1-50 Employ-

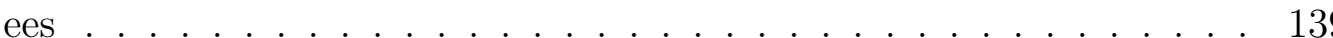

4.11 Estimation Results for Missouri and Kansas Border Firms - Entire Sample ........................ 143

4.12 Estimation Results for Missouri and Kansas Border Firms - Retail Trade ......................... . . 144

4.13 Estimation Results for Missouri and Kansas Border Firms - Food and Accommodation

4.14 Estimation Results for Missouri and Kansas Border Firms - Construction

4.15 Estimation Results for Missouri and Kansas Border Firms - Manufacturing

4.16 Estimation Results for Missouri and Kansas Border Firms - "Selected Industries Combined

4.17 Comparison of Estimation Results Between the Firm Level Regression and the Regression Without D4 Group . . . . . . . . . . . . 150

4.18 Employment Possibility Estimation Results - Entire Sample . . . . . 154

4.19 Employment Possibility Estimation Results - Retail Trade . . . . . . 154

4.20 Employment Possibility Estimation Results - Food . . . . . . . . . . 154

4.21 Employment Possibility Estimation Results - Hotel and Accommoda-

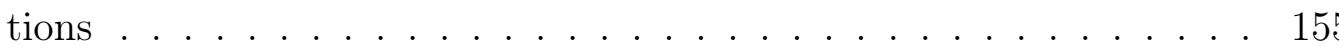

4.22 Employment Possibility Estimation Results - Construction . . . . . . 155

4.23 Employment Possibility Estimation Results - Manufacturing . . . . . 155

4.24 Employment Possibility Estimation Results - "Selected Industries Combined" Category . . . . . . . . . . . . . . . . . . 156

4.25 Labor Mobility Estimation Results - Entire Sample . . . . . . . . . . 158 
4.26 Labor Mobility Estimation Results - Retail Trade . . . . . . . . . . . 158

4.27 Labor Mobility Estimation Results - Food . . . . . . . . . . . . . . . 158

4.28 Labor Mobility Estimation Results - Hotel and Accommodations . 159

4.29 Labor Mobility Estimation Results - Construction ....... 159

4.30 Labor Mobility Estimation Results - Manufacturing . . . . . . . . . 159

4.31 Labor Mobility Estimation Results - "Selected Industries Combined" Category . . . . . . . . . . . . . . . . 160

A.1 Percentages of Some Major Invalid Codes in 2012 Q1 in Missouri Data 171

A.2 Frequency Checks for Kansas County Code . . . . . . . . . . . . . . . 172

B.1 Kansas Frequency Check for SIC Industry Code . . . . . . . . . . . 175

C.1 Missouri Payroll-to-Revenue Ratio, Based on 2007 US Census . . . . 181

D.1 Notations and Meanings for Discontinuous Records Check . . . . . . 183

E.1 Summary Table of the "Missing County" Check and the "SIC-NAICS matching after revision" Check . . . . . . . . . . . . . . . . 187

E.2 Summary of the Restriction Rule . . . . . . . . . . . . . . . . 188

H.1 Single Wave DID Estimations for the Entire Panel Sample with $\$ 400,000$ as the Threshold . . . . . . . . . . . . . . . . 196

H.2 Single Wave DID Estimations for the Food and Accomodation Industry with 1 to 50 Employees and with $\$ 400,000$ as the Threshold . . . . . 197

H.3 Single Wave DID Estimations for the Retail Trade Industry with 1 to 50 Employees with $\$ 400,000$ as the Threshold . . . . . . . . . . . 198

H.4 Single Wave DID Estimations for the Manufactoring Industry with 1 to 100 Employees with $\$ 400,000$ as the Threshold . . . . . . . . . . . 199 
H.5 Single Wave DID Estimations for the "Selected Industies Combined" category (Finance, Information and Other Service) with $\$ 400,000$ as the Threshold . . . . . . . . . . . . . . . . . . . 200

J.1 Estimation Results for Missouri and Kansas Border Firms When D4 Group is Omitted . . . . . . . . . . . . . . . . . . . . . 204

J.2 Estimation Results for the Retail Trade Industry When D4 Group is

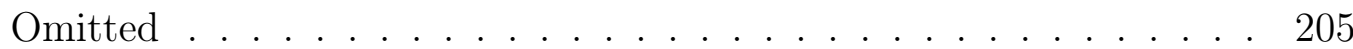

J.3 Estimation Results for the Food and Accomodation Industry When D4 Group is Omitted . . . . . . . . . . . . . . . . . . 206

J.4 Estimation Results for the Construction Industry When D4 Group is

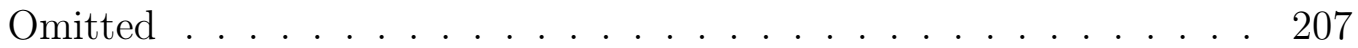

J.5 Estimation Results for the Manufacturing Industry When D4 Group is Omitted . . . . . . . . . . . . . . . . . . . . 208

J.6 Estimation Results for the "Selected Industries Combined" Category When D4 Group is Omitted . . . . . . . . . . . . . . . . . 209 


\section{Nomenclature}

\begin{tabular}{|c|c|}
\hline $\mathrm{CPI}$ & Consumer Price Index \\
\hline CPS & Current Population Survey \\
\hline DID & Difference-In-Differences \\
\hline EITC & Earned Income Tax Credit \\
\hline EMPID & Employer Identification \\
\hline FEDID & Federal Employer Identification \\
\hline FIPS & Federal Information Processing Standards \\
\hline IRS & Internal Revenue Service \\
\hline KS & Kansas \\
\hline MO & Missouri \\
\hline MORG & Merged Outgoing Rotation Groups \\
\hline NAICS & North American Industry Classification System \\
\hline $\mathrm{Q}$ & Quarter \\
\hline SIC & Standard Industrial Classification \\
\hline SSN & Social Security Number \\
\hline
\end{tabular}


Unemployment Insurance

xviii 


\begin{abstract}
The contentious debates regarding minimum wages have produced little agreement so far on the extent to which it affects employment. The dissertation intends to provide a better understanding of minimum wage impacts on employment. The literature review considers both the theoretical models and empirical studies, as well as providing a detailed examination of their methodologies. Two empirical studies form the core of the dissertation. One study estimates the minimum wage impacts using state-level CPS data from 1979 to 2011 in a panel regression framework. The other study explores a natural experiment due to a legislated increase of the minimum wage in Missouri but not in Kansas. Comparing firms in the Kansas City metropolitan area on both sides of the state boundary, the analysis considers minimum wage effects at both the firm-level and individual-level for various groups of firm sizes and different earners. The analysis is performed on multiple selected broad industries. This dissertation finds that in general minimum wage reduces total employment. However, the impacts of minimum wage policy do vary substantially across industries and across groups. Firms with no more than 10 employees and new firms are more likely to experience increase in employment with the increase of minimum wages. In addition, due to substitution effects, people with wages above the minimum wages could get increased chance of being employed from this policy. In contrast, most of the estimates for people who work very few hours are insignificant. However, in the industries with higher proportions of low wage workers, that is, in retail trade and food industries, the probability of being employed for these employees is reduced. The major policy implication is that our empirical findings throw light on the importance of distinguishing between industries and between workers with different earnings.
\end{abstract}




\section{Chapter 1}

\section{Introduction}

Minimum wage is the lowest hourly wage rate that employers must pay to employees. Economists and policymakers have been interested in the effect of a binding minimum wage for a long time. Does an increase in minimum wage reduce employment? Why do some studies find minimum wages do not affect the employment or even find that it encourages employment? Does minimum wage impact differ across industries or across differential earning groups? Research has examined these questions using various data and identification methods, but contradictory results continue to be found. My research is targeted to explore the employment effects of minimum wages. Two empirical studies are discussed in this dissertation. The first one is a state-level panel data analysis using nationwide data from Current Population Survey (CPS). The second one, which is my major focus, checks the impact of Missouri state minimum wage.

One strand of minimum wage papers is based on CPS data. A large number of these papers examine the minimum wage impacts on teenage employment for the following two reasons. First, teenagers have lower skill levels and tend to be lowearning workers. They also tend to work part-time in food, retail trade or other relative low wage industries. Since minimum wage may have stronger effects on low- 
earning worker and in low wage industries, researchers are particularly interested in discussing the effects on teenage employment. Second, teenagers are always linked to their families. So, unlike adults, there is not much state-to-state migration among teenagers in response to their own employment opportunities. In recent years, an increasing number of states have implemented state minimum wages, which provides researchers more variation in minimum wages. The first study will examine the minimum wage impacts on teenage employment using CPS data from 1979 to 2011.

Missouri established a state minimum wage and indexed it to the consumer price index (CPI) beginning in January 2007. In 2006, following the proposal for a state minimum wage in Missouri ${ }^{1}$, there was continuous debates regarding whether Missouri should establish a state minimum wage. Some economists argued that the minimum wage increases would reduce employment opportunities, overwhelming any benefits from a higher wage for low skilled workers. The Kansas City metropolitan area straddles the border between Missouri and Kansas. Two sides of the Kansas City metropolitan area share similar economies and institutions. Unlike Missouri, Kansas has no state minimum wage and so only enforces the federal minimum wage. Implementation of Missouri's minimum wage represents a natural experiment. The close geographic proximity and the availability of data from these two states provide us a valuable opportunity to explore the minimum wage effects on employment in our study. So the second study in my dissertation explores the employment effects of the Missouri minimum wage on both the firm level and the individual level.

My proposal consists of five chapters. The first chapter is the introduction, where I describe research questions and provide a detailed summary. The next chapter is the literature review. In this part, I discuss the theoretical framework of the minimum wage literature, empirical studies and several papers focusing on Missouri state minimum wage. Chapter 3 summarizes the first study, which is the CPS-based

\footnotetext{
${ }^{1}$ Missouri Proposition B (Raising Minimum Wage Act) was approved on November, 2006.
} 
research. The second study regarding the state minimum wage impacts in Missouri is presented in Chapter 4. The last chapter is the conclusion. In addition, several data issues are discussed in the appendix.

\section{Dissertation Summary}

In chapter 2 , first I review the minimum wage research, which covers the three approaches in minimum wage research and the contentious debates over the contradictory results. The second section is the theoretical framework. Alternative models provide explanations for the puzzle of contradictory results. The basic model is the perfectly competitive labor market model. According to this model, a binding minimum wage reduces employment. Substitution effects and scale effects are also discussed here. Then, I summarize Mincer (1976)'s discussion about labor mobility. If we assume not all workers are covered by the minimum wage, the labor market can be divided into covered sector and uncovered sector. When a minimum wage changes, labor moves between these two sectors. In addition, labor moves out of or into the labor market. Theoretically, the direction of the labor movement is indeterminate. But according to empirical studies, the number of workers who move to uncovered sector is always smaller than the number of workers who move out of the labor force.

As a result, the overall employment effects of minimum wages are negative. Next, I discuss the static monopsony model and the dynamic monopsony model with search frictions. These are the two models that suggest there may be no adverse employment effects. The critics of these models and the differences between these two models are also noted. From another point of view, other than changing employment levels, the minimum wage could affect the market in other ways. So the last subsection is the discussion regarding other channels of adjustment. It considers the substitution between labor and capital, the substitution between number of workers and number of 
working hours, changes of output prices, reduction in non-wage benefits, etc.

The next section of the literature review is the discussion of empirical research methodologies. I divide the research strategies into two major types. One is the difference-in-differences (DID) method, and the other one is panel data regression analysis. Both types are discussed in detail. Card and Krueger (1995)'s work starts the new wave of debate and is strongly supportive of minimum wage legislation, so their influential work is discussed first. After their work, I provide a summary of the critics and two follow-up papers. The following subsections provide a general review of the DID method and several empirical results of the case studies. In some cases, difference-in-differences-in-differences is used in the study, so I review two examples of research using this strategy. The last subsection discusses statistical problems of the DID estimators and possible corrections. The other common strategy in the minimum wage literature is the panel data analysis. I first introduce studies from 1946 to 1992, then I briefly summarize the research after 1992. Since a large proportion of panel data analysis uses CPS data, one subsection is a discussion of CPS-based papers. Later, I address some concerns in the analysis, that is, whether it is appropriate to include year effects in the regression, how to control for spatial heterogeneity, and the different ways to deal with federal minimum wage and state minimum wage.

The next section of the literature review is a discussion of some common issues in the minimum wage literature. Since a large percentage of workers are not minimum wage workers, some economists argue that studies looking at the total employment effects for all industries and all workers tend to underestimate the disemployment effects. So I first discuss the importance of identifying workers or industries with binding minimum wages. Then, I discuss the potential endogeneity issues of the minimum wage legislation. When minimum wage increases, employers can substitute capital for labor, and this substitution can require time. Some studies show that without considering the long-run effects, one can not get a complete picture of the 
impact of minimum wages. In recent years, more and more states have implemented indexed minimum wages, so people can anticipate an increase in a minimum wage in the future. Lagged effects and anticipation effects are discussed here. The last subsection is a brief introduction of some other research strategies used in minimum wage literature.

The last section of the literature review is an introduction of Missouri minimum wage policy and relevant studies. Most of these studies suggest that increasing the Missouri state minimum wage does more harm than good. They argue that the Missouri minimum wage would reduce state employment and could not help poor people. However, so far as I know, there is no empirical paper using Missouri data to explore the employment effects of minimum wages. One main purpose of my research is to examine the impacts of Missouri minimum wage using administrative data.

Chapter 3 is my panel data study using state-level data to explore the employment effects of the minimum wages from 1979 to 2011. This chapter is organized as follows. The first section is a general discussion of concerns in this study and my contribution to CPS-based research on the minimum wage. Section 2 is a short introduction of the model specification strategies. In this section, I introduce the basic model and all the specifications I use. The next section provides the data description, which covers the data source, a description of the variables used in my study and two tables showing where state minimum wages are higher than federal minimum wages. Data discrepancies are also discussed in this part. The main section presents the empirical results. First, I check whether a minimum wage increase has impacts on teenage wages. If the impact exists, minimum wages can affect teenage employment. Then, I discuss the minimum wage effects on the ratio of teenage employment to teenage population and the appropriateness of including year effects in the model. In order to capture the long-run employment effects, the one-year lagged minimum wage effects are reported. To check the minimum wage effects in the recent years, I report parallel estimation 
results for the time period from 1997 to 2011. Also, I try to find if there are any other macroeconomic controls that I can use, and I report results after corrections for autocorrelation and state heteroskedasticity. To further explore employment heterogeneity, I include region-specific year effects or state-specific linear time trends in the model. I also check the results when minimum wages have interactions with the unemployment rate. The last section is the conclusion. Generally speaking, I find that the minimum wage effects on teenage employment are negative and significant in nearly all specifications. The employment response is around $3 \%$ for a $10 \%$ increase of the minimum wage.

Chapter 4 lays out my work regarding the employment effects of Missouri minimum wage, which is the major focus of my research. In this chapter, I explore the minimum wage impacts both at the firm level and at the individual level. Section 2 describes my data, including a discussion of both its benefits and limitations, how the panel data sets are constructed. Section 3 presents the single-wave differencein-differences results. We report the DID estimates for both two sequential quarters and the same quarters in two sequential years. For the single wave DID estimation, we get mixed results. In particular, for the first Missouri minimum wage increase in 2007 Q1, most estimates are positive. We argue that the positive effects are due to lack of sufficient controls.

Section 4 in chapter 4 describes the regression identification strategies for the firm level analyses, as well as providing results and interpretation. We divide firms into four groups based on their initial firm sizes at the beginning quarter, 2006 Q3 and perform regressions for several broad industries. We then include firm fixed effects, firm size, time effects and time-industry interaction terms in turns. The estimated overall employment effects after weighting by total employment levels in each group are always negative and significant. Strong negative employment effects are found in the regressions that only control for firm effects and firm size, and from the model 
where county level unemployment rates are substituted for time fixed effects. With time fixed effects, we find moderate and significant overall employment effects in most industries, from $1 \%$ to $5 \%$ decrease in employment with a $10 \%$ increase in minimum wage. When controlling time fixed effects, in food/accommodation and manufacturing industries, the minimum wage impacts are not discernible. Firms with more than 10 employees experience a decrease in employment level when minimum wage increases in all industries. When we use the entire sample or limit data to food and accommodation, retail trade, manufacturing industry, estimates for small business firms with no more than 10 employees are positive, indicating small businesses are encouraged by an increase in the minimum wage in these industries. Other than these industries, the results are insignificant for small businesses. Last group includes firms that do not exist in 2006 Q3, which is the newly emerging firm group. Mixed results are found for this group.

Section 5 and 6 in chapter 4 utilize individual level information in our administrative data by tracking employment status over time. In section 5 , we divide individuals into five groups based on their initial quarterly earnings in 2006 Q3 for the purpose of checking whether minimum wage affects people in different earning groups differently. In the linear probability model, we include individual fixed effects, time fixed effects, seasonal terms and time trend term that are interacted with Missouri state residents. Based on theory, due to the substitution effect, people with higher hourly wage rates experience a greater chance of employment when the minimum wage increases, because employers have an incentive to substitute them for workers whose wages increase. Our estimation results are in line with this expectation. However, we fail to detect discernible impacts for people whose estimated hourly wage rates are between $\$ 1.65$ and $\$ 4.55$. We assume full time workers work 43 hours weekly on average, so quarterly earnings are divided by 512 hours to get the estimated hourly wage rates. If individual's estimated hourly wage rate is lower than $\$ 1.65$, he is very 
likely to work very few hours in the quarter instead of earning such a low hourly wage. Our results suggest that in retail trade and food industry, minimum wage increases declines these individuals' possibilities of being employed. Other than these two industries, the estimates are insignificant. In section 6 , we check whether patterns of labor mobility are affected by Missouri minimum wage. If our data do have the power to detect minimum wage effects, we would find that for Missouri residents, increases in the Missouri minimum wage decreases the chance of employment in Missouri and raise the possibility of finding jobs in Kansas. In contrast, Missouri minimum wage would increase the probability of employment for Kansas residents and decrease their chances of getting jobs in Missouri. The estimates do have the expected signs.

The last chapter of this thesis is the conclusion. In this chapter, I briefly summarize the work I have done and discuss the main findings. My original contributions to the minimum wage literate and the policy implications are also discussed. Further research possibilities are introduced as well. Last but not least, after the bibliography, several appendixes are attached to discuss how we address the data issues and construct the panels used. 


\section{Chapter 2}

\section{Literature Review}

\subsection{Background}

Generally speaking, there are three branches of the minimum wage literature. The dominant strand examines the employment effects of minimum wages. Economists use different empirical data to reveal the relationship between minimum wage increases and employment levels. A large number of papers show that increasing the minimum wage results in a reduction of employment. These results are consistent with the competitive labor market model. On the other hand, some papers challenge the conventional results, finding that there is no adverse employment effect. Some studies even find positive employment effects. The most contribution from this side is a book written by Card and Krueger (1995), which is discussed in detail later. Starting with their work, there has been extensive debates regarding to minimum wage effects on employment.

The second strand examines the hours effects of the minimum wages. When the minimum wage increases, employers can also adjust the number of hours each employee works. Employers can either reduce the average hours worked for all workers or increase working hours of remaining workers to make up for the loss of employment. 
Some economists argue that without examining the hours effects, the employment effects can not give a complete picture of the change of labor demanded due to minimum wage increases (Couch and Wittenburg (2001)). Some authors suggest that the small minimum wage effect is due to the exclusion of hours effects. Couch and Wittenburg (2001) use state level data and find that minimum wages decrease the total hours worked by teenagers. However, the results of Zavodny (2000) do not indicate adverse hours effects, suggesting that firms do not reduce the hours worked by teenagers. A recent paper by Sabia (2009a), based on monthly CPS data, finds that minimum wages have moderate adverse effects on employment and weekly hours worked in the retail industry.

The last strand examines other consequences or beneficial effects of the minimum wage increase from several policy prospectives. These consequences include but are not limited to the wage distribution, schooling for teenagers and working experience accumulation. People would like to understand whether minimum wage legislation is an effective way to raise income in low-income families and to reduce poverty, which are central goals of the legislation, or to check other beneficial effects. Back to 1946, Stigler (1946) argued that the 1939 minimum wage increase would not reduce poverty efficiently. Sabia and Burkhauser (2010) find that state and federal minimum wage increases have had no effect on state poverty rates in recent years. There are several reasons why the minimum wage increases may not reduce poverty. First, for those people whose earnings are below the poverty-line, most of them have wage rates above the minimum wage. Their earnings are relatively low because they work fewer hours than others. A large proportion of minimum wage workers are teenagers, and they do not necessarily live in poor families. These teenagers may not be permanent low wage workers, since most of them will finish high school and get a college education. In addition, because of the adverse employment effect, increasing minimum wages crowds out some less skilled workers and makes them jobless. These people should 
be a primary target of the minimum wage, but they may not benefit from it. So economists argue that minimum wage legislation has a very limited impact on poverty. In most cases, a direct income transfer (for example: EITC) is better than an indirect one, such as the minimum wage. From another point of view, Neumark and Nizalova (2007) study the longer-run labor market effects of minimum wages for workers who were subject to minimum wages at young ages. Their empirical results indicate that minimum wages have negative longer-run effects, which is even more serious than the short-run effects. For teenagers, the longer they are exposed to minimum wages, the less they earn in late 20's. Because of the adverse employment effects, young workers would experience reduced tenure and skill/experience accumulation. The minimum wage could also discourage school enrollment and reduce the time teenagers stay in school. Neumark (2006) further stresses that higher minimum wages could reduce training, schooling and work experiences. Without such human capital investments, it is even more difficult for a low wage worker to find a higher-paid job. In contrast, study from Cardoso (2011) suggests that higher minimum wages do not jeopardize young workers' future labor market outcomes.

Since Stigler (1946), many economists agree that minimum wages can reduce employment. There are a large number of papers supporting such effects, which are consistent with the competitive model predictions. However, this result was challenged in 1990s. Research based on a variety of approaches argued that there was no adverse employment effect. In some papers, positive and statistically significant impacts of the minimum wage on employment were found. Katz and Krueger (1992) studied the federal minimum wage increase in 1991 in the fast-food industry in Texas. Using survey data, they find a significantly positive effect of minimum wages on employment. Among papers finding no adverse effect, the most influential and important work is by Card and Krueger (1995). In their book, "Myth and Measurement: The New Economics of the Minimum Wage," they re-evaluate some previous time-series 
research regarding teenage employment and report results from some case studies of the minimum wage increases. The most famous study is the case study in the fastfood industry in New Jersey and Pennsylvania. Based on theses studies, their bottom line is that there is little evidence in support of adverse employment effects. The contentious debate has continued since then. Research has examined the question using various data and various identification methods, but contradictory results continue to be found.

\subsection{Theoretical Framework}

This section discusses the theoretical part of the minimum wage literature. The alternative theoretical frameworks provide different angles to uncover the puzzle of the controversial results.

\subsubsection{Perfectly Competitive Labor Market Model}

If the labor market is a perfectly competitive market and the minimum wage is set

above the equilibrium wage, the minimum wage is the price of labor. In Figure 2.1, from supply and demand analysis, more labor is supplied than demanded at this higher wage, which creates a surplus of labor. Due to this binding minimum wage, employers tend to increase the use of capital, hire fewer workers or reduce their working hours. These changes result in a decline in employment.

Suppose there are only two inputs, capital and labor. Figure 2.2 illustrates the change of labor and capital when the minimum wage increases. The original level of the isoquant curve is $q_{1}$ and the original level of the isocost line is AA'. Increasing the cost of labor has two effects. One is the substitution effect, which drives down the use of labor and increases the use of its substitute (capital), holding the output level constant. It is shown in Figure 2.2 by the movement of isocost lines from AA' to BB' 


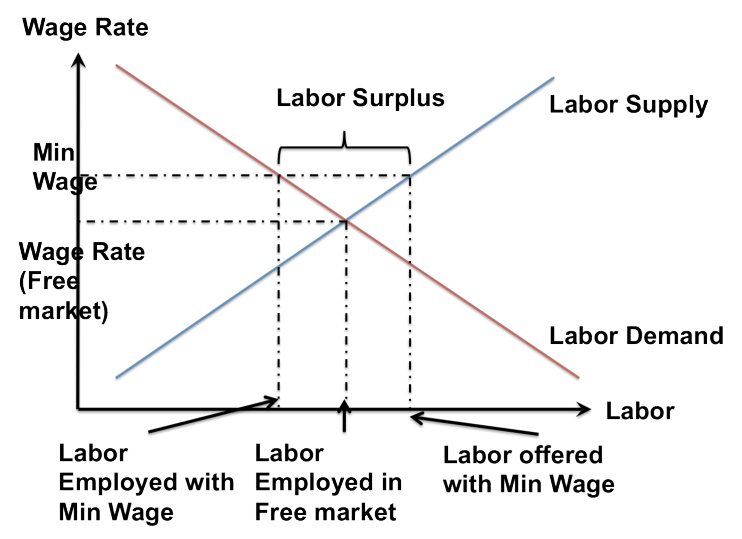

Figure 2.1: A Binding Minimum Wage in a Perfectly Competitive Market

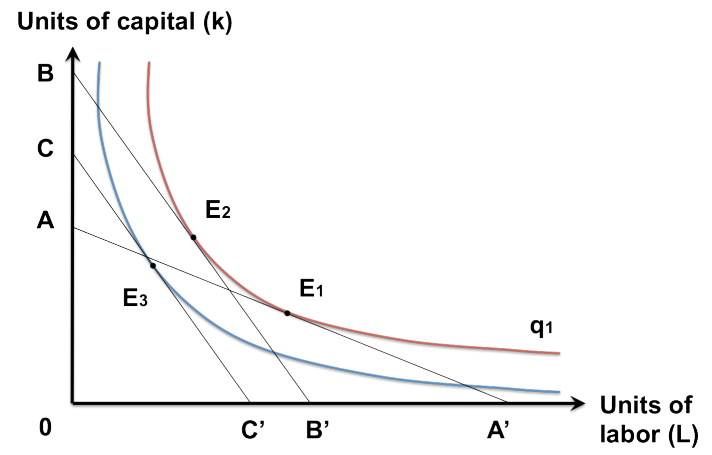

Figure 2.2: Substitution Effect and Scale Effect

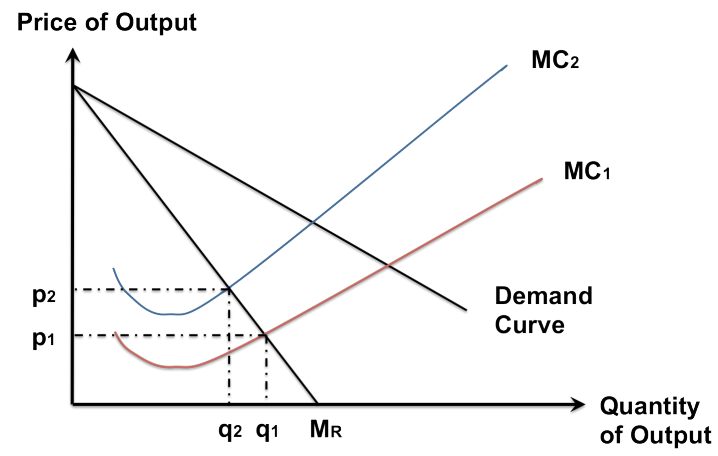

Figure 2.3: Determination of the Optimal Quantity Level 
and by the change of tangent point from $E_{1}$ to $E_{2}$. There is also a scale effect. The costs of producing are higher, so the marginal costs of producing have increased as well. In order to maximize the profit, firms must reduce their outputs. This is shown in Figure 2.3, in which the marginal cost curve moves from $M C_{1}$ to $M C_{2}$. To make $\mathrm{MC}=\mathrm{MR}$, an increase in marginal cost leads to a decrease in the level of quantity produced, from $q_{1}$ to $q_{2}$. Holding everything else constant, this change of quantity level shifts the isocost line BB' to $\mathrm{CC}^{\prime}$ in Figure 2.2. The new tangent point is $E_{3}$. This scale effects drives down the units of labor further. This perfectly competitive market theory is the basic theory that supports the argument of negative employment effects of minimum wages.

\subsubsection{Labor Mobility}

There are several other theories in support of the adverse employment effects. Labor mobility is one of them. In many cases, not all industries or sectors are covered by the minimum wage laws. Some sectors are exempt from the minimum wage. For example, in Missouri, if a firm's annual gross income is less than $\$ 500,000$, it is exempted from the state minimum wage. Mincer (1976) provides both theoretical and empirical analysis to discuss the labor mobility between covered and uncovered sectors. He shows that increases in the minimum wage causes workers to leave the market as well as inducing unemployment, so that unemployment is always less than the excess supply of labor. To simplify the model, suppose there are two sectors in the labor market, one covered by minimum wage legislation, and the other the uncovered sector. The uncovered sector behaves like the perfectly competitive market, so unemployment does not exist in this sector. The outflow of labor is shown in Figure 2.4, $W_{o}$ and $E_{o}$ are the initial equilibrium wage rate and employment level in the covered sector. When the minimum wage rate $W_{m}$ is imposed, the labor demanded level falls to $E_{m}$. Mincer shows that the intersection of labor supply curve and line MR determines 


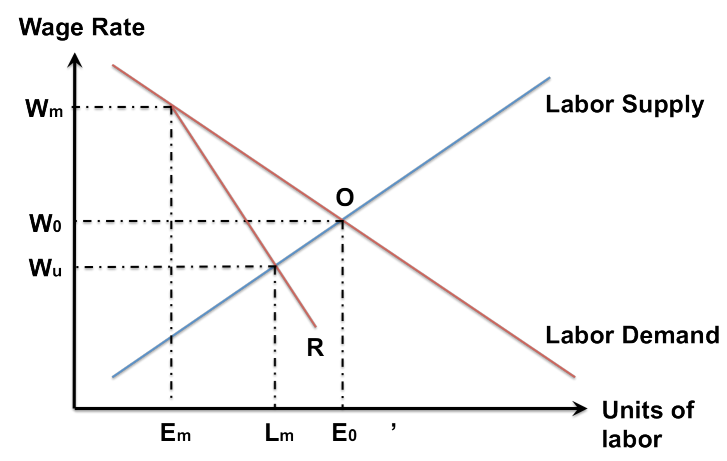

Figure 2.4: Labor Mobility

the wage rate in the uncovered sector $W_{u}$ and the employment level in the covered sector $L_{m}$. Since $W_{m}$ is higher than $W_{u}$, it is worth waiting and finding a job in the covered sector. The unemployment is $L_{m}-E_{m}$, which measures the number of people who show up but cannot find a job. The disemployment effect is $E_{0}-E_{m}$, which measures the reduction in employment. $E_{o}-L_{m}$ is the number of workers who move out of the covered sectors. These workers either go to the uncovered sectors or move out of the labor market. When labor flows to the uncovered sector, the wage rate in the uncovered sector falls. More workers are demanded in this competitive market, so some fraction of $E_{o}-L_{m}$ is absorbed and the rest leave the labor force. What discussed above is the outflow of labor from covered sector to uncovered sector or move out of labor force. In theory, if MR' line is above the demand curve, labor mobility could be the opposite case, which is the inflow of labor, from uncovered sector to the covered sector or movement into the labor force. In summary, minimum wages can generate labor mobility between covered sectors and uncovered sectors, and between the labor market and non-market activities. Theoretically, the direction of the mobility is not predictable. However, Mincer provides empirical evidence showing that the unemployment is always smaller than the disemployment effects. As a result, the overall effects of minimum wages on the labor force are negative. 


\subsubsection{Monopsony Model}

\subsubsection{Static Monopsony Model}

In a perfectly competitive labor market, an increase in minimum wage always reduces the units of labor demanded. However, these conventional results are challenged by some economists. They argue that a minimum wage can actually increase the level of employment. Their arguments are supported by the monopsony model. Monopsony occurs when a single buyer faces a large number of sellers in the market. This single buyer has some market power to control the price. There are several differences between a competitive market and a monopsony market. In a perfectly competitive labor market, individual firms face a perfectly elastic labor supply curve. While, in a monopsony market, the labor supply curve is upward sloping. In a competitive market, the marginal cost of labor equals the wage rate. But if the firms have some monopsony power, the marginal cost of labor exceeds the wage rate. As shown in Figure 2.5, the marginal cost curve $(M C)$ is above the labor supply curve. Because of diminishing marginal return of labor, the marginal revenue product of labor $\left(M R P_{L}\right)$ is a downward sloping curve. In order to maximize profit, $M C_{L}=M R P_{L}$, which is point $\mathrm{A}$ in the figure. The monopsony outcomes are represented by this point, with wage rate $W_{m s}$ and $L_{m s}$ units of labor. The efficient outcome is represented by point $\mathrm{C}$, with higher labor level than the monopsony outcomes. The shaded area ABC is

the deadweight loss due to monopsony power. A minimum wage $(M W)$ increase is imposed in Figure 2.6. it is binding and higher than the monopsony wage rate. The marginal cost is constant up to point $\mathrm{D}$, the intersection of the minimum wage line and the labor supply curve. The new profit-maximizing level of outcome is point D. The new employment level $L_{M W}$ is higher than before. The new marginal cost curve includes two parts, the bold horizontal line and the bold upward sloping line. The marginal cost of labor is actually decreased, so the firm maximizes profits with a 


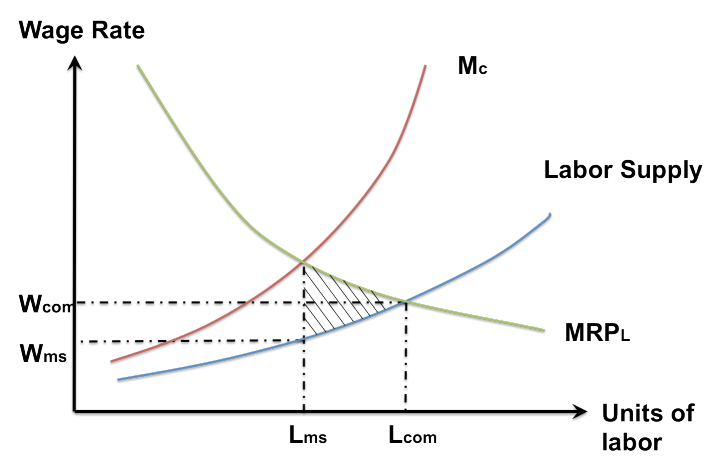

Figure 2.5: Monopsony Model

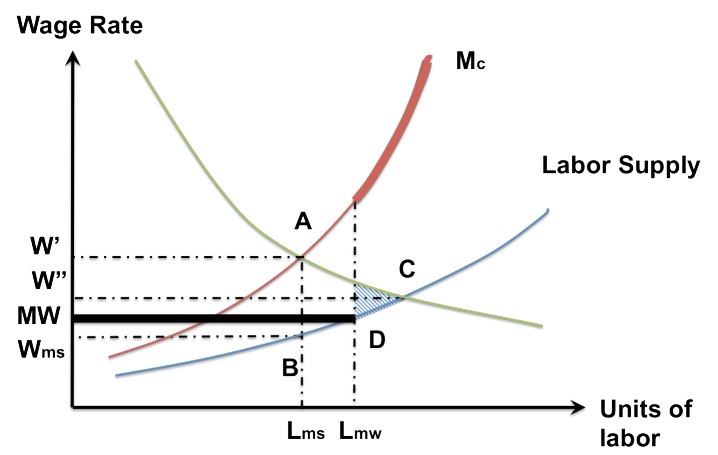

Figure 2.6: Monopsony Model with Minimum Wage

higher level of employment. In addition, the shaded deadweight lost shrinks as well. As a result, some economists argue that minimum wage is good for the economy, since it can increase employment levels and improve social welfare. However, if the minimum wage rate exceeds $w^{\prime \prime}$, the employment level actually decreases, although employment does not fall below the monopsony level until wage rate exceeds $w "$. To summarize, if firms have some monopsony power, increasing minimum wages can cause the employment level to rise, fall, or remain constant, depending on the size of the increase.

When this monopsony model is used to predict effects of the minimum wage increases, critics note several difficulties. First, low-wage industries, which are more likely to be influenced by the minimum wages, are unlikely to have monopsony power. Firms with monopsony power are those that hire a large proportion of labor in a market, whereas low-wage industries, such as fast-food and retail industries, gener- 
ally consist of many small firms with few employees. Second, in the long run, the labor supply curve, even to an apparent monopsony, may not be upward sloping. Firms have monopsony power because of imperfect information, search friction or geographic barrier, etc. However, in the long run, these conditions may not exist or they may become weaker. In order to keep the employees from moving to other firms or industries, employers need to pay wages approaching the competitive rate. The labor supply curve becomes flatter. As a results, the employment level may raises in the short run, but falls in the long run when the conditions for monopsony diminish. Third, it is hard to explain why minimum wage workers are in the monopsony markets. Common examples of monopsony models are mining towns, professional sports leagues and the market for professors, etc. Ashenfelter et al. (2010) summarize several papers that measuring the monopsony power by estimating the elasticity of labor supply. The monopsony power is found in labor markets for teachers and nurses. The problem is that most of these occupations are not minimum wage jobs. Fourth, the monopsony model is usually simplified as a single firm in the market. It is less applicable to an industry, or several industries. When minimum wages are imposed, even if some firms with monopsony power increase their employment levels, the total employment level may fall or remain constant. Last but not least, if the employment rises as the minimum wage increases, the output level should rise and the output price should fall. However, so far there is little evidence supporting this argument. Rather, studies often find that output prices do not adjust to the minimum wage increase or the prices actually increase. Powers (2009) is an example of these studies.

\subsubsection{Dynamic Monopsony Model with Search Friction (Imperfect In- formation)}

Dynamic monopsony models could also explain the empirical findings of no adverse employment effect of the minimum wage. Card and Krueger (1995) argue that the 
monopsony power in the low wage industry is due to the imperfect information. In a competitive market, people have perfect information about the job opportunities. Employers could lose all the workers if the wage rate is lower than other employers and they could fill out the openings rapidly by offering the prevailing wage in the market. In a monopsony market with imperfect information, employees only have limited information about job openings. If the wage rate is lower than the market price, employers could lose workers, but they do not lose all workers at once, because workers need sometime to receive better offers. If the wage offer is above the market price, employers may not find all the desired workers, since the job opportunities are the information available to only a proportion of the potential employees. To overcome the search frictions, which are due to the imperfect information, employers either pay a much higher wage or wait for a longer time to recruit new workers. From this point of view, an increase in minimum wages could attract more workers and induce higher employment levels.

The dynamic monopsony model is more practical, comparing with the basic monopsony model theory, which applies to the market with only one or two firms, since the dynamic monopsony model could explain the situation that there are many competitors existing in the labor market. As long as the search friction (imperfect information) exists, firms have some wage setting powers. Burdett and Mortensen (1989) proposes a equilibrium wage setting model. Unemployed workers have different reservation wages. An increase in minimum wages could increase employment, since the higher wage is more likely to be above workers' reservation wages. In addition, a large proportion of the increased employees are from the initially smaller or lower wage industry. 


\subsubsection{Channels of Adjustments}

When minimum wage increases, firms experience higher costs. One response is to reduce employment. There are also other factors for the employers to adjust in response of higher costs. This subsection discusses several possible channels of adjustments that could absorb the costs.

\subsubsection{Substitution Effects_-Employment Composition}

Suppose there are two types of workers with different productivities, high-skilled and low-skilled workers. These two types of workers are substitutes. With the imposing of higher minimum wage, employers tend to replace low-skilled workers with highskilled ones. If this is a case, the employment for low-skilled workers is reduced, but the total employment level is ambiguous without further assumptions.

\subsubsection{Short-Run vs. Long-Run}

As discussed in section 2.1, suppose there are only two inputs in the production, labor and capital. When the minimum wage increases, labor cost increases, employers can substitute advanced macherinary for low-skilled workers. However, capital is the fixed input in the short-run, it needs some time to adjust. Without taking long-run substitution between labor and capital into account, the employment effect would not capture the complete minimum wage effect. Usually, the long-run effect is larger than the contemporaneous effect. It can explain why most non negative effects are derived from the models that do not account for employment adjustments. To incorporate the longer-run minimum wage effect, economists include a one year lagged minimum wage in their models. However, some economists argue that longer-run effects are not likely to occur. Card and Krueger (1995) argue that because of the high turn over rates in fast food industry and the time length between announcement and effective date of the minimum wage legislation, long-run effects are not likely to occur. 


\subsubsection{Hours Effects}

Another substitution is between the number of hours each employee works and the number of employees hired. Instead of reducing employment levels, employers can either reduce the average working hours for all workers. They can also increase the working hours of remaining workers to make up for the loss of employment. Some economists argue that the small minimum wage effect is due to the exclusion of hours effects.

\subsubsection{Price Effects}

In the competitive model, if the minimum wage increases cost, the firm's total production level would fall as well. As a consequence, the market supply would decrease, which causes an increase of the output prices. In this case, the cost of increasing the minimum wage is partially passed to the consumers. However, if there are some firms competing with minimum wage firms that themselves pay their workers above the minimum wage, since the minimum wage is not binding for these firms, with higher output prices, these firms could benefit from the increase of the minimum wage by earnings more profits. Although minimum wage firms would reduce employment or withdraw from the market, the competing firms could raise employment. The total employment effect is indetermininant.

Aaronson et al. (2007) estimate how the output prices respond to minimum wage increases in restaurant sector. Their results are that both store-level and aggregated county-level output prices rise with increasing minimum wages. They provide a general model of employment determination to show that employment is always negatively related with the output price in markets with monopsony power. As a results, their estimates of output prices explicitly imply that minimum wages reduce the employment level. 


\subsubsection{Reduction in Non-Wage Benefits}

From another point of view, a minimum wage could reduce the non-wage benefits, so that the workers are no better off. These non-wage benefits can be health insurance, pension, vocation or job training. Workers, especially low skilled worker would like to finance job trainings by accepting lower wages. With a binding minimum wage, employers is likely to reduce job trainings, which might prevent these workers to accept the low wages.

\subsubsection{Wage Distribution}

Minimum wage also might affects high wage earners, although these workers are not directly affected by the minimum wage. If we assume wage rates are determined by workers' productivities. Low wage workers and high wage workers have different productivity levels, so that they have different wage rates. If these two kinds of workers are gross substitutes, increasing in the minimum wage would reduce the employment of low wage workers and increase the employment of high wage workers. In this case, high wage workers could be compensated with higher wage. It these two kinds of workers are gross complements, higher minimum wage would lower their employment levels. Because of increasing cost, employers tend to cut the salaries or bonus for high wage workers. Consequently, the wage distribution in the firm is compressed.

\subsubsection{Other Possible Channels of Adjustment}

There are some other possible channels of adjustments. In response to a minimum wage, employers are expected to increase demands on workers. Minimum wage in one sector could increase the demand of substitutes in another sector. Higher minimum wages are more likely to keep workers in the firms and to increase the possibility of attracting new workers. 
Schmitt (2013) summarizes recent minimum wage studies and examines eleven possible channels to absorb the increased cost from the increase of minimum wages. According to his study, the most important adjustment channels are to reduce labor turnover rate, to increase managerial attention, to slightly reduce high wage earners' earnings, and to moderately increase product prices.

\subsection{Empirical Research Methodologies}

The common empirical research strategies and methodologies in the minimum wage literature are discussed in this section. Two major parts of this section are the two major research methodologies used to estimate the employment effects of minimum wages. One is the difference-in-differences (DID) method, and the other one is the panel data regression analysis. At the end of the section, other strategies and some common issues in the minimum wage research are considered.

\subsubsection{Natural Experiment —— Difference-In-Differences Method \\ 2.3.1.1 Work by Card and Krueger (1995)}

Since minimum wage research was greatly influenced by Card and Krueger (1995), their research is discussed first. In their book "Myth and Measurement: The New Economics of The Minimum Wage," they reported the results for two case studies and re-evaluate several previous time-series analyses of teenage employment. Their bottom line is that there is little evidence to support the claim of adverse employment effects. Their most famous study is the case study in the fast-food industry in New Jersey and Pennsylvania. On April 1, 1992, the New Jersey state minimum wage was increased from $\$ 4.25$ to $\$ 5.05$, while, at the same time, there was no minimum wage change in the neighboring state, Pennsylvania. They collected survey data from fast-food restaurants in these two states, using them as a natural experiment with 
New Jersey as the treated case and Pennsylvania as the control case. There were two waves of the survey. One was in February 1992, which was right before the minimum wage increased. The other wave was in March 1993, less than one year after the increase. They used the DID method in an attempt to ensure that the estimated employment effects were only due to the minimum wage changes. They found that there was no effect on employment, and in some model specifications, they got positive effects, although the estimates were not statistically significant. In addition, they also provided a theoretical model to support their results. They argued that there was some monopsony power in the fast-food industry, which is due to informational imperfections.

Their work challenged the conventional conclusions. It has been criticized for various reasons. In order to use the DID method, there are some assumptions that have to be satisfied. The first one is that time 1 should be sufficiently before the time of policy intervention to make sure that no adjustment can be made prior to time 1 . Otherwise, DID cannot capture the true treatment effect. The second assumption is that time 2 must be sufficiently long after the time of intervention to make sure to capture the entire effect. The last assumption is that, without this treatment, the differences between control group and treatment group should be the same in two periods. If this assumption fails, the control group may not be a valid one.

Regarding their work, the second wave of the data was gathered less than one year after the effective date of the minimum wage. Card and Krueger asserted that the employment effect could be captured in such a short period for two reasons. One was that people already knew that there would be an increase of state minimum wage several months before the effective date, so they should have enough time to respond. The other reason was the high turn-over rates in the fast-food industry, so that there was no need to wait for a longer period. However, some economists still argue that their data were too short run to capture important minimum wage effects, 
especially the substitution between labor and capital. It is argued that if Card and Krueger could have taken this longer run effect into account, most likely they would have found adverse effects. Second, it has been questioned whether their study is really a "natural" experiment. The first wave was surveyed in February 1992, which was only one month before the effective date on the legislation. Although Card and Krueger believed that the anticipation effect was negligible because the high turnover rates, there is still no way to guarantee there was no adjustment before the first wave. If people have already responded to the new minimum wage before the first wave, this experiment cannot reveal the true employment effects. Critics also question the possibility of monopsony power in such a high turnover industry and they question the quality of the telephone survey data. It is shown in Neumark and Wascher (2000) that severe measurement errors exist in the data. In addition, since Card and Krueger's case study is limited to the fast-food industry, some economists note that this sub-sector of the economy may not respond as does the full economy. The fast-food industry may not even be a representative of the entire eating and drinking sector. Fast-food and table-service restaurants are substitutes. If fast-food restaurants benefit due to minimum wage increases, the table-service restaurants may actually lose market share and experience job loss. If this is the case, it is hard to predict the employment effect in the entire sector, let alone the entire economy.

Two follow-up papers of Card and Krueger (1995) need to be mentioned. In 2000, Neumark and Wascher (2000) published a paper on the case study in New Jersey and Pennsylvania. Instead of survey data, they used administrative payroll data covering a subset of the restaurants as in the Card and Krueger's study. They showed that the survey data suffered from severe measurement error and were more variable than the payroll data. Card and Krueger used number of workers to construct FTE (full time equivalent) as the measurement of the employment, whereas Neumark and Wascher used the total number of hours worked. Their re-evaluation of the effects of the 
state minimum wage increase in New Jersey in 1992 found that the minimum wage increase caused a decline in employment in New Jersey. Card and Wittenburg (2000) provided a reply to Neumark and Wascher's study. They used the Bureau of Labor Statistics (BLS) employer-reported data to replicate their case study and examined the effect of the 1996 federal minimum wage increase. According to their results, although some individual fast-food restaurants might benefit or lose employment, the New Jersey state minimum wage had little or no effects on the total employment of state fast-food sector. These results were consistent with their previous study, but the positive estimates in this paper were smaller. They pointed out problems of the payroll data used by Neumark and Wascher (2000). Since these data were provided by Employment Policies institute (EPI), which was supported by fast-food industry, EPI might well be more likely to provide data from restaurants which lost employment after the minimum wage increase, that is, selection bias may exist.

\subsubsection{Brief Review of The Methodology}

DID is a common method to identify the employment effects for a specific state minimum wage increases. It is straightforward and provides an easy way to avoid some endogeneity problems. The simplest case is two group/two period analysis. Suppose there are two groups $g=1,2$ and two periods $t=1,2$. $i$ represents each observation and $y$ is the outcome. One group $g_{1}$ experiences the minimum wage increases in $t_{2}$ and the control group $g_{2}$ does not. These two groups have everything in common except the minimum wage. DID examines the treatment effect before and after the minimum wage is effective. DID estimator can be express as:

$$
\begin{aligned}
& \quad \delta=\left\{E\left[y_{\text {igt }} \mid g=1, t=2\right]-E\left[y_{\text {igt }} \mid g=1, t=1\right]\right\}-\left\{E\left[y_{\text {igt }} \mid g=2, t=2\right]-E\left[y_{\text {igt }} \mid\right.\right. \\
& g=2, t=1]\}
\end{aligned}
$$

Case studies usually use this method and focus on the minimum wage effects in a particular state or industry. These case studies are more likely to find small or 
no adverse employment effects. One advantage of DID is that by taking differences, researchers can get the treatment effect without worrying about other economic factors. The case studies of the minimum wage using DID methods are always criticized in terms of the assumption as discussed above. One additional major criticism of this method is that case studies focus on narrow industry or state, but no economic theory can predict what happens in a particular industry. In effect, such results have low external validity and can not be used to answer the general questions "what are the employment effects of minimum wage legislation?"

\subsubsection{Results of Case Studies}

Singell and Terborg (2007) explored the minimum wage changes in Oregon and Washington. Oregon raised the state minimum wages in three successive years from 1997 to 1999. Washington raised the state minimum wages in 1999, 2000 and 2001. They examined the employment changes in different sectors and found negative employment effects in the eating and drinking sector. In the hotel and lodging sector, the disemployment effect was not found, which the authors argued was because the minimum wage was not likely to be binding.

Dube et al. (2007) estimate the effects of a citywide minimum wage in San Francisco (SF). They compare San Francisco with neighboring Alameda County. This panel survey study includes data for both table-service and fast-food restaurants. They find that the citywide minimum wage has no negative impact on the employment levels or hours. There are four different control groups in their study: the restaurants in Almeda, the restaurants in SF that originally paid higher than the minimum wage, the small restaurants (4-8 current workers) in SF that are exempt from the minimum wage, and all these controls together as another group. Besides simple DID estimation, they also introduce a measure of the treatment as "treatment intensity," which is the percentage of workers whose hourly wage rates were less than 
the new minimum wage prior to the increase in the affected restaurants. This paper finds that the minimum wage increase did not reduce the employment level in the affected restaurants.

Antonova et al. (2009) include two sets of state comparisons and focus on the food industry. One compares employment in Vermont with New Hampshire, the other compares Illinois and Indiana. Vermont and Illinois both experienced minimum wage increases during 2005 - 2006, while the other two states did not. They use individual level survey data from the CPS. The dependent variables in their paper are the total hours worked and individual employment status. They also divide individuals into several detailed social groups based on the information about age, income and education. The adverse employment impact is only found for Vermont workers, when the regression is restricted to employees under the age of 23. All other specifications fail to yield statistically significant results.

Sabia et al. (2012) use DID to estimate the employment effects for 16 - 29 year old employees who do not have a high school diploma. They find that New York state minimum wage does reduce the employment for young and less educated employees. In addition to using individual states as comparison groups, they also aggregate data from the comparison states and the treatment group to form a synthetic control group to test the validity of the comparison groups and to provide addition evidence of the minimum wage effects.

\subsubsection{Difference-In-Differences-In-Differences}

In some cases, difference-in-differences-in-differences (DDD, triple differences) estimation method is used in the minimum wage studies. There are several possible situations that this approach is valuable. First, one assumption of DID is that the differences between treatment and control groups in two periods must be the same, without the treatment. With DDD method, we can relax this assumption, since the 
difference would be cancelled out. Alatas and Cameron (2003) explore the impact of minimum wage in Indonesia. By using survey data for firms with more than 20 employees, they calculate the matched DID estimates across two adjacent regions based on the value-added per worker, which can be used to represent a firm's productivity. They also present DDD estimates, which allow firms in the two regions to have different employment growth rates. This DDD estimate is similar to the DID estimate, and the only difference is that $y_{i g t}$ is calculated as the employment difference across firms. Their results provide no evidence that minimum wage affects employment adversely for large firms. They do find negative employment effects for small firms.

Second, DDD could be useful when the within-state comparison is introduced with the across-state comparison. The within-state comparison can avoid the possibility that time trends are different across states. In this case, we can get two DID estimates for the within-state comparisons. Then, the DDD estimate is the different of these two DID estimates. Sabia and Burkhauser (2008) use DID to estimate the employment effects in New York for the 2004 - 2006 minimum wage increase. The dependent variable in their paper is an indicator for whether an individual is employed in the last week. The minimum wage variable is also an indicator, which is equal to one if the individual is in New York. Besides the across-state comparisons, they also present the results for the within-state comparisons by using triple differences. In this case, the control groups are the more highly-educated or experienced people in New York. Their results suggest that the increase of New York minimum wage reduces the employment for less-educated or less experienced workers. By using their estimates and other estimates from previous literature, they simulate the distributional results for the next New York minimum wage hike. They find that this proposed minimum wage hike would do more harm than good, since only 20 percent of the benefits would go to the target people. 


\subsubsection{Statistical Problems of DID Estimators}

Bertrand et al. (2004) argue that the standard errors in the DID estimates are inconsistent, because of serial correlation in the error terms. So DID studies that fail to consider the serial correlation tend to overestimate the statistical significance of the treatment effects. They suggest several methods to solve this problem. The most common one used in the DID literature is to use clustered standard errors. In order for clustering to be effective, the number of cross-sectional units need to be relatively large. The problem is that in some papers, this condition cannot be satisfied. Card and Krueger (1995) only have four cross-sectional groups: New Jersey before and after groups, Pennsylvania before and after groups. In other case studies, the number of groups is usually small as well. Another method that performs well for a small number of groups is to collapse time series data into only two periods: before and after the treatment. Donald and Lang (2007) further argue that, in the simple two group/ two period analysis, no matter how many observations from either treatment or control group are added into the sample, the weighted least squares DID estimator is unbiased, but is not consistent, since it does not converge in probability to the true value. Usually the minimum wage changes no more than once each year, but the dependent variables are measured at a less aggregated level. If the correlations within group/ period cells are non-zero, the standard errors for the more aggregated variables tend to be understated. As a result, people can obtain statistically significant treatment effects even if the true effects are zero.

\subsubsection{Panel Data Analysis}

The second major category is panel data studies that use a longer time period data. 


\subsubsection{Earlier Research (1946 to 1992) — Time Series Analysis}

Stigler (1946) asserted that a binding minimum wage reduced employment of lowskilled workers. Before the early 1990s, most economists agreed that increasing minimum wages reduced employment levels. These time series studies normally used aggregate national data to examine the effects of federal minimum wages on teenagers or less-skilled workers. Brown et al. (1982) surveyed the previous studies and found that typically a $10 \%$ increase in the minimum wage reduced teenage employment by $1-3 \%$. All of the papers summarized by Brown et al. (1982) used the same data source, the CPS data. In several earlier studies, the minimum wage variable used was the Kaitz index, defined as the ratio of minimum wage to the adult average wage rate multiplied by the percentage of teenage population covered by the minimum wage.

These studies have several limitations. First, federal minimum wages normally do not change more than once in a calendar year. The aggregated national data cannot capture much variation in the minimum wage variable. Second, Card and Krueger (1995) argue that these earlier studies suffer from "publication bias" and the major disadvantage of the time series studies is the lack of sufficient control. Once they use same data from these papers and correct the model specification, the disemployment effect diminishes. In addition, Card et al. (1994) criticize the use of the Kaitz index, since it is difficult and imprecise to measure minimum wage coverage for teenagers.

\subsubsection{Brief Introduction of Panel Data Analysis after 1992}

Since the late 1980s, states have implemented their own state minimum wages. As a result, state level variation or other regional level variation is taken into account in the analysis. Panel data analysis is the most common way to analyze employment effects. In general, both negative and non-negative employment effects are found in this branch of literature. By using a long panel, which is usually more than 10 years, these studies include more macroeconomic information about both economic 
growth and recessions. Economists have studied the employment effect at different levels, such as research at nationwide level or in a particular state or industry. Most national-level studies use CPS data and estimate the employment effects on teenagers. The reason that they examine the teenager employment is that this group is less likely to undertake state-to-state migration in response to labor market opportunities. Migration may respond to the minimum wage, so estimated employment effects of the minimum wage could be bias. For studies using geographic data where units are states, all estimates are weighted by population weights to account for sampling bias. These weights are designed to account for oversampling or under-sampling of the geographic divisions. The standard errors are clustered at the geographic division level. There are also some studies at the state level. Since most of the minimum wage workers are in some low-wage industries, there are papers discussing the employment effects at the industry level, such as the fast-food industry and retail industry. Nationwide, half of all low wage workers are employed in the retail industry.

\subsubsection{CPS-Based Papers}

Many studies use CPS data to examine the minimum wage effects on teenage employment. Conflicting results are found among these papers as well. Neumark and Wascher (1992) use May CPS data and construct a model with state fixed effects and year effects. The model is:

$$
E_{i t}=\alpha_{0}+\alpha_{1} M W_{i t}+X_{i t} \beta+Y_{t} \gamma+S_{i} \delta+\varepsilon_{i t},
$$

where $i$ identifies the state and $t$ represents the year. $E_{i t}$ is the employment to population ratio for the group under study. $M W_{i t}$ is the coverage-adjusted minimum wage variable, which is the minimum wage level multiplied by the coverage, then

divided by the average wage. $X_{i t}$ is a set of control variables, including the proportion 
of population in the age group, the prime age male unemployment rate, and the school enrollment rates in some specifications. $Y_{t}$ and $S_{i}$ are year effects and state effects, respectively. $\alpha_{1}$ is the estimate of interest. They conclude that for the year 19731989, a $10 \%$ increase in minimum wages causes the teenage employment ratio to be reduced by $1-2 \%$.

Card and Krueger (1995)argue that Neumark and Wascher (1992) mis-specify the model and re-estimate the model. There are two major differences between these two papers. First, the minimum wage variable Card and Krueger (1995) use is the natural log of the higher of the state and federal minimum wage, while Neumark and Wascher (1992) use the coverage-adjusted minimum wage. Second, Card and Krueger (1995) do not include school enrollment rate as a control variable. The control variables are the state-level adult unemployment rate, the adult wage rate and the share of teenagers. They find that the disemployment effect of the minimum wage does not exist.

Deere et al. (1995)'s study is different from previous studies in two ways. First, they use average monthly CPS data to construct annual observations. Second, they ignore the effects of state minimum wage increases and create one dummy variables for each federal minimum wage increase in the examined period. These dummies are equivalent to using year fixed effects for the year with federal minimum wage increase and prevent using year fixed effects for the year without federal minimum wage changes. Adverse minimum wage effects are found in this paper.

Burkhauser et al. (2000) use monthly rather than annual CPS data and re-estimate the model preferred by Card and Krueger (1995) to investigate the minimum wage increase from 1979 through 1997. The employment elasticities in their paper are estimated in range from -0.1 to -0.6 . The large negative elasticities are found in the specifications without further controls for year/state fixed effects, seasonal adjustment and recession. 
Sabia (2009b) re-estimates the same model using monthly CPS data up to 2004. He includes year dummies in the regression and finds a disemployment effect of the minimum wage. The estimated elasticities are in the range of -0.2 to -0.3 . In addition, Sabia also estimates equations predicting hours of work per worker and finds negative hours elasticities.

Orrenius and Zavodny (2008) construct annual state observations from the CPS and focus on less-educated adult immigrants and all teenagers. Instead of using the unemployment rate, they use the natural log of the real state gross product per capita, unemployment insurance claims and the permits for privately-owned residential construction to control for business cycle. They argue that the state unemployment rate used in earlier literature is a lag indicator, while the three control variables they use capture the current economic situation. Using their specifications, they fail to find adverse minimum wage effects on teenage employment and on less-educated adult immigrants.

\subsubsection{Concerns in the Panel Data Analysis}

Among panel data studies of minimum wages, there are several concerns worth noting.

Appropriateness of Including Year Effects Most CPS-based analyses use several dummy control variables, such as state, month and recession dummies. Card and Krueger (1995) include year effects in the model and get a positive employment effect. Burkhauser et al. (2000) find that the year effects in the model are driving the "non-negative" results, since the insignificant results are only found in the specifications with year dummies. They argue that including year effects is inappropriate, because most variation in the minimum wages used in Card and Krueger(1995) is wiped out due to the inclusion of the year dummies. They use an auxiliary regression to show how much variation in the minimum wage variable is lost because year dum- 
mies are included in the regression. According to their view, including year effects in the model removes most variation in the minimum wage variable due to the changes in the federal minimum wage, since federal minimum wages normally do not change more than once in a calendar year. As a result, there is only a relatively small amount of variation left, which occurs when a state has higher minimum wages than the federal level. Therefore, the estimated minimum wage effects rely heavily on state-level minimum wage changes. The problem is that there are not many states that have higher minimum wages than the federal levels. Instead of including year dummies, they suggest using recession dummies as an alternative control for macroeconomic conditions.

In contrast, Neumark and Wascher (2007) argue that year effects should be included in the analysis. They argue that the macroeconomic controls included in the model are not able to capture the national trends in such a long time period (1979 - 1997). Results suffer from the omitted variable bias if year effects are excluded. They also point out that federal minimum wage variation is not fully eliminated by including year dummies, because federal minimum wage increases have different effects for states with own state minimum wages levels. Sabia (2009b) is also in favor of including year effects. He exploits more recent state variation in minimum wages and finds the negative relationship between minimum wages and employment.

Spatial Heterogeneity Since economists use different levels of data in the literature, it is important to control for geographic variation when examining the impact of the minimum wage law. Otherwise the estimates suffer from the omitted variable bias. Neumark and Wascher (1992) and other earlier panel data analyses include state dummies in order to control the trends of state specific economic conditions. However, only controlling for the state fixed effects is not adequate. In long period panels, the geographic-specific effects may not be stable over time. If geographic divisions 
have different trends over time, the true minimum wage effects can not be captured. One common strategy to solve this problem is to let the geographic effects vary over time. An increasing number of papers apply this strategy as one model specification. Neumark and Wascher (2007) get mixed results once they include state specific linear time trends. The disemployment effects are found for young minority teenagers only. Sabia (2009a) finds modest disemployment effects in the retail industry. His results are robust to several specifications, including consideration of long-run effect and correction for autocorrelation. The only exception is that once he controls for state time trends, the adverse effect diminishes.

Dube et al. (2010) explore all contiguous county-pairs that are located on opposite sides of a state boundary. They use Quarterly Census of Employment and Wages (QCEW) data from 1990 to 2006 and focus on restaurants. They argue that considering only time and space fixed effects biases the estimates, since counties may have different effects over time, so the interaction terms of time and space are needed. They compare the estimation results with and without considering the spatial heterogeneity (the interaction terms). Their results show that when only the time period fixed effects are considered, the negative employment effects are obtained. However, once the spatial autocorrelation of counties right across borders is taken into account, the employment effects are close to 0. In addition, they also consider whether spillovers exist across borders. They suggest that there are two possible directions of spillovers. One is the "amplification effect," which means that the disemployment effects are stronger in border areas than in the interior parts of the states. This happens when minimum wage reduces employment in the treatment group and the employment increases in the control group across border as displaced workers take uncovered jobs. The other is the "attenuation effect". The higher wages in border counties attract more workers, which worsen the disemployment in the interior counties of the states with higher minimum wages. With search frictions, the control group in the other 
state could also slightly raise wage rate to recruit and retain employers. If this is the case, the DID estimator should be smaller than the true values. They use the average employment in interior counties as a control and estimate the "spatial differenced specification". Their results indicate no significant spillover effects.

Allegretto et al. (2011) use CPS data and include census division-specific time fixed effects and state specific linear time trends in the model. They find no significant minimum wage effects on teenage employment. Unlike the other papers which use state level data and define the teenage employment ratio as the dependent variable, they use individual level observations and the dependent variable is a dichotomous employment variable, which equals one if the teenager is working.

However, in contrast, Meer and West (2013) argue that one reason for the nonadverse effects is due to including state-specific time trends in the model. They conduct a simulation to show including state-specific time trends in the model would attenuate the employment effects, since it could potentially reduce the minimum wage variation. They suggest to use the job growth rate instead to estimate the employment effects and their estimation results based on three different panels consistently imply that minimum wages would reduce net job growth rate. In particular, they separate job creation and job destruction. They find that minimum wage policy has no impact on job destruction and has a significant negative impact on job creation.

Neumark and Wascher (2013) also argue that the particular identification strategies which are discussed above in Dube et al. (2010) and Allegretto et al. (2011) lead to no adverse effects, since they throw out so much valuable and useful variation in the data. By using same data and model specification, Neumark and Wascher (2013) suggest several ways to control for unobservable trends and succeed in find the disemployment effects. 
State Minimum Wages vs. Federal Minimum Wages Usually, economists use the effective minimum wage, which is the higher of the federal and state minimum wage, as the measure of the minimum wage in their models. Theoretically, statelevel minimum wage effects should be larger than the federal minimum wage effects because of the potential for mobility.Bazen and Gallo (2009) separate out the impact of these two sets of the minimum wages using first-difference models. They find that in the 1980s and the 1990s, the state level minimum wages had no negative effect on employment. However, the federal minimum wage hikes did have adverse effects in 1990s.

Addison et al. (2012) construct a similar model, but include year effects. They use county-level data for the restaurants-and-bar sector. Once year effects are included, they do not find the adverse effect. Furthermore, when they use a subsample that only includes states that have higher minimum wages than the federal one, they find negative employment effects, which indicates that minimum wage law may be more binding in the states with higher minimum wages. They also separate the full-service and limited-service restaurants and only find the negative employment effect in the limited-service restaurants, which they suggest means that the minimum wages are more likely to be binding in these restaurants.

\subsubsection{Common Issues and Other Strategies}

\subsubsection{Binding Minimum Wages}

Orazem and Mattila (2002) argue that the employment effects estimated in previous studies are for total employment. For a large proportion of workers, the minimum wage is not binding, so the estimation results tend to underestimate the employment effects of minimum wages. They propose to disaggregate workers by their hourly wages. In their firm-level analysis, once workers are separated into a sub-minimum wage group (workers whose original wages are below the new minimum wage) and a 
super-minimum wage group (workers whose original wages are above the new minimum wage), they find larger disemployment effects, the elasticities ranging from -0.3 to -0.85. Unlike other papers which use the employment level or the employment-topopulation ratio as the dependent variable, they use the employment growth rate.

Thompson (2009) isolates workers in counties where minimum wages are more likely to be binding. He uses county level data to measure the employment effects for teenagers from 1996 to 2000. He divides the counties from 15 states into highand low- impact groups and compares the employment effects in these two types of counties using DID estimation. The high- and low- impact groups are identified based on the bottom and top thirds or top fifth of average quarterly earnings of teenagers. If all counties are included in the estimation, small and statistically insignificant results are found. If he only includes the counties where the minimum wages are above the market-clearing wages, the employment effects are negative. These disemployment effects are even stronger in small counties. As a result, he argues that the small or non-negative employment effects in literature are actually the average effects for regions where the minimum wage is not binding and those where it is binding.

\subsubsection{Endogeneity}

One possible bias that may account for finding of non-negative employment effects is potential endogeneity of minimum wage legislation. Politicians decide when to increase the minimum wages. Politicians tend to increase minimum wages at the time when economy grows faster. In this case, even the disemployment of minimum wages exist, people cannot tell because of the growth of employment. If minimum wages legislation is partly determined by supply and demand conditions in the labor market, so the minimum wage and employment levels are endogenous, the estimates have a positive bias. It is not surprising to find the non-negative employment effects in this case. If it is important, such endogeneity will affect results in both panel data 
analysis and natural experiment studies. In some panel data analysis, the dependent variable, employment level or employment to population ratio is regressed on the minimum wage variable and other control variables. One needs to make sure that the minimum wage variable is uncorrelated with the error term. In the differencesin-differences studies, if the assumption that the two groups share similar economic and regional conditions fails, the endogeneity problem exists. This is to say, the treated group experiences a higher employment growth rate, which causes politicians to increase the minimum wage. Zavodny (1998) suggests two methods to control for the endogeneity bias. One is to use an instrument, which is correlated with the minimum wage and uncorrelated with the error term. The other is to use a minimum wage that is more likely to be uncorrelated with economic conditions, for example, a minimum wage resulting from a referendum vote.

\subsubsection{Lagged and Anticipation Effects}

To incorporate the long-run minimum wage effects, economists include a one year lagged minimum wage in the models. Burkhauser et al. (2000) find that both the current and lagged minimum wage effects are negative and significant. Campolieti et al. (2006) use Canadian data and suggest that the estimates are larger with the lagged adjustment. Baker et al. (1999) also use Canadian data and discuss the longer-run minimum wage effects. They find that the first difference estimates of the minimum wage is positive, which means there is no adverse employment effect. However, they estimate effects up to a fourth difference. All the estimated results from these further differences are negative, which is consistent with the neoclassical prediction. Frequency-domain-based decomposition is used to separate the minimum wage into high and low frequency components. Their results indicate that the high-frequency variation in the data has a positive minimum wage effect and the low-frequency variation has a negative effect. 
In recent years, several states implemented minimum wage indexation policies. Up through 2011, there are ten states that adjusting their minimum wages annually based on the consumer price index from the previous year. This policy keeps the real minimum wage constant and makes the minimum wage increases predictable. Does this indexation affect the results? From the employers' side, they may adjust their hiring decisions this year if they know there would be minimum wage increases in the following years. If this occurs, the minimum wage effects may be underestimated unless anticipation effects are considered. In order to examine long-term effects of minimum wages, there is also some research checking the dynamic responses to minimum wage changes by including long term window distributed lags. Dube et al. (2010) find no anticipation or lagged employment effects in their studies of the restaurant sector when a six year window is included. This six year window includes two years leads and four year lags, and the increment is every two quarters. Allegretto et al. (2011) use similar dynamic specifications to show that after controlling heterogeneity, anticipation does not affect the employment effects.

\subsubsection{Individual-Level Analysis}

Among the minimum wage papers, a vast number of them focus on investigating fims' employment decisions and lack of details regarding the individual behaviors. Giuliano (2013) use detailed personnel data from US retail firms in several states to examine the heterogeous minimum wage effects on differnet types of individuals. She seperate employees into teenage and adults and check whether they respond differently and whether firm's composition shifts to minimum wage changes. Her bottom line is that the employment effects depend on the relative size of new minimum wage and the initial average wage rates in the market. Her results suggest that compulsory increase in average wage have no significant impacts on total employment. In contrast, increase in teenage wage results an increase in teeange employment. As a results, her paper 
is in support of imperfect competitive model and explains why minimum wage may have small or little impact on overall employment.

\subsubsection{Other Research Strategies}

This subsection documents some papers that use research strategies, other than DID and panel data analysis.

Several recent minimum wage studies are based on time series analysis. Unlike the traditional time-series studies, these studies incorporate a structural break test to check whether there is a significant discontinuity of the dependent variable at the time when there is an increase of the minimum wage. This approach is particularly valuable when no appropriate control group can be found. Lee and Suardi (2011) use aggregated quarterly data on Australian teenage employment from 1992 to 2008. During this period, there were eleven minimum wage increases, so they use the multiple structural breaks model. Their results suggest no significant negative employment effects for teenagers. They suggest this may be because the minimum wage increase in Australia is predictable and adjusted with the change of price levels.

Instead of examining the employment levels, Pedace and Rohn (2011) provides a new angle to evaluate the minimum wage legislation. They examine the minimum wage effects on unemployment spell length. They argue that theoretically minimum wages can either extend or shorten unemployment spells. Unemployment duration is increased if unstable jobs are created for less skilled workers. However, unemployment duration can also be reduced. Some less-skilled workers may prefer to remain in current jobs, since if they quit the current jobs, they may have difficulty finding new ones and they also face increasing living costs because of increasing minimum wages. Their empirical results suggest that higher minimum wages lower the unemployment duration for older males and males with at least high school diploma. In contrast, the unemployment duration is extended for older females, high school drop-out males 
and less-skilled workers.

\subsection{Missouri State Minimum Wage}

In January 2007, when the federal minimum wage was still $\$ 5.15$, Missouri increased the state minimum wage to $\$ 6.50$. This is an 26.2 percent increase in the Missouri minimum wage. Thereafter, Missouri minimum wage was indexed to the CPI, so the state minimum wage increases annually by the rate of inflation. This state minimum wage law covers all firms except small firms whose annual revenues are less than $\$ 500,000$. The only exception is the construction industry, where every employee is covered by the state minimum wage law ${ }^{1}$. When Missouri's minimum wage was placed on the ballot as Proposition B, economists and politicians debated whether Missouri should implement a state minimum wage. At that time, most economists argued that the increasing state minimum wage would do more harm than good for Missouri. Neumark (2006) argued that the disemployment effects would be particularly strong in Missouri, since the state minimum wage would be indexed to the inflation. Since it would cause a permanent increase in wages, employers would eventually response by cutting employment. Troske and Yelowitz (2006) predicted that over 18,000 workers would lose their jobs and over $\$ 340$ million in annual costs would occur for Missouri firms if the state minimum wage increased to $\$ 6.50$ in 2007 . Instead of increasing the state minimum wages, they suggested expanding other government programs, such as the Earned Income Tax Credit or childcare subsidies. Macpherson (2006) also questioned the effectiveness of the Missouri minimum wage legislation. He predicted that about only $20 \%$ of the income gains from increasing state minimum wages would

\footnotetext{
${ }^{1}$ This exception is not explicitly listed on the Missouri Department of Labor and Industrial Relations website or written in any document. However, staff in Division of Labor Standards, Wage and Hour Section told us that all firms in the construction industry are covered by the minimum wage regardless of their annual income. The ballot initiative that established the minimum wage specified that only firms in retail and service would be exempted based on revenue, but according to the staff, this has been interpreted to include all industries except construction. In this analysis, we apply the Missouri minimum wage exemption rule to every industry except for construction.
} 
go to the families below the poverty line.

A large percent of population in Missouri lives in border cities. Macpherson (2006) note that 58 percent of population lived in the Saint Louis or Kansas City metropolitan areas. The issue is whether employment could move, that is, whether employees living in Missouri side of Kansas city metropolitan areas could find jobs across the state line to Kansas, while those living in Saint Louis could find employment opportunities in Illinois. As a result, when estimating the employment effects in Missouri, one needs to take these spillovers into account. From another point of view, one advantage of these border cities is that it provides us a great identification strategy to explore the effects of the Missouri's minimum wage. Since Kansas does not have state minimum wages, the Kansas side of the Kansas City metropolitan area can act as a control group. 


\section{Chapter 3}

\section{A Panel Data Analysis Using More Recent CPS Monthly Data}

\subsection{Concerns in My Study}

In this part, I replicate the work done by Burkhauser et al. (2000) and Sabia (2009b), and I also extend the time period to 2011. There are several concerns that I want to address in my study. First, is it proper to include year effects in the model? Card and Krueger (1995) include year effects and get a positive employment effect. Burkhauser et al. (2000) argue that the inclusion of year dummies are driving the "non-negative" results. So they propose including other macroeconomic controls in the model, such as recession dummies for each month instead of year dummies. In contrast, Neumark and Wascher (2007) argue that year effects should be included in the time series analysis. Sabia (2009b) is also in favor of including year effects. In my paper, I describe the frequency and magnitude of the state level minimum wage changes and I suggest that there is enough variation to identify the minimum wage effect in recent years. In my analysis, I find that for the sample period from 1979 to 1997, including year dummies gives the results of the non-significant estimates. However, if I extend the 
sample period to 2011, which include more state level variation, the estimates become negative and statistically significant at $1 \%$ level. After the analyses, I conclude that whether we can get "meaningful" estimates is time sensitive. One should make sure that there is enough state level minimum wage changes in the examined period before including the year effects in the model. I consider the estimates with year dummies are more accurate. So I use this specification as a benchmark when I perform the robustness checks.

The second question that I want to explore is, "How can one account for the longrun minimum wage effects?" When the minimum wage increases, employers can not only adjust the number of workers they hire, they can also substitute more-skilled workers and advance machinery for less-skilled workers. Without taking these kinds of long-run substitutions into account, the estimated employment effects may not be able to capture the true minimum wage effect. This may be one reason to explain why most "non negative" effects are estimated in the models that do not account for long-run effects. Minimum wages can be implemented as much as one year after the legislation is passed. The problem is that it is hard to capture these long-run effects, since the passing date of the minimum wage law is not the exact time when people start to expect a minimum wage increase. However, people may start to react once they expect an increase of the minimum wage. So economists try different ways to capture these long-run effects. Burkhauser et al. (2000) include a one year lagged minimum wage variable in their models. They find that both the current and lagged minimum wage effects are negative and significant for the specifications without year effects. When year effects are included, the estimate for the current minimum wage variable is insignificant, but the estimate for the one-year lagged minimum wage variable is negative and statistically significant. Campolieti et al. (2006) use Canadian data and show that the estimates are larger with the lagged adjustments. Baker et al. (1999) also use Canadian data and discuss the long-run minimum wage effects. They find 
that the first difference estimates of the minimum wage is positive, which means there is no adverse employment effect. All the estimated results from the longer differences are negative, which is consistent with the neoclassical prediction. I follow the work by Burkhauser et al. (2000) and include a one-year lagged minimum wage variable in the model. My results show that for the sample period from 1979 to 1997, without year effects, the estimates for the current and lagged minimum wages are negative and significant. But the estimates are positive and insignificant with the inclusion of year dummies. However, if I extend sample period to 2011, the estimates are negative and significant in all the specifications.

The third concern in my paper is about the heterogeneity. First, I correct the autocorrelated errors and the state heteroskedasticity. After these corrections, I still find significant disemployment effects of the minimum wages, and the estimated impacts are larger. Allegretto et al. (2011) argue that failure to control for heterogeneity in minimum wage impacts will result in biased estimates of the employment effects. They suggest that different states respond differently over time to the minimum wage changes, so it is not enough to control for state effects and year effects. They suggest checking spatial heterogeneity and long-run growth in state level of time trends. They use quarterly CPS data and find no significant minimum wage effects after controlling these factors. In my paper, I estimate the different teenage employment patterns for the nine Census divisions and check the estimation results including the regional year dummies or state specific linear time trends as robustness checks. I find that the employment elasticity is smaller in magnitude with the region-specific year dummies, but it is still negative and significant. However, with the state specific linear trends, the disemployment effects are eliminated.

The last concern is about the indexation and anticipation of the minimum wage increase. Allegretto et al. (2011) use dynamic models to show that after controlling heterogeneity, anticipation does not affect the employment effects. However, in recent 
years, there are several states have the indexation policy. In order to maintain the real values of the minimum wages, up to 2011, there are ten states that adjust their minimum wages annually based on the consumer price index from the previous year. This policy keeps the real minimum wage constant and make the minimum wage increases predictable. Will this indexation affect the results? From the employers' side, they may adjust their hiring decisions this year if they know there would be minimum wage increases in the following years. If this is true, then the minimum wage effects may be underestimated without considering the anticipation. Allegretto et al. (2011) include a set of index dummies in the model and make these dummies interact with the minimum wage variable. Their results suggest that indexation does not contaminate the estimation results. I also include a set of index variables as a model specification and find that the estimates from non-index states and from the specification with index variables do not differ a lot from the benchmark.

In summary, my study will contribute to the CPS-based minimum wage literature in the following respects.

First, Burkhauser et al. (2000) estimate the employment effects of the minimum wage increases from 1979 to 1997, while Sabia (2009b) extends the analyses to 2004. My work uses monthly data from 1979 to 2011. Longer time periods provide new information that has not been examined since their work. Most importantly, in recent years, there is more state minimum wage variation that can be used for the identification and this variation has not been fully explored by Sabia (2009b). In addition, in the federal minimum wage history, there is a 10 -year period with no increase in the federal minimum wage, i.e, the federal minimum wage was set at $\$ 4.75$ in 1997 and next raised to $\$ 5.15$ in 2007 . It would be worth exploring and discussing this interval. The examined period in my paper covers the recession in 2008 and 2009. It should be interesting to check the minimum wage effects when the economy is slack. I provide three sets of results, covering time period from 1979 to 1997, from 
1979 to 2011 and from 1997 to 2011 to examine the differences in the estimates.

Second, I discuss more about the appropriateness of including year effects and inclusion of a lagged minimum wage. From above discussion, it is clear that whether to include year effects in the model is a contentious issue. I provide some analysis to show the frequency and magnitude of the state minimum wage variation in recent years, and my estimation results suggest that year effects should be included in the model in order to get meaningful estimates.

Last, but not least, I discuss the heterogeneity and minimum wage indexation issue in the CPS data. Allegretto et al. (2011) discuss the spatial heterogeneity in detail using quarterly CPS data and the employment variable they use is the dichotomous dependent variable. In my paper, I use monthly data and the dependent variable is the teenage employment to the population ratio. I find that when division-specific year effects are taken into account, the disemployment effects still exist but are smaller. This result is inconsistent with their work, which found insignificant effects. However, including state specific linear time trends in the model makes the estimate of log of the minimum wage insignificant. This result is consistent with their results. In addition, Allegretto et al. (2011) and I draw similar conclusions about the minimum wage indexation, i.e, the minimum wage indexation appears to have no impact on the teenage employment.

The remainder of this part is organized as follows. Section II is a short introduction of the model specification strategies. In this section, I introduce the basic model and all the specifications I use. The next section is the data description, which covers the data source, a description of the variables used in my study and two tables showing where states minimum wages are higher than federal minimum wages. Data discrepancies are also discussed in this part. The main section presents the empirical results. First, I check whether a minimum wage increase has impacts on teenage wages. If the impact exists, minimum wages can affect teenage employment. Then, 
I discuss the minimum wage effects on the ratio of teenage employment to teenage population and the appropriateness of including year effects in the model. In order to capture the long-run employment effects, the one-year lagged minimum wage effects are reported. To check the minimum wage effects in the recent years, I report parallel estimation results for the time period from 1997 to 2011. Also, I try to find if there are any other macroeconomic controls that I can use, and I report results after corrections for autocorrelation and state heteroskedasticity. To further explore employment heterogeneity, I include region-specific year effects or state-specific linear time trends in the model. I also check the results when minimum wages have interactions with the unemployment rate. The last section is the conclusion.

\subsection{Model Specification Strategies}

The basic specification is the model preferred by Burkhauser et al. (2000):

$$
E_{i j t}=\alpha_{0}+M W_{i j t} \beta+X_{i j t} \chi+M_{j} \lambda_{j}+S_{i} \delta_{i}+\varepsilon_{i j t}
$$

$i$ identifies states, $j$ months, and $t$ years. In this model, the dependent variable $E_{i t}$ is the ratio of teenage (age 16-19) employment to the population in state $i$ in month $j$ and year $t$. Economists prefer to use teenage employment in the time series minimum wage analysis. One reason is that, unlike adults, there is not much state-tostate migration among teenagers in response to their own employment opportunities. $M W_{i t}$ is log of the effective minimum wage, which is the higher of the federal and state

minimum wage. $X_{i t}$ is the set of control variables. $S_{i}$ identifies state dummies, which are time invariant. $M_{j}$ is a set of month dummies to provide seasonal adjustments. It is a dummy variable equal to one for each month in the year. $\beta$ is the coefficient I am interested in, which represents the employment effect of minimum wage. $\alpha_{0}$ is the intercept, $\chi, \lambda_{j}$ and $\delta_{i}$ are the coefficients to be estimated. $\epsilon_{i j t}$ is the error term. 
Burkhauser et al. (2000) discuss the appropriateness of including year effects in the model. I estimate the same model including a set of year dummies. $E_{i j t}=$ $\alpha_{0}+M W_{i j t} \beta+X_{i j t} \chi+M_{j} \lambda_{j}+S_{i} \delta_{i}+T_{t} \tau_{t}+\varepsilon_{i j t}$, where $T_{t}$ is the set of year dummies.

When considering the spatial heterogeneity, I include the division-specific year effects and state-specific linear time trends in the model separately. The specifications are $E_{i j t}=\alpha_{0}+M W_{i j t} \beta+X_{i j t} \chi+M_{j} \lambda_{j}+S_{i} \varsigma_{i}+T_{d t} \tau_{d t}+\varepsilon_{i j t}$ and $E_{i j t}=\alpha_{0}+M W_{i j t} \beta+$ $X_{i j t} \chi+M_{j} \lambda_{j}+S_{i} \varsigma_{i}+T_{t} \tau_{t}+\theta_{s} t+\varepsilon_{i j t}$, where $T_{d t}$ are the division-specific year dummies and $d$ identifies nine census divisions. $\theta_{s}$ is the coefficient for the state-specific linear time trends. In order to check whether the indexation will contaminate the results, I also have a specifications with index variables, $E_{i j t}=\alpha_{0}+M W_{i j t} \beta+X_{i j t} \chi+M_{j} \lambda_{j}+$ $S_{i} \varsigma_{i}+T_{t} \tau_{t}+$ index $_{s t} \delta_{s t}+\varepsilon_{i j t}$. index $x_{s t}$ are the index variable for state $s$ in year $t$. It is equal to one if state $s$ has the minimum wage indexation policy in year $t$ and stays from then on. Otherwise, it is zero. As another robustness check, I include an interaction term in the model to allow the unemployment rate to interact with the minimum wage variable, $E_{i j t}=\alpha_{0}+M W_{i j t} \beta+M W_{i j t} U n e m p_{i j t} \rho+X_{i j t} \chi+M_{j} \lambda_{j}+S_{i} \varsigma_{i}+T_{t} \tau_{t}+\varepsilon_{i j t}$. $U n e m p_{i j t}$ is the prime age unemployment rate for male, and $\rho$ is the coefficient for the interaction term.

\subsection{Data}

\subsubsection{Data Description}

The initial studies using CPS MORG data are by Neumark and Wascher (1992). They use May CPS data. Card and Krueger (1995) also use May CPS data from 1973 to 1989. Deere et al. (1995) average data over 12 months, and create an annual variable. Monthly data are also used in order to include more information and produce more precise estimates. Burkhauser et al. (2000) use monthly data from 1979-1997, while Sabia (2009b) uses data from 1979 to 2004. Aaronson et al. (2007) use quarterly 
data from 1990 to 2009. In this paper, I use monthly data from the merged outgoing rotation groups (MORG) of the Current Population Survey (CPS) from January 1979 to December 2011. ${ }^{1}$

My data set not only covers the time periods of previous researches, but also includes more current years. A large amount of new information is introduced. Following the work by Burkhauser et al. (2000) and Sabia (2009b), I include a set of control variables in my study to capture economic conditions and business cycles. These variables are the natural log of the wage rate of prime age workers (29-54), the share of teenage (16-19) population and the prime-age male unemployment rate. In some specifications, recession dummies are added to capture the macroeconomic conditions.

The Current Population Survey (CPS) is the government's monthly household survey of employment and labor markets, provided by the Bureau of Labor Statistics. In the CPS data set, each year there are more than 200,000 individual level observations that I can use to create state-month observations. At first, I use data from January 1979 to December 1997, which are the exact same period as BCW. Within these time periods, I construct a sample with 11,628 state-month observations. Then, I extend the data to December 2011 to explore the minimum wage effects in recent years. The sample size increases to 20,196 observations. In order to explore the ten-year federal minimum wage gap (minimum wage was $\$ 5.15$ in 1997 and next raised to $\$ 5.85$ in 2007), I also report separate estimates for the "last" period, which is from 1997 to 2011.

Table 3.3 is a general description of the variables used in this study. The dependent variable is the ratio of teenage employment (age 16-19) to teenage population. This measurement of employment has been used by Card and Krueger (1995), Burkhauser et al. (2000) and Sabia (2009b). A teenager is considered to be employed if he or she

\footnotetext{
${ }^{1}$ Before 2000, state minimum wages and the effective dates are from "The Book of the States". After 2000, the minimum wage data are from state government websites.
} 
reports "yes" to the survey question that "Is ... paid by the hour on this job?" Teenage wage and adult wage are included in the following way. If people report their hourly wages, the hourly wages are used. If hourly wages are not reported, weekly earnings and weekly working hours are collected to calculate the hourly wage rates. For all these variables, means are weighted by weights provided in MORG in each state to account for sampling bias. Because of the different levels of the refusers in different states, these weights are designed to account for oversampling or under-sampling of states. Standard deviations are reported in the parentheses. From this table, one can see that the means of control variables, such as share of teenage population, prime age male unemployment rate and recession dummies do not differ much among the three sample periods. Since the variables related to wages are not inflation adjusted, the means of these variables in the "97-11" periods are greater than the ones in the "79-97" periods. However, the mean of the dependent variable, the teenage employment ratio decreases from 0.44 in the "79-97" periods to 0.37 in the "last" period(1997-2011).

\subsubsection{Variation in State Minimum Wages}

Many states have their own state minimum wages. There are some exceptions. There are four states with minimum wage rates usually lower than the Federal level: Arkansas, Georgia, Minnesota and Wyoming. There are also several states without state minimum wage laws. They are Alabama, Louisiana, Mississippi, South Carolina and Tennessee. Table 3.1 and 3.2 describes the states and wages for which state minimum wages are higher than federal minimum wages on January 1 from 1995 to 2011. States are separated by geographic divisions. Dash lines mean that state minimum wages are either the same or lower than the federal levels. There are three phenomenon we need to pay attention to. The first is that there are many states

that have higher minimum wages. As a result, these changes can be use to identify the minimum wage effects. The second one is that during 1997 to 2007, there was no 
federal minimum wage increase. But during these 10 years, 24 states adjusted their own state minimum wages. The last is that after 2007, although the economy is in recession, many more industrialized states increase the minimum wages.

Figure 3.1 shows the number of states which have minimum wages above the federal levels. Before 1985, fewer than 5 states have higher minimum wages. Since 1997, this number increases and the peak is in 2007. In 2007, over 30 states have higher minimum wages than the federal level. After 2007, since the federal minimum wage increases again, this number drops. Sabia (2009) uses CPS data from 1979 to 2004. From figure 3.1, one can see that, in 2004, there are fewer than 15 states having higher minimum wages. This number doubles in 3 years, and this frequency is captured in my study.

Figure 3.2 shows the average percentage differences relative to the federal minimum wage, for the states with higher minimum wages above the federal levels. For the states with higher minimum wages, I calculate the monthly differences between these two wages and take the average to get an annual difference. Then, I present the average of annual differences for all the higher minimum wage states to get this figure. In 1997, the mean state minimum wage is only $5 \%$ higher than the federal level. The difference keeps increasing. In 2007, this average difference has increased to $31 \%$ higher than the federal level. In 2008, when the federal minimum wage increased to $\$ 5.85$, the average percentage increase drops significantly to $17 \%$. My study captures the greatest difference between the state and federal minimum wages in recent minimum wage history. Figure 3.1 and figure 3.2, together with table 3.13 .2 , suggest that there is enough variation in state minimum wage levels that one can use to identify the minimum wage effects.

\subsubsection{Data Discrepancy}

Burkhauser et al. (2000)also provide a table to describe the definitions of the variables 
used in their paper. For the period 1979 to 1997, most of the means and standard deviations reported in table 3.3are exactly the same as those inBurkhauser et al. (2000). The only difference is the weighted mean and standard deviation of the adult wage. The mean for the $\log$ of the prime age workers (25-54) wage is 2.13 in my sample, but the mean for this variable is 2.28 in their paper. The difference may be related to my findings estimation results are slightly different from their results. If I limit the adult wage variable to male workers only, I can get the mean 2.28. But Burkhauser et al. (2000) only describe the adult wage variable as for the prime age adults. In addition, when I use male adult wages as a control variable in the regressions, I still do not get the exact same estimates as theirs. For these reasons, I use only adult wage as the control variable.

My estimation results for comparable periods are not identical to the estimates in Burkhauser et al. (2000)'s paper or Sabia (2009b)'s paper. For example, in table 3.5, specification (3), my coefficient for minimum wage is -0.119 . The coefficient for the same specification in Burkhauser et al. (2000)'s paper is -0.130 and in Sabia (2009b)'s paper is -0.110 . There are several reasons may cause these differences. First, the different definitions of adult wage rate. I define the prime age at 25 to 54 . Burkhauser et al. (2000) do not mention how they define the prime age. We have different means for this variable. Second, it may be true that CPS revises the weights used in the MORG and also updates the weights for the previous years data to make them agree with the national population. ${ }^{2}$ Since all the estimates are weighted by the weights provided in MORG, the revisions may slightly affect the results. Sabia (2009b) suggests three possible reasons that may cause his result to differ from Burkhauser et al. (2000)'s. I may have similar problems. First, he mentions the different ways of treating "missing" observations. If some state has a small number of teens in a month, Sabia (2009b) uses the value from previous or following month instead. I do not do

\footnotetext{
${ }^{2}$ I do not find direct evidence to show when CPS changed the weights and updated for the previous years data in the comparable periods.
} 
this. As long as there are observations of teens for a state in a month, I use these observations to construct state-month observations. If there are no such observations in a given year, I drop the missing observations. However, Burkhauser et al. (2000) do not mention how they treat "missing" or small numbers of observations. Second, Sabia (2009b) describes the different definitions of the "share of teens" variable. He defines it as the ratio of teens to the state population aged at 16-64. I have the same definition as his. Burkhauser et al. (2000) define it as the share of teens in the overall state population. In the period 1979 to 1997, the means for this variable are both 0.10 in their paper and my study. So, these different definitions may only cause very minor differences in the estimation results. Third, Sabia (2009b) notes the slight coding differences. I may also have similar problems.

\subsection{Empirical Results}

In this part, I report three different sets of results. One is for the period January 1979 through December 1997, which is the period used by Burkhauser et al. (2000). The other two sets of results are derived from the whole sample (January 1979 to December 2011) and the "last" period (January 1997 to December 2011). All estimates use weights from MORG. Standard errors are clustered at state level.

\subsubsection{The Minimum Wage Effect on Teenage Wage Rate}

This analysis provides a check on whether minimum wages affect teenage wages. If an effect on teenage employment exists, the effect occurs by influencing the teenage wage rate first. Table 3.4 shows the minimum wage effect on the teenage wage. The dependent variable is the natural log of the teenage hourly wage rate. Burkhauser et al. (2000) provide the results for the sample periods 1979 to 1992, and 1979 to 1997. In this table, columns (1) - (3) are the results from 1979-1997. Columns (4) - (6) 
extend the time period to the whole sample, 1979-2011. In columns (1) and (4), year dummies are included in the regression. Recession effects are included in columns (3) and (6). From all six specifications, one can confirm that increasing minimum wage will increase the teenage wage. Columns (1) and (2) in this table are paralleled to column (3) and (4) in Burkhauser et al. (2000)'s paper table 2, the estimates are similar but not exactly the same as the reasons I mentioned in the previous section.

\subsubsection{Teenage Employment Effect}

In this part, the dependent variable is the ratio of teenage employment to the teenage population. Here, I examine the minimum wage effects on teenage employment. Various control variables are used to check the robustness of the results. Auxiliary regressions are also included to discuss the appropriateness of including year effects in the model. Table 3.5 covers the time period from January 1979 to December 1997. Table 3.6 includes more recent data, from January 1979 through December 2011.

From figure 3.1 and figure 3.2, one can see that after 1997, there is more state level variation that can be used for identification. By using more recent data, I expect to get more accurate estimates of the minimum wage effects on the teenage employment. Since the minimum wage variable is in the log form, the teenage employment elasticity is easily calculated as the ratio of minimum wage etimates to the mean of the teenage employment to teenage population. In table 3.5, Column (1) reports the results for the regression without state or time effects. The estimated minimum wage effect is -0.178, negative and significant, which is consistent with previous studies, and the estimated elasticity is -0.405 . In column (2), state effects are added into the model. The elasticity of teenage employment is -0.302 , which is smaller in magnitude than the elasticity without any controls for state or year effects, but it does not change dramatically. It shows that failure to control for the state specific effects may cause bias but the effect is small. In Column (3), besides state effects, month effects are 
also included to account for seasonal adjustments. In this specification, the results are similar to the ones in column (2). In column (4), year effects are introduced in the model. The employment effect becomes positive, but it is insignificant. The magnitude of the effect drops dramatically, from -0.178 in column (1) to 0.023 here. These results show that much of the variation in the minimum wages is captured by the year effects, which is consistent with results from Burkhauser et al. (2000). ${ }^{3}$ In column (5), when year dummies are removed and recession dummies are included as macroeconomic controls, the employment effect is negative and significant again.

Table 3.6 reports estimation results from January 1979 to December 2011. The substantive results are the same as those in table 3.5. The only difference that one must pay attention to is column (4). Here, year effects are added in the model again. The interesting finding is that the employment effect is negative and statistically significant, which is in contrast to the results of Burkhauser et al. (2000). Sabia (2009b) has a parallel analysis using data from 1979 to 2004. When year effects are included in the model, his estimate for the log of minimum wage is -0.092 , which is significant. One can conclude that by using more current data, state level minimum wages provide more variation in minimum wages across states. Including year dummies in the regression model no longer wipes out the employment effects. Column (4) shows that increases in the minimum wage decreases the teenage employment ratio. In this table, results from columns (2) to (5) are similar. They are all negative and significant, although the one from column (4) is smaller in magnitude. The elasticities of teenage employment from these specifications are larger than the elasticities in table 3.5.

\footnotetext{
${ }^{3}$ This table is paralleled to the first part of table 8 in Burkhauser et al. (2000)'s paper. In that table, they present estimates for columns (3) - (5). In column (3), their estimates for the log of minimum wage is -0.133 , while mine is -0.119 . Both of these results are negative and significant. In column (4), BCW and I both get insignificant estimates.
} 


\subsubsection{The Appropriateness of Including Year Effects}

Following the work by Burkhauser et al. (2000), the minimum wage variable I use is the effective minimum wage, which is the higher of the federal and state minimum wage. Since the federal minimum wage normally only changes once each year, it can be written as a linear function of year dummies. They argue that including year effects remove most of the variation in the federal minimum wages and the estimates therefore rely heavily on the state level variation. The estimated results in column (4), table 3.5 are consistent with their argument. They suggest that, in the specification with year effects, the estimated employment effect is not the "true" effects, because it only captures the effect when federal minimum wage and state minimum wage are different. If there are not many state minimum wages differing from the federal levels, most of the variation in the minimum wage variable is captured by the year dummies. They interpret $\beta$ as the effect of state minimum wage increases relative to the federal one. As a result, they argue that the finding in Card and Krueger (1995) of no adverse effects of the minimum wage is due to the inclusion of the year effects. They further argue that Card and Krueger (1995) have more serious problems with including year dummies, since they only use one observation for each state in each year.

FollowingBurkhauser et al. (2000), in table 3.5, auxiliary regressions are run for each model specification to check how much variation is lost due to the inclusion of the control variables in each column. The auxiliary $R^{2}$ is an indicator of how much variation in the log of minimum wage is lost. In columns (2) - (5), the log minimum wage is regressed on the additional control variables (different dummies) introduced in each column. In column (4), when the log minimum wage is regressed on the year dummies, the auxiliary $R^{2}$ is 0.932 , which is much larger than the other auxiliary $R^{2}$ s. 0.932 is also greater than the $R^{2}(0.524)$. These auxiliary regressions support their argument, that most of the variation in the minimum wage variable is explained by the year effects. They argue that this explains why, in this specification, minimum 
wages have no significant effect on the teenage employment.

However, Neumark and Wascher (2007) are in favor of including year dummies. They argue that control variables are needed to capture the business cycles and other economic trends, otherwise the estimates may have omitted variable bias. Although including year effects will reduce precision, considering the bias-efficiency trade-off, year dummies should be included in the model. In addition, they think the variation is not fully eliminated, because different states with different minimum wages will respond differently to the change of federal minimum wage. The estimates in table 3.6 are consistent with their argument. In contrast to the results in table 3.5, when I use CPS data from 1979 to 2011, including year effects in the model can still provide statistically significant estimates of the minimum wage effect. Since I have demonstrated that state minimum wages have more variation in recent years, including year effects in the model for the whole sample period will give more accurate and meaningful estimates. In this table, the auxiliary regression shows that year dummies still capture large amount of variation in the minimum wage variable.

\subsubsection{Lagged Minimum Wage Effects on Employment}

When minimum wages increase, employers can not only substitute more skilled workers for low skilled workers, they can also substitute more capital for workers. Capital may need some time to adjust. It therefore makes sense to test for long-run employment effects of minimum wages. Following previous research, a one year lagged minimum wage variable is included in the regression. The long-run employment effect is calculated as the sum of the contemporaneous effect and the lagged effect.

In table 3.7, I report results using a sample from January 1980 to December 1997. This table is a robustness check of the minimum wage effects. All the signs of the minimum wage estimates are consistent with the corresponding estimates in table 3.5. In this table, the long-run elasticity is the sum of contemporaneous elasticity 
and lagged elasticity. In general, these long-run elasticities are greater in magnitude than the corresponding elasticities in table 3.5. In all columns except (4), all the estimates for the current year minimum wage and lagged minimum wage are negative and significant. In column (4), the inclusion of year effects makes the estimates for the log of minimum wage and the lagged log of minimum wage positive, but they are not significant ${ }^{4}$. Table 3.8 presents a similar analysis using the whole sample period. In table 3.8, negative and significant estimates for the impact of the minimum wages are reported even when year dummies are included. In all columns, the estimates for the minimum wages are negative and significant at $1 \%$ level. From these comparisons, I can confirm that including year effects in the model using more current data can provide meaningful estimates. One can also see that minimum wages have negative current and lagged impacts on the teenage employment ratio.

\subsubsection{Minimum Wage Effects for More Recent Years}

In table 3.9, I present a parallel analyses using data from the most recent period (January 1997 to December 2011). The estimates in columns (1) - (3) correspond to columns (3) - (5) in table 3.5 and columns (4) - (6) correspond to columns (3) (5) in table 3.8 respectively. The only difference is the sample period. Comparing the estimates without year dummies with the corresponding estimates in the above sections, one can notice that the estimates here are larger in magnitude. One reason may be that in the this" period, especially since 2007, the economy is weak and minimum wages increased every year since 2007. Recessions may overstate the disemployment effect of minimum wages if year dummies are not included to control for the economic conditions. In the column that corresponding to column (4) in table 3.5, the coefficient for the minimum wage is negative but it is not significant with year

\footnotetext{
${ }^{4} \mathrm{BCW}$ get similar estimates in the second part of table 8 . When year dummies are included in the model, the estimate for the log of the minimum wage is 0.03 and the estimate for the lagged log of the minimum wage is -0.029 . Both of these estimates are statistically insignificant.
} 
effects. The standard error is large for this coefficient because of the smaller sample size. Column (4) corresponding to column (4) in table 3.7, which includes year effects, the estimate for current log of the minimum wage is negative and significant, but the estimate for lagged log of the minimum wage is negative and insignificant. In this table, the employment elasticities are also much larger in magnitude. since the teenage employment ratios are smaller. The teenage employment to population ratio is 0.37 in this period here, in contrast to 0.44 in the period 1979 to 1997.

\subsubsection{Alternative Macroeconomic Controls}

From the results in previous subsections, one can see that when recession dummies are included in the regression rather than year dummies, estimates with and without recession dummies do not differ much. R- squares are almost the same for these two specifications, which means recession dummies do not add much new information in the regression. This suggests the possibility that other macroeconomic controls may be needed if year dummies are excluded. In table 3.10, I include CPI in the natural $\log$ form and the growth rate of the labor force in the regression. The estimates for the minimum wage variable are significant and negative, but R-squares increase only slightly. The estimate of the impact of the minimum wage with the growth rate of labor force is similar to the one with recession dummies.

\subsubsection{Corrections for Autocorrelation and Heteroskedasticity}

As a robustness check, in this part, I correct for the first-order autocorrelated errors and allow for state level heteroskedasticity. I assume that the error term in the equation is normal $\epsilon_{i j t} \sim N\left(0, \sigma_{i}^{2}\right)$, and $\epsilon_{i j t}=\rho \epsilon_{i j-1 t}+v_{i j t}$, where $i$ identifies state, $j$ month

and $t$ year. The maximum likelihood method is used here for the regressions. Table 
3.11 reports the estimation results after these corrections ${ }^{5}$. After the corrections, the employment elasticities are similar to the ones in table 3.6. But comparing with table 3.8, the longer-run employment elasticities are slightly larger in magnitude here.

\subsubsection{Heterogeneity in Regional Level}

From table 3.13 .2 , one can see that many states with higher minimum wages are clustered in census regions, such as the Pacific and New England regions. Because of different regional economic conditions, different geographic divisions may respond differently to the minimum wage increases. Figure 3.3 shows the average teen employment to the population ratio for regions. One can see that the pattern of teen employment ratios are similar, but the levels are different over time for most of geographic divisions. This figure suggests the possibility of regional level heterogeneity. Instead of including year dummies in the model, Aaronson et al. (2007) include census division-specific time effects in the model to control for this regional level heterogeneity. Following their work, I create sets of year dummies for the nine census divisions and substitute these variables for the year dummies. The specification is: $E_{i j t}=\alpha_{0}+M W_{i j t} \beta+X_{i j t} \chi+M_{j} \lambda_{j}+S_{i} \varsigma_{i}+T_{d t} \tau_{d t}+\varepsilon_{i j t}$, where d stands for nine divisions, $T_{d t}$ is the region specific year dummies and $\tau_{d t}$ is the corresponding coefficient. 6 .

Table 3.12 reports the estimation results. I include the same control variables as before, and state and month dummies as well. Column (1) here is the result from Table 3.6 column (4) as a benchmark. Column (2) is the result from the regression with division-specific year dummies. One can see that in column (2), the employment elasticity is only -0.151 . The disemployment effect is much smaller if regional heterogeneity is taken into account, but it remains statistically significant. Without

\footnotetext{
${ }^{5}$ I also adjusted for autocorrelation and state heteroskadaticity seperately. The results do not differ much from table 3.11. So I do not include those separate tables in this paper.

${ }^{6}$ Please refer to section II for detailed definitions of the variables used here.
} 
controlling for these dummies, Aaronson et al. (2007) get the disemployment effects of the minimum wage. However, the disemployment effects are totally wiped out by the division-specific year dummies. The employment elasticity is only -0.036 . Both Aaronson et al. (2007) and my work indicate failure to control for this heterogeneity will overstate the minimum wage effects on the employment.

\subsubsection{Heterogeneity in State Level Time Trends}

In this subsection, I examine the influence of long-run growth across states by including state specific linear time trends. The estimation model is $E_{i j t}=\alpha_{0}+M W_{i j t} \beta+$ $X_{i j t} \chi+M_{j} \lambda_{j}+S_{i} \varsigma_{i}+T_{t} \tau_{t}+\theta_{s} t+\varepsilon_{i j t}$, where $T_{t}$ represents the year dummies and $\theta_{s}$ identifies state-specific linear time trends. For the whole sample period (79-11), the estimates for the log of the minimum wage are statistically significant with the inclusion of year dummies, I use this specification as a benchmark and add time trends into the model. When state specific linear time trends are included in the regression in table 3.13 , the disemployment effect of minimum wage disappears. The coefficient is -0.015 , which is not significant. ${ }^{7}$

\subsubsection{Indexation of Minimum Wages}

In 2001, Washington was the first state passed a minimum wage law that adjusted the state minimum wage using the prior year US consumer price index. As of 2011, there are ten states with inflation adjusted state level minimum wages. The detail of the indexation states is table 3.14. In order to check whether the indexation policy changes the employment effects. Aaronson et al. (2007) include an index variable and interact it with the minimum wage variable to check whether the indexation policy matters. In this part, I only report two sets of results. One with the sample limits

\footnotetext{
${ }^{7}$ When the state specific linear trends are included in the model with state effects and year effects, the estimates in ADR's paper is negative and significant. The employment elasticity is -0.034 .
} 
to states without indexation. The other is for all states, but with an index indicator. The model is $E_{i j t}=\alpha_{0}+M W_{i j t} \beta+X_{i j t} \chi+M_{j} \lambda_{j}+S_{i} \varsigma_{i}+T_{t} \tau_{t}+i n d e x_{s t} \delta_{s t}+\varepsilon_{i j t}$. For the index variables, if one state has the indexation in a given year, it equals one. The index variable equals one for this state in the following year as well. Otherwise, it is zero. From table 3.14 in the appendix, one can see that in those ten states, two are from the Pacific Division (Washington and Oregon) and four are from the Mountain Division (Arizona, Colorado, Montana and Nevada). These states are highly clustered by regions. Due to the presence of regional heterogeneity, I also report estimates with division-specific dummies variables.

Column (2) in table 3.15 which is for all 51 states without considering indexation, provides a benchmark specification. In column (1), all indexed states are excluded. The employment elasticity is -0.232 , which is very similar to column (2). Column (3) is the results for all 51 states with index variables included in the specification. The employment elasticity is -0.234 , which is almost exactly the same as the one in column (1). Both estimates for the minimum wage variable are significant. These comparisons show that indexation in recent years does not change the estimated disemployment effect of the minimum wages. When division-specific year dummies are included in the regression, the disemployment effect is attenuated. In column (4), the elasticity is -0.149 , which suggests there is heterogeneity at the regional level as well.

\subsubsection{Interaction with Unemployment Rate}

From figure 3.3, one can see that the teenage employment ratio has declined substantially since 2007. One reason for it is the recession in 2008-2009 and the weak economy ever since. The unemployment rate is relatively high during these years. To check whether the recession will affect the results, ADR include an interaction term for the $\log$ of the minimum wage and the overall unemployment rate. In this subsection, I include an interaction term in the model $E_{i j t}=\alpha_{0}+M W_{i j t} \beta+M W_{i j t} U n e m p_{i j t} \rho+$ 
$X_{i j t} \chi+M_{j} \lambda_{j}+S_{i} \varsigma_{i}+T_{t} \tau_{t}+\varepsilon_{i j t}$, where unemp $_{i j t}$ is the prime age male unemployment rate. Since the female or teenage unemployment rates may be more sensitive or vulnerable to the economic shocks, prime age male unemployment rate is a better indicator of the business cycles than the overall unemployment rate.

In this case, the point employment elasticity is estimated as $\beta+\rho$.unempijt. In table 3.16, column (2) shows the results with the interaction. The employment elasticity is -0.250 and the estimate is negative and significant. Here, I use the mean of the unemployment rate for the period 1979 to 2011, which is 0.05 , to calculate this employment elasticity. This robustness check suggests that the minimum wage effect will not be affected by the business cycles.

\subsection{Summary of the Study}

In the minimum wage literature, there are several papers using CPS data. Even researchers using the same data set can still get conflicting results because of different time periods or model specifications. In this study, using monthly data from January 1979 to December 2011, I find that the minimum wage effects on teenage employment are negative and significant in nearly all specifications. In general, the employment response is around $3 \%$ for a $10 \%$ increase of the minimum wage.

Economists argue about whether it is appropriate to include year dummies in the model. My study indicates the influence of year effects depends on the time period. Since state minimum wages provide enough variation at a given point in time in recent years, one does not need to worry too much about the bias-efficiency trade-off. It's appropriate to include year effects in the time series analysis of minimum wages. Including year effects can provide more accurate minimum wage estimates. In my study, the estimates are negative and statistically significant with the inclusion of year dummies. In order to capture the "true" employment effect of the minimum wage, one 
should take long-run effects into account. I provide estimates of the one-year lagged minimum wage; the long-run employment elasticity is -0.255 . The disemployment effects are larger when I use the recent data, from 1997 to 2011. I also report some robustness checks. People suggest different states may have different employment patterns. Once controlling for the regional heterogeneity, the disemployment effect still exists but is smaller. However, if the state-specific linear trends are taken into account, the adverse minimum wage effect disappears and the estimate is not significant. In recent years, up to 2011, there are 10 states that have indexed minimum wages to adjust inflation. I include indicator variables for such indexed minimum wages for the sample with 51 states and run the regression for non-index states to show that indexation and anticipation do not affect the disemployment effects. In the end, I check the interaction between the minimum wage variable and the prime age unemployment rate, finding that the business cycles do not change the estimated results.

To summarize, most of my results confirm the disemployment effects of the minimum wage. For the sample period from 1979 to 2011, in the specifications that do not consider the spatial heterogeneity issues, all the estimates of the log of the minimum wages are negative and statistically significant. The employment elasticities are within the range from -0.1 to -0.6 . The disemployment effects are in general greater in the period 1997 to 2011. In the specifications without considering the year effects, the employment elasticities are around -0.6. The employment elasticities are larger when considering the long-run employment effects and correcting for autocorrelation and state heteroskedasticity. However, the disemployment effects are attenuated if the division-specific dummies are included to control for the spatial heterogeneity. In this case, the employment elasticity is -0.151 . There are some specifications where the adverse minimum wage effects are eliminated. One is the specification with year dummies included for the period from 1979 to 1997. In this specification, both the 
estimates for the log of the minimum wage and the one-year lagged log of the minimum wage are positive, but are not significant. The other specification is when state-specific linear trends are included in the model for the period 1979 to 2011 . In this specification, the minimum wage estimate is negative and insignificant. Based on my results, minimum wage indexation and business cycles do not affect the minimum wage effects on teenage employment.

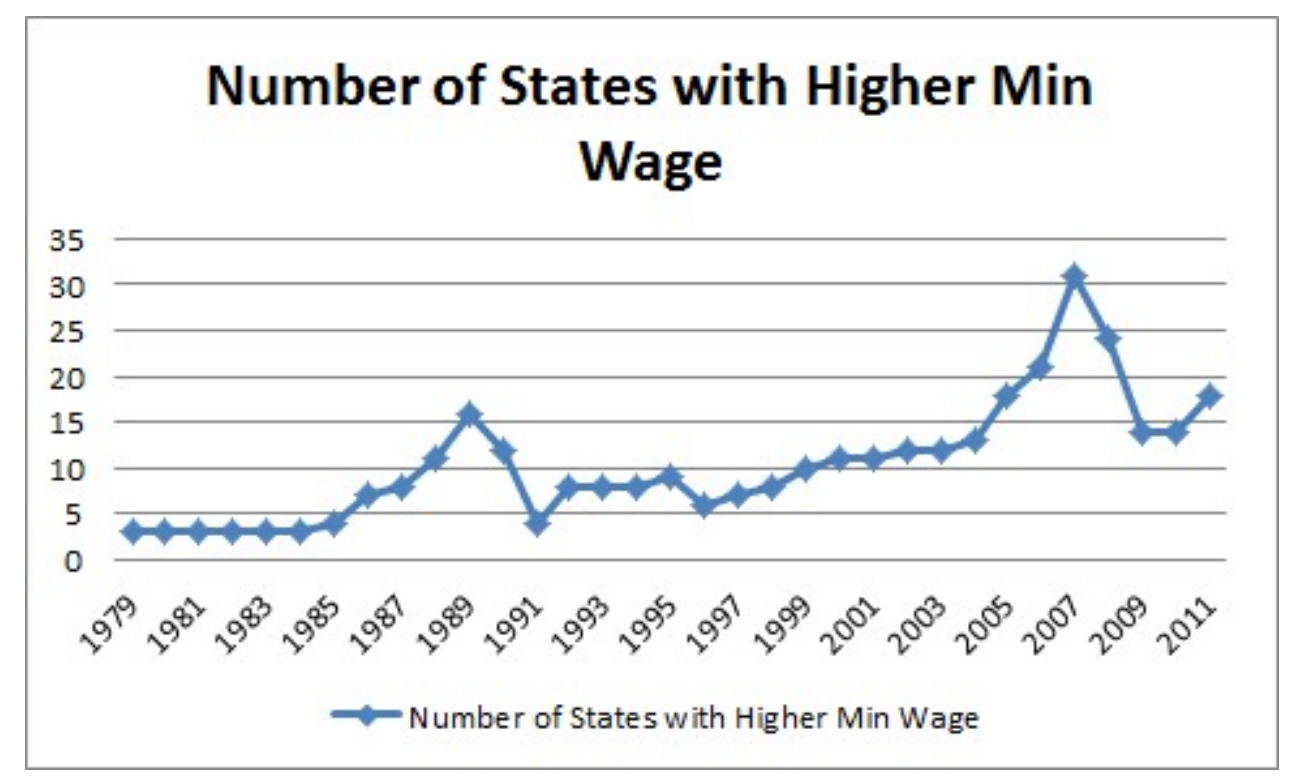

Figure 3.1: Number of States with Higher Minimum Wages

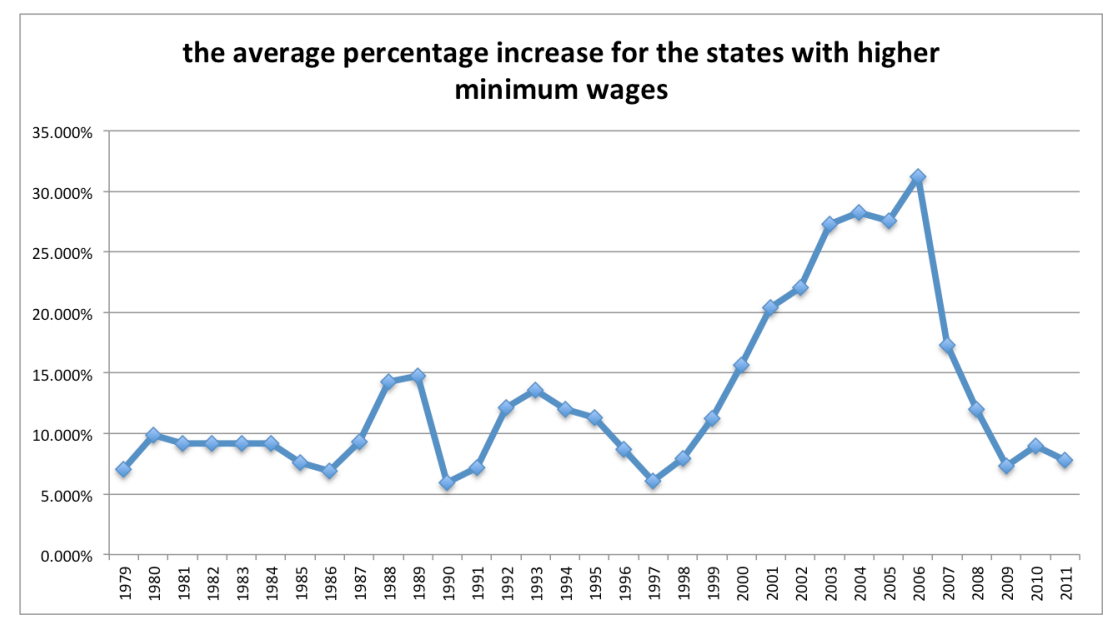

Figure 3.2: Average Percentage Difference Relative to Federal Minimum Wages for the States with Higher Minimum Wages 


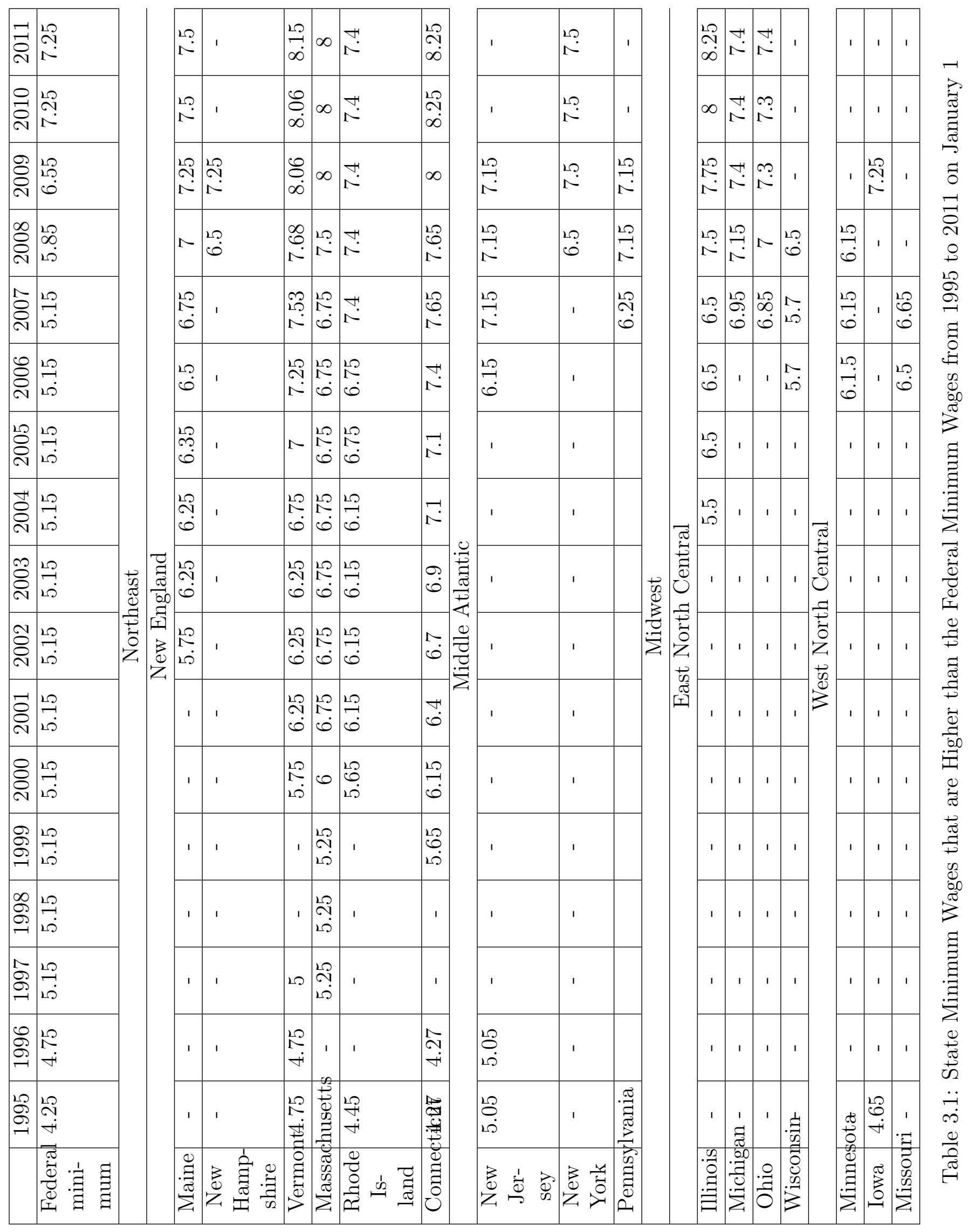




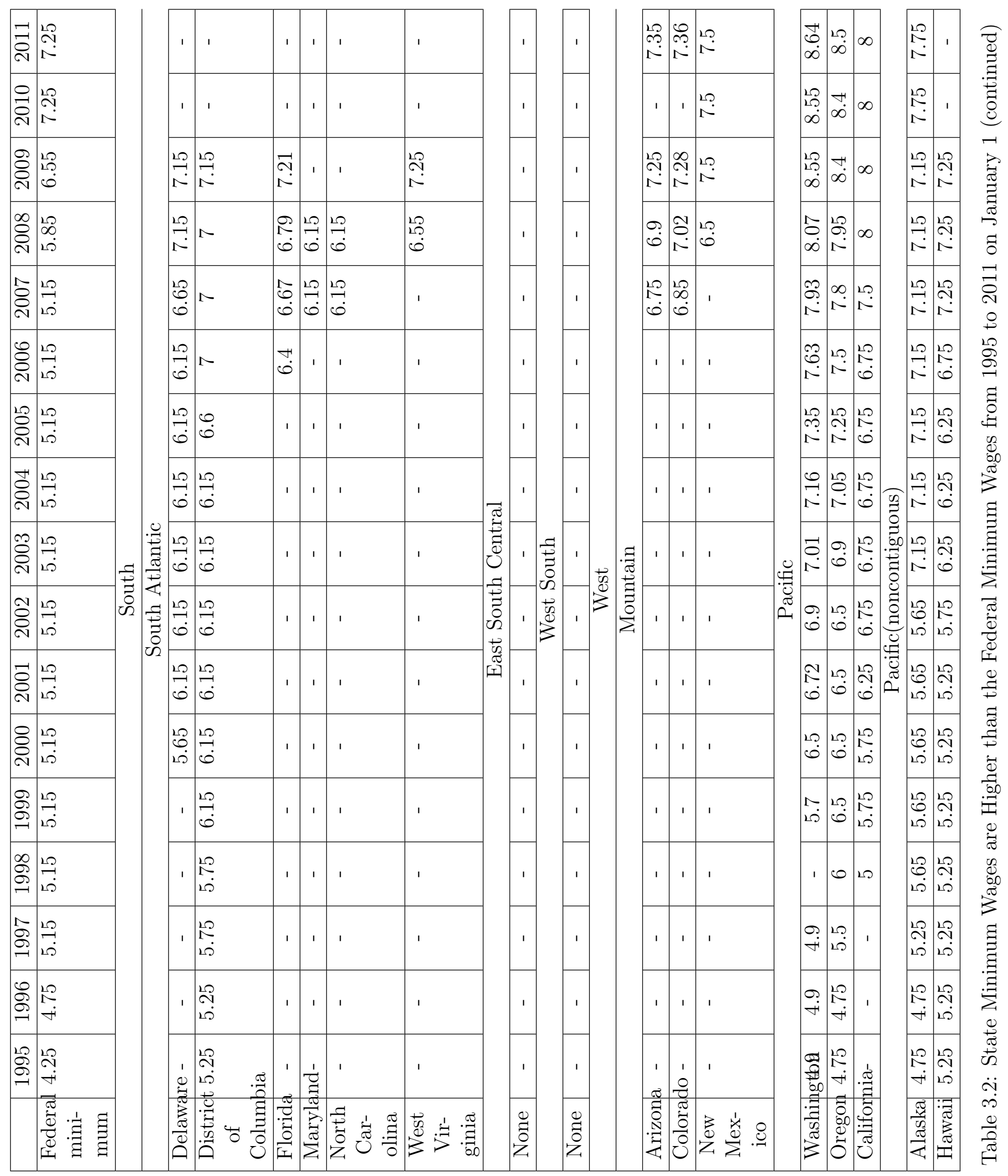




\begin{tabular}{|c|c|c|c|c|}
\hline Variable Names & Description & Mean(Sd) 79-97 & Mean(Sd) 97-11 & Mean(Sd) 79-11 \\
\hline dependent variable & $\begin{array}{l}\text { ratio of teenage } \\
\text { employment (16-19) to } \\
\text { teenage population }\end{array}$ & $0.44(0.14)$ & $0.37(0.15)$ & $0.41(0.15)$ \\
\hline teenage wage & $\begin{array}{l}\text { natural log of wage of } \\
\text { employed teenagers }\end{array}$ & $1.48(0.22)$ & $1.99(0.23)$ & $1.70(0.34)$ \\
\hline minimum wage & $\begin{array}{l}\text { natural log of higher of } \\
\text { federal or state minimum } \\
\text { wage }\end{array}$ & $1.31(0.15)$ & $1.78(0.16)$ & $1.51(0.28)$ \\
\hline adult wage & $\begin{array}{l}\text { natural log of the prime } \\
\text { age workers }(25-54) \text { wage }\end{array}$ & $2.13(0.23)$ & $2.65(0.16)$ & $2.37(0.33)$ \\
\hline share of teenagers & $\begin{array}{l}\text { proportion of teenage } \\
\text { population to the state } \\
\text { population }(16-64)\end{array}$ & $0.10(0.02)$ & $0.09(0.02)$ & $0.09(0.02)$ \\
\hline unemployment rate & $\begin{array}{l}\text { the prime age males } \\
\text { unemployment rate in the } \\
\text { state }\end{array}$ & $0.05(0.03)$ & $0.05(0.03)$ & $0.05(0.03)$ \\
\hline state effects & $\begin{array}{l}\text { dummy variables equal to } \\
\text { one for each state }\end{array}$ & - & - & - \\
\hline month effects & $\begin{array}{l}\text { dummy variables equal to } \\
\text { one for each month in the } \\
\text { year }\end{array}$ & - & - & - \\
\hline year effects & $\begin{array}{l}\text { dummy variables equal to } \\
\text { one for each year }\end{array}$ & - & - & - \\
\hline recession dummies & $\begin{array}{l}\text { dummy variable equals to } \\
\text { one if the economy is } \\
\text { officially in a recession in } \\
\text { a month }\end{array}$ & $0.13(0.34)$ & $0.14(0.35)$ & $0.14(0.35)$ \\
\hline number of states & $\begin{array}{l}50 \text { states and District of } \\
\text { Columbia }\end{array}$ & 51 & 51 & 51 \\
\hline sample size & $\begin{array}{l}\text { years*12 months*51 } \\
\text { states }\end{array}$ & 11,628 & 9,180 & 20,196 \\
\hline
\end{tabular}

Table 3.3: Description of the Variables Used in the Study 


\begin{tabular}{|c|c|c|c|c|c|c|}
\hline & \multicolumn{3}{|c|}{ 1979-1997 } & \multicolumn{3}{|c|}{$1979-2011$} \\
\hline variables & (1) & $(2)$ & $(3)$ & (4) & $(5)$ & (6) \\
\hline $\begin{array}{l}\text { log state } \\
\text { minimum } \\
\text { wage }\end{array}$ & $\begin{array}{c}0.332^{* * *} \\
(0.057)\end{array}$ & $\begin{array}{c}0.554^{* * *} \\
(0.049)\end{array}$ & $\begin{array}{c}0.553^{* * *} \\
(0.050)\end{array}$ & $\begin{array}{c}0.167^{* * *} \\
(0.025)\end{array}$ & $\begin{array}{c}0.488^{* * *} \\
(0.018)\end{array}$ & $\begin{array}{c}0.484^{* * *} \\
(0.019)\end{array}$ \\
\hline $\begin{array}{l}\text { log adult } \\
\text { wage }\end{array}$ & $\begin{array}{c}0.203^{* * *} \\
(0.039)\end{array}$ & $\begin{array}{c}0.409^{* * *} \\
(0.035)\end{array}$ & $\begin{array}{c}0.410^{* * *} \\
(0.035)\end{array}$ & $\begin{array}{c}0.134^{* * *} \\
(0.026)\end{array}$ & $\begin{array}{c}0.514^{* * *} \\
(0.016)\end{array}$ & $\begin{array}{c}0.517^{* * *} \\
(0.017)\end{array}$ \\
\hline $\begin{array}{l}\text { share of } \\
\text { teenagers }\end{array}$ & $\begin{array}{l}-0.019 \\
(0.062)\end{array}$ & $\begin{array}{l}-0.105 \\
(0.071)\end{array}$ & $\begin{array}{l}-0.107 \\
(0.071)\end{array}$ & $\begin{array}{c}0.075 \\
(0.075)\end{array}$ & $\begin{array}{c}0.076 \\
(0.085)\end{array}$ & $\begin{array}{c}0.062 \\
(0.086)\end{array}$ \\
\hline $\begin{array}{l}\text { unemployme } \\
\text { rate }\end{array}$ & $\begin{array}{l}\text { at }- \\
0.250^{* * *} \\
(0.075)\end{array}$ & $\begin{array}{c}- \\
0.523^{* * *} \\
(0.065)\end{array}$ & $\begin{array}{c}- \\
0.525^{* * *} \\
(0.066)\end{array}$ & $\begin{array}{c}- \\
0.195^{* * *} \\
(0.052)\end{array}$ & $\begin{array}{c}- \\
0.578^{* * *} \\
(0.054)\end{array}$ & $\begin{array}{c}- \\
0.586^{* * *} \\
(0.055)\end{array}$ \\
\hline $\begin{array}{l}\text { state } \\
\text { effects }\end{array}$ & Yes & Yes & Yes & Yes & Yes & Yes \\
\hline $\begin{array}{l}\text { seasonal } \\
\text { adjust- } \\
\text { ments }\end{array}$ & Yes & Yes & Yes & Yes & Yes & Yes \\
\hline year effects & Yes & No & No & Yes & No & No \\
\hline recession & - & - & $\begin{array}{c}0.001 \\
(0.003)\end{array}$ & - & - & $\begin{array}{c}0.008 * * \\
* \\
(0.003)\end{array}$ \\
\hline$R^{2}$ & 0.781 & 0.767 & 0.767 & 0.885 & 0.872 & 0.872 \\
\hline $\mathrm{N}$ & 11628 & 11628 & 11628 & 20196 & 20196 & 20196 \\
\hline
\end{tabular}

Note: $* * *$ means estimates are significant at $1 \%$ level. $* *$ and $*$ are for $5 \%$ and $10 \%$ levels respectively.

Table 3.4: Minimum Wage Effect on Teenage Wage Rate 


\begin{tabular}{|l|c|c|c|c|c|}
\hline variables & $(1)$ & $(2)$ & $(3)$ & $(4)$ & $(5)$ \\
\hline \hline log of & - & - & - & 0.023 & - \\
minimum & $0.178^{* * *}$ & $0.133^{* * *}$ & $0.119^{* * *}$ & $(0.045)$ & $0.116^{* * *}$ \\
wage & $(0.055)$ & $(0.018)$ & $(0.019)$ & & $(0.020)$ \\
\hline $\begin{array}{l}\text { log of } \\
\text { adult wage }\end{array}$ & 0.073 & 0.031 & 0.020 & 0.034 & 0.015 \\
$(0.052)$ & $(0.020)$ & $(0.018)$ & $(0.027)$ & $(0.017)$ \\
\hline $\begin{array}{l}\text { share of } \\
\text { teenagers }\end{array}$ & 0.177 & -0.007 & 0.009 & -0.009 & 0.019 \\
\hline unemployment & - & - & - & - & - \\
rate & $1.023^{* * *}$ & $0.876^{* * *}$ & $0.735^{* * *}$ & $0.553^{* * *}$ & $0.724^{* * *}$ \\
& $(0.115)$ & $(0.072)$ & $(0.065)$ & $(0.076)$ & $(0.066)$ \\
\hline $\begin{array}{l}\text { state } \\
\text { effects }\end{array}$ & No & Yes & Yes & Yes & Yes \\
\hline $\begin{array}{l}\text { seasonal } \\
\text { adjust- } \\
\text { ments }\end{array}$ & No & No & Yes & Yes & Yes \\
\hline year effects & No & No & No & Yes & No \\
\hline $\begin{array}{l}\text { recession } \\
\text { dummies }\end{array}$ & - & - & - & - & $-0.007^{* *}$ \\
\hline$R^{2}$ & 0.076 & 0.353 & 0.515 & 0.524 & 0.516 \\
\hline $\begin{array}{l}\text { auxiliary } \\
R^{2}\end{array}$ & - & 0.015 & 0.003 & 0.932 & 0.039 \\
\hline elasticity & -0.405 & -0.302 & -0.270 & 0.052 & -0.264 \\
\hline
\end{tabular}

Table 3.5: Minimum Wage Effect on the Ratio of Teenage Employment to Teenage Population (January 1979 to December 1997) 


\begin{tabular}{|c|c|c|c|c|c|}
\hline variables & (1) & $(2)$ & (3) & (4) & $(5)$ \\
\hline $\begin{array}{l}\text { log of } \\
\text { minimum } \\
\text { wage }\end{array}$ & $\begin{array}{c}- \\
0.252^{* * *} \\
(0.040)\end{array}$ & $\begin{array}{c}- \\
0.191^{* * *} \\
(0.008)\end{array}$ & $\begin{array}{c}- \\
0.191^{* * *} \\
(0.008)\end{array}$ & $\begin{array}{c}- \\
0.100^{* * *} \\
(0.019)\end{array}$ & $\begin{array}{c}- \\
0.189^{* * *} \\
(0.008)\end{array}$ \\
\hline $\begin{array}{l}\log \text { of } \\
\text { adult wage }\end{array}$ & $\begin{array}{l}0.085^{* *} \\
(0.038)\end{array}$ & $\begin{array}{c}0.019 \\
(0.012)\end{array}$ & $\begin{array}{c}0.018 \\
(0.012)\end{array}$ & $\begin{array}{c}0.032 \\
(0.024)\end{array}$ & $\begin{array}{c}0.016 \\
(0.012)\end{array}$ \\
\hline $\begin{array}{l}\text { share of } \\
\text { teenagers }\end{array}$ & $\begin{array}{c}0.213 \\
(0.175)\end{array}$ & $\begin{array}{c}-0.101 * * \\
(0.050)\end{array}$ & $\begin{array}{l}-0.092^{*} \\
(0.055)\end{array}$ & $\begin{array}{l}-0.016 \\
(0.048)\end{array}$ & $\begin{array}{l}-0.085 \\
(0.054)\end{array}$ \\
\hline $\begin{array}{l}\text { unemployme } \\
\text { rate }\end{array}$ & $\begin{array}{l}\text { nt } \quad- \\
1.022^{* * *} \\
(0.110)\end{array}$ & $\begin{array}{c}- \\
0.996^{* * *} \\
(0.056)\end{array}$ & $\begin{array}{c}- \\
0.909^{* * *} \\
(0.058)\end{array}$ & $\begin{array}{c}- \\
0.509^{* * *} \\
(0.061)\end{array}$ & $\begin{array}{c}- \\
0.904^{* * *} \\
(0.060)\end{array}$ \\
\hline $\begin{array}{l}\text { state } \\
\text { effects }\end{array}$ & No & Yes & Yes & Yes & Yes \\
\hline $\begin{array}{l}\text { seasonal } \\
\text { adjust- } \\
\text { ments }\end{array}$ & No & No & Yes & Yes & Yes \\
\hline year effects & No & No & No & Yes & No \\
\hline recession & - & - & - & - & $\begin{array}{l}-0.004 \\
(0.003)\end{array}$ \\
\hline$R^{2}$ & 0.229 & 0.453 & 0.546 & 0.578 & 0.546 \\
\hline auxiliary $R^{2}$ & - & 0.029 & 0.030 & 0.952 & 0.021 \\
\hline elasticity & -0.615 & -0.466 & -0.466 & -0.244 & -0.461 \\
\hline
\end{tabular}

Table 3.6: Minimum Wage Effect on the Ratio of Teenage Employment to Teenage Population (January 1979 to December 2011) 


\begin{tabular}{|c|c|c|c|c|c|}
\hline Variables & (1) & (2) & $(3)$ & (4) & (5) \\
\hline $\begin{array}{l}\log \\
\text { minimum } \\
\text { wage }\end{array}$ & $\begin{array}{c}- \\
0.095^{* * *} \\
(0.031)\end{array}$ & $\begin{array}{c}- \\
0.076^{* * *} \\
(0.025)\end{array}$ & $\begin{array}{c}-0.054^{* *} \\
(0.024)\end{array}$ & $\begin{array}{c}0.019 \\
(0.046)\end{array}$ & $\begin{array}{c}-0.044^{*} \\
(0.023)\end{array}$ \\
\hline $\begin{array}{l}\text { log } \\
\text { minimum } \\
\text { wage } \\
\text { lagged } 1 \\
\text { year }\end{array}$ & $\begin{array}{c}-0.096^{* *} \\
(0.046)\end{array}$ & $\begin{array}{c}- \\
0.079^{* * *} \\
(0.024)\end{array}$ & $\begin{array}{c}- \\
0.098^{* * *} \\
(0.023)\end{array}$ & $\begin{array}{c}0.015 \\
(0.020)\end{array}$ & $\begin{array}{c}- \\
0.107^{* * *} \\
(0.020)\end{array}$ \\
\hline $\begin{array}{l}\text { log adult } \\
\text { wage }\end{array}$ & $\begin{array}{c}0.081 \\
(0.060)\end{array}$ & $\begin{array}{c}0.050^{* * *} \\
(0.019)\end{array}$ & $\begin{array}{l}0.048^{* *} \\
(0.018)\end{array}$ & $\begin{array}{c}0.037 \\
(0.027)\end{array}$ & $\begin{array}{l}0.043^{* *} \\
(0.018)\end{array}$ \\
\hline $\begin{array}{l}\text { share of } \\
\text { teenagers }\end{array}$ & $\begin{array}{c}0.091 \\
(0.203)\end{array}$ & $\begin{array}{l}-0.030 \\
(0.085)\end{array}$ & $\begin{array}{l}-0.027 \\
(0.058)\end{array}$ & $\begin{array}{c}-0.018 \\
(0.058)\end{array}$ & $\begin{array}{c}-0.016 \\
(0.059)\end{array}$ \\
\hline $\begin{array}{l}\text { unemployme } \\
\text { rate }\end{array}$ & $\begin{array}{l}\text { nt } \quad- \\
0.991^{* * *} \\
(0.127)\end{array}$ & $\begin{array}{c}- \\
0.845^{* * *} \\
(0.075)\end{array}$ & $\begin{array}{c}- \\
0.693^{* * *} \\
(0.067)\end{array}$ & $\begin{array}{c}- \\
0.571^{* * *} \\
(0.076)\end{array}$ & $\begin{array}{c}- \\
0.685^{* * *} \\
(0.068)\end{array}$ \\
\hline $\begin{array}{l}\text { state } \\
\text { effects }\end{array}$ & $\mathrm{No}$ & Yes & Yes & Yes & Yes \\
\hline $\begin{array}{l}\text { seasonal } \\
\text { adjust- } \\
\text { ments }\end{array}$ & $\mathrm{No}$ & No & Yes & Yes & Yes \\
\hline year effects & No & No & No & Yes & No \\
\hline recession & - & - & - & - & $\begin{array}{c}-0.007^{* *} \\
(0.003)\end{array}$ \\
\hline$R^{2}$ & 0.069 & 0.348 & 0.511 & 0.518 & 0.511 \\
\hline $\begin{array}{l}\text { long-run } \\
\text { elasticity }\end{array}$ & -0.434 & -0.352 & -0.345 & 0.076 & -0.343 \\
\hline
\end{tabular}

Table 3.7: One Year Lagged Minimum Wage Effects on the ratio of Teenage Employment to Teenage Population (January 1980 - December 1997) 


\begin{tabular}{|c|c|c|c|c|c|}
\hline Variables & (1) & $(2)$ & (3) & (4) & (5) \\
\hline $\begin{array}{l}\log \\
\text { minimum } \\
\text { wage }\end{array}$ & $\begin{array}{c}- \\
0.145^{* * *} \\
(0.028)\end{array}$ & $\begin{array}{c}- \\
0.118^{* * *} \\
(0.019)\end{array}$ & $\begin{array}{c}- \\
0.116^{* * *} \\
(0.020)\end{array}$ & $\begin{array}{c}- \\
0.059^{* * *} \\
(0.018)\end{array}$ & $\begin{array}{c}- \\
0.107^{* * *} \\
(0.017)\end{array}$ \\
\hline $\begin{array}{l}\text { log } \\
\text { minimum } \\
\text { wage } \\
\text { lagged } 1 \\
\text { year }\end{array}$ & $\begin{array}{c}- \\
0.119^{* * *} \\
(0.029)\end{array}$ & $\begin{array}{c}- \\
0.081^{* * *} \\
(0.021)\end{array}$ & $\begin{array}{c}- \\
0.085^{* * *} \\
(0.022)\end{array}$ & $\begin{array}{c}- \\
0.049^{* * *} \\
(0.017)\end{array}$ & $\begin{array}{c}- \\
0.092^{\text {*** }} \\
(0.020)\end{array}$ \\
\hline $\begin{array}{l}\text { log adult } \\
\text { wage }\end{array}$ & $\begin{array}{c}0.093 \\
* * \\
(0.043)\end{array}$ & $\begin{array}{c}0.023 \\
* \\
(0.013)\end{array}$ & $\begin{array}{c}0.024 \\
* \\
(0.013)\end{array}$ & $\begin{array}{c}0.033 \\
(0.023)\end{array}$ & $\begin{array}{c}0.022 \\
(0.013)\end{array}$ \\
\hline $\begin{array}{l}\text { share of } \\
\text { teenagers }\end{array}$ & $\begin{array}{c}0.187 \\
(0.179)\end{array}$ & $\begin{array}{l}-0.096^{*} \\
(0.050)\end{array}$ & $\begin{array}{l}-0.085 \\
(0.054)\end{array}$ & $\begin{array}{l}-0.017 \\
(0.049)\end{array}$ & $\begin{array}{l}-0.071 \\
(0.053)\end{array}$ \\
\hline $\begin{array}{l}\text { unemployme } \\
\text { rate }\end{array}$ & $\begin{array}{l}\text { nt }- \\
1.006^{* * *} \\
(0.112)\end{array}$ & $\begin{array}{c}- \\
0.997^{* * *} \\
(0.054)\end{array}$ & $\begin{array}{c}- \\
0.908^{* * *} \\
(0.056)\end{array}$ & $\begin{array}{c}- \\
0.516^{* * *} \\
(0.061)\end{array}$ & $\begin{array}{c}- \\
0.901^{* * *} \\
(0.057)\end{array}$ \\
\hline $\begin{array}{l}\text { state } \\
\text { effects }\end{array}$ & $\mathrm{No}$ & Yes & Yes & Yes & Yes \\
\hline $\begin{array}{l}\text { seasonal } \\
\text { adjust- } \\
\text { ments }\end{array}$ & No & No & Yes & Yes & Yes \\
\hline year effects & $\mathrm{No}$ & $\mathrm{No}$ & $\mathrm{No}$ & Yes & No \\
\hline recession & - & - & - & - & $\begin{array}{c}- \\
0.007^{* * *} \\
(0.003)\end{array}$ \\
\hline$R^{2}$ & 0.224 & 0.449 & 0.541 & 0.573 & 0.542 \\
\hline $\begin{array}{l}\text { long-run } \\
\text { elasticity }\end{array}$ & -0.644 & -0.485 & -0.490 & -0.255 & -0.485 \\
\hline
\end{tabular}

Table 3.8: One Year Lagged Minimum Wage Effects on the Ratio of Teenage Employment to Teenage Population (January 1980 - December 2011) 


\begin{tabular}{|c|c|c|c|c|c|c|}
\hline Variables & (1) & (2) & (3) & (4) & (5) & (6) \\
\hline & \multicolumn{3}{|c|}{$\begin{array}{c}\text { table } \\
3.5 \\
(3)-(5)\end{array}$} & \multicolumn{3}{|c|}{$\begin{array}{c}\text { table } \\
3.7 \\
(3)-(5)\end{array}$} \\
\hline $\begin{array}{l}\log \\
\text { minimum } \\
\text { wage }\end{array}$ & $\begin{array}{c}- \\
0.201^{* * *} \\
(0.019)\end{array}$ & $\begin{array}{l}-0.048 \\
(0.033)\end{array}$ & $\begin{array}{c}- \\
0.209^{* * *} \\
(0.019)\end{array}$ & $\begin{array}{c}- \\
0.151^{* * *} \\
(0.018)\end{array}$ & $\begin{array}{l}-0.036^{*} \\
(0.021)\end{array}$ & $\begin{array}{c}- \\
0.165^{* * *} \\
(0.018)\end{array}$ \\
\hline $\begin{array}{l}\log \\
\text { minimum } \\
\text { wage } \\
\text { lagged } 1 \\
\text { year }\end{array}$ & - & - & - & $\begin{array}{c}- \\
0.060^{* * *} \\
(0.023)\end{array}$ & $\begin{array}{l}-0.016 \\
(0.028)\end{array}$ & $\begin{array}{c}-0.053^{* *} \\
(0.024)\end{array}$ \\
\hline $\begin{array}{l}\text { log adult } \\
\text { wage }\end{array}$ & $\begin{array}{c}- \\
0.154^{* * *} \\
(0.020)\end{array}$ & $\begin{array}{c}0.032^{*} \\
(0.017)\end{array}$ & $\begin{array}{c}- \\
0.158^{* * *} \\
(0.020)\end{array}$ & $\begin{array}{c}- \\
0.146^{* * *} \\
(0.020)\end{array}$ & $\begin{array}{c}0.031^{*} \\
(0.018)\end{array}$ & $\begin{array}{c}- \\
0.150^{* * *} \\
(0.021)\end{array}$ \\
\hline $\begin{array}{l}\text { share of } \\
\text { teenagers }\end{array}$ & $\begin{array}{c}0.203^{* * *} \\
(0.077) \\
\end{array}$ & $\begin{array}{c}0.059 \\
(0.068)\end{array}$ & $\begin{array}{c}0.198^{* * *} \\
(0.076) \\
\end{array}$ & $\begin{array}{c}0.203^{* * *} \\
(0.077) \\
\end{array}$ & $\begin{array}{c}0.060 \\
(0.067)\end{array}$ & $\begin{array}{c}0.198^{* * *} \\
(0.076)\end{array}$ \\
\hline unemploymer & at - & $\begin{array}{c}- \\
0.331^{* * *}\end{array}$ & - & - & $\begin{array}{c}- \\
0.331^{* * *}\end{array}$ & - \\
\hline rate & $\begin{array}{c}0.629^{* * *} \\
(0.088) \\
\end{array}$ & $(0.072)$ & $\begin{array}{c}0.614^{* * *} \\
(0.086) \\
\end{array}$ & $\begin{array}{c}0.610^{* * *} \\
(0.092) \\
\end{array}$ & $(0.072)$ & $\begin{array}{c}0.598^{* * *} \\
(0.090) \\
\end{array}$ \\
\hline $\begin{array}{l}\text { state } \\
\text { effects }\end{array}$ & Yes & Yes & Yes & Yes & Yes & Yes \\
\hline $\begin{array}{l}\text { seasonal } \\
\text { adjust- } \\
\text { ments }\end{array}$ & Yes & Yes & Yes & Yes & Yes & Yes \\
\hline year effects & No & Yes & No & No & Yes & No \\
\hline recession & - & - & $\begin{array}{c}0.015^{* * *} \\
(0.003)\end{array}$ & - & - & $\begin{array}{c}0.014^{* * *} \\
(0.003)\end{array}$ \\
\hline$R^{2}$ & 0.555 & 0.585 & 0.557 & 0.556 & 0.585 & 0.557 \\
\hline elasticity & -0.543 & -0.130 & -0.565 & -0.570 & -0.141 & -0.589 \\
\hline
\end{tabular}

Table 3.9: Minimum Wage Effect on Teenage Employment (January 1997 to December 2011) 


\begin{tabular}{|c|c|c|c|}
\hline variables & (1) & $(2)$ & (3) \\
\hline $\begin{array}{l}\text { log of } \\
\text { minimum } \\
\text { wage }\end{array}$ & $\begin{array}{c}- \\
0.189^{* * *} \\
(0.008)\end{array}$ & $\begin{array}{c}- \\
0.105^{* * *} \\
(0.019)\end{array}$ & $\begin{array}{c}- \\
0.188^{* * *} \\
(0.008)\end{array}$ \\
\hline $\begin{array}{l}\log \text { of } \\
\text { adult wage }\end{array}$ & $\begin{array}{c}0.016 \\
(0.012) \\
\end{array}$ & $\begin{array}{c}0.113^{* * *} \\
(0.015)\end{array}$ & $\begin{array}{c}0.017 \\
(0.012)\end{array}$ \\
\hline $\begin{array}{l}\text { share of } \\
\text { teenagers }\end{array}$ & $\begin{array}{l}-0.085 \\
(0.054)\end{array}$ & $\begin{array}{c}- \\
0.145^{* * *} \\
(0.051)\end{array}$ & $\begin{array}{l}-0.094^{*} \\
(0.055)\end{array}$ \\
\hline unemployme & at & - & - \\
\hline rate & $\begin{array}{c}0.904^{* * *} \\
(0.060)\end{array}$ & $\begin{array}{c}0.914^{* * *} \\
(0.054)\end{array}$ & $\begin{array}{c}0.902^{* * *} \\
(0.058)\end{array}$ \\
\hline $\begin{array}{l}\text { state } \\
\text { effects }\end{array}$ & Yes & Yes & Yes \\
\hline $\begin{array}{l}\text { seasonal } \\
\text { adjust- } \\
\text { ments }\end{array}$ & Yes & Yes & Yes \\
\hline year effects & No & No & No \\
\hline recession & $\begin{array}{l}-0.004 \\
(0.003)\end{array}$ & - & - \\
\hline $\log$ of CPI & - & $\begin{array}{c}- \\
0.001^{* * *} \\
(0.000)\end{array}$ & - \\
\hline $\begin{array}{l}\text { growth } \\
\text { rate of the } \\
\text { labor force }\end{array}$ & - & - & $\begin{array}{l}1.68^{* * *} \\
(0.214)\end{array}$ \\
\hline$R^{2}$ & 0.546 & 0.550 & 0.547 \\
\hline elasticity & -0.461 & -0.256 & -0.459 \\
\hline
\end{tabular}

Table 3.10: Employment Effect with Alternative Microeconomic Controls (from January 1979 to December 2011) 


\begin{tabular}{|c|c|c|c|c|c|c|}
\hline Variables & (1) & $(2)$ & (3) & (4) & $(5)$ & (6) \\
\hline & \multicolumn{3}{|c|}{$\begin{array}{c}\text { table } \\
3.6 \\
(4)-(6) \\
\end{array}$} & \multicolumn{3}{|c|}{$\begin{array}{c}\text { table } \\
3.8 \\
(4)-(6) \\
\end{array}$} \\
\hline $\begin{array}{l}\log \\
\text { minimum } \\
\text { wage }\end{array}$ & $\begin{array}{c}- \\
0.195^{* * *} \\
(0.007) \\
\end{array}$ & $\begin{array}{c}- \\
0.108^{* * *} \\
(0.013)\end{array}$ & $\begin{array}{c}- \\
0.190^{* * *} \\
(0.007) \\
\end{array}$ & $\begin{array}{c}- \\
0.123^{* * *} \\
(0.014) \\
\end{array}$ & $\begin{array}{c}- \\
0.075^{* * *} \\
(0.018)\end{array}$ & $\begin{array}{c}- \\
0.108^{* * *} \\
(0.014)\end{array}$ \\
\hline $\begin{array}{l}\log \\
\text { minimum } \\
\text { wage } \\
\text { lagged } 1 \\
\text { year }\end{array}$ & - & - & - & $\begin{array}{c}- \\
0.084^{* * *} \\
(0.014)\end{array}$ & $\begin{array}{c}-0.045^{* *} \\
(0.018)\end{array}$ & $\begin{array}{c}- \\
0.096^{* * *} \\
(0.014)\end{array}$ \\
\hline $\begin{array}{l}\text { log adult } \\
\text { wage }\end{array}$ & $\begin{array}{c}0.032^{* * *} \\
(0.006)\end{array}$ & $\begin{array}{c}0.027^{* * *} \\
(0.010)\end{array}$ & $\begin{array}{c}0.028^{* * *} \\
(0.006)\end{array}$ & $\begin{array}{c}0.042^{* * *} \\
(0.007)\end{array}$ & $\begin{array}{l}0.026^{* *} \\
(0.001)\end{array}$ & $\begin{array}{c}0.039^{* * *} \\
(0.007)\end{array}$ \\
\hline $\begin{array}{l}\text { share of } \\
\text { teenagers }\end{array}$ & $\begin{array}{l}-0.068^{*} \\
(0.040) \\
\end{array}$ & $\begin{array}{c}-0.031 \\
(0.040)\end{array}$ & $\begin{array}{l}-0.059 \\
(0.040) \\
\end{array}$ & $\begin{array}{l}-0.078^{*} \\
(0.041) \\
\end{array}$ & $\begin{array}{l}-0.035 \\
(0.041)\end{array}$ & $\begin{array}{l}-0.064 \\
(0.042) \\
\end{array}$ \\
\hline $\begin{array}{l}\text { unemployme } \\
\text { rate }\end{array}$ & $\begin{array}{c}\text { nt }- \\
0.731^{* * *} \\
(0.024)\end{array}$ & $\begin{array}{l}-0.407 \\
(0.027)\end{array}$ & $\begin{array}{c}- \\
0.749^{* * *} \\
(0.024)\end{array}$ & $\begin{array}{c}- \\
0.726^{* * *} \\
(0.025)\end{array}$ & $\begin{array}{c}-\overline{-} \\
0.416^{* * *} \\
(0.027)\end{array}$ & $\begin{array}{c}- \\
0.718^{* * *} \\
(0.025)\end{array}$ \\
\hline $\begin{array}{l}\text { state } \\
\text { effects }\end{array}$ & Yes & Yes & Yes & Yes & Yes & Yes \\
\hline $\begin{array}{l}\text { seasonal } \\
\text { adjust- } \\
\text { ments }\end{array}$ & Yes & Yes & Yes & Yes & Yes & Yes \\
\hline year effects & No & Yes & No & No & Yes & No \\
\hline $\begin{array}{l}\text { recession } \\
\text { dummies }\end{array}$ & - & - & $\begin{array}{c}- \\
0.006^{* * *} \\
(0.002)\end{array}$ & - & - & $\begin{array}{c}- \\
0.009^{* * *} \\
(0.002)\end{array}$ \\
\hline elasticity & -0.476 & -0.263 & -0.463 & -0.505 & -0.293 & -0.498 \\
\hline
\end{tabular}

Table 3.11: Minimum Wage Effect on Teenage Employment after Correction for Statelevel Autocorrelation and Heteroskedasticity(January 1979 to December 2011) 


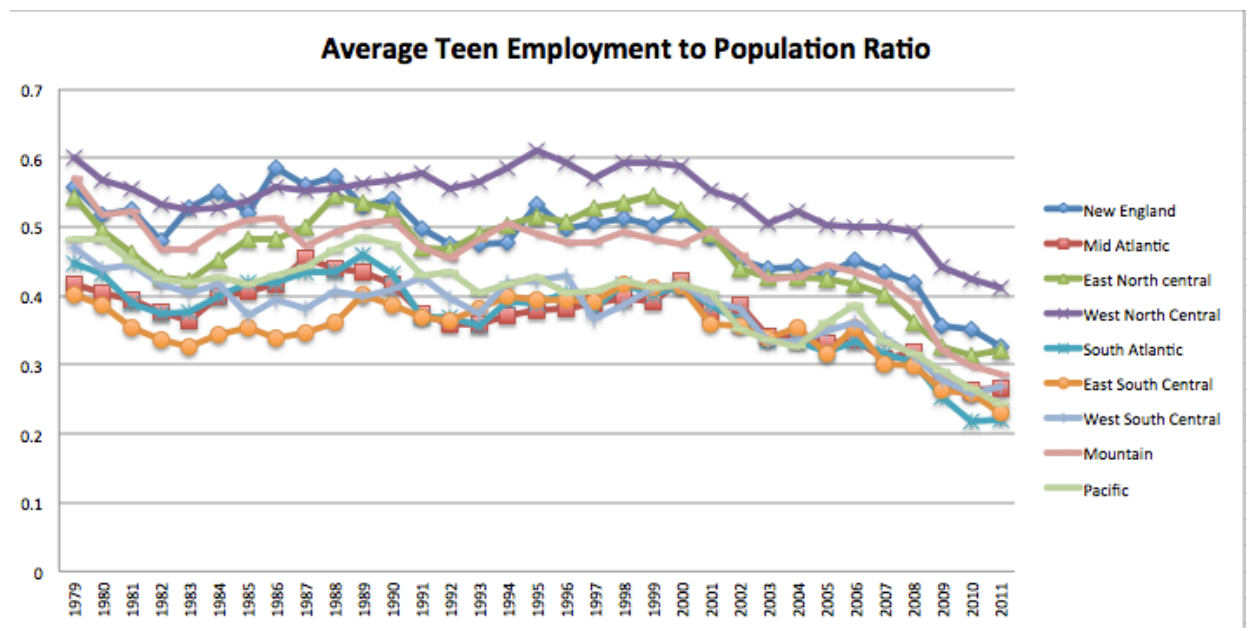

Figure 3.3: Average Teenage Employment to Population Ratio in Regional Level

\begin{tabular}{|c|c|c|}
\hline Variables & $(1)$ & $(2)$ \\
\hline \hline log of minimum wage & $-0.100^{* * *}(0.019)$ & $-0.062^{* *}(0.025)$ \\
\hline year effects & Yes & - \\
\hline division-specific year effects & - & Yes \\
\hline elasticity & -0.244 & -0.151 \\
\hline
\end{tabular}

Table 3.12: Minimum Wage Effect on the Teenage Employment Ratio with Year Dummies and Division Specific Year Dummies, from January 1979 to December 2011

\begin{tabular}{|c|c|c|}
\hline Variables & $(1)$ & $(2)$ \\
\hline \hline log of minimum wage & $-0.100^{* * *}(0.019)$ & $-0.015(0.039)$ \\
\hline year effects & Yes & Yes \\
\hline state specific linear time trends & - & Yes \\
\hline elasticity & -0.244 & -0.037 \\
\hline
\end{tabular}

Table 3.13: Minimum Wage Effect on the Teenage Employment Ratio with Time Trends, from January 1979 to December 2011 


\begin{tabular}{|c|c|}
\hline year & states \\
\hline \hline 2001 & Washington \\
\hline 2002 & Washington \\
\hline 2003 & Washington \\
\hline 2004 & Oregon, Washington \\
\hline 2005 & Oregon, Washington \\
\hline 2006 & Florida, Oregon, Washington \\
\hline 2007 & Florida, Nevada, Oregon, Vermont, Washington \\
\hline 2008 & Arizona, Colorado, Florida, Missouri, Montana, Nevada, Ohio, Oregon, Vermont, Washington \\
\hline 2009 & Arizona, Colorado, Florida, Missouri, Montana, Nevada, Ohio, Oregon, Vermont, Washington \\
\hline 2010 & Arizona, Colorado, Florida, Missouri, Montana, Nevada, Ohio, Oregon, Vermont, Washington \\
\hline 2011 & Arizona, Colorado, Florida, Missouri, Montana, Nevada, Ohio, Oregon, Vermont, Washington \\
\hline
\end{tabular}

Table 3.14: States with Indexation

\begin{tabular}{|c|c|c|c|c|}
\hline Variables & Non-index states & \multicolumn{3}{|c|}{ all states } \\
\hline \hline & $(1)$ & $(2)$ & $(3)$ & $(4)$ \\
\hline log of minimum wage & $-0.095^{* * *}(0.020)$ & $-0.100^{* * *}(0.019)$ & $-0.096^{* * *}(0.018)$ & $-0.061^{* * *}(0.024)$ \\
\hline index & - & - & Yes & Yes \\
\hline year effects & Yes & Yes & Yes & - \\
\hline division-specific year effects & - & - & - & Yes \\
\hline elasticity & -0.232 & -0.244 & -0.234 & -0.149 \\
\hline
\end{tabular}

Table 3.15: Minimum Wage Effect on the Teenage Employment Ratio with Indexation, from January 1979 to December 2011

\begin{tabular}{|c|c|c|}
\hline variables & $(1)$ & $(2)$ \\
\hline \hline log of minimum wage & $-0.100^{* * *}(0.019)$ & $-0.128^{* * *}(0.019)$ \\
\hline MW $^{*}$ unemp & - & $0.509^{* * *}(0.152)$ \\
\hline year effects & Yes & Yes \\
\hline elasticity & -0.244 & -0.250 \\
\hline
\end{tabular}

Table 3.16: Minimum Wage Effect on the Teenage Employment Ratio with Unemployment Interaction, from January 1979 to December 2011 


\section{Chapter 4}

\section{Employment Effects of Missouri State}

\section{Minimum wage}

\subsection{Introduction}

Several states have set their state minimum wages based on local economic conditions. Missouri established a state minimum wage and indexed it to the consumer price index (CPI) beginning in January 2007. Economists have argued that the Missouri minimum wage increases would reduce employment opportunities, overwhelming any benefits from a higher wage for low skill workers.

There are several papers discussing the impact of Missouri state minimum wage, which are discussed in chapter 2. But all these papers are based on the observations before 2007. So far, to our best knowledge, this study is the first empirical study to explore Missouri state minimum wage effects after 2007, when state minimum wage was effective. Our data are Missouri and Kansas administrative payroll data from 2006 to 2012. The Kansas City metropolitan area straddles the border between Missouri and Kansas. Two sides of the Kansas City metropolitan area share similar economies and institutions. Unlike Missouri, Kansas has no state minimum wage and 
so only enforces the federal minimum wage. Implementation of Missouri's minimum wage represents a natural experiment. The close geographic proximity and the availability of data from these two states provide us a valuable opportunity to explore the minimum wage effects on employment in our study. This chapter introduces the methodologies we use in the study and provides empirical results and interpretations. In general, we examine the employment impact for each single wave of minimum wage increases and construct multi-period multi-group panel data to estimate the effects on different firm size groups. Furthermore, we also explore how individuals respond to minimum wage and the employment effects on different earning groups.

This chapter is organized with the following sections. Section 2 introduces the history of Missouri state minimum wage. Section 3 describes our data, which includes the benefits and limitations, how we construct the data set, and provides data descriptions. Section 4 presents the single-wave difference-in-differences results. Section 5 presents the firm level regression identification strategies, results, interpretations and a short summary. Section 6 and 7 analyze the minimum wage at the individual-level. Section 6 discusses the probability of being employed for each individual and section 7 considers worker movements between the two states and within each state.

\subsection{Missouri Minimum Wage}

Table 4.1 provides the history of minimum wage changes in Missouri and Kansas from 2006 to 2012. In 2006, Missouri and Kansas had the same federal minimum wage $\$ 5.15$. On January 1 2007, Missouri increased the state minimum wage to $\$ 6.50$. Then, it is raised to $\$ 6.65$ in January 2008 and to $\$ 7.05$ in January 2009. During the same period, Kansas experienced several federal minimum wage increases. The federal minimum wage increased to $\$ 5.85$ in July 2007 , then it increased to $\$ 6.55$ one year later. In January 2009, the federal minimum wage increased to $\$ 7.05$. In 
July 2009 , the federal minimum wage increased to $\$ 7.25$, and there was no difference between Missouri and Kansas minimum wages thereafter ${ }^{1}$.

\subsection{Data}

We have the Unemployment Insurance Wage Record Data, which are provided by the Missouri Department of Labor and Industrial Relations and the Kansas Department of Labor. They are the quarterly employee-level payroll data on earnings for all working people filled by employers subject to Unemployment Insurance reporting requirements in Missouri and Kansas. Since most of workers are covered by the Unemployment Insurance, our data cover nearly all working population in two states. The data available to us in Missouri changed in the third quarter of $2006^{2}$. Wage record data available to us prior to this quarter do not contain the industry and location identifiers that we need. Since Missouri first raised the state minimum wage on January 12007 , including data prior to 2007 does not add much explanatory power to the employment effects of state minimum wages. After 2009, there is no minimum wage change in both states. Adding quarters after 2009 has no direct impact on minimum wages, but the longer panel could benefit our analysis for the following reason. When we control for firm level fixed effects in the model, these quarters provide us a better control of individual firms. Consequently, in the analysis, our sample period is from 2006 Q3 to 2012 Q1 (23 quarters in total).

\footnotetext{
${ }^{1}$ On January 1 2013, the Missouri minimum wage increased again to $\$ 7.35$. Since the ending quarter in our data is the first quarter of 2012, 2013 minimum wage difference is not discussed in this paper.

${ }^{2}$ For the rest of the paper, I use Q to label quarters. For example, 2006 Q3 is the third quarter of 2006 .
} 


\subsubsection{Advantages and Limitations of Data}

The wage record data provide us many benefits. First, in contrast to population survey data, which suffer from inaccuracies due to re-call problems and non-response, our data are payroll data collected from employers and follow in accord with UI requirements. So the accuracy and continuity are ensured. Compared to individuallevel survey, our employer-based data could provide a better measurement of the employment effects. Second, our data include information for all firms covered by Unemployment Insurance reporting requirements. This means our data cover firms and establishments in all industries. This provides better estimates of the universe or one or two industries, so that we can have a better evaluation of the overall impact of the minimum wage, which is directly relevant to policy-making. In addition, our population data can provide us more accurate estimates than would a subsample. Third, unique ID numbers for all firms allow us to track all firms and their employees throughout the sample period. In the analysis, we can control for the firm level variation. Fourth, our data are individual level data and each person can be identified by a unique social security number. This employee-level data allow us to analyze the employment effects for individuals in various ways. In addition to the firm-level analysis, we do explore heterogenous effects among groups of people with different earnings. Last but not least, the wage record data include detailed information, such as the the firm's industry code and location (county), which allows us to limit our analysis to Kansas City metropolitan area border and also allows us to utilize the industry information.

Our data have some limitations as well. First, in these quarterly data, the reported earnings are the total income earned in three months. There is no measure of working hours or hourly wage rate, so that we cannot estimate the hours effect in the analysis or use the hourly wage to identify those we expect to be directly affected by the minimum wage. Another problem related to the quarterly data is that quarterly 
total employment level at any particular time point cannot be identified, since the records for both coming and leaving employees are observed in the same quarter. Second, it's not unusual for one person to hold more than one job, i.e, one person has multiple earning records in the data in a given quarter. However, there is no direct way to distinguish between full time and part time employment in the data. Third, Missouri minimum wage only applies to firms whose annual revenues are more than $\$ 500,000$. Because of the $\$ 500,000$ minimum wage exemption threshold in Missouri, we need to identify which Missouri firms are covered by the state minimum wage and which firms are not. The biggest limitation of our data is that we have limited information on each firm. Since there is no employer's revenue information in the data, we cannot identify firms subject to Missouri minimum wage exemption directly. Last, our data do not contain information on the characteristics of employees, so that we can not identify the differential employment effects across demographic groups.

\subsubsection{Data Issues}

We have spent a fair amount of time dealing with data issues. This subsection briefly discusses some problems and the solutions implemented ${ }^{3}$. We need to use the county code to identify each firm's location. The data administrative difference between Missouri and Kansas is worth noting ${ }^{4}$. In the Missouri data, only half of the employee wage records are assigned valid location codes. All employees in firms with multiple locations are assigned codes "999" or "900". In contrast, in the Kansas data, at least 98 percent of the cases have valid location measures, so that their locations can be explicitly identified. In the analysis, we must take this difference into consideration. For Missouri firms, large firms are more likely to be multiple location firms. In Kansas data, there are two firm identifiers. One is serial number, which is a unique sequential number assigned by the Kansas Department of Human Resources when the employer

\footnotetext{
${ }^{3}$ More data problems are discussed in Appendix .

${ }^{4}$ Detailed discussion can be found in Appendix A.
} 
is established. The other one is the federal number. For multi-location firms, the parent has a federal ID that all of the subordinate establishments use, but each employer is given a unique serial numbers so they can be identified independently. In other words, one federal id could be associated with several serial numbers and several locations. We decide to use federal id as the firm identifier in Kansas data. If one federal id corresponds to multiple locations, we exclude all records associated this federal id to avoid firms jump in or out of the border or suddenly changes of the employment levels. In order to make Missouri and Kansas data comparable, we further examine Missouri firms by firm size within two-digit broad industries and limit both Missouri and Kansas data to the groups (based on industry and firm size) for which at least $80 \%$ of the cases are assigned valid county codes ${ }^{5}$.

Other data issues relate to the industry codes. The Missouri data use the NAICS (North American Industry Classification System) code to identify industries. In the Kansas data, the industry identifier is the SIC (Standard Industrial Classification Code), which predated the NAICS. One problem with SIC is that government agencies of Kansas stopped assigning SIC codes to new established firms at the end of 2007. In most cases, we only use the first two digits of the NAICS code to identify the broad industry categories for firms. One task for us is to convert SIC code in Kansas data into the NAICS code ${ }^{6}$. In general, the converting process is smooth. However, we do find two obstacles. The first one is that NAICS reclassifies some industry categories, which causes one four-digit SIC code to match with several different NAICS codes, where these different NAICS codes belong to different broad industry categories. In this case, that SIC code can not be converted to one NAICS code. Our solution is that we try to find if there is any primary NAICS code that at least $70 \%$ of the cases with the same SIC code can be converted to this primary NAICS. If we can find such

\footnotetext{
${ }^{5}$ The check is done for both 2006Q3 data and 2012Q1 data. The Missouri data structures do not differ much between these two periods.

${ }^{6}$ Converting can be primarily done by using the crosswalks provided online. The reference website is www.naics.com.
} 
a primary NAICS, all cases are converted to this broad industry. Otherwise, we have to exclude all cases with the four-digit SIC. In addition to using the official crosswalk to convert SIC, we also use $2006 \mathrm{Q} 4^{7}$ Missouri data as a reference ${ }^{8}$. A second problem is that NAICS assigns new codes for some emerging industries. For example, NAICS broad category " 55 " is for firms involved in management of companies and enterprises, for which there is no matching category in the SIC system. We have excluded Missouri firms with NAICS code "55" from the analysis. However, we believe this exclusion does not bias our results since employee records in this category are always less then $2 \%$ of the data and employees in this category are not likely to be affected by minimum wages. ${ }^{9}$

\subsubsection{Missouri Minimum Wage Exemption}

Missouri state minimum wage law covers all firms except those firms whose annual revenues are less than $\$ 500,000$. The only exemption is the construction industry. All firms in this industry are covered regardless of revenue ${ }^{10}$. Due to this $\$ 500,000$ minimum wage exemption rule, in the Missouri data, we must separate firms into those covered by the state minimum wage and those exempted. If we knew firms' annual revenues, we could use $\$ 500,000$ as a threshold. However, our data resource is the Missouri payroll data. The only income variable we have is employees' quarterly earnings. We have to use these earnings to estimate a firm's gross revenue. The rule is

\footnotetext{
${ }^{7}$ Missouri implemented state minimum wage in January 2007. 2006 Q4 is the last quarter before implementation. In order to minimize the industrial difference between two states, we choose this quarter as a reference. Since Missouri data have both SIC and NAICS codes, the actual matching based on Missouri data is used as a supplement of the official crosswalk.

${ }^{8}$ Detailed discussion regarding SIC and NAICS matching is in Appendix B B.

${ }^{9}$ Detailed procedures for the SIC - NAICS conversion and revision can be found in the Appendix

${ }^{10}$ We spoke with a DOLIR representative about the rules. We were told in practice all construction firms are covered by the state minimum wage law. Although we can't find any official document that explicitly states that all construction firms in Missouri are covered by the state minimum wage, including all these firms in the state minimum wage covered group does not bias our results for two reasons. First, all workers on public construction projects are covered by the prevailing wage law, which guaranteed that they are paid no less than the state minimum wage. Second, in practice, hourly wage rate paid for most private contractors are much higher than the minimum wage.
} 
described as follows. First, we get the payroll to revenue ratios by industry ${ }^{11}$. Second, to determine if a firm is subject to the minimum wage, for a given quarter in one year, we calculate the sum of UI earnings paid to employees over the previous calendar year $^{12}$. Then, these annual payments are divided by the corresponding industry ratio to get an estimate of the annual gross revenue. If the calculated prior year revenue is less than $\$ 500,000$ and the firm is not in the construction sector ${ }^{13}$, this employer is assumed to be exempted from the Missouri state minimum wage in this quarter. If the employer does not have payroll records for all previous four quarters, we still apply the rule to this employer by counting the earning records from "missing" quarter(s) as 0 .

In addition, we need to set up a rule for new firms, since they do not have a prior year employee earning records. The first thing to check is that whether they are truly new firms or they are just "old" firms that changed name or merged. This is an issue regarding discontinuous records ${ }^{14}$. In general, if they are new firms, we treat them as minimum exempted firms initially. If they are formed from "old" firms, we check the revenues from "old" firms and apply the rule to these revenues.

\subsubsection{Data Description}

In the analysis, we focus on counties near the Kansas/Missouri border, in particular, the counties in the Kansas City Metropolitan area ${ }^{15}$. In Missouri, there are nine counties included: Platte, Clinton, Clay, Jackson, Cass, Bates, Lafayette, Ray and

\footnotetext{
${ }^{11}$ Appendix $\mathrm{C}$ provides a table of the ratios. The sales and annual payroll statistics for Missouri are from US 2007 economic census data. The ratios are calculated by using annual payroll divided by sales. Since we cannot find the ratio for public administration industry category from the same data source, it is excluded from the analysis.

${ }^{12}$ In determining whether a firm is subject to the minimum wage, the Missouri DOLIR website specifies that firms are required to submit documentations on prior year's revenues. Since we do not have information about a firm's fiscal year, we assume it corresponds to the calendar year.

${ }^{13}$ At this stage, we use the strict $\$ 500,000$ as the threshold. Later, we can relax the threshold as robustness check.

${ }^{14}$ More detailed discussions are in Appendix D.

${ }^{15}$ http://www.census.gov/econ/census02/maps/metro/33000us312m.pdf. Here is a map for the Kansas metro area.
} 
Caldwell. In Kansas, we include Leavenworth, Wyandotte, Johnson, Miami, Linn and Franklin. We refer to these sets of counties as the Kansas and Missouri "border counties".

Table 4.2 provides a list of variables and terms relevant to the paper. For the firm-level analysis, all border firms in the data can be divided into five categories in each quarter. We try to make firms from these two states comparable, so Kansas and Missouri firms are categorized in the same way. First, we identify all firms in the construction industry, since all these firms are covered by the minimum wage. The second category is the excluded firms, which includes firms with missing NAICS and firms in management or public administrative service industries. The next two categories are for the firms identified as covered by the Missouri minimum wage, and exempted firms, respectively. The last category is for the newly emerging firms in a given quarter. Since these firms do not have previous earning records and most of them are small starting firms, they are initially treated as exempted firms. In the firm-level analysis, the major outcome variable is firm-level employment. It is not unusual that one person has multiple wage records in a given quarter. However our data cannot identify part time and full time jobs, we simply count the number of distinct employees in each firm as the employment level for a firm. For a large number of firms, they do not exist for the entire 23 sample quarters, so that we do not have continuous records for these firms. Consequently, our data form an unbalanced panel. For the individual-level analysis, the dependent variable is the binary employment status. We track each individual's employment status over 23 sample quarters by using encrypted SSN, and form a strongly balanced panel.

In the firm level analysis, in order to estimate the effect of Missouri minimum wages, we construct two groups. We first find all Missouri border firms that are covered by the state minimum wage law, which we call the Missouri border minimum wage covered group. To make the firm size and characteristics comparable in the 
analysis, we construct a second group, which includes Kansas firms with previous year's revenues greater than $\$ 500,000$ and all firms in the construction industry. This group is the desired comparison group to the firms in the Missouri minimum wage covered group, since these firms satisfy the coverage criteria for the Missouri minimum wage, but these firms are not covered by the Missouri law. We call this group Kansas border pseudo-covered group.

Table 4.3 presents a description of our data. Initially, Kansas border has more observations than Missouri border, where each observation is one individual record in a quarter. The average numbers of firms for these two states are similar. The average employment level for Missouri border minimum wage covered firms is 27 employees in one firm, while the average employment level in Kansas border comparison group is 44 . Once we limit the sample to minimum wage covered groups, the employment levels are larger than the ones for border groups, since larger firms are more likely to exceed the $\$ 500,000$ threshold and covered by the minimum wage. The Kansas average employment is higher than the Missouri average employment because of the data construction difference explained before. We need to use the county code to determine whether a firm is in the border area. In Missouri, multiple location firms are all assigned 999 county code, which cannot be used to identify the county. But in Kansas, multiple location firms are assigned the specific county code for each establishment in the firm. Given this difference, some large firms are omitted in Missouri panel. In order to account for this data difference, we then limit the Kansas firms to the no multiple location firms and constraint both states' data to the firm size groups for which at least $80 \%$ of the cases are assigned valid county codes. After selecting $^{16}$, the employment levels per firm for Missouri and Kansas panel are the same, which are 13 employees in a firm on average.

\footnotetext{
${ }^{16}$ The detailed selecting rule can be found in the appendix E.
} 


\subsubsection{Employment Levels}

Figure 4.1 is the plot of quarterly employment levels in Missouri and Kansas, respectively. Missouri employment level is almost double the Kansas employment level, since Missouri's total resident population is almost double that for Kansas. In general, we can see that both states follow similar trends, although in some quarters, Kansas employment level fluctuates more. The employment level in the first quarter of a calendar year is generally lower than the employment levels in other quarters both in Missouri and Kansas. Missouri minimum wage increases in the first quarter of 2007, 2008 and 2009, but one cannot conclude that the lower employment levels in the first quarters are caused by the minimum wage changes. The employment level is always found to be higher in the last quarter of each year, because of the seasonal demand for temporary workers. In addition, the employment level is lower during the recession periods.

In the upper graph of figure 4.2 , the highest line is the employment level for Missouri border minimum wage covered firms. The other line is for Kansas border pseudo-covered firms. This figure shows the employment levels for Missouri and Kansas border firms selected to be comparable, according to the following procedures. First, both firms are limited to the ones with only one location over the entire sample period so that multi-site firms are excluded. Second, since Kansas labor department stopped assigning SIC industry codes to new firms after 2007 Q4, we limit both the Missouri and Kansas samples to the firms that existed before 2007 Q4. As a result, the employment levels exhibit a decreasing pattern, since new firms that replace firms that go out of businesses are not included. Another reason for this decreasing pattern could be if the distribution of employers shifted to relatively smaller firms during this period. Third, firms are limited to the industry groups for which at least $80 \%$ of the cases are assigned valid county codes and SIC - NAICS can be matched for most cases. Our final firm level panels for both states shows very similar trends over time. Last, 
by applying the $\$ 500,000$ minimum wage rule, both panel are limited to the firms exceed this threshold. The middle graph shows the employment levels for Missouri and Kansas exempted firms. Since these firms are picked using the same subsetting rule, they follow the same decreasing pattern as the upper group. Missouri exempted firms have greater fluctuations. The employment levels in the first quarter usually experience a sharp decline. The lower plot of Figure 4.2 is the history of federal and Missouri state minimum wages. The lines passing through graphs indicate the change of minimum wages. The last minimum wage change in our window is 2009 Q3, when the federal minimum wage increased to $\$ 7.25$. After that quarter, the two states have same minimum wages.

\subsection{Single Wave Difference-in-Differences Employment Estimation}

Our analysis is based on the assumption that firms near the Missouri/Kansas border would display similar employment patterns in the absence of Missouri's minimum wage. Enactment of Missouri minimum wage is then a natural experiment that allows us to estimate the employment effect of a state minimum wage.

The difference-in-differences method is a common way to identify the employment effects for a specific state minimum wage increase. It is straightforward and provides an easy way to avoid some endogeneity problems. The simplest case is two group/ two periods analysis. One group experiences the treatment and the other group does not. In our application, DID compares the outcome difference for the two groups before and after the minimum wage is effective. One advantage of DID is that by taking differences, one can get the treatment effects without worrying about other economic factors. In order to use this method as the identification strategy, there are several assumptions that need to be satisfied. The first one is that the earlier time should 
be sufficiently before the time of policy intervention to make sure that no adjustment can be made prior to that point. Otherwise, DID cannot capture the true treatment effect. The second assumption is that the later time must be sufficiently long after the time of intervention so that the treatment has had enough time to operate. The last assumption is that, without the treatment, the differences between control group and treatment group would be the same in two periods. If this assumption fails, the control group may not be a valid one.

In our study, since Missouri minimum wage legislation resulted from a referendum vote, the assumptions are likely to be satisfied. Several other papers also have ruled out the possibility of anticipation or lagged effects of minimum wage increase. See Dube et al, (2010) as an example. The close geographic proximity implies that Missouri and Kansas border areas share a common labor market, so we expect that the Kansas side of the Kansas City metropolitan area is a valid control group. From Figure 4.1 and 4.2, one can tell that Missouri and Kansas border counties follow similar economic trends, with similar economic cycles. Their employment levels tend to increase or decrease at the same quarters. Table 4.4 summarizes information on the industry distributions in Missouri and Kansas border counties in 2012 Q1. Panel 4.4a presents the NAICS distribution according to industrial classification for all Missouri and Kansas border firms and panel 4.4b presents the frequencies for Missouri border Minimum wage covered firms and Kansas border pseudo-covered firms after applying the subsetting rules. These comparisons show both similarities and differences in industry structures.

One can see that in panel a, Missouri has more capital-intensive industries than Kansas. Other than that, the "missing industry" category is quite different for these two states. This difference is a result of data construction. As noted above, very few employee records are associated with invalid industry code in Missouri, so only $0.11 \%$ of observations are in the "missing industry" category in Missouri. In contrast, 
all new firms after 2007Q4 are assigned 0000 SIC codes in Kansas data ${ }^{17}$. In addition, when we convert the SIC codes to the NAICS codes, some SIC codes cannot be matched with any NAICS codes. Consequently in 2012 Q1, in total 39.13\% of employee records in Kansas data have missing industry codes. After omitting missing industry ${ }^{18}$, Missouri and Kansas groups exhibits almost the same industry structures, suggesting that these two sets of firms are more comparable in size and other firm characteristics. In the analysis, we combine several industries together, the "selected industries combined" category takes up to $50 \%$ of all the cases in both states. For construction, manufacturing, retail trade and food and accommodations, the percentage distributions across states are very similar. In addition, so far as we know, during the relevant periods, there are no other major policy shifts in Missouri and Kansas that could change the employment level. From the analysis and comparison above, one can further conclude that Kansas side of Kansas City metropolitan area is a valid control group.

In this section, we provide results of DID estimation for each wave of minimum wage changes to check whether the changes of employment levels have the expected signs. The general idea is to compare the Missouri border covered group with the Kansas border firms whose estimated annual revenues are greater than $\$ 500,000$. This is a across-border comparison. We compare the differences between the change of natural log of aggregated employment levels in two groups. The general form of the treatment effects is the average before-after differences between the two groups.

$$
\left(\ln E M P_{G 1, t_{2}}-\ln E M P_{G 1, t_{1}}\right)-\left(\ln E M P_{G 2, t_{2}}-\ln E M P_{G 2, t_{1}}\right)
$$

where $G 1$ is for Missouri and $G 2$ represents Kansas. The Missouri minimum wage applies for $G 1$ firms in period $t_{2}$. For each quarter-pair, the analysis is limited to

\footnotetext{
${ }^{17}$ Employee records from these new firms accounts for $16.85 \%$ of the observations in 2012Q1.

${ }^{18}$ Appendix E describes how the firms are limited based on firm sizes and industries.
} 
firms that exist in the first quarter of the two.

Table 4.5 to table 4.10 presents the single wave DID results. The upper panels show the results based on employment level changes in two sequential quarters, and the lower panels show the results based on the employment level changes in the same quarter of two sequential years to difference out any seasonal effects. We do not report standard errors in the tables. Since our sample is so large, all estimates are easily significant. In order to make the cases more comparable, we not only report the results using the entire state panels, we also report the results for each relevant broad industry category so that we can check whether minimum wage impacts differ by industries. In each panel, the first two columns list the two prior and subsequent quarters, the highlighted quarters indicate that Missouri minimum wage changed in time 2. The next two columns are the prior and subsequent changes in the natural log of aggregated employment level changes in Missouri border covered firms and Kansas border pseudo-covered firms, respectively. The difference between these two numbers is the DID estimator that we are interested in, which is shown in the fifth column. The estimates are also highlighted indicating when the Missouri minimum wage increased. To present the results more clearly, the last two columns list the minimum wage history in Missouri and Kansas and the numbers in bold suggest the changes.

Table 4.5 is the results for the entire sample, including all relevant industries. 2007 Q1 is the first time that Missouri minimum wage was enacted. When the employment level in this quarter is compared to the previous quarter, $2006 \mathrm{Q} 4$, we see a $7.66 \%$ employment decrease in Missouri covered group and a 10.09\% employment decrease in Kansas pseudo-covered group, so the DID estimator is $2.43 \%$. According to the competitive labor market model, we expect to see a greater decrease in employment for the firms that are covered by the state minimum wage and a negative DID estimator. We can not say that the observed employment changes in these two quarters 
are caused by the minimum wage. It could be caused by the seasonal employment patterns, since both Missouri and Kansas experience a decrease in employment. The employment level usually tends to be high in the last quarter for the reason that some firms are likely to hire seasonal part-time workers. If this is the case, regardless of minimum wage changes, we may find decreasing employment levels.

For the second Missouri minimum wage increase, the DID estimator is $0.3 \%$ increase. Although the estimator is still positive, the estimated effect is smaller. One reason to expect a smaller effect is that there is only a $2.3 \%$ increase in Missouri minimum wage from 2007 Q4 to 2008 Q1, but it is a $26.2 \%$ increase in Missouri minimum wage initially in $2007 \mathrm{Q} 1$, from $\$ 5.15$ to $\$ 6.50$.

When state minimum wage increased to $\$ 7.05$ in 2009 Q1, Missouri experienced a slightly greater employment level decrease, which yields the DID estimator to be $0.9 \%$ decrease. One may notice that the employment changes in the third and fourth columns are all negative, which is a result of our data subsetting rule. However, since we limit Missouri and Kansas data in the same way, this decreasing pattern should not bias the DID results. In the third quarter of 2009, the federal minimum wage increased to $\$ 7.25$. So in this quarter, both states experience a minimum wage increase. For Missouri, the wage rate increased from $\$ 7.05$ to $\$ 7.25$, while in Kansas, the minimum wage increased from $\$ 6.55$ to $\$ 7.25$. The DID estimator is $0.08 \%$ decrease. Since the effective increase is greater in Kansas, if the minimum wage decreases employment, the DID estimate should be positive. After 2009 Q3, the Missouri minimum wage is the same as federal one thereafter. The comparable measures for 2010 Q1-2009 Q4; 2011 Q1-2010 Q4 and 2012 Q1 -2011Q4 are also relatively very small in magnitude compared with previous three DID estimators we are interested in. From another point of view, one can tell that the employment level changes fluctuate in these 22 quarter-pair comparisons, and the employment effects of Missouri minimum wages are always small in magnitude in terms of the DID estimators, since. For these 
comparisons, we do not control for the difference between two groups' responses to seasonal factors.

The lower panel of table 4.5 is based on the comparison of employment changes of the same quarters in two sequential years. If we assume that the cyclical employment pattern is the same for each year, by taking the same quarter differences, we can rule out the possibility of seasonal employment patterns and trend effects. Due to the decreasing employment pattern resulted from the subsetting rule, the employment changes for both states are much larger in magnitude. In this panel, we cannot check the employment effect for the first minimum wage increase because we do not have 2006 Q1 employment data ${ }^{19}$. Since Missouri minimum wage increased in three successive years, the 2007 Q1 - 2008 Q1 and 2008 Q1 - 2009 Q1 comparisons capture the difference in employment resulting from an increase in the minimum wage following an earlier increase. The DID estimators are all positive up until the comparison between 2008 Q4 and 2009Q4, implying employment increases for Missouri covered firms in these periods. These impact estimates are opposite to our expectation and these effects are small. We can argue that these impacts are caused by the minimum wage increase, while it can also be argued that the changes are due to some uncontrolled factor related to the business cycles, which affect two states differently.

Table 4.6 presents the results for food and accommodation industry, a typical low wage industry, with high turn-over rates and many part-time job opportunities. This is a broad industry categories, including limited-service restaurants, full-service restaurants and hotel accommodations, etc. From the upper panel, for the first state minimum wage increase, the DID estimator is $-0.02 \%$. Although it is a negative number, it is trivial. For the next minimum wage increases, which are within the recession

\footnotetext{
${ }^{19}$ In Missouri data, 2006 Q3 is the cut-off point of data structures. Before this quarter, old Missouri data only include FIPS county measure and SIC industry code. To minimize the potential data inconsistencies, we do not use data prior to 2006 Q3.
} 
period, the DID estimators are $10.62 \%$ and $0.32 \%$ respectively. These impacts indicate that Kansas suffered relatively greater employment losses during the examined periods. In the lower panel in the analysis that control for seasonal factors, we get a larger negative impact for the first state minimum wage increase, comparing to the corresponding result in the upper panel. The estimator is $-3.56 \%$. The greatest employment response is also the 2007 Q1 and 2008 Q1 comparison, which is 14.33\%. For the next two state minimum wage increases, the impacts are moderate and have the same signs with the results from the two sequential quarters comparisons.

Retail trade is another industry involving many minimum wage workers. The DID results for this industry are presented in table 4.7. According to our results, Missouri minimum wage has very moderate impacts on Missouri employment, since the DID estimators are no greater than $4 \%$ in either the comparison for two sequential quarters or the comparison between the same quarters in two sequential years. One can notice that, in the lower panel, during the recession period, we do find the disemployment effects, implying that retail trade is more sensitive to the economic shocks.

Construction is an industry that all workers are covered by the state minimum wage, no matter how much they earn. Table 4.8 summarizes the results for this industry. Disemployment effects can not be found for any state minimum wage changes, and the impacts are moderate as well. One point worth noting is that the minimum wages are usually not binding in the construction industry and the prevailing wage for worker on public construction projects is always higher than minimum wage. Table 4.9 presents the results for manufacturing industry, and table 4.10 is for "selective industries combined" category, including "information", "real estate", "art and entertainment", "other service", "finance and insurance", "professional, scientific, and technical services", "educational services", and "health care and social assistance". Results are mixed as well. In table 4.9, the largest impact is found for the first Missouri minimum wage increase, the DID estimator indicates a $6.21 \%$ increase in minimum 
wage. Other than that, estimates are moderate.

The relevant DID estimators are summarized in figure 4.3 and figure 4.4. The DID estimators we get vary in signs for different industries and for different waves of minimum wage increases, indicating it is hard to detect the disemployment effects for all the cases. In general, the impacts are moderate and so not so seriously at variance with expectations, from $-4.38 \%$ to $6.21 \%$, except $10.62 \%$ and $14.33 \%$ increase for the Missouri minimum wage increase in 2008 in food and accommodation industry. Generally speaking, for the first Missouri minimum wage increase, it is more likely to get positive DID estimates. During the recession period, the estimates tend to be moderate and negative.

For the analysis above, we apply the strict $\$ 500,000$ Missouri minimum wage exemption rule. One problem with this threshold is that some firms may jump back and forth into the minimum wage covered group, if their annual revenues are very close to the borderline. As one robustness check, we relax this strict threshold to $\$ 400,000$, which is $20 \%$ lower than the original one. By doing this, more firms are included in the analysis, and we also have more continuous records from the firms near the threshold. We check whether the results differ or not. Our results ${ }^{20}$ show that the DID estimators are very similar to the ones presented in this section. As stated previously, we do not have firms' revenues information, so we use the average industry payroll to revenue ratios to estimate each firm's annual revenue. This robustness check rules out the possibility that our estimated revenues may bias the results.

\footnotetext{
${ }^{20}$ Results are presented in Appendix $\mathrm{H}$.
} 


\subsection{Firm-Level Regression Analysis of the Employ- ment Effects}

\subsubsection{Regression Model Specifications}

The analysis above focuses on the single wave state minimum wage changes. Many economists have argued that DID estimates can not capture the true treatment effect due to the insufficient controls. In the minimum wage literature, most positive or insignificant employment effects are found by using the DID methods. In the previous section, we find positive employment effects of the minimum wage in many cases. In this section, in order to sufficiently control for the omitted variables, we construct a multiple-period and multiple-group panel data set ${ }^{21}$ to estimate the employment effects. The model specification is estimated at the firm level and can be written as:

$\ln E M P_{i j t}=\gamma \cdot D_{1} \cdot \ln m w_{i j t}+\zeta \cdot D_{2} \cdot \ln m w_{i j t}+\kappa \cdot D_{3} \cdot \ln m w_{i j t}+\rho \cdot D_{4} \cdot \ln m w_{i j t}+\theta_{i}+\epsilon_{i j t}$

$i$ refers to each individual firm. $j$ represents different groups and $t$ indexes each quarter. We divide firms into four different categories based on their initial firm sizes in the starting quarter, 2006 Q3, so that we can explore whether minimum wage changes have different employment effects across firms sizes. As explained above, for most relevant industries, the firms are limited in size to no more than 50 employees in both states ${ }^{22}$. $D_{1}-D_{4}$ are the dummy variables for each group. $D_{1}=1$ if a firm starts as a small size firm, which has no more than 10 employees. $D_{2}=1$ if a firm starts with 11 - 20 employees. $D_{3}=1$ if a firm starts with more than 20 employees. $D_{4}=1$ if a firm is not established on the beginning quarter 2006 Q3, which means

\footnotetext{
${ }^{21}$ Appendix I describes the steps to construct this panel data set.

${ }^{22}$ Check Table E.2 as a reference.
} 
the firm is a new firm in our sample period ${ }^{23} . \quad l n m w_{i j t}$ is the natural log of the effective minimum wage, which is the Missouri state minimum wage if a Missouri firm is subject to the minimum wage in a given quarter and is the federal minimum wage if the firm is in Kansas. This is our baseline model, with firm-level fixed effect $\theta_{i}$, which captures time-invariant firm-specific factors. The dependent variable is the natural $\log$ of the employment level in firm $i$ group $j$ quarter $t$. In this regression, firms with 0 employment are dropped from the analysis, so our panel is unbalanced. $\epsilon_{i j t}$ is the error terms. In each quarter, within the state, the minimum wage only takes one value. The standard errors are clustered within state and quarter to account for any possible correlations between employers within the clusters, with the assumption that all firms in the state and quarter cluster are affected similarly by the minimum wage. According to our specification, for a single firm in Missouri across time, we are in effect comparing this firm with similar firm in Kansas, with the assumption that they response similarly to minimum wage changes.

Although we desegregate data into groups and provide estimates for each firm size group, we can also calculate the overall minimum wage effect, which is the weighted average of each group's minimum wage estimates. The weights are the total employment level in each group. $\gamma, \zeta, \kappa$ and $\rho$ are the minimum wage estimates for $D_{1}-D_{4}$ groups, respectively.

$$
\text { overall effect }=\frac{\gamma \cdot E M P_{D_{1}}+\zeta \cdot E M P_{D_{2}}+\kappa \cdot E M P_{D_{3}}+\rho \cdot E M P_{D_{4}}}{E M P_{D_{1}}+E M P_{D_{2}}+E M P_{D_{3}}+E M P_{D_{4}}}
$$

The standard errors for the overall minimum wage effect are the sum of their weighted variances and the correlations between each other.

In model specifications (4.2) and (4.3), we add time effects and time-industry interaction terms in the model, respectively.

\footnotetext{
${ }^{23}$ Due to the data limitation, the analysis is limited to firms that exist before 2007 Q4. So we can only capture firms that emerge from 2006 Q4 to 2007 Q4.
} 
$\ln E M P_{i j t}=\gamma \cdot D_{1} \cdot \ln m w_{i j t}+\zeta \cdot D_{2} \cdot \ln m w_{i j t}+\kappa \cdot D_{3} \cdot \ln m w_{i j t}+\rho \cdot D_{4} \cdot \ln m w_{i j t}+\theta_{i}+\tau_{t}+\epsilon_{i j t}$.

$\tau_{t}$ is the time effects. In this analysis, time effects are assumed to be same for all firms in both states, reflecting the fact that all firms are in very close geographic proximity.

$\ln E M P_{i j t}=\gamma \cdot D_{1} \cdot \ln m w_{i j t}+\zeta \cdot D_{2} \cdot \ln m w_{i j t}+\kappa \cdot D_{3} \cdot \ln m w_{i j t}+\rho \cdot D_{4} \cdot \ln m w_{i j t}+\theta_{i}+\tau_{t}+\tau_{t} \cdot i n d_{i j t}+\epsilon_{i j t}$.

$\tau_{t} \cdot i n d_{i j t}$ is a time-industry interaction term. Here, we allow different industries to have different time patterns. By doing so, we can distinguish the effects of economic conditions, industry structures, and the actual increase of minimum wages.

$\ln E M P_{i j t}=\gamma \cdot D_{1} \cdot \operatorname{lnm} w_{i j t}+\zeta \cdot D_{2} \cdot \operatorname{lnm}_{i j t}+\kappa \cdot D_{3} \cdot \ln m w_{i j t}+\rho \cdot D_{4} \cdot \ln m w_{i j t}+\theta_{i}+\beta \cdot$ unemployment $_{i j t}+\epsilon_{i}$

In this specification, time effects are replaced by the county-level unemployment rates in Missouri and Kansas to control for economic conditions and business cycles, allow Missouri and Kansas to respond differently.

In the last specification (5), we allow minimum wage effects to vary by industry in order to further control any differential impacts across industries.

$\ln E M P_{i j t}=\gamma \cdot D_{1} \cdot \operatorname{lnm} w_{i j t}+\zeta \cdot D_{2} \cdot \operatorname{lnm} w_{i j t}+\kappa \cdot D_{3} \cdot \ln m w_{i j t}+\rho \cdot D_{4} \cdot \ln m w_{i j t}+\theta_{i}+\tau_{t}+\delta \cdot \ln m w_{i j t} \cdot i n d_{i}+\epsilon_{i j t}$

We divide industries into broad industry categories based on the data subsetting 
rule. Specifically, $i n d_{1}=1$ if a firm is in construction industry; $i n d_{2}=1$ if a firm is in manufacturing industry; $i n d_{3}=1$ if a firm is in retail trade industry; ind $_{4}=1$ if a firm is in accommodation and food services industry; $i n d_{5}=1$ if a firm is in "selected industries combined" category.

When we estimate the entire sample where all relevant industries are included, model Specification (4.5) is our preferred model. For the regressions of each industry, model (4.3) is the preferred one.

\subsubsection{Estimation Results}

Figure 4.5 illustrates the employment level patterns for the four firm size groups. $D_{3}$ group, which is the category of firms with more than 20 employees, has the largest employment level in our data, so it is the highest line on the figure. $D_{1}$ and $D_{2}$ groups have similar employment levels and patterns. The lowest line illustrates the employment level of $D_{4}$ group, since no firm is in this group in 2006 Q3. The employment level is 0 at the beginning of the quarter. Comparing these lines, one can notice that $D_{3}$ line exhibits a decreasing patter, which indicating relatively large firms are experiencing employment reductions. Although the middle lines for $D_{1}$ and $D_{2}$ are very similar, one can still tell $D_{2}$ firms experience a relatively stronger decrease in employment level of these two. In contrast, for $D_{4}$ group, after 2007 Q4, when no new firms are introduced in this group, the employment level exhibits a very stable pattern.

Table 4.11 to table 4.16 present the regression results. The highlighted estimates indicate the significance at $10 \%$ level. On each table, the upper panel presents estimation results, and the lower panel lists the descriptive information for each firm group, including number of observations in each group, total employment level, aver- 
age employment for each group and the employment distribution .

Table 4.11 presents the estimation results for the entire panel sample, including all relevant industries. There are in total 302,618 firm level observations in the data, and 3,795,339 individual cases are counted in the sample period. The average employment for $D_{1}$ group is 5.3, and 13.9 for $D_{2}$ group. For $D_{3}$ group, it is 32.5 , since for most of broad industry categories, firms are limited to no more than 50 employees. For the firms that do not exist in 2006 Q3, the average employment is 9.5. Around half of the people are employed in the middle size firms, which is group $D_{3} . D_{1}$ and $D_{2}$ groups have similar size of total employment. The $D_{4}$ group only accounts for $5 \%$ of the total employment, since we limit our panel to the firms that exist before 2007 Q4, which is the last quarter that Kansas assigns industry information to new firms.

In the upper panel, mixed results are found for different specifications. When we only control for individual firm effects and firm size groups, in specification (1), disemployment effects are found for all four groups, although the estimate is not significant for the $D_{4}$ group. The overall minimum wage effect is -0.657 , and it is significant, implying a $10 \%$ increase in Missouri minimum wage will decrease the employment by $6.57 \%$. In specification (2), when time fixed effects are included, the estimates for $D_{2}$ and $D_{3}$ groups are still negative, but they are smaller in magnitude compared with the corresponding estimates without time fixed effects. Firms in $D_{1}$ and new firm group experience increases in employment. The total minimum wage effect is 0.166. In specification (3), time-industry interaction terms are added. The estimated minimum wage effect for $D_{1}$ group is 0.114 and for the new firm group is 0.590 . The estimate for $D_{2}$ group is -0.329 and for $D_{3}$ group is -0.430 . The overall minimum wage effect is -0.232 , which indicates a $2.32 \%$ decrease in employment associated with a $10 \%$ increase in the minimum wage. In column (4), we substitute county level unemployment rates for the time fixed effects as an alternative control of time effects. The results from specification (4) are similar to the ones from specification (1). The total 
estimated minimum wage effect is - -0.463 , implying a decline of $4.63 \%$ in employment for a $10 \%$ increase in the minimum wage. The estimate for county unemployment rate is - 0.012, suggesting higher unemployment rates reduce employment.

In column (5), we allow minimum wage to interact with different industry groups. We divide the industries into five categories. The "selective industry combined" category, which includes several service industries and finance industry, is the omitted category in the regression. In this case, we can get the estimates for different firm size groups in each industry category. Comparing with the "selected industry combined" category, construction, retail trade, manufacturing industries all experience job losses, but food and accommodation industry have an increase in employment. The overall minimum wage effect is -0.149 , implying a $1.49 \%$ employment decline with a $10 \%$ increase in the minimum wage. From the results above, we can conclude that the increase in minimum wage results in the decrease of the total employment, within the range $1.49 \%$ to $6.97 \%$ decrease. $D_{2}$ and $D_{3}$ groups always experience job losses. Firms with no more than 10 employees and new firm group may increase employment with the increasing of the minimum wage.

Retail trade and food/accommodations industries are the most intensive users of minimum wage workers. The next two tables summarize the estimation results for these two industries separately. Table 4.12 shows the results for retail trade industry only. Since we do not need to control for industry, only the results for the first three specifications are reported. In column (1), the minimum wage estimates for all four groups are negative, and are relatively larger in magnitude compared with the paralleling results in table 4.11. The total minimum wage impact estimate is -0.670. In column (2) and (3), when we control for time fixed effects and county unemployment rates, the estimates for the first three groups are still negative. But for the new firm group, the estimates are not significant at $10 \%$ level. The overall employment impacts are similar to the results for the entire panel sample. 
Table 4.13 reports the estimation results for food and accommodation industry. The sample size for this industry is 13,500 cases for 23 quarters. $D_{3}$ group accounts for $74.0 \%$ of the observations, while the frequency for $D_{1}$ group is only $3.76 \%$. This does not mean there are very few small size firms in food and accommodation industry. The small frequency for $D_{1}$ group literally suggests that small firms with no more than 10 employees are not subject to state minimum wage, since their annual revenues do not exceed $\$ 500,000$ threshold. In column (2), when we control for the time fixed effects, the estimates for $D_{1}$ and $D_{2}$ group are both positive and significant. The estimate for $D_{3}$ group is negative, but the effect is small in magnitude. The overall impact is insignificant at $10 \%$ level. One thing worth noting is that the average employment for $D_{1}$ group is 11.5 . Firms with no more than 10 employees initially are included in $D_{1}$ group, the average across all 23 quarters is greater than 10, implying some firms are increasing sizes over time.

Table 4.14 presents the results for construction industry. This is the only industry that all worker are covered by the minimum wage law. Consequently, the distributions for $D_{1}, D_{2}$ and $D_{3}$ groups are similar. The average employment levels for these groups tend to be smaller compared to other industries. Our results suggests that construction industry has a greater response to the minimum wage changes. When the time fixed effects are controlled, the overall impact is $4.97 \%$ decrease in employment with a $10 \%$ increase in minimum wage. These results are in opposite direction of the estimates from the DID estimation, where we cannot find the adverse effects.

Table 4.15 is for the estimation results of manufacturing industry. Firms are more likely to have larger sizes in this industry, so $D_{3}$ group accounts for almost $70 \%$ of the total employment. In specification (2), our results indicate that minimum wage has no impact on manufacturing employment. Table 4.16 presents results for "selected industries combined" category. This category includes several service industries, finance and information industries. All the significant estimates we find in this category are 
negative. In the regression for the entire sample and construction industry,

\subsubsection{Interpretation of Results}

The estimation results are summarized in figure 4.6. This figure depicts the employment effects by group and by industry. The percentage rates suggest the percentage change in employment level with a $10 \%$ increase in minimum wage. For the results that are not significant at $10 \%$ level, they are replaced by 0 in the graph. The estimation results shown here are from our preferred model specifications. This figure clearly shows that the overall employment impacts are generally negative and significant. $D_{2}$ and $D_{3}$ groups also always experience job losses with the increase of minimum wages. The $D_{1}$ group, which has no more than 10 employees, increases employment if the firms are in food and accommodation industry or in the estimation for the entire sample including all relevant industries. Results for $D_{4}$ group, the newly emerging firms, vary across industry. In retail trade, manufacturing, and "selective industry combined" category, the estimates for this group are insignificant. In the regression for the entire sample and construction industry, the estimates are positive are relatively strong. In food and accommodation industry, this estimate is negative.

In general, the aggregated disemployment effects found in our analysis are consistent with other minimum wage papers, both have negative signs and fall in the same range. When we control for the time fixed effects and allow minimum wages to interact with industries, the estimated effects tend to be attenuated. One reason is that our results are the aggregated employment effects, not for the minimum wage workers (such as teenagers) or for the low-wage sectors only. In addition, this analysis only considers the short-run effects. If employers need some time to accumulate capital to replace labor with machinery, the long-run labor demand would be more elastic than the short-run demand. Another reason for our findings could be caused by the reduction of working hours. Instead of reducing the number of workers, employers 
could reduce the working hours for each remaining worker. Such an effect on hours of work cannot be estimated with our data.

The disemployment effects do not always appear to exist in small (1 -10 employees) and newly emerging firms. One possible explanation is that the minimum wage is not binding in such firms. Especially for new firms, start-ups could be due to the progression of new investment or innovative ideas. In addition, new firms are the main source of job growth. When minimum wage increases, according to the competitive labor market theory, firms with binding minimum wages experience increasing costs. They respond by increasing output prices and cutting the employment or production levels. In either case, the supply of the product should decrease, leading to a price increase. In response, firms with non-binding minimum wages may benefit from higher output price and might increase employment at least in the short run. Another possible explanation could be a result of the way we divide up firms. The firms are divided based on the firm sizes at the base quarter, 2006 Q3. Some firms might fall into the small or new firms categories because of data errors. These firms could be firms missing records in the base quarter, or firms merging or changing title in that quarter. Also, these may be firms that are in transition, experiencing an employment reduction or have relocated into the border areas. These firms could grow rapidly in later quarters.

Comparing the results from separate industries, the disemployment effects vary across industries. One reason is that the average wage rates for industries are different, so the minimum wage is differentially binding in these industries. Food and drinking sectors employ a large proportion of minimum wage workers. Previous papers suggest that the increase of minimum wages is likely to reduce the employment in limitedservice restaurants. At the same time, the demand for table-service restaurants could rise because of the substitution effect. Our data do not distinguish between limitedand table service restaurants and hotel accommodation data are also included, so this 
intra-sector substitution is not identified in our analysis. The strongest disemployment effect is found in construction industry, which is opposite to our expectations, since workers in construction industry are usually paid more than the minimum wage. One can notice that the disemployment effects are much greater in magnitude for relatively larger firms in our data, the $D_{2}$ and $D_{3}$ group.

\subsubsection{Robustness Check}

$D_{4}$ group represents newly emerging firms that do not exist in 2006 Q3, so we do not have their information at the beginning quarter. In the regression, we do not control for firm size or other firm level time-varying factors. For these new firms, it is possible that some firms grow faster and push themselves pass the $\$ 500,000$ state minimum wage threshold. When this occurs, it implies that firm growth causes an increase in the firms effective minimum wage, biasing the coefficient on the minimum wage variable. In addition, it is not clear how these new firms respond to minimum wage changes. If they respond quite differently, the time fixed effects which is assumed to be same for all groups would be affected. Another problem with these new firms is that they may not be new firms, but firms without records at the beginning quarter for the reasons explained in the previous subsection. In order to address this concerns, we omit $D_{4}$ group from the regression to check whether the results differ or not.

Table 4.17 presents the estimation results comparison between the firm level regression and the same regression without D4 group. Since (4.3) is one of our preferred model specifications, the firm level regression results are from model specification (4.3), which control for time fixed effects. The estimates for each group do not differ a lot comparing with previous regression and they are presented in Appendix J. In the table, we only present the estimates for the overall employment effects, which are the weighted sum of each group estimates. From this table, one can notice that the estimates for the entire sample, retail trade, "selected industries combined" category 
do not vary if we omit $D_{4}$ group. The disemployment effect for construction industry is reduced, from $4.97 \%$ decrease to $3.26 \%$ decrease with a $10 \%$ increase in minimum wage. In the regressions with observations from all four groups, the employment impacts for food/accommodation and manufacturing industries are insignificant at $10 \%$ level. When $D_{4}$ group is omitted, we can detect the disemployment effects for these two industries. However, the effects are very small, a $0.29 \%$ decrease in employment in food and accommodation industry and a $0.23 \%$ decrease in manufacturing industry.

\subsection{Individual-Level Regression Analysis}

\subsubsection{Description of Earnings}

Section 4.4 and 4.5 analyze the employment effects of minimum wage in the firm level and discuss how the firms' employment decisions are affected. We are also interested in how an individual responds to the change of minimum wages. Does minimum wage have heterogeneous impacts on people with different earnings?

One great advantage of our data is that we have quarterly earnings for each employee. These earning records allow us to focus the analysis on low earning workers, who are more likely to be affected by the minimum wages. One limitation of our data is that we do not have information about working hours. For purposes of classifying workers by like minimum wage impacts, we assume all workers are full time workers and they work 43 hours a week. This approach can misclassify people for two reasons. First, quarterly data cannot identify an employees working status at any particular given time in the quarter. Some employees could be employed only at the beginning of that quarter, and some other employees could start to work at the end of the quarter. These workers could have a high hourly wage rate, but they are misclassified into the low earning groups. Second, we can not distinguish between full-time and part-time workers. Part-time workers could work few hours but earn a higher hourly wage. 
However, we believe the inclusion of part-time workers in the low earning analysis may not reduce the estimated impact of the minimum wage for the following two reasons. The first reason is that many part-time workers are minimum wage workers, so that they are very likely to be influenced by the change of the minimum wages. The other reason is that part-time jobs often refer to unstable employment, to workers who have difficulty finding stable full-time jobs, perhaps because they have lower productivities. These low skilled workers may be particularly likely to be affected by the minimum wage policy.

For the purpose of identifying what kind of workers are more sensitive to the minimum wage changes, we divide individuals into five wage groups based on their initial quarterly earnings in the beginning quarter, 2006 Q3. As we noted above, since we do not have information of working hours, we have to use the average working hours, which are 43 hours per week to estimate the hourly wage rate. So the total working hours for each quarter is calculated as 43 working hours per week $* 4$ weeks per month * 3 months, which equals 512 . Then, each individual's estimated hourly wage rate is quarterly earnings divided by 512. $j$ indexes groups, and individuals are divided into the following groups:

$j=1$ if an individual's estimated hourly wage rate is greater than $\$ 15$.

$j=2$ if an individual's estimated hourly wage rate is greater than $\$ 7.25$, which is the highest minimum wage in our sample period, and it is no larger than $\$ 15$.

$j=3$ if an individual's estimated hourly wage rate is within the range of $\$ 4.55$ to $\$ 7.25$. $\$ 4.55$ is $70 \%$ of the first Missouri state minimum wage, $\$ 6.50$.

$j=4$ if an individual's estimated hourly wage rate is within the range of $\$ 1.65$ to $\$ 4.55$. $\$ 1.65$ is $25 \%$ of the first Missouri state minimum wage, $\$ 6.50$.

$j=5$ if an individual's estimated hourly wage rate is less than $\$ 1.65$.

For group 1 and 2, individuals' hourly wage rates are higher than minimum wages over the entire sample period. Workers in these two groups are not directly affected 
by the minimum wage increase, and they are the higher earners according to our group definitions. For group 3 and 4, these are the groups include people who should be more sensitive to minimum wage changes, since their estimated wages are at or close to minimum wages. Group 2 and 3 people are similar in the sense of jobs, but group 2 workers could be more productive and have high skills. Group 4 tends to include those individuals who work part time or do not have stable jobs. Group 5 is the lowest earnings group. The estimated hourly wage rates for this group are quite low. Instead of earning a low hourly wage, people in this group are more likely to be workers who work very few hours or do not work for the entire quarter.

Figure 4.7 illustrates the estimated hourly wage distributions in three quarters. Panel (a) presents the distribution for 2006 Q3, which is the beginning quarter of our sample. Panel (b) present the plot for 2009 Q3, in which quarter both Missouri and Kansas increase minimum wage to $\$ 7.25$. There is no minimum wage difference between these two states thereafter. The distribution illustrated in panel (c) is for 2012 Q3, the last quarter of the sample. From these three figures, one can notice that the average estimated hourly wage is getting larger over time and the wage distribution is more compressed.

Figure 4.8 depicts the distributions of initial estimated hourly wage rates in 2006 Q3 across industries. The reference line is $\$ 6.5$, which is the first Missouri state minimum wage, and it is implemented in 2007 Q1. From these plots, we can confirm the heterogeneous effects across industries. The retail trade and the food/accommodation industries have higher proportions of low wage workers. Especially in the food/accommodation industry, over $50 \%$ of workers have estimated earnings lower than $\$ 6.50$. It is possible that these workers have low hourly wage rates. It is also possible that a large percentage workers in this industry are part-time workers, which yields them low estimated hourly wages because they are assumed to work full-time. When comparing with the reference line, we can tell that in the retail 
trade, the food/accommodation industry and the "selected industries combined" category, minimum wage is more likely to be binding. In contrast, in the construction and the manufacturing industries, there is a substantial difference between minimum wage and the average wage in the industries.

Figure 4.9 shows the estimated hourly wage pattern for each earning group. The highest curve presents the pattern for group 1 people. One can notice that this curve exhibits strong seasonal patterns, since the estimated hourly wage jumps in the last quarters. One possible reason could be the last quarter's earning includes the annual bonus or other benefits. The second highest curve present the wage rate pattern for group 2 people. It is a little above $\$ 10$ initially, and then is increasing slightly over time. The third highest curve is for group 3 people, and in general have the exact same increasing patter as the curve for group 2 people. The lowest two curves are for group 4 and 5 people respectively. Although the curve for group 5 is always lower than the curve for group 4 people, they are getting closer and closer over time. Comparing with other three curve, these two curves also exhibits a faster increasing rate.

\subsubsection{Regression Model}

In this section, we construct individual-level multi-period and multi-group panel data $^{24}$ to analyze the minimum wage effects. Unlike the panel in the previous section, the panel for individual cases does not have the firm level restrictions, such as the Missouri minimum wage exemption and the comparable firm sizes in both states. The linear probability model specification ${ }^{25}$ is written as: for each group $j$,

\footnotetext{
${ }^{24}$ The detailed construction rule can be found in the appendix K.

${ }^{25}$ Initially we try to use logit model. However, due to the large sample size and little variation within individual, the logit model cannot be estimated. As a result, we adopt the linear probability model, which still can yield unbiased estimates.
} 


$$
\text { EMPSTATUS }_{i t}=\alpha_{0}+\beta \cdot \operatorname{lnm} w_{i t}+\theta_{i}+\delta_{t}+\sum_{k=2}^{4} \gamma_{k} S_{k} \cdot M O+t s \cdot M O+\epsilon_{i t}
$$

$i$ represents each individual, which can be tracked over time by using the encrypted SSN in our data. $j$ represents hourly wage groups. Since the regressions are run for each group separately, index $j$ is not in the regression model. t indexes quarters. EMPSTATUS is binary variable, indicating an individual's employment status in quarter $t$. EMPSTATUS $=1$ if the individual is employed in quarter $t$ in either state $^{26}$; otherwise, it is 0 . Literally, this specification models the probability of being employed. We also assume that Missouri and Kansas minimum wages have same effects on employment possibilities. lnmwit is the natural log of the minimum wages. If an individual is initially employed in Missouri, regardless of his future employment location, he is assigned Missouri minimum wage for all the records. A similar rule applies if an individual works in Kansas at 2006 Q3 ${ }^{27}$. By applying these rules, we can succeed in identifying the change of employment possibilities resulting from a change in the Missouri minimum wage. $\beta$ is the estimator that we are interested in. $\theta_{i}$ is the individual fixed effect, to control for any time invariant individual characteristics. Since each person chooses the industry that he is willing to work in and we already include the individual fixed effects, industry fixed effects are omitted from the model. $\delta_{t}$ is the time fixed effects, which assumes that each quarter affects all workers in both Missouri and Kansas similarly. However, we cannot rule out the possibility that time, like business cycles or seasons, affects the two states differently. In order to address this issue, we add seasonal and time trend terms in the regression and make them interact with Missouri observations, so that we can check the time impacts of one

\footnotetext{
${ }^{26}$ For this analysis, we use the Missouri and Kansas border area to select the individuals. Then, we track these individuals' employment status within the entire Missouri and Kansas sample reservoir.

${ }^{27}$ If one person has jobs in both Missouri and Kansas initially, this person is excluded from this analysis.
} 
state relative to the other. $\sum_{k=2}^{4} \gamma_{k} S_{k} \cdot M O$ are the seasonal interaction terms, with the first quarter being dropped. $t s \cdot M O$ represents the time trend interaction term, which could capture the long term differences between two states. $\epsilon_{i t}$ is the robust error term, which is clustered within states and quarters.

\subsubsection{Estimation Results}

In this subsection, we report estimation results for each earning group in every relevant broad categories. The highlighted estimates are significant at $10 \%$ level. Although we include seasonal interaction terms in the regression, the estimates for these terms are not reported, since most of them are not significant. The left panel summarizes the results for five group regressions, and the right panel describes the relative sizes of each group. First we combine all the individual records together and check what the aggregated impacts are. Results are shown in table 4.18, The estimates for group 1, 2 and 3 are positive and significant at 10\% level, and individuals from these three groups take up to over $75 \%$ of the entire sample. The estimate for group 4 is positive but not significant, suggest there is no significant minimum wage impact for group 4 . For group 5, the chance of employment is reduced when minimum wage increases.

Table 4.19 presents the estimates for retail trade industry. In this industry, group 1 and group 2 account for $27.39 \%$ and $29.11 \%$ of the total observations. Group 3 and group4 in total account for $31.34 \%$ of the sample. The estimates for group1, 2 , 3 are all positive and significant, implying that people in these groups would have a greater chance of being employed when the minimum wage increases. According to our results, minimum wage has no impact on group 4 people. For group 5, which is the group for people working very few hours, increases in the minimum wages decreases their chances of employment. Time trend interaction terms in general have a negative impact on employment, but the impact is very small.

Table 4.20 summarizes the estimation results for the food sector, including limited- 
service and full-service restaurants ${ }^{28}$. The group distributions are quite different from the distributions in the retail trade industry. In food industry, the largest group is group 4, in which workers' initial hourly wage rates in 2006 Q3 are greater than $\$ 1.65$ and no larger than $\$ 4.55$. People in this group are more likely to be part time workers. The second largest group is group 5 , the group with lowest estimated hourly wage rates. In total, group 4 and 5 account for more than $50 \%$ of the total cases. These statistics are consistent with the facts that food industry is a low wage industry and has a high proportion of part time workers. Our estimation results suggest that minimum wage has no impact on group 4 workers and decrease the possibility of employment for group 5 workers. For the first three groups, the estimates are still positive and small. Table 8c. presents results for hotel and accommodation sector. The sample size for this sector is much smaller compared with other industries. People in this sector are clustered in group 2, 3 and 4. The estimates for group1, 2 and 4 are negative and significant. Compared to the estimates from other industries, the estimate for group 4 is larger in magnitude. It is - 0.471 , implying a $10 \%$ increase in minimum wage decreases the possibility of being employed by 0.047 . The estimates for group 3 and 5 are insignificant.

Results for the construction industry are shown in table 4.22. The sample size for this industry is large, since all Missouri construction workers are covered by state minimum wage law. Nearly half of the workers in this industry have a estimated hourly wage that is higher than $\$ 15$. Group 1 and 2 account for $75.63 \%$ of the total observations. This is consistent with the view that the minimum wage is not likely to be binding in the construction industry. For group 1, the employment possibility is decreased by $0.16 \%$ with the increase of $10 \%$ in the minimum wage. With the minimum wage, group 2 and 3 workers have a better chance of being employed. The estimates for group 4 and 5 are insignificant. Table 4.23 is a summary of regression

\footnotetext{
${ }^{28}$ Since SIC industry code does not distinguish between full-service and limited-service restaurants, we cannot separate these two sectors.
} 
results for manufacturing industry. From the group distributions, one can see that $81.94 \%$ of the observations are in group 1 and 2 , whose wages are not likely to be directly affected by the minimum wages. An increase in the minimum wages dose increase the possibility of employment for people in group 1, 2 and 3. For group 4 and 5, the group sample distributions are low, and the impact are not significant. Table 4.24 presents the results for the "selected industries combined" category. Similar to manufacturing industry, individuals in group 1 and 2 take up to $69.74 \%$ of the sample. The rest of the three groups have similar sizes. The estimation results are also similar to the ones from manufacturing. The only difference is that the estimates for the time trend interaction term are always significant.

\subsubsection{Results Summary and Discussion}

Estimation results are summarized in figure 4.10. In general, the minimum wage changes increase the chance of employment for people in group 1, 2 and 3. For group 4, six out of seven estimates we get are insignificant at $10 \%$ level. The only exception is the estimate in hotel and accommodation sector and it is -0.471 . The estimates for group 5 are either negative or insignificant. Across industries, results are similar in most industries, except in hotel and accommodation sector, where the estimates are negative in group 1, 2 and 4 and insignificant in group 3 and 5 .

Group 1 is the highest hourly earning group. With the increase of the minimum wages, people experience a greater chance of being employed. People in this group are more likely to work full time. They may be well-educated people who take managerial positions or are otherwise more experienced workers. The estimation results for group 2 is similar to the ones for group 1. For group 2 people, they could be more skilled workers and their estimated hourly wage rates are also higher than the minimum wages. There could be three reasons to support these positive impacts. First, according to the substitution effects, when the minimum wage increases, employers 
would like to hire more high skilled workers instead of low skilled workers. Second, employers would also substitute machinery and capital for labor. Consequently, more technicians and people with better education levels are employed. Third, several economists argue that the minimum wage increase should also increase monitoring and management cost, which means firms have to hire more people to do this job. As shown above, there are two exceptions. One is for the hotel and accommodation industry, where the impact is negative. However, People in group 1 only make up $8.15 \%$ of the sample in this sector. The other exception is for the construction industry. Although nearly half of the observations are from this group, the minimum wage has no impact on people in group 1 , since the minimum wage is not likely to be binding in this industry for the reasons we explain in the previous section.

Group 3 includes people whose estimated hourly wage rates are greater than $70 \%$ of the first Missouri minimum wage and no greater than the current minimum wage, that is, from $\$ 4.55$ to $\$ 7.25$. Group 4 is for the people whose estimated hourly wage rates in 2006 Q3 are between $25 \%$ to $70 \%$ of the first Missouri minimum wage, that is, in the range of $\$ 1.65$ to $\$ 4.55$. These groups are supposed to be more sensitive to minimum wage changes, since their wages would be directly affected by the change. One difference between these two groups is that group 4 people are more likely to be mid-time workers, who work 20 - 34 hours weekly. We expect to find negative estimates for these groups. However, the results are opposite to our expectations. The estimates for group 3 are always positive. From employee's side, the minimum wage policy could increase workers' incentives to maintain their current jobs or to actively find new jobs, in return to lower turnover rates and to increase productiveness. Most of the estimates for group 4 are insignificant, implying minimum wages have no impact on the employment chances for people in this group. One possible reason is that in the regression the dependent variable is binary. For people in group 4, employers can adjust their working hours accordingly instead of firing any current workers. In 
addition, instead of laying off workers, there are some other channels of adjustments, such as passing on the burden to consumers by increasing output price. Our model cannot capture these effects. Another possible reason to explain these non negative effects is that higher minimum wage could increase workers' incentives to maintain the current jobs or to actively find new jobs, which improve the matched between employers and employees, so that workers can have more stable jobs.

Group 5 is the lowest estimated hourly earning group. Rather than earning a low hourly wage, workers from this group presumably work less than 20 hours per week. In retail trade and food industry, estimates for this group are negative and significant. These two are the minimum wage industries with high turn-over rates and cluster of part time workers. Besides these people themselves choose to work fewer than others, employers also prefer to hire people who can work more hours and maintain stable status so that they can lower training costs and increase employees' productivities. As a result, even though the minimum wage increases, the possibility of being employed for group 5 declines. In addition, we can not identify whether these people lose jobs or just leave the labor market. The estimates in other industries are insignificant, suggesting the minimum wage changes have no direct impact on people in this group. These group 5 estimates justify the economists's arguments that a high percentage of poor people can not benefit from the minimum wage increases. A more cost-effective way to redistribute towards these people is to implement policy regarding direct transfer and targeted beneficiaries, such as EITC.

\subsection{Regression Analysis Regarding Labor Mobility}

\subsubsection{Regression Model}

To further explore the minimum wage impacts on employment, we also check whether minimum wages affects labor mobility by state. Within the Kansas City metro area, 
because of close geographic distance, businesses may migrate over the state border. Increasing the Missouri minimum wages may also change the patterns of the labor movement between Missouri and Kansas. In this section, still using the individuallevel panel, we construct two multi-period and multi-group panels. In section 4.6, we are only interested in individual's employment status in the sample period, regardless of job locations. Here, we particularly identify whether an individual is employed in Missouri or Kansas. Generally speaking, the panels are constructed in the following way. Initially, we have information for each working individual in Missouri and Kansas border firms in 2006 Q3 ${ }^{29}$. Then, we track their later employment status to see if they have jobs in Missouri or Kansas. Consequently, we have two panels. One is the Missouri panel for workers who are initially employed in Missouri, and include information of their employment in Missouri and Kansas across the sample period. Similarly, the other one is the Kansas panel. For workers who are initially employed in Kansas, their future employment status in both states are included in this panel.

The regressions are separated by states and by state of employment. The model is specified as following:

$$
\text { EMPSTATUS }_{i t}=\alpha_{0}+\beta \cdot \operatorname{lnm} w_{i t}+\sum_{k=2}^{4} \gamma_{k} S_{k}+q_{1} t+q_{2} t^{2}+\epsilon_{i t}
$$

$i$ indexes individual, and $t$ is for each quarter. EMPSTATUS $S_{i t}$ is a binary variable, indicating an individual's employment status in either state. The dependent variable has two forms. Specifically, EMP $P_{M O i t}$ indicates individuals's employment information in Missouri.EMP $P_{k s i t}$ indicates employment status in Kansas. $l n m w_{i t}$ is the natural $\log$ of the Missouri minimum wage. Unlike the regressions in previous section, the minimum wage variable is either the Missouri or the federal minimum wage based on initial employment at the beginning quarter. Since we are interested in the labor mobility induced by the increase of the Missouri minimum wage, we only

\footnotetext{
${ }^{29}$ The selecting rule is very similar to the rule for section 4.6. Appendix $\mathrm{K}$ describes the details.
} 
use the Missouri minimum wage as the regressor. $\sum_{k=2}^{4} \gamma_{k} S_{k}$ controls seasonal effects. The first season is dropped to avoid collinearity. Instead of including time fixed effects in the model, we add linear and quadratic time trends by assuming the shift is the same for each quarter. $\epsilon_{i t}$ is the robust error term and clustered within quarters.

We use this model to further check whether our administrative data have the power to identify the minimum wage impacts on employment. If the regression estimates are insignificant, it means that there is no power in the data to detect minimum wage impacts. Figure 4.11 illustrates the expected labor movement patterns across states with the intervention of Missouri minimum wage policy. The horizontal axis represents time (quarter) and the vertical axis represents employment possibility, which is from 0 to 1 . The discontinuity indicates the time of Missouri minimum wage intervention. For people who are initially employed in Kansas, Figure 4.11a depicts the expected pattern of their continuous employment in Kansas. Over time, the probability is declining. However, with the Missouri minimum wage increase and the spill-over effects, this policy would harm Kansas residents, since it is relatively harder for Missouri people to find jobs in Missouri and they move across border to seek jobs in Kansas, which makes Kansas labor market more competitive.

Still for Kansas residents, figure 4.11b illustrates the expected pattern of their future employment in Missouri. Initially, the probability is 0 , since they work in Kansas at the starting quarter. Later on, the probability increases. When minimum wage is raised in the market, the Missouri labor market becomes tighter and it is more difficult to find a job there according to theory. As a result, for Kansas residents, Missouri minimum wage would reduce the probability of finding a job in Missouri. For Missouri residents, their expected employment patterns are illustrated in figure 4.11c and 4.11d. Figure 4.11c describes the pattern of continuos employment in Missouri. After the minimum wage increases, the possibility is supposed to decrease. Figure $4.11 \mathrm{~d}$ shows the probability of getting a job in Kansas. The probability is 0 
at beginning and increasing over time. Because of minimum wages, the chances of getting a job in Missouri would be reduced as explained before. So Missouri people would come across border line and search for job opportunities in Kansas. As a result, the employment possibility increases. We expect to see positive estimates from the regression. To detect the labor movement, for each state panel, we run the regression twice, with the outcome the employment status in the initial state and the employment status in the other state.

\subsubsection{Estimation Results}

We run the regressions for each of the five earning groups by industry and by the four situations we explain above. Table $4.25^{30}$ presents the results for the entire sample. Highlighted estimators are significant at 10\% level. For "KS-KS" situation, we expect to find negative impacts, and the estimates are consistent with our expectations. For Kansas residents, the Missouri minimum wages decrease their chances of being employed in Kansas, except for group 2. For the "KS-MO" situation, we expect to find negative signs. However, the estimates for "KS-MO" are all positive and significant at $10 \%$ level, suggesting their possibilities of finding jobs in Missouri are increases around $1 \%$ with a $10 \%$ increase in Missouri minimum wages. For Missouri residents, their chances of being employment are reduced, and the strongest reduction occurs in group 5. For Missouri workers in group 5, 10\% increase in the Missouri minimum wage decreases their chances of being employed by $9 \%$. The estimates for "MO-KS" are all positive and statistically significant. The only exemption is for group 1. Our results suggest that Missouri residents in the highest estimated hourly wage group are not affected by state minimum wages.

Table 4.26 presents the estimation results for the retail trade industry. From group 1 to group5, the disemployment effects become greater and greater, from -

\footnotetext{
${ }^{30}$ Label "KS-KS" means we use Kansas panel and the dependent variable is the employment status in Kansas. Similar definitions apply for the other three labels.
} 
$0.85 \&$ to $-7.79 \%$ with a $10 \%$ increase of Missouri minimum wage. The estimates for "KS-MO" situation have opposite signs, but the effects are much smaller, from 0.0072 to 0.0149 unit change with $10 \%$ change in Missouri minimum wage. These results may suggest that some people who lost or quit jobs in Kansas succeed in finding jobs in Missouri. In the Missouri panel, for people in group 1, 2 and 4, our results imply that the minimum wage increases the chance of getting jobs in Kansas. Meanwhile, the chance of continuous employment in Missouri is reduced for all groups except the highest earning group.

Table 4.27 summarizes the results for the food sector. For group 1, the possibility of Missouri residents being employed in Kansas is reduced. All other three estimates are insignificant, since these people from highest earning group are not likely to be directly affected by minimum wages. Both food and retail trade are low wage industries and they share some common characteristics, all other estimates from this table are similar to the results from table 4.26. For people in group 5, minimum wage greatly hinders their continuous employment in initial states by $10 \%$ if Missouri minimum wage increases by $10 \%$.

Table 4.28 presents the estimation results for the hotel and accommodation sector. One can see that more than half of the estimates are not significant at $10 \%$ level, implying minimum wage changes have no impact on people in these groups. Group 3 includes people whose estimated hourly wage rates are between $\$ 4.55$ and $\$ 7.25$. This is the group of people who are most likely to work full time and are directly affected by the increasing of the minimum wages. For this group's people in Kansas panel, the chances of keeping employment is reduced by $4.22 \%$ and the chances of getting jobs in Missouri increased by $2.04 \%$ with $10 \%$ increase of the Missouri minimum wage. For people in Missouri panel, the possibility of continuous employment decreases by 5\%. Looking at "MO-KS" column, only the estimate for group 2 is significant at $10 \%$ level. The findings that many estimates from "MO-KS" and "KS-MO" are insignificant 
imply that in hotel and accommodation sector, Missouri minimum wage has nearly no ripple effect. One possible reason is that firms in this sector are not mobile when they choose locations.

Results for the construction industry are shown in table 4.29. Missouri minimum wage stimulates the labor movement between two states. The estimates from "KSMO" and "MO-KS" columns are all positive and significant at 10\% level. For the labor movement within the states, only the estimates for group 2 and 3 are significant. The negative estimates indicate the chance of keeping employment is reduced. Table 4.30 presents the results for manufacturing industry. For group 1 people, only the continuous employment in Kansas is reduced by Missouri minimum wage increases. For people in group 2, the probability of continuous employment in Kansas is increased by $1.54 \%$ with $10 \%$ increase of minimum wage. The movements between states are also encouraged. For group 3, the continuous employment in either states is hindered, since the estimates are negative and significant. Missouri minimum wage increases the possibility of moving from Missouri to Kansas, but it has no impact on the movement from the other direction. For group 4 people, other than the chance of keeping employment in Missouri is reduced, the possibilities of "MO-KS" and "KSMO" movements are both increased. For group 5, we only get one significant estimate, that is for the "MO-KS" movement, the chance is increased. When comes to "selective industries combined" category, all the estimates are significant and are shown in table 4.31. The estimates for continuous employments are negative, and the estimates for across state movements are positive.

Our estimation results still vary by groups and by industries. Generally speaking, after controlling seasonal effects, linear and quadratic time trends, Missouri minimum wage reduces the chance of continuous employment in either states and encourages the possibility of moving across state. Looking at people in different earning groups, for the highest earning people, that is, people in group 1, the impacts are either 
insignificant at $10 \%$ level or very small, ranging from $0.49 \%$ to $1.43 \%$ changes with $10 \%$ increasing in Missouri minimum wage. For people in group 2, most of the estimates are significant and have the expected signs. The impacts get stronger as earnings decline. The strongest disemployment impacts are found in group 5. For people in this group, the significant estimates from within state movements are from $7.51 \%$ to $9.99 \%$ with a $10 \%$ increase in Missouri minimum wage. One can also see that estimates across industries do not differ a lot. Low wage industries, such as retail trade and food industries, do not exhibit greater responses to Missouri minimum wage changes in terms of labor mobility.

\subsection{Conclusion}

In this chapter, we use administrative payroll data in Missouri and Kansas to examine the impact of Missouri minimum wage on employment in depth. In particular, we focus on the Missouri and Kansas border area - the Kansas City metropolitan area. The close geographic distance provide us a great opportunity to explore the minimum wage effects by comparing the differences between Missouri side of the Kansas metro area and Kansas side of the area. In general, the tests are performed in both firm-level and individual-level.

In the firm-level analysis, we first investigate the impacts for each single wave of the minimum wage changes by using DID method by checking the DID estimators for two sequential quarters and the same quarters in two sequential years. The results we get vary in signs for different industries and for different waves of minimum wage increases. It is hard to detect the disemployment effect among these cases, since DID method for single wage of policy changes may lack of sufficient controls. In general, the impacts are moderate and so not so seriously at variance with expectations. When Missouri first increased state minimum wage, the employment level in Missouri tend 
to be increased. During the recession period, the estimates tend to be moderate and negative.

Then, we construct a multi-period and multi-group panel data including Missouri border firms that are subject to the state minimum wage and similar Kansas border firms. Firms are divided into four groups based on their initial employment level at the beginning quarter of the sample, 2006 Q3. Our estimation results suggest employment effects of minimum wages vary by industries and by firm sizes. In general, our findings are consistent with previous papers. The weighted overall employment effects of the four groups are negative and significant among different model specifications, within the range from $1.47 \%$ to $8.16 \%$ decrease in employment with a $10 \%$ increase in minimum wage. The exceptions are the food and accommodation industry and the manufacturing industry, where we fail to find the adverse aggregated impacts. For the groups with initial firm sizes greater than 10, the minimum wage increases result in job losses. However, for small businesses, with no larger than 10 employees, results vary by industries. Positive effects are found for the firms in the food and accommodation, retail trade, manufacturing industries and the regression including all the relevant industries. For the newly emerging firms, estimation results are mixed. Employments are encouraged in the manufacturing industry and in the regression using the entire sample. In contrast, employments are discouraged in the construction industry. The most common case for newly emerging firms is that we fail to find any discernible effect in all other industries.

In the individual-level analysis, we are particular interested in finding whether people with different earnings respond differently to minimum wage changes as theory states. So we divide individuals into five groups based on their initial quarterly earnings in 2006 Q3. Using a linear probability model predicting individual employment, we find that minimum wage actually raise the employment opportunities for people with initial estimated hourly wage rate greater than $\$ 4.55$. Disemployment 
effects are not found for people with hourly wage rate between $\$ 1.65$ to $\$ 4.55$. For people with lowest earnings, the estimates are either negative or insignificant. All these results do not vary a lot across industries. Furthermore, we also utilize the individual-level observations to explore whether Missouri minimum wage have impacts on individual's continuous employment within states or labor movement across the state border. Our results generally suggest that the probability of continuous employment within initial states are discouraged and the labor movements across states are encouraged. 


\begin{tabular}{|c|c|c|}
\hline & January - June & July - December \\
\hline \multirow{2}{*}{2006} & \multicolumn{2}{|c|}{ Missouri $\$ 5.15$} \\
\hline & \multicolumn{2}{|c|}{ Kansas \$5.15 } \\
\hline \multirow{2}{*}{2007} & \multicolumn{2}{|c|}{$\$ 6.50$} \\
\hline & $\$ 5.15$ & $\$ 5.85$ \\
\hline \multirow{2}{*}{2008} & \multicolumn{2}{|c|}{$\$ 6.65$} \\
\hline & $\$ 5.85$ & $\$ 6.55$ \\
\hline \multirow{2}{*}{2009} & $\$ 7.05$ & $\$ 7.25$ \\
\hline & $\$ 6.55$ & $\$ 7.25$ \\
\hline \multirow{2}{*}{2010} & \multicolumn{2}{|c|}{$\$ 7.25$} \\
\hline & \multicolumn{2}{|c|}{$\$ 7.25$} \\
\hline \multirow{2}{*}{2011} & \multicolumn{2}{|c|}{$\$ 7.25$} \\
\hline & \multicolumn{2}{|c|}{$\$ 7.25$} \\
\hline \multirow{2}{*}{2012} & \multicolumn{2}{|c|}{$\$ 7.25$} \\
\hline & \multicolumn{2}{|c|}{$\$ 7.25$} \\
\hline
\end{tabular}

MO Kansas

Table 4.1: Minimum Wage History in Missouri and Kansas from 2006 to 2012

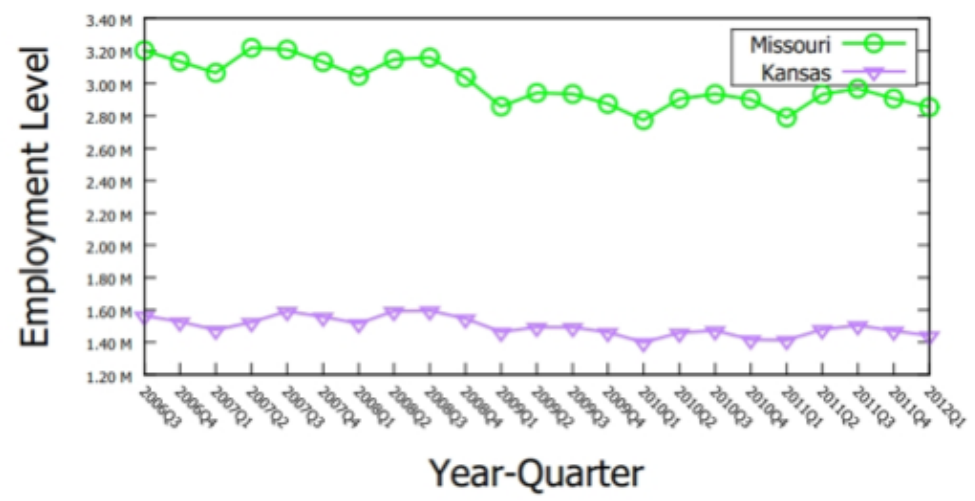

Figure 4.1: Missouri and Kansas Employment Level Plot 


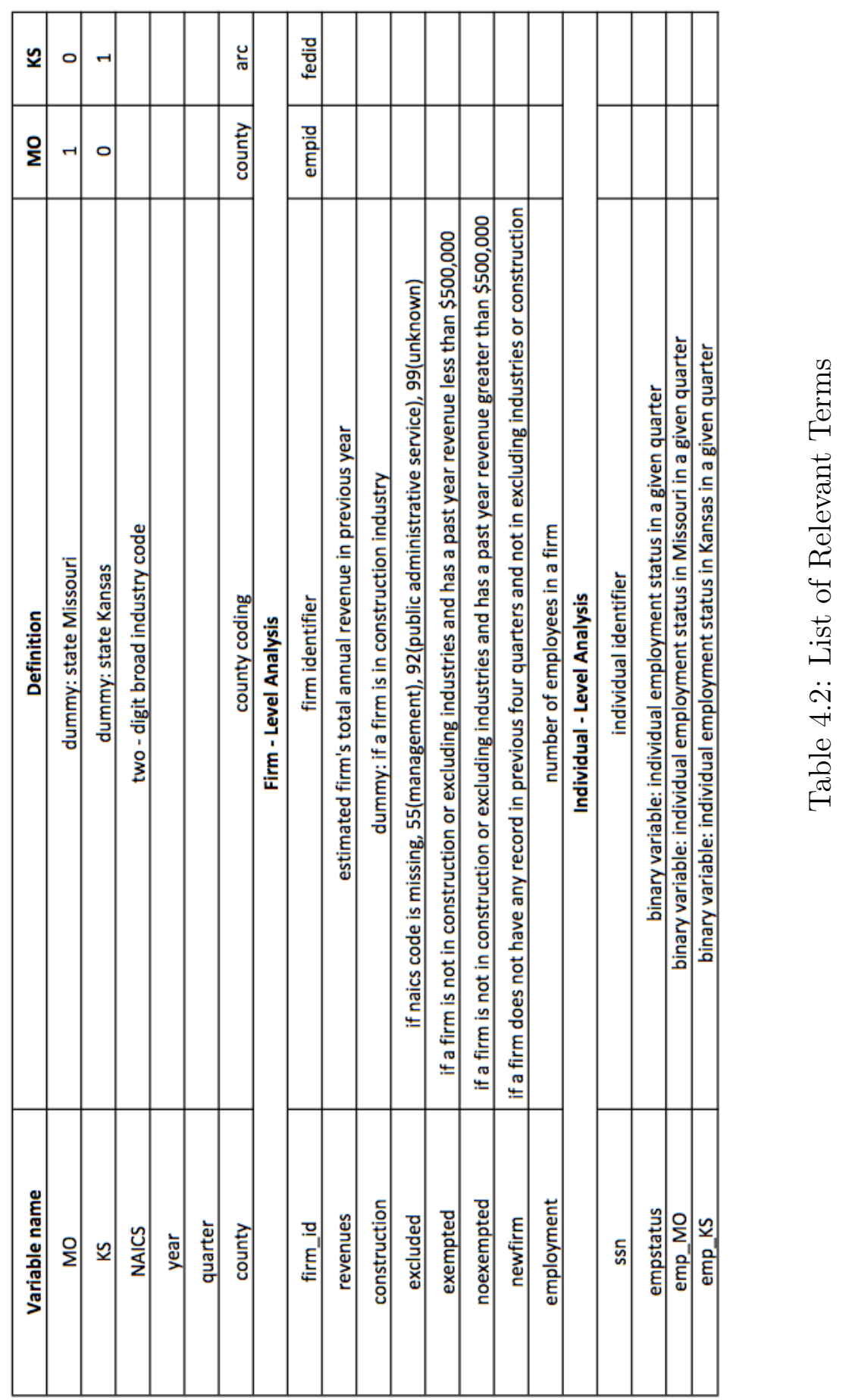




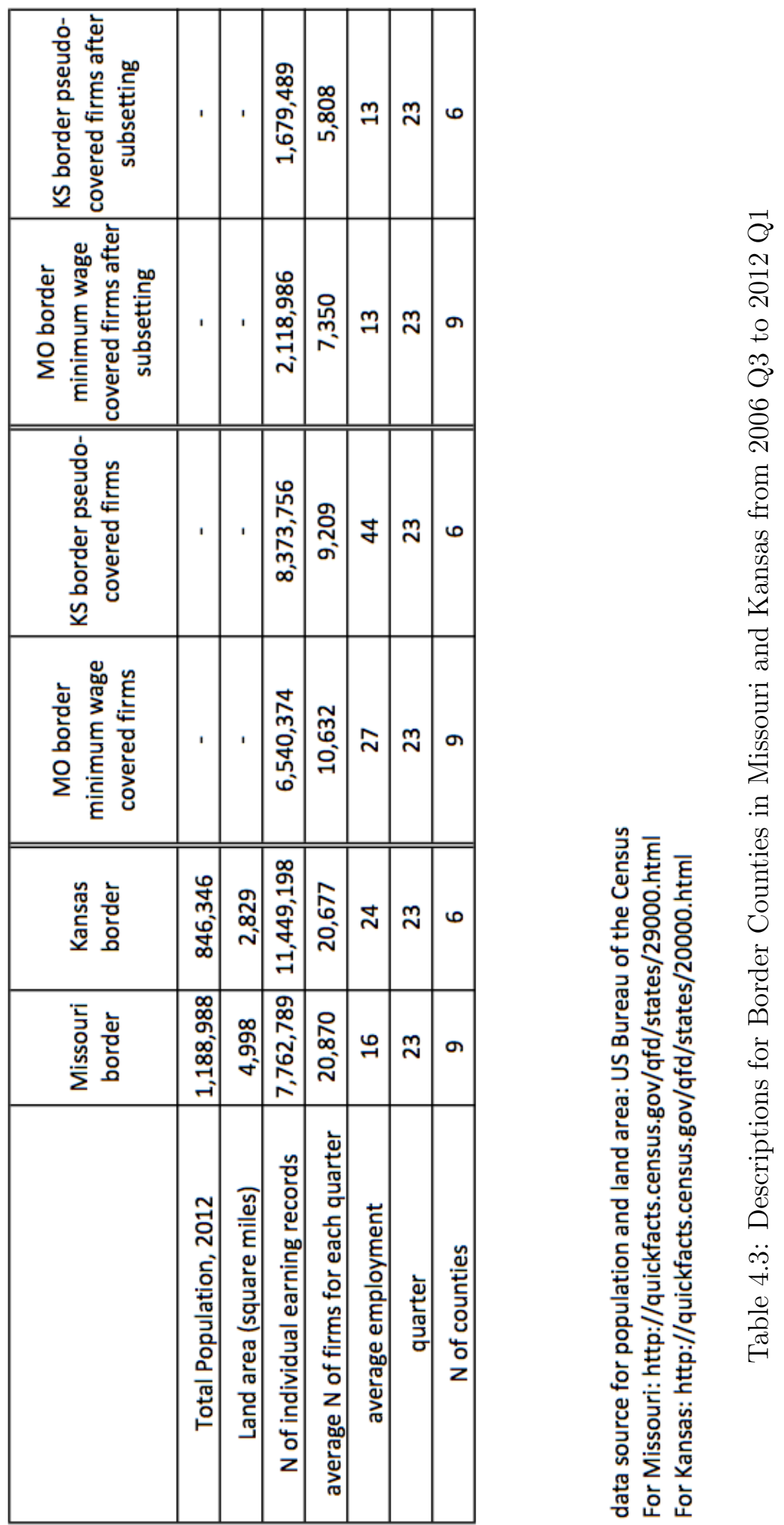



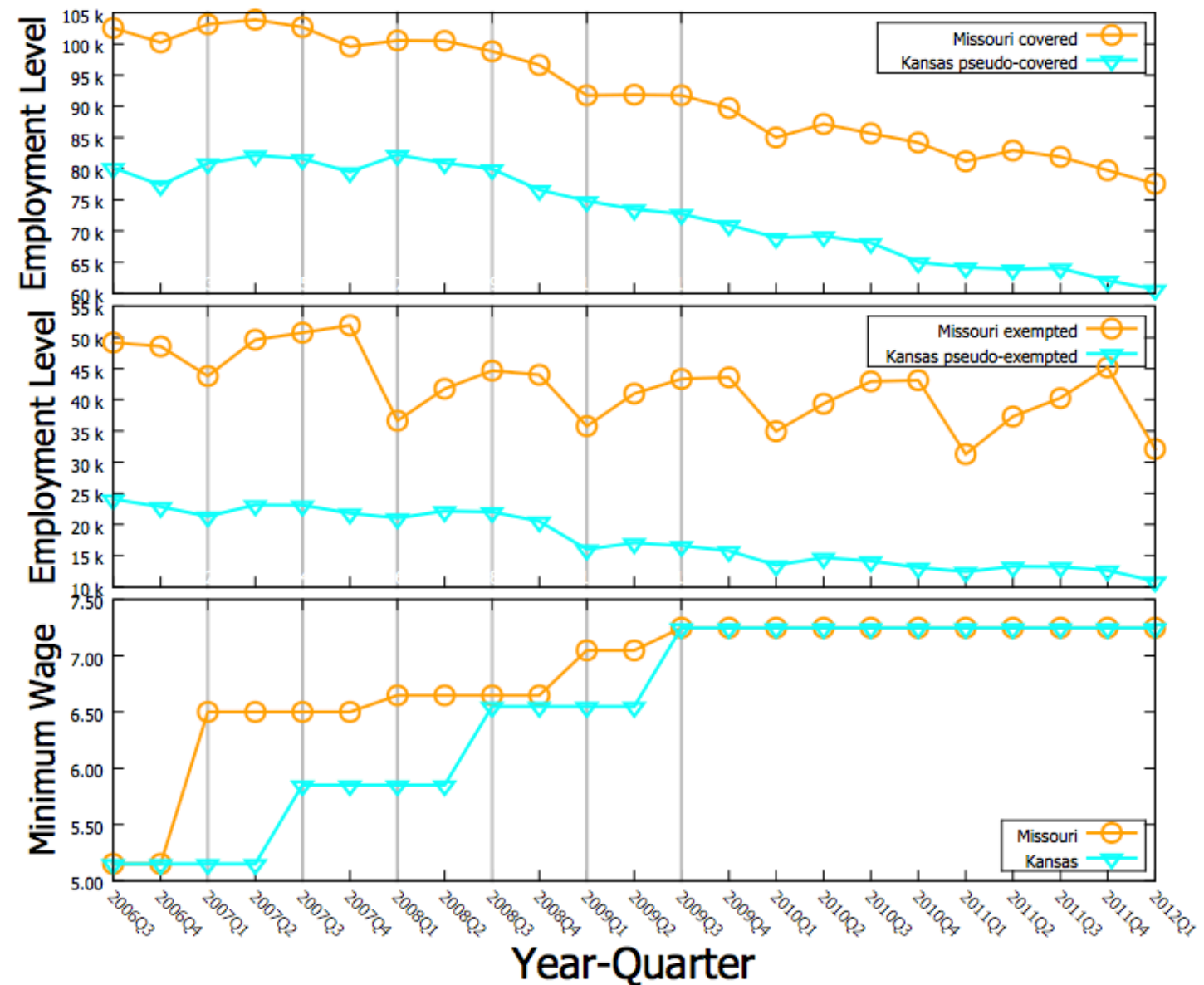

Figure 4.2: Plot of Employment Level for Missouri and Kansas Border Firms after Selecting, with the Corresponding Minimum Wage Changes 


\begin{tabular}{|c|c|c|c|c|c|}
\hline & & \multicolumn{2}{|c|}{ Missouri Border } & \multicolumn{2}{|c|}{ Kansas Border } \\
\hline & & \multicolumn{2}{|c|}{ 2012Q1 } & \multicolumn{2}{|c|}{$2012 Q 1$} \\
\hline naics & industry & frequency & percent & frequency & percent \\
\hline 0 & missing industries & 420 & $0.11 \%$ & 201585 & $39.13 \%$ \\
\hline 11 & Agriculture, Forestry, Fishing and Hunting & 1494 & $0.38 \%$ & 504 & $0.10 \%$ \\
\hline 21 & Mining, Quarrying, and Oil and Gas Extraction & 220 & $0.06 \%$ & 508 & $0.10 \%$ \\
\hline 22 & Utilities & 541 & $0.14 \%$ & 2890 & $0.56 \%$ \\
\hline 23 & Construction & 28177 & $7.10 \%$ & 15429 & $3.00 \%$ \\
\hline $31-33$ & Manufacturing & 46791 & $11.80 \%$ & 30235 & $5.87 \%$ \\
\hline 42 & Wholesale Trade & 18373 & $4.63 \%$ & 6445 & $1.25 \%$ \\
\hline $44-45$ & Retail Trade & 29635 & $7.47 \%$ & 46138 & $8.96 \%$ \\
\hline $48-49$ & Transportation and Warehousing & 18253 & $4.60 \%$ & 11488 & $2.23 \%$ \\
\hline 51 & Information & 7047 & $1.78 \%$ & 5889 & $1.14 \%$ \\
\hline 52 & Finance and Insurance & 16076 & $4.05 \%$ & 22232 & $4.32 \%$ \\
\hline 53 & Real Estate and Rental and Leasing & 6884 & $1.74 \%$ & 2620 & $0.51 \%$ \\
\hline 54 & Professional, Scientific, and Technical Services & 32802 & $8.27 \%$ & 21237 & $4.12 \%$ \\
\hline 56 & $\begin{array}{c}\text { Administrative and Support and Waste Management } \\
\text { and Remediation Services }\end{array}$ & 27111 & $6.83 \%$ & 18774 & $3.64 \%$ \\
\hline 61 & Educational Services & 14637 & $3.69 \%$ & 39501 & $7.67 \%$ \\
\hline 62 & Health Care and Social Assistance & 71627 & $18.06 \%$ & 54371 & $10.55 \%$ \\
\hline 71 & Arts, Entertainment, and Recreation & 10726 & $2.70 \%$ & 1548 & $0.30 \%$ \\
\hline 72 & Accommodation and Food Services & 44720 & $11.27 \%$ & 28428 & $5.52 \%$ \\
\hline 81 & Pther Services (except Public Administration & 21163 & $5.33 \%$ & 5333 & $1.04 \%$ \\
\hline
\end{tabular}

(a) Missouri and Kansas Border Firms

\begin{tabular}{|c|c|c|c|c|c|}
\hline & & \multicolumn{2}{|c|}{ Missouri Border } & \multicolumn{2}{|c|}{ Kansas Border } \\
\hline & & \multicolumn{2}{|c|}{$2012 Q 1$} & \multicolumn{2}{|c|}{$2012 Q 1$} \\
\hline naics & industry & frequency & percent & frequency & percent \\
\hline 23 & Construction & 11861 & $15.28 \%$ & 8348 & $13.76 \%$ \\
\hline 31-33 & Manufacturing & 11348 & $14.62 \%$ & 8039 & $13.25 \%$ \\
\hline $44-45$ & Retail Trade & 9730 & $12.54 \%$ & 7721 & $12.73 \%$ \\
\hline & Selected Industries Combined & 37082 & $47.78 \%$ & 30995 & $51.10 \%$ \\
\hline 72 & Accommodation and Food Services & 7581 & $9.77 \%$ & 5547 & $9.15 \%$ \\
\hline
\end{tabular}

(b) Missouri Border Minimum Wage Covered Firms and Kansas Border Pseudo-Covered Firms after Further Limitations

Table 4.4: Frequency Check of NAICS Industry Structure 


\begin{tabular}{|c|c|c|c|c|c|c|c|c|}
\hline \multicolumn{5}{|c|}{ All Industries Together } & \multirow{2}{*}{\multicolumn{4}{|c|}{ Minimum Wage History }} \\
\hline \multicolumn{5}{|c|}{ Comparison within Kansas Border } & & & & \\
\hline & & $\begin{array}{c}\text { Missouri } \\
\text { Minimum Wage } \\
\text { Covered Firms } \\
\end{array}$ & $\begin{array}{c}\text { Kansas Minimum } \\
\text { Wage Pseudo- } \\
\text { Coverd Firms }\end{array}$ & & \multicolumn{2}{|c|}{ Missouri } & \multicolumn{2}{|c|}{ Kansas } \\
\hline \multicolumn{9}{|l|}{ one quarter } \\
\hline time 1 & time 2 & Inempt2 - Inempt1 & Inempt2 - Inempt1 & DID estimtor & time 1 & time 2 & time 1 & time 2 \\
\hline 20063 & 20064 & -0.0702 & -0.0873 & 0.0171 & \multicolumn{4}{|c|}{$\$ 5.15$} \\
\hline 20064 & 20071 & -0.0766 & -0.1009 & 0.0243 & $\$ 5.15$ & $\$ 6.50$ & \multirow{2}{*}{\multicolumn{2}{|c|}{$\$ 5.15$}} \\
\hline 20071 & 20072 & -0.0153 & -0.0227 & 0.0074 & \multirow{3}{*}{\multicolumn{2}{|c|}{$\$ 6.50$}} & & \\
\hline 20072 & 20073 & -0.0347 & -0.0423 & 0.0076 & & & $\$ 5.15$ & $\$ 5.85$ \\
\hline 20073 & 20074 & -0.0736 & -0.0760 & 0.0024 & & & \multirow{3}{*}{\multicolumn{2}{|c|}{$\$ 5.85$}} \\
\hline 20074 & 20081 & -0.0933 & -0.0966 & 0.0033 & $\$ 6.50$ & $\$ 6.65$ & & \\
\hline 20081 & 20082 & -0.0282 & -0.0403 & 0.0121 & \multirow{3}{*}{\multicolumn{2}{|c|}{$\$ 6.65$}} & & \\
\hline 20082 & 20083 & -0.0526 & -0.0447 & -0.0079 & & & $\$ 5.85$ & $\$ 6.55$ \\
\hline 20083 & 20084 & -0.0771 & -0.0917 & 0.0146 & & & \multirow{3}{*}{\multicolumn{2}{|c|}{$\$ 6.55$}} \\
\hline 20084 & 20091 & -0.1243 & -0.1151 & -0.0092 & $\$ 6.65$ & $\$ 7.05$ & & \\
\hline 20091 & 20092 & -0.0358 & -0.0438 & 0.0080 & \multicolumn{2}{|c|}{$\$ 7.05$} & & \\
\hline 20092 & 20093 & -0.0392 & -0.0384 & -0.0008 & $\$ 7.05$ & $\$ 7.25$ & $\$ 6.55$ & $\$ 7.25$ \\
\hline 20093 & 20094 & -0.0704 & -0.0616 & -0.0088 & \multirow{10}{*}{\multicolumn{4}{|c|}{$\$ 7.25$}} \\
\hline 20094 & 20101 & -0.1105 & -0.0981 & -0.0124 & & & & \\
\hline 20101 & 20102 & -0.0083 & -0.0210 & 0.0127 & & & & \\
\hline 20102 & 20103 & -0.0371 & -0.0355 & -0.0016 & & & & \\
\hline 20103 & 20104 & -0.0554 & -0.0836 & 0.0282 & & & & \\
\hline 20104 & 20111 & -0.0912 & -0.0889 & -0.0023 & & & & \\
\hline 20111 & 20112 & -0.0073 & -0.0257 & 0.0184 & & & & \\
\hline 20112 & 20113 & -0.0367 & -0.0238 & -0.0129 & & & & \\
\hline 20113 & 20114 & -0.0597 & -0.0639 & 0.0042 & & & & \\
\hline 20114 & 20121 & -0.0811 & -0.0762 & -0.0049 & & & & \\
\hline \multicolumn{9}{|l|}{ one year } \\
\hline time 1 & time 2 & Inempt2 - Inempt1 & Inempt2 - Inempt1 & DID estimtor & time 1 & time 2 & time 1 & time 2 \\
\hline 20063 & 20073 & -0.1211 & -0.1466 & 0.0255 & \multirow{2}{*}{$\$ 5.15$} & $\$ 6.50$ & \multirow{4}{*}{$\$ 5.15$} & $\$ 5.85$ \\
\hline 20064 & 20074 & -0.1225 & -0.1357 & 0.0132 & & $\$ 6.50$ & & \\
\hline 20071 & 20081 & -0.1378 & -0.1402 & 0.0024 & \multirow{4}{*}{$\$ 6.50$} & $\$ 6.65$ & & $\$ 5.85$ \\
\hline 20072 & 20082 & -0.1440 & -0.1557 & 0.0117 & & & & \\
\hline 20073 & 20083 & -0.1470 & -0.1638 & 0.0168 & & $\$ 6.65$ & \multirow{4}{*}{$\$ 5.85$} & $\$ 6.55$ \\
\hline 20074 & 20084 & -0.1448 & -0.1766 & 0.2048 & & & & \\
\hline 20081 & 20091 & -0.1839 & -0.1900 & 0.0061 & \multirow{4}{*}{$\$ 6.65$} & $\$ 7.05$ & & $\$ 6.55$ \\
\hline 20082 & 20092 & -0.1885 & -0.2007 & 0.0122 & & $\$ 7.05$ & & \\
\hline 20083 & 20093 & -0.1859 & -0.1982 & 0.0123 & & $\$ 7.25$ & \multirow{4}{*}{$\$ 6.55$} & $\$ 7.25$ \\
\hline 20084 & 20094 & -0.1731 & -0.1748 & 0.0017 & & & & \\
\hline 20091 & 20101 & -0.1684 & -0.1622 & -0.0062 & & $\$ 7.25$ & & $\$ 7.25$ \\
\hline 20092 & 20102 & -0.1408 & -0.1329 & -0.0079 & $\$ 7.05$ & & & \\
\hline 20093 & 20103 & -0.1481 & -0.1330 & -0.0151 & & & & \\
\hline 20094 & 20104 & -0.1280 & -0.1452 & 0.0172 & & & & \\
\hline 20101 & 20111 & -0.1115 & -0.1224 & 0.0109 & & & & \\
\hline 20102 & 20112 & -0.1099 & -0.1341 & 0.0242 & & & & \\
\hline 20103 & 20113 & -0.1165 & -0.1187 & 0.0022 & & & & \\
\hline 20104 & 20114 & -0.1257 & -0.1178 & -0.0079 & & & & \\
\hline 20111 & 20121 & -0.1122 & -0.1065 & -0.0057 & & & & \\
\hline
\end{tabular}

Table 4.5: Single Wave DID Estimations for the Entire Panel Sample 


\begin{tabular}{|c|c|c|c|c|c|c|c|c|}
\hline \multicolumn{5}{|c|}{ Food and Accomodation, NAICS:72, 1 - 50 Employees } & \multirow{2}{*}{\multicolumn{4}{|c|}{ Minimum Wage History }} \\
\hline & \multicolumn{3}{|c|}{ Comparison within Kansas Border } & & & & & \\
\hline & & $\begin{array}{c}\text { Missouri } \\
\text { Minimum Wage } \\
\text { Covered Firms }\end{array}$ & $\begin{array}{c}\text { Kansas Minimum } \\
\text { Wage Pseudo- } \\
\text { Coverd Firms }\end{array}$ & & \multicolumn{2}{|c|}{ Missouri } & \multicolumn{2}{|c|}{ Kansas } \\
\hline time 1 & time 2 & Inempt2 - Inempt1 & Inempt2 - Inempt1 & DID estimtor & time 1 & time 2 & time 1 & time 2 \\
\hline 20063 & 20064 & -0.1120 & -0.1173 & 0.0053 & \multicolumn{4}{|c|}{$\$ 5.15$} \\
\hline 20064 & 20071 & -0.1174 & -0.1172 & -0.0002 & $\$ 5.15$ & $\$ 6.50$ & \multirow{2}{*}{\multicolumn{2}{|c|}{$\$ 5.15$}} \\
\hline 20071 & 20072 & -0.0725 & -0.1310 & 0.0585 & \multirow{3}{*}{\multicolumn{2}{|c|}{$\$ 6.50$}} & & \\
\hline 20072 & 20073 & -0.1051 & -0.1006 & -0.0045 & & & $\$ 5.15$ & $\$ 5.85$ \\
\hline 20073 & 20074 & -0.1151 & -0.1602 & 0.0451 & & & \multirow{3}{*}{\multicolumn{2}{|c|}{$\$ 5.85$}} \\
\hline 20074 & 20081 & -0.1127 & -0.2189 & 0.1062 & $\$ 6.50$ & $\$ 6.65$ & & \\
\hline 20081 & 20082 & -0.0703 & -0.1133 & 0.0430 & \multirow{3}{*}{\multicolumn{2}{|c|}{$\$ 6.65$}} & & \\
\hline 20082 & 20083 & -0.1280 & -0.0913 & -0.0367 & & & $\$ 5.85$ & $\$ 6.55$ \\
\hline 20083 & 20084 & -0.1376 & -0.1856 & 0.0480 & & & \multirow{3}{*}{\multicolumn{2}{|c|}{$\$ 6.55$}} \\
\hline 20084 & 20091 & -0.1346 & -0.1378 & 0.0032 & $\$ 6.65$ & $\$ 7.05$ & & \\
\hline 20091 & 20092 & -0.0526 & -0.0908 & 0.0382 & \multicolumn{2}{|c|}{$\$ 7.05$} & & \\
\hline 20092 & 20093 & -0.0673 & -0.0613 & -0.0060 & $\$ 7.05$ & $\$ 7.25$ & $\$ 6.55$ & $\$ 7.25$ \\
\hline 20093 & 20094 & -0.1367 & -0.1404 & 0.0037 & \multirow{10}{*}{\multicolumn{4}{|c|}{$\$ 7.25$}} \\
\hline 20094 & 20101 & -0.1244 & -0.1258 & 0.0014 & & & & \\
\hline 20101 & 20102 & -0.0685 & -0.0684 & -0.0001 & & & & \\
\hline 20102 & 20103 & -0.0759 & -0.0711 & -0.0048 & & & & \\
\hline 20103 & 20104 & -0.1043 & -0.1273 & 0.0230 & & & & \\
\hline 20104 & 20111 & -0.1133 & -0.0804 & -0.0329 & & & & \\
\hline 20111 & 20112 & -0.0936 & -0.0704 & -0.0232 & & & & \\
\hline 20112 & 20113 & -0.0305 & -0.0909 & 0.0604 & & & & \\
\hline 20113 & 20114 & -0.1226 & -0.1304 & 0.0078 & & & & \\
\hline 20114 & 20121 & -0.1129 & -0.1005 & -0.0124 & & & & \\
\hline \multicolumn{9}{|l|}{ one year } \\
\hline time 1 & time 2 & Inempt2 - Inempt1 & Inempt2 - Inempt1 & DID estimtor & time 1 & time 2 & time 1 & time 2 \\
\hline 20063 & 20073 & -0.2147 & -0.1791 & -0.0356 & \multirow{2}{*}{$\$ 5.15$} & $\$ 6.50$ & \multirow{4}{*}{$\$ 5.15$} & $\$ 5.85$ \\
\hline 20064 & 20074 & -0.2092 & -0.2335 & 0.0243 & & $\$ 6.50$ & & \\
\hline 20071 & 20081 & -0.1721 & -0.3154 & 0.1433 & \multirow{4}{*}{$\$ 6.50$} & $\$ 6.65$ & & $\$ 5.85$ \\
\hline 20072 & 20082 & -0.1711 & -0.2856 & 0.1145 & & & & \\
\hline 20073 & 20083 & -0.2008 & -0.2584 & 0.0576 & & $\$ 6.65$ & \multirow{4}{*}{$\$ 5.85$} & $\$ 6.55$ \\
\hline 20074 & 20084 & -0.2090 & -0.2975 & 0.0885 & & & & \\
\hline 20081 & 20091 & -0.2507 & -0.2518 & 0.0011 & \multirow{4}{*}{$\$ 6.65$} & $\$ 7.05$ & & $\$ 6.55$ \\
\hline 20082 & 20092 & -0.2709 & -0.2257 & -0.0452 & & $\$ 7.05$ & & \\
\hline 20083 & 20093 & -0.2443 & -0.2438 & -0.0005 & & $\$ 7.25$ & \multirow{4}{*}{$\$ 6.55$} & $\$ 7.25$ \\
\hline 20084 & 20094 & -0.2162 & -0.2296 & 0.0134 & & & & \\
\hline 20091 & 20101 & -0.2096 & -0.2066 & -0.0030 & \multirow{2}{*}{$\$ 7.05$} & $\$ 7.25$ & & $\$ 7.25$ \\
\hline 20092 & 20102 & -0.2262 & -0.2146 & -0.0116 & & & & \\
\hline 20093 & 20103 & -0.2559 & -0.2019 & -0.0540 & & & & \\
\hline 20094 & 20104 & -0.2211 & -0.2168 & -0.0043 & & & & \\
\hline 20101 & 20111 & -0.1689 & -0.2014 & 0.0325 & & & & \\
\hline 20102 & 20112 & -0.1708 & -0.2217 & 0.0509 & & & & \\
\hline 20103 & 20113 & -0.1851 & -0.2107 & 0.0256 & & & & \\
\hline 20104 & 20114 & -0.2124 & -0.1532 & -0.0592 & & & & \\
\hline 20111 & 20121 & -0.2258 & -0.1807 & -0.0451 & & & & \\
\hline
\end{tabular}

Table 4.6: Single Wave DID Estimations for the Food and Accommodation Industry with 1 to 50 Employees 


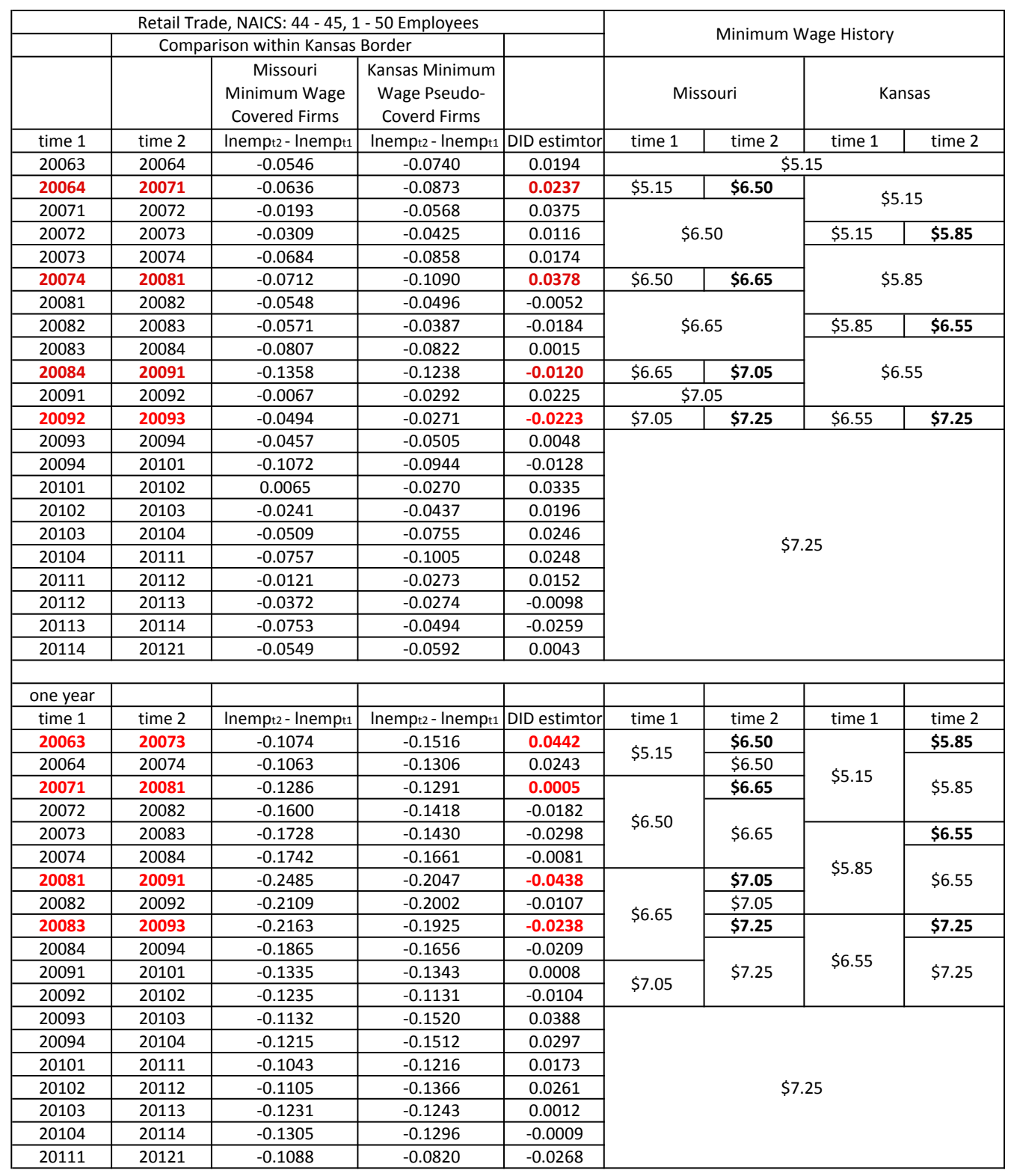

Table 4.7: Single Wave DID Estimations for the Retail Trade Industry with 1 to 50 Employees 


\begin{tabular}{|c|c|c|c|c|c|c|c|c|}
\hline \multicolumn{5}{|c|}{ Construction, NAICS: 23, with 1 - 50 Employees } & \multirow{2}{*}{\multicolumn{4}{|c|}{ Minimum Wage History }} \\
\hline & \multicolumn{3}{|c|}{ Comparison within Kansas Border } & & & & & \\
\hline & & $\begin{array}{c}\text { Missouri } \\
\text { Minimum Wage } \\
\text { Covered Firms }\end{array}$ & $\begin{array}{c}\text { Kansas Minimum } \\
\text { Wage Pseudo- } \\
\text { Coverd Firms }\end{array}$ & & \multicolumn{2}{|c|}{ Missouri } & \multicolumn{2}{|c|}{ Kansas } \\
\hline time 1 & time 2 & Inempt2 - Inempt1 & Inempt2 - Inempt1 & DID estimtor & time 1 & time 2 & time 1 & time 2 \\
\hline 20063 & 20064 & -0.1013 & -0.1444 & 0.0431 & \multicolumn{4}{|c|}{$\$ 5.15$} \\
\hline 20064 & 20071 & -0.1135 & -0.1195 & 0.0060 & $\$ 5.15$ & $\$ 6.50$ & \multirow{2}{*}{\multicolumn{2}{|c|}{$\$ 5.15$}} \\
\hline 20071 & 20072 & 0.0052 & 0.0130 & -0.0078 & \multirow{3}{*}{\multicolumn{2}{|c|}{$\$ 6.50$}} & & \\
\hline 20072 & 20073 & -0.0381 & -0.0633 & 0.0252 & & & $\$ 5.15$ & $\$ 5.85$ \\
\hline 20073 & 20074 & -0.1064 & -0.1041 & -0.0023 & & & \multirow{3}{*}{\multicolumn{2}{|c|}{$\$ 5.85$}} \\
\hline 20074 & 20081 & -0.1622 & -0.1564 & -0.0058 & $\$ 6.50$ & $\$ 6.65$ & & \\
\hline 20081 & 20082 & -0.0168 & -0.0026 & -0.0142 & \multirow{3}{*}{\multicolumn{2}{|c|}{$\$ 6.65$}} & & \\
\hline 20082 & 20083 & -0.0641 & -0.0728 & 0.0087 & & & $\$ 5.85$ & $\$ 6.55$ \\
\hline 20083 & 20084 & -0.1129 & -0.1330 & 0.0201 & & & \multirow{3}{*}{\multicolumn{2}{|c|}{$\$ 6.55$}} \\
\hline 20084 & 20091 & -0.2127 & -0.1919 & -0.0208 & $\$ 6.65$ & $\$ 7.05$ & & \\
\hline 20091 & 20092 & -0.0337 & -0.0721 & 0.0384 & \multicolumn{2}{|c|}{$\$ 7.05$} & & \\
\hline 20092 & 20093 & -0.0553 & -0.0661 & 0.0108 & $\$ 7.05$ & $\$ 7.25$ & $\$ 6.55$ & $\$ 7.25$ \\
\hline 20093 & 20094 & -0.1138 & -0.1109 & -0.0029 & \multirow{10}{*}{\multicolumn{4}{|c|}{$\$ 7.25$}} \\
\hline 20094 & 20101 & -0.2002 & -0.1850 & -0.0152 & & & & \\
\hline 20101 & 20102 & 0.0512 & 0.0160 & 0.0352 & & & & \\
\hline 20102 & 20103 & -0.0275 & -0.0471 & 0.0196 & & & & \\
\hline 20103 & 20104 & -0.0885 & -0.1281 & 0.0396 & & & & \\
\hline 20104 & 20111 & -0.1516 & -0.1341 & -0.0175 & & & & \\
\hline 20111 & 20112 & 0.0201 & -0.0411 & 0.0612 & & & & \\
\hline 20112 & 20113 & -0.0228 & -0.0205 & -0.0023 & & & & \\
\hline 20113 & 20114 & -0.0651 & -0.0832 & 0.0181 & & & & \\
\hline 20114 & 20121 & -0.1116 & -0.1063 & -0.0053 & & & & \\
\hline \multicolumn{9}{|l|}{ one year } \\
\hline time 1 & time 2 & Inempt2 - Inempt1 & Inempt2 - Inempt1 & DID estimtor & time 1 & time 2 & time 1 & time 2 \\
\hline 20063 & 20073 & -0.1635 & -0.1914 & 0.0279 & \multirow{2}{*}{$\$ 5.15$} & $\$ 6.50$ & \multirow{4}{*}{$\$ 5.15$} & $\$ 5.85$ \\
\hline 20064 & 20074 & -0.1806 & -0.1502 & -0.0304 & & $\$ 6.50$ & & \\
\hline 20071 & 20081 & -0.2208 & -0.1994 & -0.0214 & \multirow{4}{*}{$\$ 6.50$} & $\$ 6.65$ & & $\$ 5.85$ \\
\hline 20072 & 20082 & -0.2385 & -0.2181 & -0.0204 & & & & \\
\hline 20073 & 20083 & -0.2311 & -0.2331 & 0.0020 & & $\$ 6.65$ & \multirow{4}{*}{$\$ 5.85$} & $\$ 6.55$ \\
\hline 20074 & 20084 & -0.2250 & -0.2509 & 0.0259 & & & & \\
\hline 20081 & 20091 & -0.2712 & -0.2455 & -0.0257 & \multirow{4}{*}{$\$ 6.65$} & $\$ 7.05$ & & $\$ 6.55$ \\
\hline 20082 & 20092 & -0.2684 & -0.3299 & 0.0615 & & $\$ 7.05$ & & \\
\hline 20083 & 20093 & -0.2681 & -0.3130 & 0.0449 & & $\$ 7.25$ & \multirow{4}{*}{$\$ 6.55$} & $\$ 7.25$ \\
\hline 20084 & 20094 & -0.2554 & -0.2842 & 0.0288 & & & & \\
\hline 20091 & 20101 & -0.2613 & -0.2906 & 0.0293 & \multirow{2}{*}{$\$ 7.05$} & $\$ 7.25$ & & $\$ 7.25$ \\
\hline 20092 & 20102 & -0.1640 & -0.1877 & 0.0237 & & & & \\
\hline 20093 & 20103 & -0.1433 & -0.1931 & 0.0498 & & & & \\
\hline 20094 & 20104 & -0.1208 & -0.1865 & 0.0657 & & & & \\
\hline 20101 & 20111 & -0.1123 & -0.1311 & 0.0188 & & & & \\
\hline 20102 & 20112 & -0.1425 & -0.1752 & 0.0327 & & & & \\
\hline 20103 & 20113 & -0.1383 & -0.1566 & 0.0183 & & & & \\
\hline 20104 & 20114 & -0.1220 & -0.1209 & -0.0011 & & & & \\
\hline 20111 & 20121 & -0.0845 & -0.1079 & 0.0234 & & & & \\
\hline
\end{tabular}

Table 4.8: Single Wave DID Estimations for the Construction Industry with 1 to 50 Employees 


\begin{tabular}{|c|c|c|c|c|c|c|c|c|}
\hline \multicolumn{5}{|c|}{ Manufacturing, NAICS: 31 - 33, with 1 - 100 Employees } & \multirow{2}{*}{\multicolumn{4}{|c|}{ Minimum Wage History }} \\
\hline & \multicolumn{3}{|c|}{ Comparison within Kansas Border } & & & & & \\
\hline & & $\begin{array}{c}\text { Missouri } \\
\text { Minimum Wage } \\
\text { Covered Firms }\end{array}$ & $\begin{array}{c}\text { Kansas Minimum } \\
\text { Wage Pseudo- } \\
\text { Coverd Firms }\end{array}$ & & \multicolumn{2}{|c|}{ Missouri } & \multicolumn{2}{|c|}{ Kansas } \\
\hline time 1 & time 2 & Inempt2 - Inempt1 & Inempt2 - Inempt1 & DID estimtor & time 1 & time 2 & time 1 & time 2 \\
\hline 20063 & 20064 & -0.0430 & -0.0601 & 0.0171 & \multicolumn{4}{|c|}{$\$ 5.15$} \\
\hline 20064 & 20071 & -0.0324 & -0.0945 & 0.0621 & $\$ 5.15$ & $\$ 6.50$ & \multirow{2}{*}{\multicolumn{2}{|c|}{$\$ 5.15$}} \\
\hline 20071 & 20072 & -0.0347 & -0.0292 & -0.0055 & \multirow{3}{*}{\multicolumn{2}{|c|}{$\$ 6.50$}} & & \\
\hline 20072 & 20073 & -0.0110 & -0.0258 & 0.0148 & & & $\$ 5.15$ & $\$ 5.85$ \\
\hline 20073 & 20074 & -0.0431 & -0.0343 & -0.0088 & & & \multirow{3}{*}{\multicolumn{2}{|c|}{$\$ 5.85$}} \\
\hline 20074 & 20081 & -0.0593 & -0.0541 & -0.0052 & $\$ 6.50$ & $\$ 6.65$ & & \\
\hline 20081 & 20082 & -0.0210 & -0.0742 & 0.0532 & \multirow{3}{*}{\multicolumn{2}{|c|}{$\$ 6.65$}} & & \\
\hline 20082 & 20083 & -0.0419 & -0.0410 & -0.0009 & & & $\$ 5.85$ & $\$ 6.55$ \\
\hline 20083 & 20084 & -0.0556 & -0.0608 & 0.0052 & & & \multirow{3}{*}{\multicolumn{2}{|c|}{$\$ 6.55$}} \\
\hline 20084 & 20091 & -0.0920 & -0.0916 & -0.0004 & $\$ 6.65$ & $\$ 7.05$ & & \\
\hline 20091 & 20092 & -0.0665 & -0.0542 & -0.0123 & \multicolumn{2}{|c|}{$\$ 7.05$} & & \\
\hline 20092 & 20093 & -0.0275 & -0.0337 & 0.0062 & $\$ 7.05$ & $\$ 7.25$ & $\$ 6.55$ & $\$ 7.25$ \\
\hline 20093 & 20094 & -0.0434 & -0.0010 & -0.0424 & \multirow{10}{*}{\multicolumn{4}{|c|}{$\$ 7.25$}} \\
\hline 20094 & 20101 & -0.0759 & -0.0524 & -0.0235 & & & & \\
\hline 20101 & 20102 & -0.0329 & -0.0209 & -0.0120 & & & & \\
\hline 20102 & 20103 & -0.0233 & -0.0366 & 0.0133 & & & & \\
\hline 20103 & 20104 & -0.0359 & -0.0249 & -0.0110 & & & & \\
\hline 20104 & 20111 & -0.0483 & -0.0757 & 0.0274 & & & & \\
\hline 20111 & 20112 & -0.0147 & -0.0476 & 0.0329 & & & & \\
\hline 20112 & 20113 & -0.0276 & -0.0260 & -0.0016 & & & & \\
\hline 20113 & 20114 & -0.0412 & -0.0386 & -0.0026 & & & & \\
\hline 20114 & 20121 & -0.0545 & -0.0568 & 0.0023 & & & & \\
\hline \multicolumn{9}{|l|}{ one year } \\
\hline time 1 & time 2 & Inempt2 - Inempt1 & Inempt2 - Inempt1 & DID estimtor & time 1 & time 2 & time 1 & time 2 \\
\hline 20063 & 20073 & -0.0937 & -0.1296 & \begin{tabular}{|l|}
0.0359 \\
\end{tabular} & \multirow{2}{*}{$\$ 5.15$} & $\$ 6.50$ & \multirow{4}{*}{$\$ 5.15$} & $\$ 5.85$ \\
\hline 20064 & 20074 & -0.0891 & -0.1103 & 0.0212 & & $\$ 6.50$ & & \\
\hline 20071 & 20081 & -0.1203 & -0.1049 & -0.0154 & \multirow{4}{*}{$\$ 6.50$} & $\$ 6.65$ & & $\$ 5.85$ \\
\hline 20072 & 20082 & -0.0890 & -0.1667 & 0.0777 & & & & \\
\hline 20073 & 20083 & -0.1176 & -0.2035 & 0.0859 & & $\$ 6.65$ & \multirow{4}{*}{$\$ 5.85$} & $\$ 6.55$ \\
\hline 20074 & 20084 & -0.1336 & -0.201 & 0.0674 & & & & \\
\hline 20081 & 20091 & -0.1714 & -0.2063 & 0.0349 & \multirow{4}{*}{$\$ 6.65$} & $\$ 7.05$ & & $\$ 6.55$ \\
\hline 20082 & 20092 & -0.1940 & -0.1826 & -0.0114 & & $\$ 7.05$ & & \\
\hline 20083 & 20093 & -0.1908 & -0.1777 & -0.0131 & & $\$ 7.25$ & \multirow{4}{*}{$\$ 6.55$} & $\$ 7.25$ \\
\hline 20084 & 20094 & -0.1770 & -0.1461 & -0.0309 & & & & \\
\hline 20091 & 20101 & -0.1722 & -0.118 & -0.0542 & \multirow{2}{*}{$\$ 7.05$} & $\$ 7.25$ & & $\$ 7.25$ \\
\hline 20092 & 20102 & -0.1237 & -0.0666 & -0.0571 & & & & \\
\hline 20093 & 20103 & -0.1382 & -0.064 & -0.0742 & & & & \\
\hline 20094 & 20104 & -0.1400 & -0.0721 & -0.0679 & & & & \\
\hline 20101 & 20111 & -0.0964 & -0.0936 & -0.0028 & & & & \\
\hline 20102 & 20112 & -0.0915 & -0.1235 & 0.0320 & & & & \\
\hline 20103 & 20113 & -0.0954 & -0.1026 & 0.0072 & & & & \\
\hline 20104 & 20114 & -0.1001 & -0.1448 & 0.0447 & & & & \\
\hline 20111 & 20121 & -0.0836 & -0.1144 & 0.0308 & & & & \\
\hline
\end{tabular}

Table 4.9: Single Wave DID Estimations for the Manufacturing Industry with 1 to 100 Employees 


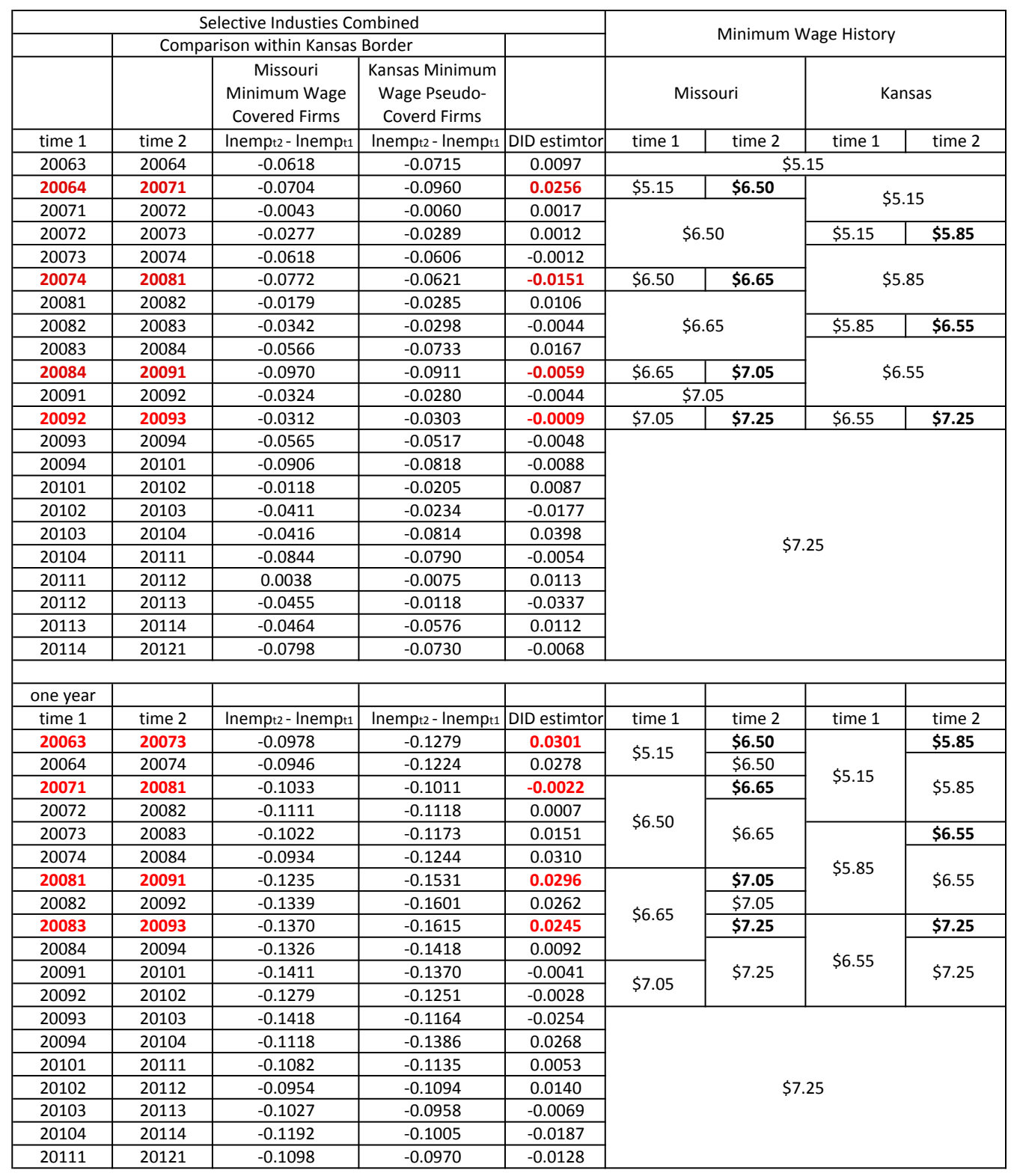

Table 4.10: Single Wave DID Estimations for the "Selected Industries Combined" category (Finance, Information and Other Service) with 1-50 Employees 


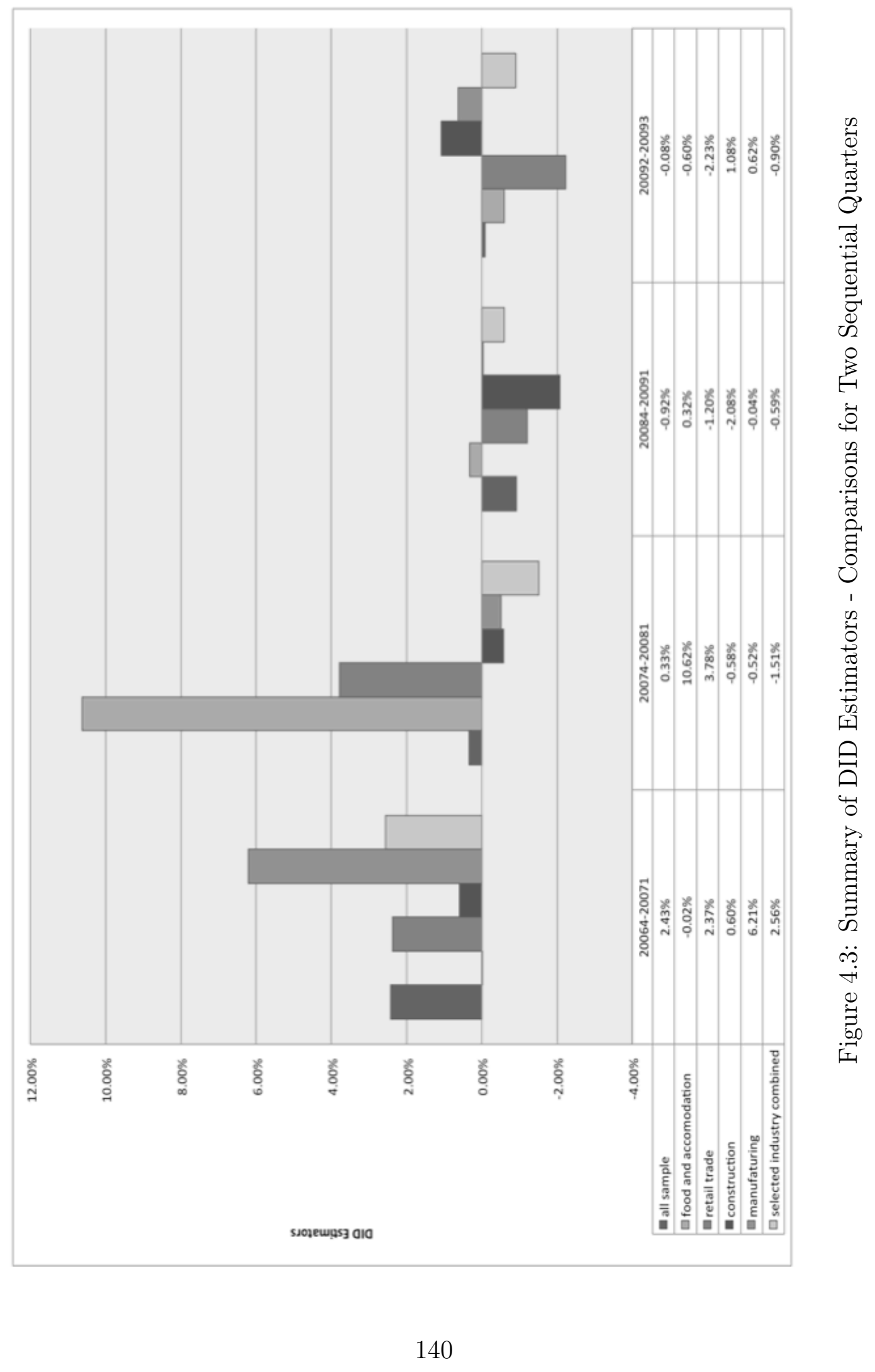




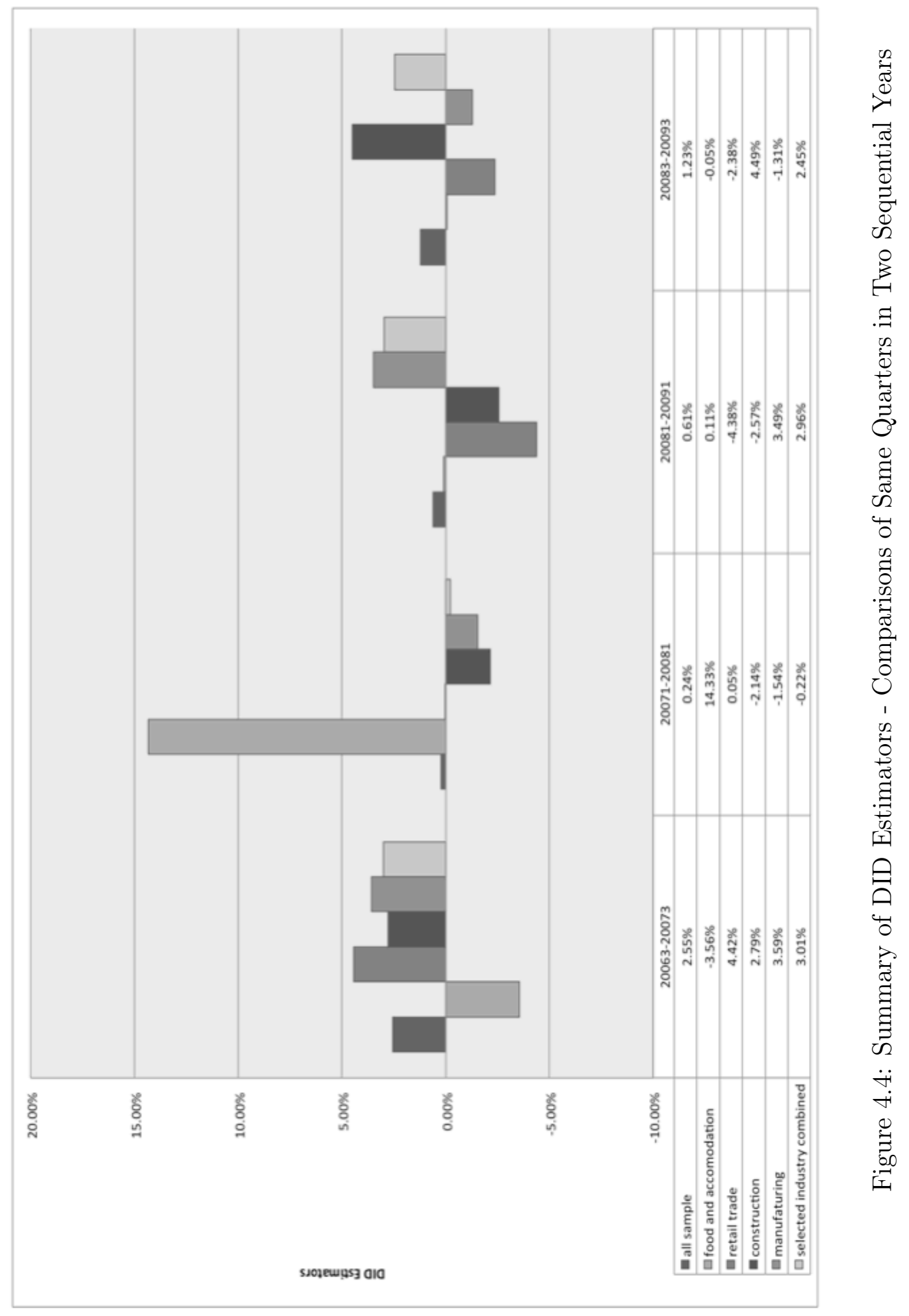




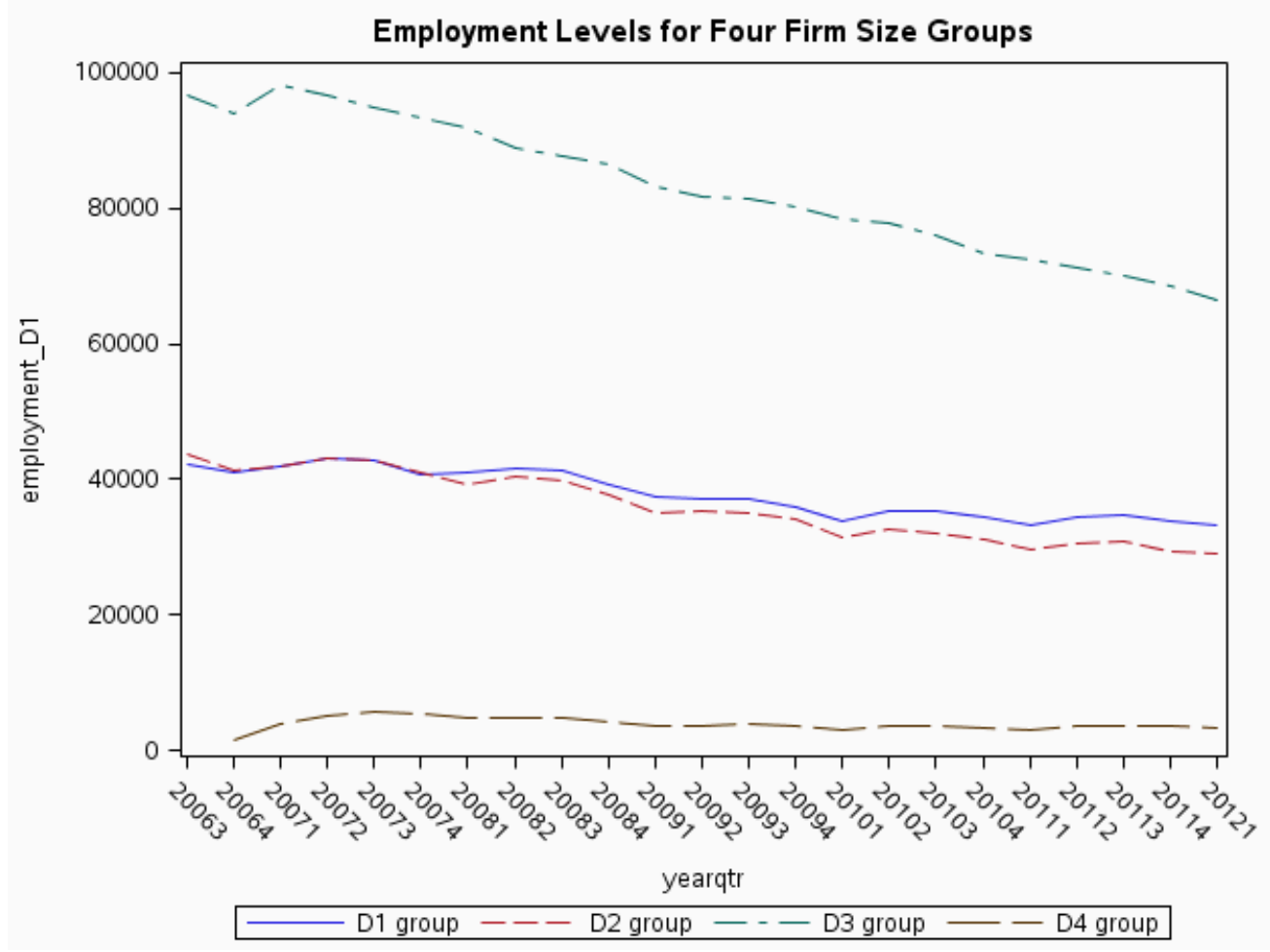

Figure 4.5: Employment Level Plot of Four Firm Size Groups 
Estimation Results

\begin{tabular}{|c|c|c|c|c|c|}
\hline \multirow[t]{2}{*}{ Variables and Controls } & \multicolumn{5}{|c|}{ Missouri and Kansas Border Firms } \\
\hline & (1) & $(2)$ & (3) & (4) & (5) \\
\hline \multirow[t]{2}{*}{ D1*Inmw } & -0.378 & 0.103 & 0.114 & -0.189 & 0.333 \\
\hline & $(0.043)$ & $(0.055)$ & $(0.055)$ & $(0.037)$ & $(0.057)$ \\
\hline \multirow[t]{2}{*}{$\mathrm{D} 2 * \ln m w$} & -0.731 & -0.239 & -0.329 & -0.536 & -0.096 \\
\hline & $(0.071)$ & $(0.037)$ & $(0.041)$ & $(0.064)$ & $(0.039)$ \\
\hline \multirow[t]{2}{*}{ D3*Inmw } & -0.810 & -0.317 & -0.430 & -0.616 & -0.203 \\
\hline & $(0.072)$ & $(0.048)$ & $(0.053)$ & $(0.067)$ & $(0.048)$ \\
\hline \multirow[t]{2}{*}{ D4*Inmw } & -0.088 & 0.425 & 0.590 & 0.133 & 0.762 \\
\hline & $(0.085)$ & $(0.080)$ & $(0.104)$ & $(0.093)$ & $(0.095)$ \\
\hline \multirow[t]{2}{*}{ overall minimum wage effects } & -0.657 & -0.166 & -0.232 & -0.463 & -0.149 \\
\hline & $(0.004)$ & $(0.004)$ & $(0.004)$ & $(0.004)$ & $(0.002)$ \\
\hline \multicolumn{6}{|l|}{ controls } \\
\hline firm & yes & yes & yes & yes & yes \\
\hline firm size & yes & yes & yes & yes & yes \\
\hline time & no & yes & yes & no & yes \\
\hline time*industry & no & no & yes & no & no \\
\hline \multirow[t]{2}{*}{ county unemployment } & no & no & no & -0.012 & no \\
\hline & & & & $(0.000)$ & \\
\hline industry-Inmw interaction & no & no & no & no & yes \\
\hline \multirow[t]{2}{*}{ ind $1 * \ln m w$} & - & - & - & - & -0.549 \\
\hline & - & - & - & - & $(0.032)$ \\
\hline \multirow[t]{2}{*}{ ind $2 * \ln m w$} & - & - & - & - & -0.221 \\
\hline & - & - & - & - & $(0.018)$ \\
\hline \multirow[t]{2}{*}{ ind3*Inmw } & - & - & - & - & -0.199 \\
\hline & - & - & - & - & $(0.012)$ \\
\hline \multirow[t]{2}{*}{ ind4*Inmw } & - & - & - & - & 0.162 \\
\hline & - & - & - & - & $(0.029)$ \\
\hline
\end{tabular}

Description

\begin{tabular}{|c|c|c|c|c|}
\hline & observation & $\begin{array}{c}\text { total } \\
\text { employment }\end{array}$ & $\begin{array}{c}\text { average } \\
\text { employment }\end{array}$ & $\begin{array}{l}\text { perentage } \\
\text { rate of } \\
\text { employment }\end{array}$ \\
\hline D1: firms with 1 - 10 employees & 164,519 & 871,951 & 5.3 & $22.97 \%$ \\
\hline D2: firms with 11 - 20 employees & 59,413 & 825,841 & 13.9 & $21.76 \%$ \\
\hline D3:more than 20 employees & 58,697 & $1,907,653$ & 32.5 & $50.26 \%$ \\
\hline D4: firms started after 2006 Q3 & 19,989 & 189,896 & 9.5 & $5.00 \%$ \\
\hline total & 302,618 & $3,795,339$ & - & $100.00 \%$ \\
\hline
\end{tabular}

Table 4.11: Estimation Results for Missouri and Kansas Border Firms - Entire Sample 
Retail Trade

Missouri and Kansas Border Firms in Retail Trade with 1 - 50 Employees

\begin{tabular}{|c|c|c|c|}
\hline & (1) & (2) & (3) \\
\hline \multirow[t]{2}{*}{$\mathrm{D} 1 * \operatorname{lnmw}$} & -0.294 & 0.238 & -0.090 \\
\hline & $(0.040)$ & $(0.059)$ & $(0.031)$ \\
\hline \multirow[t]{2}{*}{$\mathrm{D} 2 * \ln m w$} & -0.695 & -0.156 & -0.487 \\
\hline & $(0.072)$ & $(0.050)$ & $(0.066)$ \\
\hline \multirow[t]{2}{*}{$\mathrm{D} 3 * \ln m w$} & -0.974 & -0.445 & -0.773 \\
\hline & $(0.079)$ & $(0.051)$ & $(0.070)$ \\
\hline \multirow[t]{2}{*}{$\mathrm{D} 4 * \operatorname{lnmw}$} & -0.339 & 0.162 & -0.129 \\
\hline & $(0.086)$ & $(0.112)$ & $(0.098)$ \\
\hline \multirow[t]{2}{*}{ overall minimum wage effect } & -0.670 & -0.139 & -0.466 \\
\hline & $(0.007)$ & $(0.007)$ & $(0.007)$ \\
\hline \multicolumn{4}{|l|}{ controls } \\
\hline firm & yes & yes & yes \\
\hline firm size & yes & yes & yes \\
\hline time & no & yes & no \\
\hline \multirow[t]{2}{*}{ county unemployment } & no & no & -0.019 \\
\hline & & & $(0.002)$ \\
\hline
\end{tabular}

\begin{tabular}{|c|c|c|c|c|}
\hline & observation & $\begin{array}{c}\text { total } \\
\text { employment }\end{array}$ & $\begin{array}{l}\text { average } \\
\text { employment }\end{array}$ & $\begin{array}{l}\text { perentage rate } \\
\text { ef } \\
\text { employment }\end{array}$ \\
\hline D1: firms with 1 - 10 employees & 24,545 & 139,907 & 5.7 & $28.68 \%$ \\
\hline D2: firms with 11 - 20 employees & 9,698 & 128,983 & 13.3 & $26.44 \%$ \\
\hline D3:more than 20 employees & 6,937 & 192,155 & 27.7 & $39.38 \%$ \\
\hline D4: firms started after 2006 Q3 & 2,557 & 26,849 & 10.5 & $5.50 \%$ \\
\hline total & 43,737 & 487,893 & - & $100.00 \%$ \\
\hline
\end{tabular}

Table 4.12: Estimation Results for Missouri and Kansas Border Firms - Retail Trade 
Food and Accomodation

Missouri and Kansas Border Firms in Food and Accomodation with 1 - 50 Employees

\begin{tabular}{|c|c|c|c|}
\hline & $(1)$ & $(2)$ & $(3)$ \\
\hline $\mathrm{D} 1^{*} \operatorname{Inmw}$ & 0.020 & $\mathbf{0 . 4 9 4}$ & $\mathbf{0 . 2 1 4}$ \\
\hline & $(0.100)$ & $(0.129)$ & $(0.096)$ \\
\hline $\mathrm{D} 2^{*} \operatorname{lnmw}$ & $-\mathbf{0 . 1 8 2}$ & $\mathbf{0 . 2 7 3}$ & 0.013 \\
\hline & $(0.059)$ & $(0.067)$ & $(0.076)$ \\
\hline $\mathrm{D} 3^{*} \operatorname{Inmw}$ & $-\mathbf{0 . 5 4 9}$ & $-\mathbf{0 . 0 8 7}$ & $-\mathbf{0 . 3 5 4}$ \\
\hline & $(0.074)$ & $(0.049)$ & $(0.080)$ \\
\hline $\mathrm{D} 4{ }^{*} \operatorname{Inmw}$ & $-\mathbf{0 . 5 6 0}$ & 0.061 & $-\mathbf{0 . 3 4 2}$ \\
\hline & $(0.192)$ & $(0.189)$ & $(0.179)$ \\
\hline & -0.480 & -0.006 & $-\mathbf{0 . 2 8 3}$ \\
\hline overall minimum wage effect & $(0.005)$ & $(0.005)$ & $(0.005)$ \\
\hline & & & \\
\hline controls & yes & yes & yes \\
\hline firm & yes & yes & yes \\
\hline firm size & no & yes & no \\
\hline time & no & no & $-\mathbf{0 . 0 1 8}$ \\
\hline & & & $(0.004)$ \\
\hline
\end{tabular}

\begin{tabular}{|c|c|c|c|c|}
\hline & observation & $\begin{array}{c}\text { total } \\
\text { employment }\end{array}$ & $\begin{array}{l}\text { average } \\
\text { employment }\end{array}$ & $\begin{array}{l}\text { perentage } \\
\text { rate of } \\
\text { employment }\end{array}$ \\
\hline D1: firms with 1 - 10 employees & 1,163 & 13,375 & 11.5 & $3.76 \%$ \\
\hline D2: firms with 11 - 20 employees & 2,821 & 46,829 & 16.6 & $13.18 \%$ \\
\hline D3:more than 20 employees & 8,477 & 266,178 & 31.4 & $74.90 \%$ \\
\hline D4: firms started after 2006 Q3 & 1,039 & 28,988 & 27.9 & $8.16 \%$ \\
\hline total & 13,500 & 355,369 & - & $100.00 \%$ \\
\hline
\end{tabular}

Table 4.13: Estimation Results for Missouri and Kansas Border Firms - Food and Accommodation 
Construction

Missouri and Kansas Border Firms in Construction with 1 - 50 Employees

\begin{tabular}{|c|c|c|c|}
\hline & $(1)$ & $(2)$ & $(3)$ \\
\hline & $-\mathbf{0 . 6 8 6}$ & 0.049 & $-\mathbf{0 . 3 7 6}$ \\
\hline & $(0.077)$ & $(0.064)$ & $(0.066)$ \\
\hline & $\mathbf{- 1 . 5 2 5}$ & $-\mathbf{0 . 7 6 0}$ & $\mathbf{- 1 . 2 0 2}$ \\
\hline $\mathrm{D}^{*}{ }^{*} \operatorname{lnm} w$ & $(0.139)$ & $(0.062)$ & $(0.124)$ \\
\hline & $\mathbf{- 1 . 5 4 2}$ & $-\mathbf{0 . 7 6 8}$ & $\mathbf{- 1 . 2 1 6}$ \\
\hline $\mathrm{D} 3^{*} \operatorname{lnmw}$ & $(0.128)$ & $(0.089)$ & $(0.120)$ \\
\hline & 0.050 & $-\mathbf{0 . 8 7 9}$ & $\mathbf{0 . 4 4 4}$ \\
\hline $\mathrm{D} 4{ }^{*} \operatorname{nmw}$ & $(0.107)$ & $(0.125)$ & $(0.004)$ \\
\hline & $\mathbf{- 1 . 1 4 1}$ & $-\mathbf{0 . 4 9 7}$ & $-\mathbf{0 . 8 1 6}$ \\
\hline & $(0.006)$ & $(0.006)$ & $(0.006)$ \\
\hline overall minimum wage effect & & & \\
\hline & yes & yes & yes \\
\hline controls & yes & yes & yes \\
\hline firm & no & yes & no \\
\hline firm size & no & no & -0.030 \\
\hline time & & & $(0.004)$ \\
\hline county unemployment & & &
\end{tabular}

\begin{tabular}{|c|c|c|c|c|}
\hline & observation & $\begin{array}{c}\text { total } \\
\text { employment }\end{array}$ & $\begin{array}{l}\text { average } \\
\text { employment }\end{array}$ & $\begin{array}{l}\text { perentage } \\
\text { rate of } \\
\text { employment }\end{array}$ \\
\hline D1: firms with 1 - 10 employees & 55,532 & 216,575 & 3.9 & $33.90 \%$ \\
\hline D2: firms with 11 - 20 employees & 11,699 & 143,898 & 12.3 & $22.52 \%$ \\
\hline D3:more than 20 employees & 9,455 & 235,430 & 24.9 & $36.85 \%$ \\
\hline D4: firms started after 2006 Q3 & 8,438 & 43,034 & 5.1 & $6.74 \%$ \\
\hline total & 85,124 & 638,936 & - & $100.00 \%$ \\
\hline
\end{tabular}

Table 4.14: Estimation Results for Missouri and Kansas Border Firms - Construction 
Manufacturing

Missouri and Kansas Border Firms in Manufacturing with 1 - 100 Employees

\begin{tabular}{|c|c|c|c|}
\hline & $(1)$ & $(2)$ & $(3)$ \\
\hline & $-\mathbf{0 . 4 2 6}$ & $\mathbf{0 . 3 5 3}$ & $-\mathbf{0 . 1 1 3}$ \\
\hline & $(0.052)$ & $(0.063)$ & $(0.047)$ \\
\hline $\mathrm{D}^{*} \operatorname{lnmw}$ & $\mathbf{- 0 . 7 2 2}$ & 0.079 & $\mathbf{- 0 . 3 9 5}$ \\
\hline & $(0.083)$ & $(0.056)$ & $(0.067)$ \\
\hline $\mathrm{D}^{*} \operatorname{lnmw}$ & $\mathbf{- 0 . 8 9 0}$ & -0.094 & $\mathbf{- 0 . 5 7 4}$ \\
\hline & $(0.083)$ & $(0.063)$ & $(0.077)$ \\
\hline $\mathrm{D}^{*} \operatorname{lnmw}$ & -0.454 & $\mathbf{0 . 4 2 8}$ & -0.099 \\
\hline & $(0.259)$ & $(0.239)$ & $(0.255)$ \\
\hline $\mathrm{D} 4^{*} \operatorname{lnmw}$ & $\mathbf{- 0 . 7 9 5}$ & 0.002 & $-\mathbf{0 . 4 7 7}$ \\
\hline & $(0.003)$ & $(0.003)$ & $(0.003)$ \\
\hline overall minimum wage effect & & & \\
\hline & & yes & yes \\
\hline controls & yes & yes & yes \\
\hline firm & no & yes & no \\
\hline firm size & no & no & $-\mathbf{0 . 0 3 0}$ \\
\hline time & & & $(0.003)$ \\
\hline county unemployment & & & \\
\hline & & &
\end{tabular}

\begin{tabular}{|c|c|c|c|c|}
\hline & observation & $\begin{array}{c}\text { total } \\
\text { employment }\end{array}$ & $\begin{array}{c}\text { average } \\
\text { employment }\end{array}$ & $\begin{array}{c}\text { perentage rate } \\
\text { of employment }\end{array}$ \\
\hline D1: firms with 1 - 10 employees & 11,189 & 62,658 & 5.6 & $11.89 \%$ \\
\hline D2: firms with 11 - 20 employees & 5,808 & 80,731 & 13.9 & $15.32 \%$ \\
\hline D3:more than 20 employees & 9,146 & 366,755 & 40.1 & $69.61 \%$ \\
\hline D4: firms started after 2006 Q3 & 1,025 & 16,708 & 16.3 & $3.17 \%$ \\
\hline total & 27,168 & 526,852 & - & $100.00 \%$ \\
\hline
\end{tabular}

Table 4.15: Estimation Results for Missouri and Kansas Border Firms - Manufacturing 
Selected Industries Combined (information and Other Services)

Missouri and Kansas Border Firms in "Selected Industry Combined" Category

\begin{tabular}{|c|c|c|c|}
\hline & (1) & (2) & (3) \\
\hline \multirow[t]{2}{*}{ D1*Inmw } & -0.132 & 0.033 & -0.065 \\
\hline & $(0.030)$ & $(0.056)$ & $(0.028)$ \\
\hline \multirow[t]{2}{*}{$\mathrm{D} 2 * \operatorname{lnmw}$} & -0.465 & -0.299 & -0.396 \\
\hline & $(0.055)$ & $(0.044)$ & $(0.051)$ \\
\hline \multirow[t]{2}{*}{ D3*Inmw } & -0.534 & -0.367 & -0.465 \\
\hline & $(0.056)$ & $(0.047)$ & $(0.054)$ \\
\hline \multirow[t]{2}{*}{$\mathrm{D} 4 * \operatorname{lnmw}$} & -0.166 & 0.035 & -0.097 \\
\hline & $(0.086)$ & $(0.081)$ & $(0.090)$ \\
\hline \multirow[t]{2}{*}{ overall minimum wage effect } & -0.404 & -0.236 & -0.335 \\
\hline & $(0.006)$ & $(0.006)$ & $(0.006)$ \\
\hline \multicolumn{4}{|l|}{ controls } \\
\hline firm & yes & yes & yes \\
\hline firm size & yes & yes & yes \\
\hline time & no & yes & no \\
\hline \multirow[t]{2}{*}{ county unemployment } & no & no & -0.019 \\
\hline & & & $(0.002)$ \\
\hline
\end{tabular}

\begin{tabular}{|c|c|c|c|c|}
\hline & observation & $\begin{array}{c}\text { total } \\
\text { employment }\end{array}$ & $\begin{array}{c}\text { average } \\
\text { employment }\end{array}$ & $\begin{array}{l}\text { perate of } \\
\text { rage } \\
\text { employment }\end{array}$ \\
\hline D1: firms with 1 - 10 employees & 72,090 & 439,749 & 6.1 & $24.59 \%$ \\
\hline D2: firms with 11 - 20 employees & 29,387 & 426,112 & 14.5 & $23.83 \%$ \\
\hline D3:more than 20 employees & 24,682 & 849,061 & 34.4 & $47.48 \%$ \\
\hline D4: firms started after 2006 Q3 & 6,930 & 73,458 & 10.6 & $4.11 \%$ \\
\hline total & 133,089 & $1,788,379$ & - & $100.00 \%$ \\
\hline
\end{tabular}

Table 4.16: Estimation Results for Missouri and Kansas Border Firms - "Selected Industries Combined" 


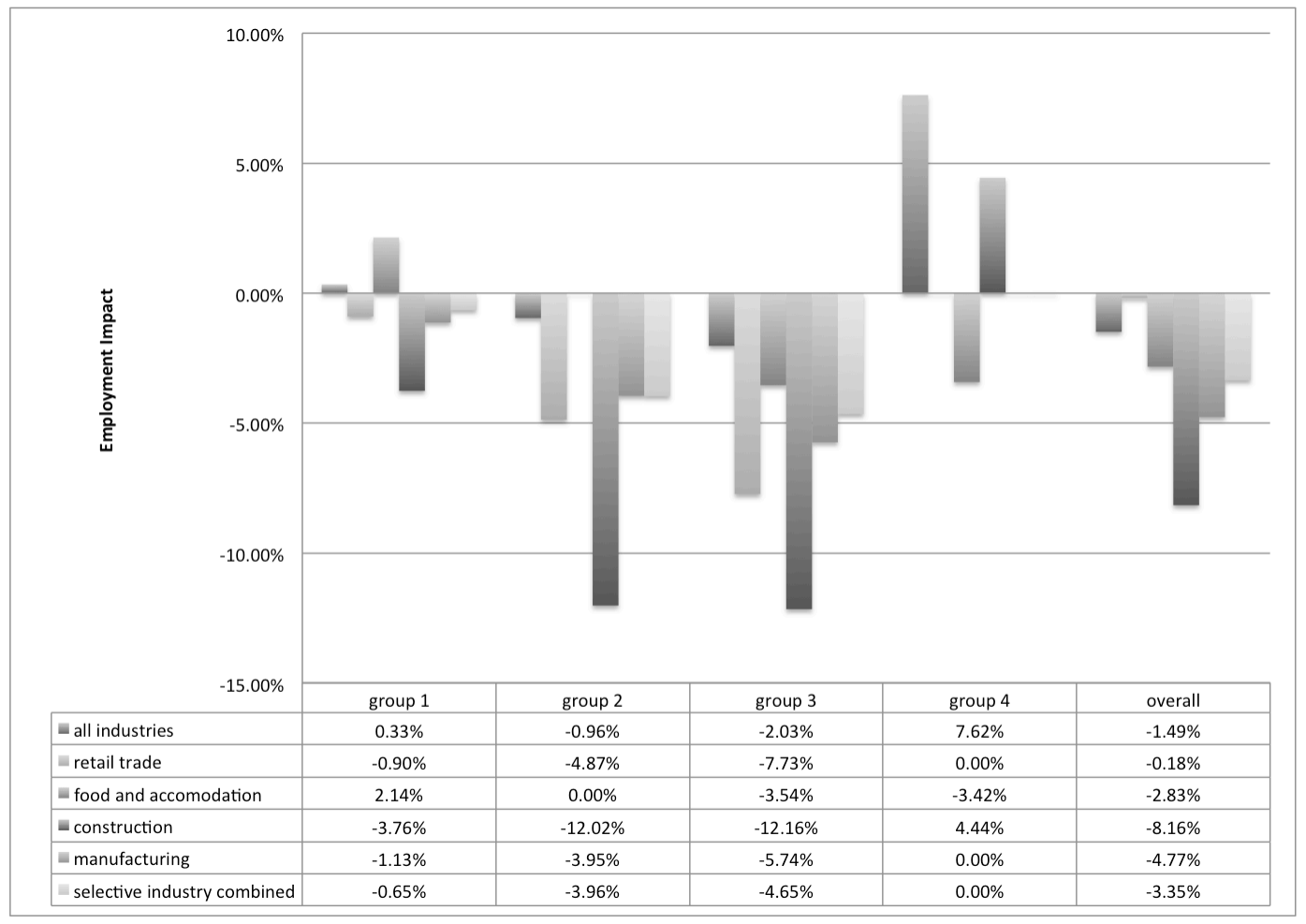

Figure 4.6: Estimation Results Summary for the Firm-Level Analysis 


\begin{tabular}{|c|c|c|}
\hline \multirow{2}{*}{ Industry } & $\begin{array}{c}\text { Firm Level } \\
\text { Regression }\end{array}$ & $\begin{array}{c}\text { Regression Without } \\
\text { D4 Group }\end{array}$ \\
\hline \multirow{2}{*}{ All Relevant Industries } & $-\mathbf{0 . 2 3 2}$ & $-\mathbf{0 . 2 2 6}$ \\
\cline { 2 - 3 } & $(0.004)$ & $(0.006)$ \\
\hline \multirow{2}{*}{ Retail Trade } & -0.139 & -0.138 \\
\cline { 2 - 3 } & $(0.007)$ & $(0.005)$ \\
\hline \multirow{2}{*}{ Food and Accomodation } & -0.006 & -0.029 \\
\cline { 2 - 3 } & $(0.005)$ & $(0.006)$ \\
\hline \multirow{2}{*}{ Construction } & -0.497 & -0.326 \\
\cline { 2 - 3 } & $(0.006)$ & $(0.004)$ \\
\hline \multirow{2}{*}{ Manufacturing } & 0.002 & -0.023 \\
\cline { 2 - 3 } & $(0.003)$ & $(0.003)$ \\
\hline \multirow{2}{*}{ Selected Industries Combined } & $-\mathbf{0 . 2 3 6}$ & $-\mathbf{0 . 2 3 4}$ \\
\cline { 2 - 3 } & $(0.006)$ & $(0.005)$ \\
\hline
\end{tabular}

Table 4.17: Comparison of Estimation Results Between the Firm Level Regression and the Regression Without D4 Group 


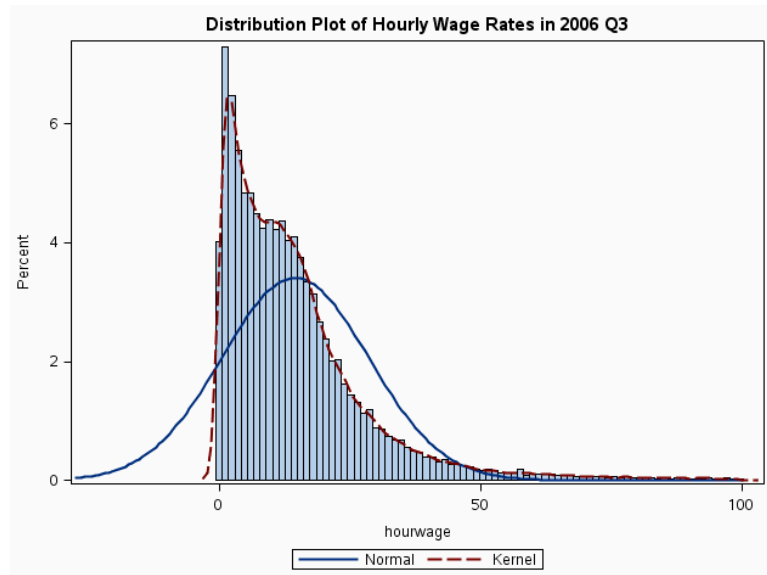

(a) $2006 \mathrm{Q} 3$

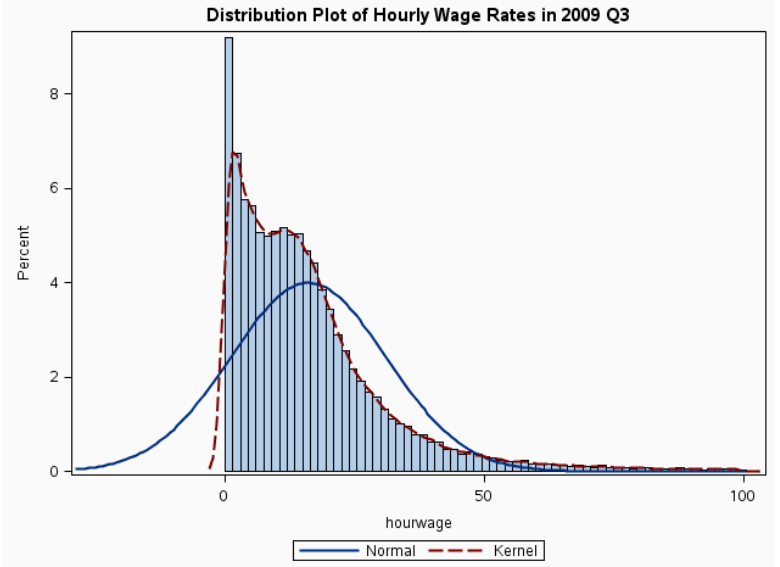

(b) 2009 Q3

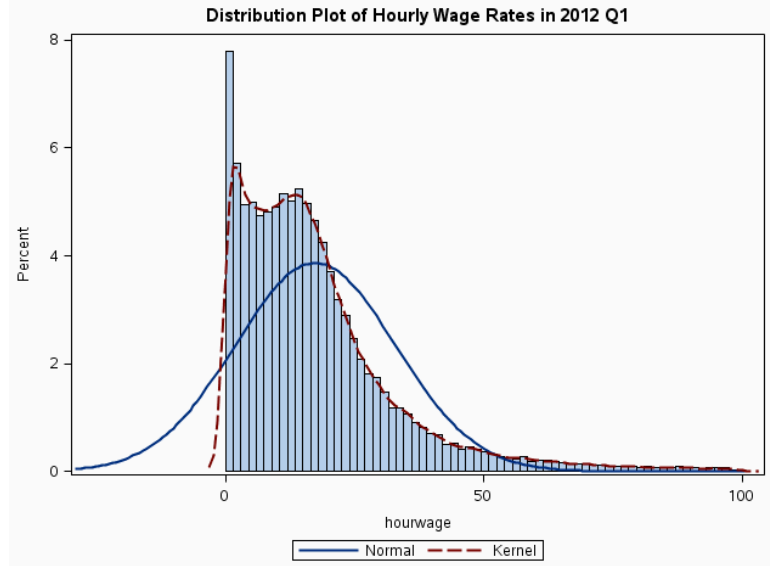

(c) $2012 \mathrm{Q} 1$

Figure 4.7: Distribution of Estimated Hourly Wage Rate (Trimmed at \$100) 


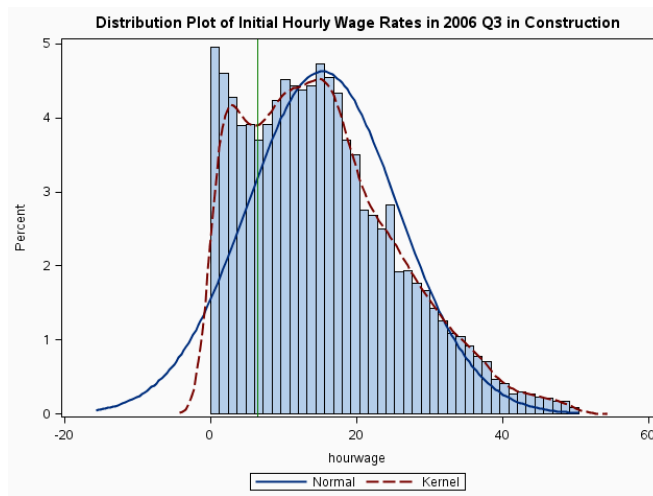

(a) Construction

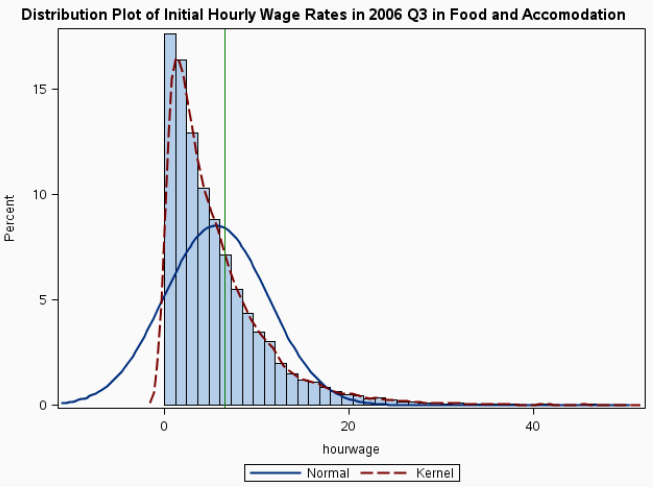

(c) Food and Accommodations

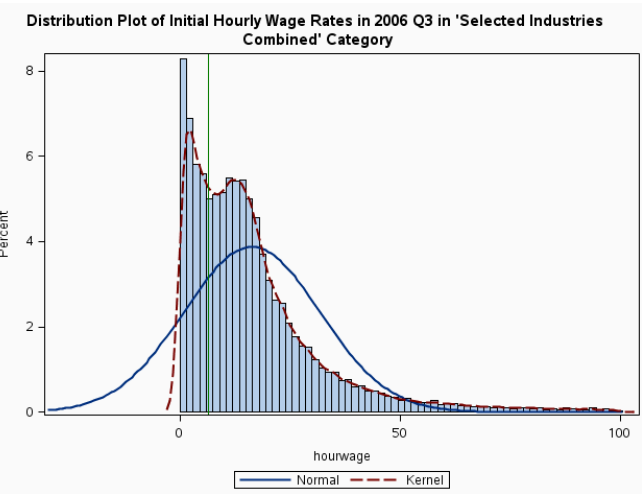

(e) "Selected Industries Combined" Category

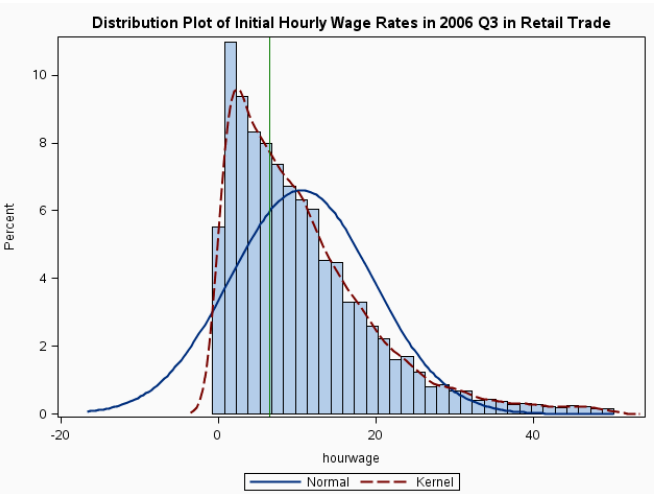

(b) Retail Trade

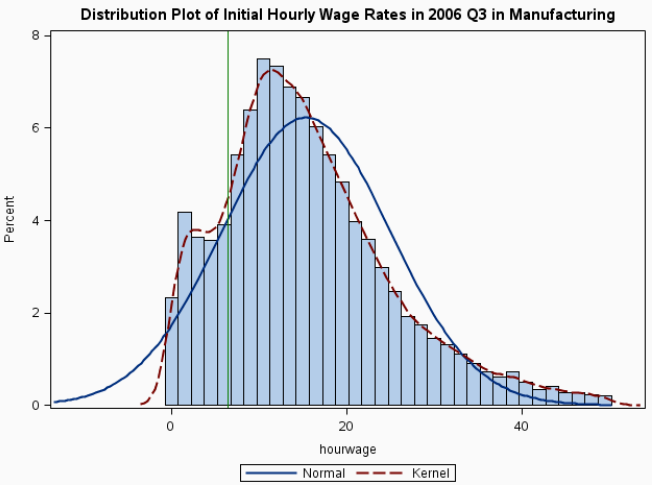

(d) Manufacturing

Figure 4.8: Distribution Plots of Initial Estimated Hourly Wages in 2006 Q3 in Relevant Industries 


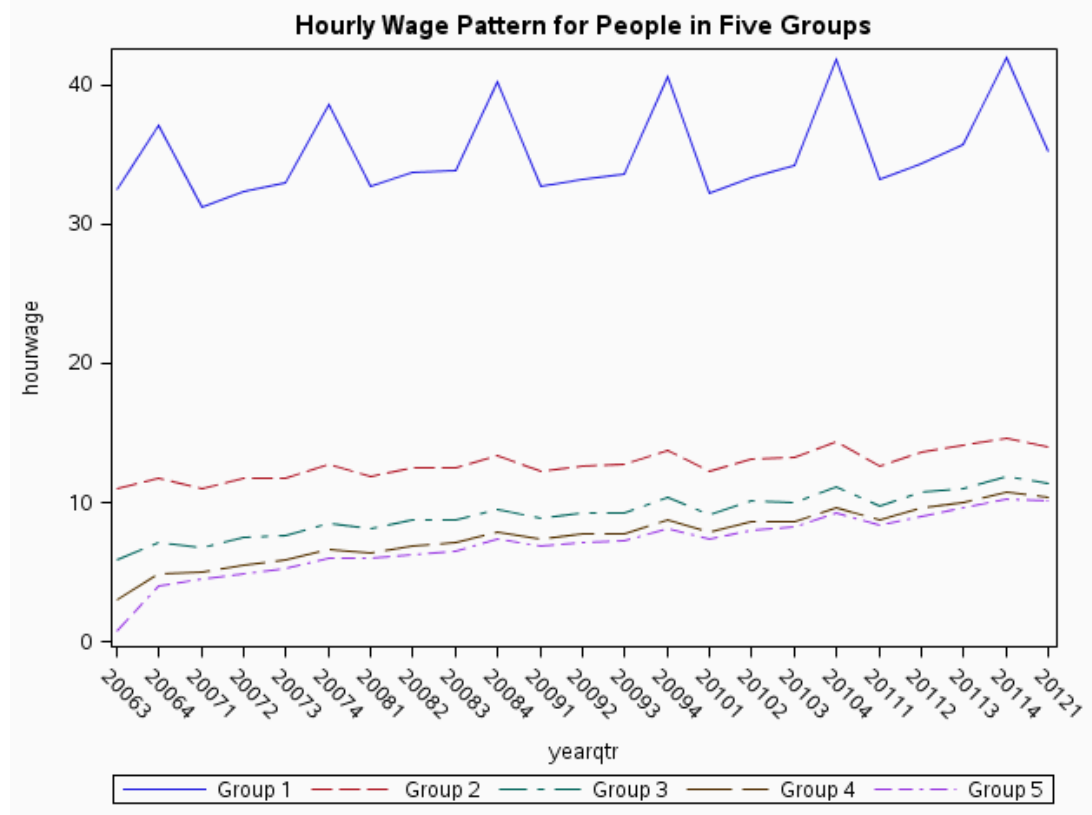

Figure 4.9: Hourly Wage Patterns for Five Earning Groups 


\begin{tabular}{|c|c|c|}
\hline \multirow{2}{*}{} & Inmw & time trend*MO \\
\hline \multirow{2}{*}{ group1 } & $\mathbf{0 . 0 5 6}$ & $\mathbf{0 . 0 0 0 5}$ \\
\cline { 2 - 3 } & $(0.016)$ & $(0.0001)$ \\
\hline \multirow{2}{*}{ group2 } & $\mathbf{0 . 0 6 4}$ & 0.0002 \\
\cline { 2 - 3 } & $(0.021)$ & $(0.0002)$ \\
\hline \multirow{2}{*}{ group3 } & $\mathbf{0 . 1 0 2}$ & -0.0004 \\
\cline { 2 - 3 } & $(0.023)$ & $(0.0003)$ \\
\hline \multirow{2}{*}{ group4 } & 0.027 & -0.0004 \\
\cline { 2 - 3 } & $(0.022)$ & $(0.0003)$ \\
\hline \multirow{2}{*}{ group5 } & $-\mathbf{0 . 0 3 7}$ & -0.0001 \\
\cline { 2 - 3 } & $(0.015)$ & $(0.0002)$ \\
\hline
\end{tabular}

\begin{tabular}{|c|c|c|c|}
\hline sample size & $\begin{array}{c}\text { percentage } \\
\text { of the } \\
\text { sample size }\end{array}$ & MO sample & KS sample \\
\hline $1,928,872$ & $37.46 \%$ & $1,026,881$ & 901,991 \\
\hline $1,407,002$ & $27.32 \%$ & 845,204 & 561,798 \\
\hline 542,340 & $10.53 \%$ & 349,646 & 192,694 \\
\hline 739,542 & $14.36 \%$ & 462,162 & 277,380 \\
\hline 531,530 & $10.32 \%$ & 329,521 & 202,009 \\
\hline $5,149,286$ & $100 \%$ & $3,013,414$ & $2,135,872$ \\
\hline
\end{tabular}

Table 4.18: Employment Possibility Estimation Results - Entire Sample

\begin{tabular}{|c|c|c|}
\hline \multirow{2}{*}{} & Inmw & time trend*MO \\
\hline \multirow{2}{*}{ group1 } & $\mathbf{0 . 0 7 3}$ & -0.0006 \\
\cline { 2 - 3 } & $(0.016)$ & $(0.0002)$ \\
\hline \multirow{2}{*}{ group2 } & $\mathbf{0 . 0 9 1}$ & 0.0002 \\
\cline { 2 - 3 } & $(0.018)$ & $(0.0002)$ \\
\hline \multirow{2}{*}{ group3 } & $\mathbf{0 . 0 5 8}$ & -0.0011 \\
\cline { 2 - 3 } & $(0.013)$ & $(0.0001)$ \\
\hline \multirow{2}{*}{ group4 } & 0.016 & -0.0014 \\
\cline { 2 - 3 } & $(0.018)$ & $(0.0002)$ \\
\hline \multirow{2}{*}{ group5 } & $-\mathbf{0 . 1 7 3}$ & 0.0012 \\
\cline { 2 - 3 } & $(0.050)$ & $(0.0006)$ \\
\hline
\end{tabular}

\begin{tabular}{|c|c|c|c|}
\hline sample size & \begin{tabular}{|c|}
$\begin{array}{c}\text { percentage of } \\
\text { the sample } \\
\text { size }\end{array}$ \\
\end{tabular} & MO sample & KS sample \\
\hline 156,584 & $27.39 \%$ & 85,146 & 71,438 \\
\hline 166,451 & $29.11 \%$ & 99,567 & 66,884 \\
\hline 76,337 & $13.35 \%$ & 46,437 & 29,900 \\
\hline 102,879 & $17.99 \%$ & 58,489 & 44,390 \\
\hline 69,529 & $12.16 \%$ & 38,387 & 31,142 \\
\hline 571,780 & $100.00 \%$ & 328,026 & 243,754 \\
\hline
\end{tabular}

Table 4.19: Employment Possibility Estimation Results - Retail Trade

\begin{tabular}{|c|c|c|}
\hline \multirow{2}{*}{} & Inmw & time trend*MO \\
\hline \multirow{2}{*}{ group1 } & $\mathbf{0 . 0 6 7}$ & $\mathbf{0 . 0 0 0 9}$ \\
\cline { 2 - 3 } & $(0.058)$ & $(0.0004)$ \\
\hline \multirow{2}{*}{ group2 } & $\mathbf{0 . 0 5 3}$ & -0.0007 \\
\cline { 2 - 3 } & $(0.027)$ & $(0.0002)$ \\
\hline \multirow{2}{*}{ group3 } & $\mathbf{0 . 0 7 5}$ & -0.0004 \\
\cline { 2 - 3 } & $(0.018)$ & $(0.0002)$ \\
\hline \multirow{2}{*}{ group4 } & 0.008 & -0.0002 \\
\cline { 2 - 3 } & $(0.022)$ & $(0.0003)$ \\
\hline \multirow{2}{*}{ group5 } & -0.070 & 0.00008 \\
\cline { 2 - 3 } & -0.029 & $(0.003)$ \\
\hline
\end{tabular}

\begin{tabular}{|c|c|c|c|}
\hline sample size & \begin{tabular}{|c} 
percentage of \\
the sample \\
size
\end{tabular} & MO sample & KS sample \\
\hline 27,830 & $6.51 \%$ & 16,468 & 11,362 \\
\hline 83,858 & $19.63 \%$ & 51,198 & 32,660 \\
\hline 76,751 & $17.97 \%$ & 49,726 & 27,025 \\
\hline 136,344 & $31.92 \%$ & 79,971 & 56,373 \\
\hline 102,419 & $23.97 \%$ & 57,914 & 44,505 \\
\hline 427,202 & $100.00 \%$ & 255,277 & 171,925 \\
\hline
\end{tabular}

Table 4.20: Employment Possibility Estimation Results - Food 


\begin{tabular}{|c|c|c|}
\hline \multirow{2}{*}{} & Inmw & time trend*MO \\
\hline \multirow{2}{*}{ group1 } & $-\mathbf{0 . 1 3 4}$ & 0.0002 \\
\cline { 2 - 3 } & $(0.075)$ & $(0.0009)$ \\
\hline \multirow{2}{*}{ group2 } & $-\mathbf{0 . 1 2 7}$ & -0.0018 \\
\cline { 2 - 3 } & $(0.057)$ & $(0.0005)$ \\
\hline \multirow{2}{*}{ group3 } & 0.094 & $\mathbf{0 . 0 0 2 6}$ \\
\cline { 2 - 3 } & $(0.093)$ & $(0.0008)$ \\
\hline \multirow{2}{*}{ group4 } & -0.471 & -0.0031 \\
\cline { 2 - 3 } & $(0.079)$ & $(0.0008)$ \\
\hline \multirow{2}{*}{ group5 } & 0.040 & -0.0017 \\
\cline { 2 - 3 } & $(0.093)$ & $(0.0011)$ \\
\hline
\end{tabular}

\begin{tabular}{|c|c|c|c|c|}
\hline sample size & \begin{tabular}{|c|}
$\begin{array}{c}\text { percentage } \\
\text { of the } \\
\text { sample size }\end{array}$ \\
\end{tabular} & MO sample & KS sample & \\
\hline 3,634 & $8.15 \%$ & 1,541 & 2,093 & \\
\hline 13,087 & $29.36 \%$ & 6,969 & 6,118 & \\
\hline 9,660 & $21.67 \%$ & 5,957 & 3,703 & \\
\hline 10,856 & $24.36 \%$ & 6,808 & 4,048 & \\
\hline 7,337 & $16.46 \%$ & 4,531 & 2,806 & \\
\hline 44,574 & $100 \%$ & 25,806 & 18,768 & total \\
\hline
\end{tabular}

Table 4.21: Employment Possibility Estimation Results - Hotel and Accommodations

\begin{tabular}{|c|c|c|}
\hline \multirow{2}{*}{} & Inmw & time trend*MO \\
\hline \multirow{2}{*}{ group1 } & -0.016 & $\mathbf{0 . 0 0 0 9}$ \\
\cline { 2 - 3 } & $(0.032)$ & $(0.0003)$ \\
\hline \multirow{2}{*}{ group2 } & $\mathbf{0 . 0 7 7}$ & $\mathbf{0 . 0 0 0 6}$ \\
\cline { 2 - 3 } & $(0.030)$ & $(0.0002)$ \\
\hline \multirow{2}{*}{ group3 } & $\mathbf{0 . 0 8 5}$ & 0.0007 \\
\cline { 2 - 3 } & $(0.042)$ & $(0.0005)$ \\
\hline \multirow{2}{*}{ group4 } & -0.008 & 0.0005 \\
\cline { 2 - 3 } & $(0.035)$ & $(0.0004)$ \\
\hline \multirow{2}{*}{ group5 } & 0.051 & -0.0003 \\
\cline { 2 - 3 } & $(0.039)$ & $(0.0005)$ \\
\hline
\end{tabular}

\begin{tabular}{|c|c|c|c|}
\hline sample size & $\begin{array}{l}\text { percentage } \\
\text { of the } \\
\text { sample size }\end{array}$ & MO sample & KS sample \\
\hline 383,709 & $48.03 \%$ & 215,694 & 168,015 \\
\hline 220,501 & $27.60 \%$ & 125,718 & 94,783 \\
\hline 63,963 & $8.01 \%$ & 37,927 & 26,036 \\
\hline 80,086 & $10.02 \%$ & 44,735 & 35,351 \\
\hline 50,623 & $6.34 \%$ & 28,589 & 22,034 \\
\hline 798,882 & $100.00 \%$ & 452,663 & 346,219 \\
\hline
\end{tabular}

Table 4.22: Employment Possibility Estimation Results - Construction

\begin{tabular}{|c|c|c|}
\hline \multirow{2}{*}{} & Inmw & time trend*MO \\
\hline \multirow{2}{*}{ group1 } & $\mathbf{0 . 0 9 1}$ & $\mathbf{0 . 0 0 0 4}$ \\
\cline { 2 - 3 } & $(0.016)$ & $(0.0002)$ \\
\hline \multirow{2}{*}{ group2 } & $\mathbf{0 . 0 7 6}$ & $-\mathbf{0 . 0 0 0 4}$ \\
\cline { 2 - 3 } & $(0.025)$ & $(0.0002)$ \\
\hline \multirow{2}{*}{ group3 } & $\mathbf{0 . 1 0 6}$ & -0.0006 \\
\cline { 2 - 3 } & $(0.051)$ & $(0.0005)$ \\
\hline \multirow{2}{*}{ group4 } & 0.073 & -0.0029 \\
\cline { 2 - 3 } & $(0.052)$ & $(0.0006)$ \\
\hline \multirow{2}{*}{ group5 } & -0.003 & -0.0023 \\
\cline { 2 - 3 } & $(0.062)$ & $(0.0007)$ \\
\hline
\end{tabular}

\begin{tabular}{|c|c|c|c|c|}
\hline sample size & $\begin{array}{l}\text { percentage } \\
\text { of the } \\
\text { sample size }\end{array}$ & MO sample & KS sample & \\
\hline 306,705 & $49.10 \%$ & 166,566 & 140,139 & \\
\hline 205,160 & $32.84 \%$ & 124,246 & 80,914 & \\
\hline 40,710 & $6.52 \%$ & 24,518 & 16,192 & \\
\hline 44,137 & $7.07 \%$ & 26,266 & 17,871 & \\
\hline 27,968 & $4.48 \%$ & 16,744 & 11,224 & \\
\hline 624,680 & $100 \%$ & 358,340 & 266,340 & total \\
\hline
\end{tabular}

Table 4.23: Employment Possibility Estimation Results - Manufacturing 


\begin{tabular}{|c|c|c|}
\hline \multirow{2}{*}{} & Inmw & time trend*MO \\
\hline \multirow{2}{*}{ group1 } & $\mathbf{0 . 0 6 7}$ & $\mathbf{0 . 0 0 0 8}$ \\
\cline { 2 - 3 } & $(0.013)$ & $(0.0001)$ \\
\hline \multirow{2}{*}{ group2 } & $\mathbf{0 . 0 4 4}$ & $\mathbf{0 . 0 0 0 5}$ \\
\cline { 2 - 3 } & $(0.020)$ & $(0.0002)$ \\
\hline \multirow{2}{*}{ group3 } & $\mathbf{0 . 0 8 6}$ & -0.0007 \\
\cline { 2 - 3 } & $(0.018)$ & $(0.0002)$ \\
\hline \multirow{2}{*}{ group4 } & 0.008 & -0.0008 \\
\cline { 2 - 3 } & $(0.052)$ & $(0.0003)$ \\
\hline \multirow{2}{*}{ group5 } & -0.019 & -0.0004 \\
\cline { 2 - 3 } & $(0.019)$ & $(0.0002)$ \\
\hline
\end{tabular}

\begin{tabular}{|c|c|c|c|}
\hline sample size & $\begin{array}{l}\text { percentage } \\
\text { of the } \\
\text { sample size }\end{array}$ & MO sample & KS sample \\
\hline $1,022,764$ & $42.80 \%$ & 511,175 & 511,589 \\
\hline 643,655 & $26.94 \%$ & 359,191 & 284,464 \\
\hline 225,055 & $9.42 \%$ & 133,101 & 91,954 \\
\hline 288,351 & $12.07 \%$ & 164,381 & 123,970 \\
\hline 209,737 & $8.78 \%$ & 115,529 & 94,208 \\
\hline $2,389,562$ & $100.00 \%$ & $1,283,377$ & $1,106,185$ \\
\hline
\end{tabular}

Table 4.24: Employment Possibility Estimation Results - "Selected Industries Combined" Category

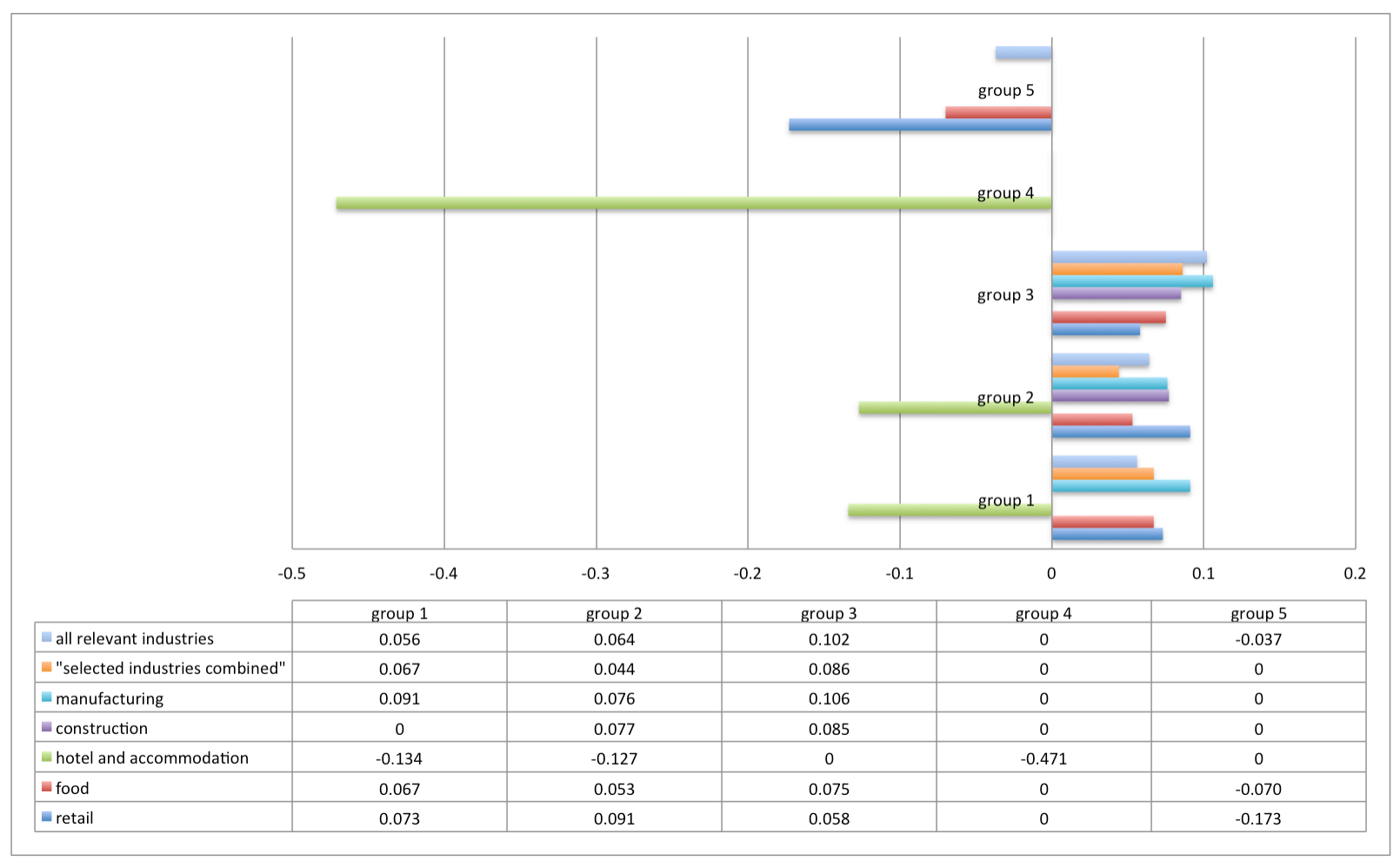

Figure 4.10: Estimation Results Summary for the Individual-Level Analysis 


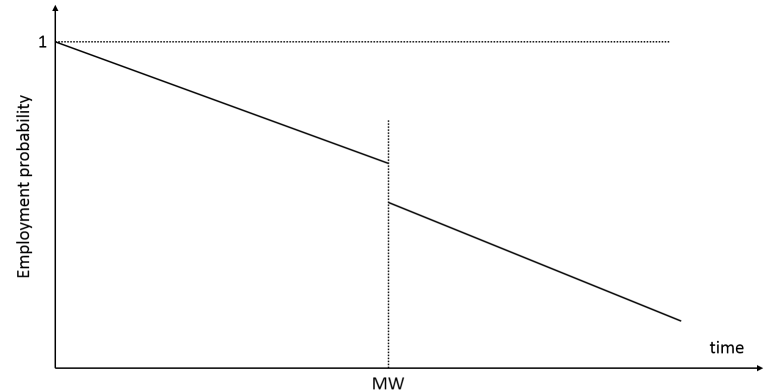

KS $\rightarrow$ KS

(a) Kansas Residents in Kansas

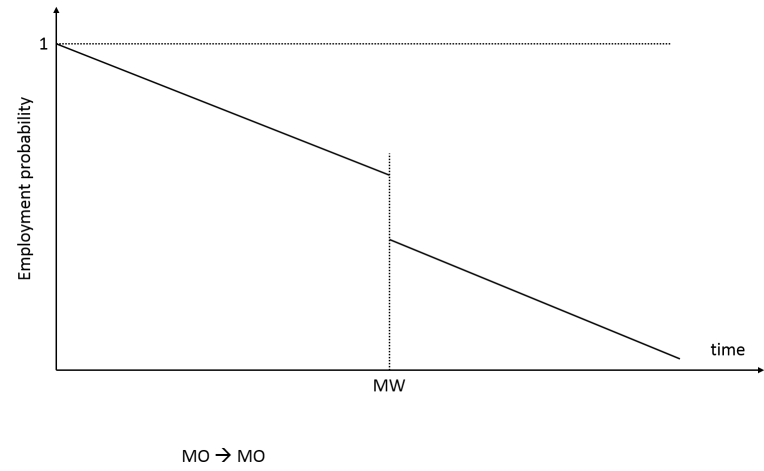

(c) Missouri Residents in Kansas

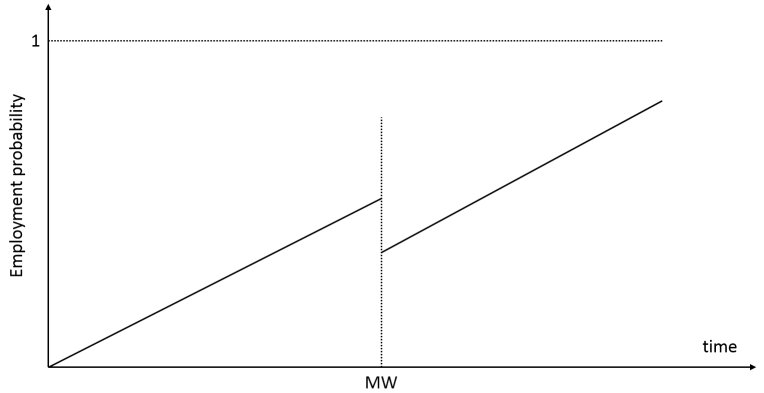

KS $\rightarrow$ MO

(b) Kansas Residents in Missouri

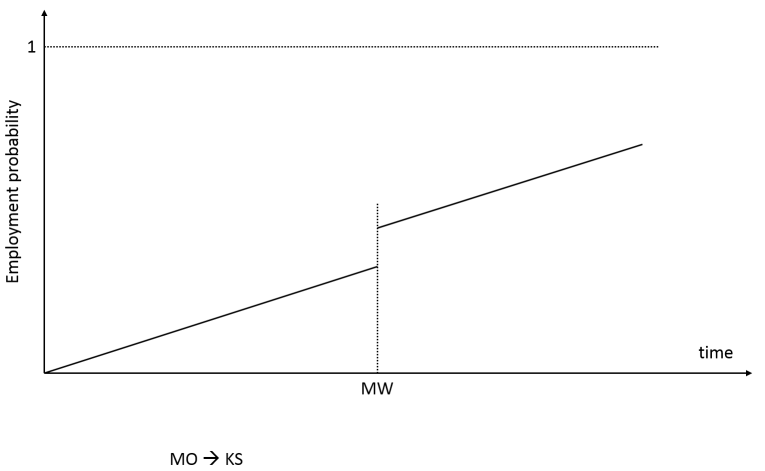

(d) Missouri Residents in Kansas

Figure 4.11: Employment Possibility Illustration 


\begin{tabular}{|c|c|c|c|c|}
\hline & $\mathrm{KS}-\mathrm{KS}$ & $\mathrm{KS}-\mathrm{MO}$ & $\mathrm{MO}-\mathrm{KS}$ & $\mathrm{MO}-\mathrm{MO}$ \\
\hline \multirow{2}{*}{ group1 } & $-\mathbf{0 . 1 1 3}$ & $\mathbf{0 . 0 7 3}$ & 0.008 & -0.021 \\
\cline { 2 - 5 } & $(0.022)$ & $(0.027)$ & $(0.009)$ & $(0.016)$ \\
\hline \multirow{2}{*}{ group2 } & $\mathbf{0 . 2 4 2}$ & $\mathbf{0 . 1 0 9}$ & $\mathbf{0 . 0 6 3}$ & -0.140 \\
\cline { 2 - 5 } & $(0.052)$ & $(0.038)$ & $(0.027)$ & $(0.039)$ \\
\hline \multirow{2}{*}{ group3 } & $-\mathbf{0 . 4 2 2}$ & $\mathbf{0 . 1 0 9}$ & $\mathbf{0 . 1 3 2}$ & $-\mathbf{0 . 2 8 9}$ \\
\cline { 2 - 5 } & $(0.155)$ & $(0.041)$ & $(0.042)$ & $(0.101)$ \\
\hline \multirow{2}{*}{ group4 } & $-\mathbf{0 . 5 4 3}$ & $\mathbf{0 . 1 2 6}$ & $\mathbf{0 . 1 5 0}$ & $-\mathbf{0 . 4 6 8}$ \\
\cline { 2 - 5 } & $(0.281)$ & $(0.049)$ & $(0.058)$ & $(0.228)$ \\
\hline \multirow{2}{*}{ group5 } & $-\mathbf{0 . 8 7 4}$ & $\mathbf{0 . 1 4 1}$ & $\mathbf{0 . 1 4 7}$ & -0.902 \\
\cline { 2 - 5 } & $(0.478)$ & $(0.051)$ & $(0.087)$ & $(0.499)$ \\
\hline
\end{tabular}

Table 4.25: Labor Mobility Estimation Results - Entire Sample

\begin{tabular}{|c|c|c|c|c|}
\hline & $\mathrm{KS}-\mathrm{KS}$ & $\mathrm{KS}-\mathrm{MO}$ & $\mathrm{MO}-\mathrm{KS}$ & $\mathrm{MO}-\mathrm{MO}$ \\
\hline \multirow{2}{*}{ group1 } & $-\mathbf{0 . 0 8 5}$ & $\mathbf{0 . 0 7 2}$ & $\mathbf{0 . 0 6 0}$ & 0.034 \\
\cline { 2 - 5 } & $(0.026)$ & $(0.034)$ & $(0.018)$ & $(0.022)$ \\
\hline \multirow{2}{*}{ group2 } & $-\mathbf{0 . 1 8 0}$ & $\mathbf{0 . 1 0 6}$ & $\mathbf{0 . 1 0 8}$ & $-\mathbf{0 . 0 8 6}$ \\
\cline { 2 - 5 } & $(0.038)$ & $(0.031)$ & $(0.041)$ & $(0.036)$ \\
\hline \multirow{2}{*}{ group3 } & $-\mathbf{0 . 3 3 6}$ & $\mathbf{0 . 1 3 3}$ & 0.047 & -0.252 \\
\cline { 2 - 5 } & $(0.104)$ & $(0.045)$ & $(0.032)$ & $(0.098)$ \\
\hline \multirow{2}{*}{ group4 } & $-\mathbf{0 . 4 2 8}$ & $\mathbf{0 . 0 7 1}$ & $\mathbf{0 . 0 7 9}$ & -0.388 \\
\cline { 2 - 5 } & $(0.192)$ & $(0.039)$ & $(0.028)$ & $(0.201)$ \\
\hline \multirow{2}{*}{ group5 } & $-\mathbf{0 . 7 7 9}$ & $\mathbf{0 . 1 4 9}$ & 0.051 & -0.856 \\
\cline { 2 - 5 } & $(0.401)$ & $(0.062)$ & $(0.037)$ & $(0.482)$ \\
\hline
\end{tabular}

Table 4.26: Labor Mobility Estimation Results - Retail Trade

\begin{tabular}{|c|c|c|c|c|}
\hline & $\mathrm{KS}-\mathrm{KS}$ & $\mathrm{KS}-\mathrm{MO}$ & $\mathrm{MO}-\mathrm{KS}$ & $\mathrm{MO}-\mathrm{MO}$ \\
\hline \multirow{2}{*}{ group1 } & -0.049 & 0.067 & -0.049 & 0.065 \\
\cline { 2 - 5 } & $(0.055)$ & $(0.043)$ & $(0.021)$ & $(0.046)$ \\
\hline \multirow{2}{*}{ group2 } & $-\mathbf{0 . 3 2 9}$ & $\mathbf{0 . 1 2 1}$ & 0.056 & -0.225 \\
\cline { 2 - 5 } & $(0.062)$ & $(0.037)$ & $(0.036)$ & $(0.072)$ \\
\hline \multirow{2}{*}{ group3 } & $-\mathbf{0 . 3 6 0}$ & $\mathbf{0 . 0 8 2}$ & $\mathbf{0 . 1 3 6}$ & $-\mathbf{0 . 2 6 7}$ \\
\cline { 2 - 5 } & $(0.078)$ & $(0.036)$ & $(0.139)$ & $(0.075)$ \\
\hline \multirow{2}{*}{ group4 } & $-\mathbf{0 . 5 1 4}$ & $\mathbf{0 . 0 9 4}$ & $\mathbf{0 . 0 9 7}$ & -0.493 \\
\cline { 2 - 5 } & $(0.172)$ & $(0.038)$ & $(0.048)$ & $(0.168)$ \\
\hline \multirow{2}{*}{ group5 } & $-\mathbf{0 . 9 8 5}$ & $\mathbf{0 . 1 6 2}$ & $\mathbf{0 . 1 2 3}$ & -0.999 \\
\cline { 2 - 5 } & $(0.471)$ & $(0.052)$ & $(0.048)$ & $(0.482)$ \\
\hline
\end{tabular}

Table 4.27: Labor Mobility Estimation Results - Food 


\begin{tabular}{|c|c|c|c|c|}
\hline & $\mathrm{KS}-\mathrm{KS}$ & $\mathrm{KS}-\mathrm{MO}$ & $\mathrm{MO}-\mathrm{KS}$ & $\mathrm{MO}-\mathrm{MO}$ \\
\hline \multirow{2}{*}{ group1 } & 0.129 & $\mathbf{0 . 0 7 7}$ & 0.040 & -0.001 \\
\cline { 2 - 5 } & $(0134)$ & $(0.042)$ & $(0.041)$ & $(0.124)$ \\
\hline \multirow{2}{*}{ group2 } & 0.019 & 0.079 & $\mathbf{0 . 0 6 1}$ & -0.088 \\
\cline { 2 - 5 } & $(0.091)$ & $(0.065)$ & $(0.051)$ & $(0.072)$ \\
\hline \multirow{2}{*}{ group3 } & $-\mathbf{0 . 4 2 2}$ & $\mathbf{0 . 2 0 4}$ & 0.103 & -0.500 \\
\cline { 2 - 5 } & $(0.104)$ & $(0.038)$ & $(0.050)$ & $(0.094)$ \\
\hline \multirow{2}{*}{ group4 } & -0.383 & 0.105 & 0.054 & -0.921 \\
\cline { 2 - 5 } & $(0.323)$ & $(0.106)$ & $(0.044)$ & $(0.358)$ \\
\hline \multirow{2}{*}{ group5 } & $\mathbf{- 0 . 9 2 8}$ & $\mathbf{0 . 1 6 0}$ & 0.186 & -0.970 \\
\cline { 2 - 5 } & $(0.658)$ & $(0.083)$ & $(0.071)$ & $(0.592)$ \\
\hline
\end{tabular}

Table 4.28: Labor Mobility Estimation Results - Hotel and Accommodations

\begin{tabular}{|c|c|c|c|c|}
\hline & $\mathrm{KS}-\mathrm{KS}$ & $\mathrm{KS}-\mathrm{MO}$ & $\mathrm{MO}-\mathrm{KS}$ & $\mathrm{MO}-\mathrm{MO}$ \\
\hline \multirow{2}{*}{ group1 } & -0.075 & $\mathbf{0 . 1 3 7}$ & $\mathbf{0 . 0 6 1}$ & -0.035 \\
\cline { 2 - 5 } & $(0.052)$ & $(0.044)$ & $(0.034)$ & $(0.038)$ \\
\hline \multirow{2}{*}{ group2 } & $-\mathbf{0 . 4 9 2}$ & $\mathbf{0 . 1 9 0}$ & $\mathbf{0 . 1 2 0}$ & $-\mathbf{0 . 3 2 3}$ \\
\cline { 2 - 5 } & $(0.108)$ & $(0.040)$ & $(0.045)$ & $(0.078)$ \\
\hline \multirow{2}{*}{ group3 } & $\mathbf{- 0 . 6 9 6}$ & $\mathbf{0 . 1 9 6}$ & $\mathbf{0 . 2 0 9}$ & $-\mathbf{0 . 5 8 0}$ \\
\cline { 2 - 5 } & $(0.367)$ & $(0.076)$ & $(0.078)$ & $(0.206)$ \\
\hline \multirow{2}{*}{ group4 } & -0.930 & $\mathbf{0 . 2 5 2}$ & $\mathbf{0 . 1 1 7}$ & -0.746 \\
\cline { 2 - 5 } & $(0.590)$ & $(0.096)$ & $(0.058)$ & $(0.473)$ \\
\hline \multirow{2}{*}{ group5 } & -1.193 & $\mathbf{0 . 1 9 6}$ & $\mathbf{0 . 2 2 2}$ & -1.197 \\
\cline { 2 - 5 } & $(0.813)$ & $(0.091)$ & $(0.074)$ & $(0.733)$ \\
\hline
\end{tabular}

Table 4.29: Labor Mobility Estimation Results - Construction

\begin{tabular}{|c|c|c|c|c|}
\hline & $\mathrm{KS}-\mathrm{KS}$ & $\mathrm{KS}-\mathrm{MO}$ & $\mathrm{MO}-\mathrm{KS}$ & $\mathrm{MO}-\mathrm{MO}$ \\
\hline \multirow{2}{*}{ group1 } & $-\mathbf{0 . 0 7 3}$ & 0.012 & 0.008 & 0.034 \\
\cline { 2 - 5 } & $(0.031)$ & $(0.011)$ & $(0.009)$ & $(0.037)$ \\
\hline \multirow{2}{*}{ group2 } & $\mathbf{0 . 1 5 4}$ & $\mathbf{0 . 1 0 8}$ & $\mathbf{0 . 0 6 3}$ & 0.009 \\
\cline { 2 - 5 } & $(0.052)$ & $(0.042)$ & $(0.027)$ & $(0.027)$ \\
\hline \multirow{2}{*}{ group3 } & $-\mathbf{0 . 5 1 0}$ & 0.056 & $\mathbf{0 . 1 3 2}$ & $-\mathbf{0 . 3 7 8}$ \\
\cline { 2 - 5 } & $(0.218)$ & $(0.036)$ & $(0.042)$ & $(0.143)$ \\
\hline \multirow{2}{*}{ group4 } & -0.383 & $\mathbf{0 . 1 3 6}$ & $\mathbf{0 . 1 5 0}$ & -0.608 \\
\cline { 2 - 5 } & $(0.323)$ & $(0.057)$ & $(0.058)$ & $(0.362)$ \\
\hline \multirow{2}{*}{ group5 } & -0.628 & 0.109 & $\mathbf{0 . 1 4 7}$ & -1.151 \\
\cline { 2 - 5 } & $(0.414)$ & $(0.074)$ & $(0.087)$ & $(0.546)$ \\
\hline
\end{tabular}

Table 4.30: Labor Mobility Estimation Results - Manufacturing 


\begin{tabular}{|c|c|c|c|c|}
\hline & $\mathrm{KS}-\mathrm{KS}$ & $\mathrm{KS}-\mathrm{MO}$ & $\mathrm{MO}-\mathrm{KS}$ & $\mathrm{MO}-\mathrm{MO}$ \\
\hline \multirow{2}{*}{ group1 } & -0.143 & $\mathbf{0 . 0 6 9}$ & $\mathbf{0 . 0 6 1}$ & -0.040 \\
\cline { 2 - 5 } & $(0.018)$ & $(0.026)$ & $(0.017)$ & $(0.015)$ \\
\hline \multirow{2}{*}{ group2 } & $-\mathbf{0 . 1 9 6}$ & $\mathbf{0 . 0 8 3}$ & $\mathbf{0 . 0 8 9}$ & -0.142 \\
\cline { 2 - 5 } & $(0.048)$ & $(0.036)$ & $(0.029)$ & $(0.041)$ \\
\hline \multirow{2}{*}{ group3 } & $-\mathbf{0 . 3 8 0}$ & $\mathbf{0 . 0 9 2}$ & $\mathbf{0 . 0 9 0}$ & -0.580 \\
\cline { 2 - 5 } & $(0.137)$ & $(0.039)$ & $(0.031)$ & $(0.206)$ \\
\hline \multirow{2}{*}{ group4 } & $-\mathbf{0 . 4 8 8}$ & $\mathbf{0 . 1 2 6}$ & $\mathbf{0 . 0 8 7}$ & $-\mathbf{0 . 4 2 4}$ \\
\cline { 2 - 5 } & $(0.266)$ & $(0.046)$ & $(0.040)$ & $(0.210)$ \\
\hline \multirow{2}{*}{ group5 } & -0.751 & $\mathbf{0 . 1 2 0}$ & $\mathbf{0 . 1 2 5}$ & -0.784 \\
\cline { 2 - 5 } & $(0.417)$ & $(0.037)$ & $(0.046)$ & $(0.443)$ \\
\hline
\end{tabular}

Table 4.31: Labor Mobility Estimation Results - "Selected Industries Combined" Category 


\section{Chapter 5}

\section{Conclusion}

Traditionally, economists were in agreement that minimum wage reduces employment, especially for teenagers and in low wage industries, such as food and retail trade. In recent years, this statement has been challenged both theoretically and empirically. A substantial number of empirical studies find that minimum wages have no impact on employment, or even have positive employment effects. Therefore, the contentious debates regarding minimum wages continue.

This dissertation explores minimum wage impacts on employment. A perfectly competitive model implies that a binding minimum wage floor decreases employment by creating a surplus of labor. Alternatively, monopsony model illustrates that if a firm has some monopsony power, increasing minimum wages can cause the employment level to rise, fall, or remain constant, depending on the size of the increase. As a result, a moderate minimum wage increase could increase income without the penalty of reducing employment. A tremendous number of papers analyze the empirical consequences of minimum wage policy in depth by applying various methods and by using different data. In chapter 2 , this dissertation investigates the minimum wage literature by summarizing the theoretical models of minimum wage impacts and discussing the empirical methodologies used in detail. 
The main empirical findings are summarized in Chapter 3 and 4 . In chapter 3, using state level CPS data, I explore the minimum wage effects on teenage employment from 1979 to 2011 following the work by Burkhauser et al. (2000). The dependent variable in the model is the teenage to population ratio and the minimum wage variable is the natural log of the effective minimum wage, which is the higher of the federal and state minimum wages. State and month fixed effects are included in the specification models. Adult wage, share of teenagers and prime-age male unemployment rate are also controlled. I find that the minimum wage effects on teenage employment are negative and significant in nearly all specifications. In general, the employment response is around $3 \%$ for a $10 \%$ increase of the minimum wage, indicating the employment elasticities within the range from -0.1 to -0.6 . One argument regarding this model set up is the appropriateness of including year effects in the model, since they may wipe out most of the variation in the federal minimum wages and the estimates therefore rely heavily on the state level variation. So some economists argue that including the year effects result insignificant employment effects. My results indicate that this result does depend on the sample period. In recent years, an increasing number of states implement their own state minimum wages, which provide enough variation in the regression. So even year effects are included, I still find significant disemployment effect.

To allow the minimum wage policy to fully function, a one-year lag of the minimum wage variable is introduced into the model. Stronger disemployment effects are found when the long-run impacts are considered. In addition, since different states may have different employment patterns, two checks are performed. First, states are clustered by census division to control for spatial heterogeneity. In this case, disemployment effects are smaller in magnitude. Second, state-specific time trends are introduced in the model and I fail to detect adverse employment effect in this model specification. One new phenomenon of minimum wage is that up to 2011, including Missouri, there 
are 10 states making minimum wage to index with CPI. My results suggest that minimum wage indexation has no impact on employment. Furthermore, I also find that there is no anticipation effect of minimum wages and business cycles do not affect the estimates.

My major analysis is presented in chapter 4. By taking advantage of Missouri and Kansas administrative payroll data, we explore the employment effects of Missouri minimum wages. The Kansas City metro area straddles the border of Missouri and Kansas. Missouri first implemented a state minimum wage in 2007 Q1, while in Kansas only the federal minimum wages apply. The close geographic proximity and the different minimum wage policies form a natural experiment and provide us a great opportunity to examine Missouri minimum wage impacts. Our sample period is from 2006 Q3 to 2012 Q1. We adopt DID method and conduct firm-level analysis. First, we check the DID estimates for each single wave of the minimum wage increase. Two sets of estimates are reported. One is for two sequential quarter, and the other is for the same quarters in two sequential years. For the first Missouri minimum wage increase in 2007 Q1, we find positive estimates. For later quarters, mixed results are found. We argue that the failure of find consistent disemployment effects is caused by insufficient controls in the simple analysis with only two periods.

We then construct a multi-period and multi-group panel data analysis including Missouri border firms that are subject to the state minimum wage and similar Kansas border firms. For the purpose of checking how the minimum wage affects firms' employment decisions, firms are divided into four groups based on their initial firm sizes at the beginning quarter, 2006 Q3, so that we can check whether different types of firms respond to minimum wage changes differently. In the aggregated regression, our preferred models is the one with firm fixed effects, time effects and time-industry interaction terms. In addition to using the entire sample, which includes all relevant industries, we also run separate regressions for several broad industries, and in partic- 
ular low wage industries, such as retail trade and food/accommodation industries. In the regression for each broad industry, the preferred model includes firm fixed effects and time effects.

Once the employment effects are aggregated by using the total number of employees in each group as weight, we find the overall employment effects are always negative and significant across specifications and industries, within the range from $1.47 \%$ to $8.16 \%$ decrease in employment level with a $10 \%$ increase in minimum wage. The exceptions are the food/accommodation industry and the manufacturing industry, where the impacts are not statistically significant when time fixed effects are controlled. The strongest adverse effect from our preferred models is found in the construction industry, and the estimate with time fixed effects is -0.497 . For the regression including all relevant industries, the estimate is -0.166 with both firm and time fixed effects, and it is -0.149 if time-industry interaction terms are added. We do find firms have differential responses to the changes in the minimum wages. Small business firms with no more than 10 employees respond differently across industries. In food and accommodation, retail trade, manufacturing industries and the regression including all the relevant industries, we find positive employment effects. For firms with more than 10 employees, the disemployment effects are detected in most cases. If a firm does not have information in 2006 Q3, it is separated in a group. We find no evidence of job losses for newly emerging firms in this group. However, in the manufacturing industry, in which new firms could have procession of large-scale capital, the employment appear to grow with increasing minimum wage. In construction industry, the employment for new firms is reduced.

To further explore the minimum wage impacts, we also exploit individual information to examine the minimum wage impacts on the probability of being employed for people from different earning groups. So we divide individuals into five groups based on their initial quarterly earnings in 2006 Q3. The linear probability regression 
model for this individual-level analysis includes individual fixed effects, time fixed effects, seasonal terms and time trend term which are interacted with Missouri data. In general, including time fixed effects reduce the magnitude of estimated employment effects. Our estimation results still vary by industries. As expected, due to the substitution effects, the chance of being employed for higher earning people in increased. For people whose earnings are between $\$ 1.65$ to $\$ 4.55$, who are supposed to be directly affected by minimum wage increases, we cannot find the expected disemployment effects except for hotel and accommodation sectors. All other estimates are not significant at $10 \%$ level, suggesting minimum wages have no observable impacts on job opportunities. For people who work very few hours in each quarter, we find that their employment opportunities are reduced in retail trade and food industry, and the regression using the entire sample. Other than these, the estimates are insignificant. In addition, we separate Missouri and Kansas residents and check whether Missouri minimum wages have the power to detect the employment effects from our data. In particular, we examine how Missouri minimum wage impacts subsequent employment within the initial state and the labor movement across states. In general, our results indicate the continuous employment within states are reduced and the labor movements across borders are raised slightly by an increase in the minimum wage.

This dissertation will contribute to the minimum wage literature in the following ways. The CPS-based research has three major contributions. First, Burkhauser et al. (2000) estimate the employment effects of the minimum wage increases from 1979 to 1997, while Sabia (2009b) extends the analyses to 2004. My work uses monthly data from 1979 to 2011. Longer time periods provide new information that has not been examined since their work. Most importantly, in recent years, there is more state minimum wage variation that can be used for identification. Further more, my work not only covers the 10-year period with no increase in the federal minimum 
wage, but also covers the recession period that has not been discussed before. Second, Burkhauser et al. (2000) argue that it is papers that include year controls, which fail to find adverse employment effects of the minimum wage. By plotting the frequency and magnitude of the state minimum wage in variation in recent years, I point out that even though year fixed effects wipe out some federal minimum wage variation, there is still enough state minimum wage variation that can be used for identification. So I state that whether to include the year effects depends on the variation of state minimum wages. I also find that when division-specific year effects are taken into account, the disemployment effects still exist but are smaller. However, including state specific linear time trends in the model makes the estimate of $\log$ of the minimum wage insignificant. The minimum wage indexation appears to have no impact on the teenage employment.

Missouri - Kansas study makes several contributions to the literature as well. First, before the first Missouri minimum wage increase, there are several papers discussing the potential impacts of this policy. However, so far to our best knowledge, this research is the first to examine the actual employment effects after the Missouri minimum wage was implemented. Second, our Missouri and Kansas payroll data provide us a great opportunity to explore the employment effects, so that we can get a complete picture of the impacts and provide a better understanding of minimum wage impacts, not limited to a narrow sector or special group. Third, in the firm-level analysis, we not only estimate the overall employment effects, but also we disaggegate the data and report the estimates across industries and across different firm size groups. We do find the minimum wage impacts vary by industry and firm size. Last, in the individual-level analysis, we report estimates for different earnings groups to check the heterogenous effects, which is not always discussed in previous papers. In summary, our results in general vary across industries and across firm size or earning groups, which signal the need of future studies of heterogeneous effects among groups. 
The dissertation reaches several conclusions regarding the increase of statutory minimum wages. The empirical analysis undertaken in general suggests that minimum wage decreases employments. However, firms with less than 10 employees and newly emerging firms tend to increase employment with minimum wage increases. From the individual-level analysis, we find that minimum wages actually increase the chances of being employed for people with higher earnings, due to the substitution effects. For people whose estimated hourly wage rates are between $\$ 1.65$ and $\$ 4.55$, we get little or no effects. For people who work very few hours, most of the estimates are insignificant. But in industries with higher proportions of low wage workers, that is, in retail trade and food industries, the probability of being employed for these employees is reduced.

The nationwide debate on the minimum wage is active among US politicians. Our findings have valuable policy implications. Minimum wage policy is designed to help poor people by raising their incomes. However, the individual analysis shows that low earners, that is, individuals with estimated hourly earnings less than $\$ 4.55$, do not benefit from this policy. In contrast, we find positive effects on people with high earnings, which suggests minimum wage may go to people who do not need them and have a very limited influence on poverty. Our firm-level analysis and CPS-based research also consistently suggests minimum wage reduces the overall employment levels. For policy makers, our results could provide empirical grounds for them to consider the tradeoffs between the two policy goals, raising the income of poor people at the cost of creating unemployment. Our findings throw light on the importance of distinguishing between industries and between workers with different earnings.

This dissertation uses various methods to examine the employment effects of minimum wages. However, minimum wage can affect employment and market through other channels. The first channel is the reduction of working hours for current employees. As discussed above, we cannot find disemployment effects for low earners. 
One can argue that an employer can reduce number of hours worked for employees instead of firing them. This scenario cannot be examined using our data. The second channel is through changing the wages of higher earning individuals, whose earnings are not directly affected by minimum wage. When minimum wage increases, these people may experience a reduction in earnings. Other unobserved channels could be increasing product prices, changing in productivity, customer satisfaction, non-wage benefits and labor turnover rates. If the actual minimum wage impacts are the adjustments through the above channels, the employment effects should be smaller. So one limitation of this study is that all analysis focuses on examining the employment effects and does not explore other channel of adjustments, which are also very important regarding the minimum wage impacts. Another important limitation is in regard to our need to limit certain Missouri and Kansas data. Because of data construction differences, we need to limit the analysis to firms with only one location, with 1 - 50 employees and those existing before 2007 Q4. Consequently, we cannot test how minimum wage affect small business creation or examine the effects on large or multiplication firms. One more limitation is that our data is only for Missouri and Kansas, so our individual-level analysis do not include individuals who move out of these states or out of labor force.

The limitations of this dissertation indeed suggest several opportunities for future studies. Given the data limitation, we cannot check whether the minimum wage impacts differ among demographic groups, which would be a topic for further studies. In the firm-level Missouri-Kansas analysis,we focus on the changes of employment levels. The impact on firm's creation and destruction is also an area worthy of research. From another prospective, employment effects are not the only area relevant to the impacts of minimum wage increases. More studies are needed to discuss other channels of adjustments regarding the minimum wage changes. One should check whether employers respond the increasing cost by reducing working hours for cur- 
rent employees. In addition, our payroll data cannot distinguish between full time and part time jobs on hours. Further analysis can construct full-time equivalent employment given these two kinds jobs can be identified separately or check the composition shift between these two. In addition, directly relevant to policy-making, one could discuss whether minimum wage increases can succeed in reducing poverty and inequality. Another respect is regarding the labor movement between covered and uncovered sectors. Since Missouri minimum wage has the exemption rule, one can separate firms into minimum wage covered firms and minimum wage exempted firm and further check the spill-over effects. 


\section{Appendix A}

\section{Geographic Codes}

\section{A.1 Missouri}

In the Missouri data, there are two measures that identify county. One is "FIPS", which is a part of a description of employer identifier (EAN) in UI-employee record. The other one is the "county" measure, obtained from IRS records. After talking to the staff in Missouri labor deparment, we decide to use "county" measure. We have the following problems with regard to those geographic codes. ${ }^{1}$

\section{A.1.1 Invalid Codes}

In each quarterly Missouri data set, there are around 3,000,000 records, each of which identifies earnings paid by a particular employer to a particular employee. However, only about $50 \%$ of the records are associated with valid geographic codes, no matter which location measure is used. Here, "valid" means the codes can be used to uniquely identify the counties in Missouri. A small number of the invalid codes are very likely due to input error or other kinds of errors. There are several invalid codes worth mentioning, since they account for significant parts of the data. Table A.1 lists an example of some typical invalid "county"codes in the first quarter of 2012. As one

\footnotetext{
${ }^{1}$ This summary only includes several major tables. All other tables are available upon request.
} 


\begin{tabular}{|c|c|c|}
\hline invalid codes & meaning & percentage measured by "county" \\
\hline 415 & - & $1.01 \%$ \\
\hline 900 & State Wide locations & $39.91 \%$ \\
\hline 995 & State Wide: used for salesmen & $3.39 \%$ \\
\hline 999 & State Wide: primary location is unknown & $1.15 \%$ \\
\hline valid code & uniquely identify the county & $54.54 \%$ \\
\hline
\end{tabular}

Table A.1: Percentages of Some Major Invalid Codes in 2012 Q1 in Missouri Data

can see from the table, the sums of the four invalid codes listed for both measures are around $45 \%$ of the total observations in a given quarter. Code "900" and "999" both mean statewide locations. The difference between them is that " 900 " are more likely to be associated with chain stores like Walmart, while "999" means no primary location or the primary location is unknown. When "county" measure is used, "900" accounts for $39.91 \%$ of the total employee records in that quarter and "999" is only $1.15 \%$ of the data. In practice, since neither of these codes can identify the counties, in the analysis, we just combine them as missing.

\section{A.1.2 Multiple "County" Codes for One Employer ID}

Another concern is whether all records with the same employer id have the same geographic code. There are two possible situations of this multiple code problem. The first situation is that one employer is associated with both valid and invalid geographic codes. The other situation is that multiple valid geographic codes can be found with one employer. After some checking, in Missouri data, the most common case is one employer with one valid "county" code. The next common case is one employer with only invalid code(s). Both situations of the multiple code problem can be found in the data, but neither of the situations has a percentage higher than $3 \%$, so we believe that excluding records in these two situations do not affect our analysis. 


\begin{tabular}{|c|c|c|c|c|c|c|}
\hline \multicolumn{9}{|c|}{2012 Q1 (1440007) } & \multicolumn{2}{|c|}{2009 Q2 (1492565) } & \multicolumn{2}{|c|}{2006 Q3 (1562558) } \\
\hline FIPS & frequency & percentage & frequency & percentage & frequency & percentage \\
\hline $\begin{array}{c}\text { valid county } \\
\text { code }\end{array}$ & 1422126 & $98.76 \%$ & 1470312 & $98.51 \%$ & 1530833 & $97.97 \%$ \\
\hline 397 & 2023 & $0.14 \%$ & 3173 & $0.21 \%$ & 5013 & $0.32 \%$ \\
\hline 399 & 6125 & $0.43 \%$ & 7404 & $0.50 \%$ & 12774 & $0.82 \%$ \\
\hline 900 & 528 & $0.04 \%$ & 273 & $0.02 \%$ & 249 & $0.02 \%$ \\
\hline 995 & 1422 & $0.10 \%$ & 2880 & $0.19 \%$ & 2544 & $0.16 \%$ \\
\hline 999 & 4678 & $0.32 \%$ & 4639 & $0.31 \%$ & 6357 & $0.41 \%$ \\
\hline all others & 3065 & $0.21 \%$ & 3884 & $0.26 \%$ & 4774 & $0.31 \%$ \\
\hline $\begin{array}{c}\text { border } \\
\text { counties }\end{array}$ & 515699 & $35.81 \%$ & 524823 & $35.16 \%$ & 549885 & $35.19 \%$ \\
\hline
\end{tabular}

Table A.2: Frequency Checks for Kansas County Code

\section{A.2 Kansas}

The construction of Kansas data is different from Missouri data. Table A.2 is a basic frequency check of the county code in the Kansas data. In Missouri data, only half of the employee records are associated with valid location codes. In Kansas data, over $98 \%$ of the cases have valid county codes.

\section{A.2.1 Multiple FIPS Codes for One Employer ID}

The next step is to check whether Kansas data has the multiple code problem. To test this, we divide employers into five groups by the size of employment( 1-9 employees, 10-49 employees, 50-99 employees, 100-499 employees and more than 500 employees). In each group category, there are very few employers having more than one FIPS code. The total number of employee records is less than $4 \%$ of the data.

For the group with more than 500 employers, in most quarters only 5 to 6 employers have multiple area codes. They are very large employers, with a total number of more than 50,000 employees. Since the total proportion of these cases is less than $4 \%$ of the data and very few employers are involved, we decided to exclude these cases 
from the analysis.

\section{A.2.2 Difference in DATA Construction}

The difference between Missouri and Kansas data needs to be emphasized. As mentioned before, only around $50 \%$ of Missouri records have valid location codes, no matter which location measure is used. But in Kansas data, almost all records have valid location codes. Some invalid codes in Missouri refer to statewide locations, such as "900" and "999". Multiple locations are very common for large firms or chain stores, like Walmart or Macdonald's. In Missouri data, these firms are very likely to be assigned invalid codes. There is no way to identify their locations. In contrast, in Kansas data, these firms are included in the data and they are assigned different FIPS codes or same FIPS code based on the primary locations. Clearly, Kansas data is constructed differently from Missouri data. 


\section{Appendix B}

\section{Industry Codes}

\section{B.1 Missouri - NAICS code}

In the Missouri data, we use the NAICS (North American Industry Classification System) code to identify industry. Most Missouri firms can be classified by the NAICS code.

\section{B.2 Kansas - SIC code}

\section{B.2.1 Missing SIC Code}

In the Kansas data, the industry identifier is the SIC (Standard Industrial Classification Code), the code used prior to the NAICS. The US started to implement the NAICS codes in 1997. This change causes one problem in Kansas data. Table B.1 is a frequency check of industry categories using the first two digits of the SIC codes in Kansas data. What we need to pay attention to here is the dramatically increasing number of the records with missing SIC code. In 2006 Q3, there are only 639 missing cases, which account for $0.04 \%$ of the data. In 2009 Q2, this percentage increases to 7.86\%. At the end, in 2012 Q1, 242,598 cases are assigned missing SIC code. These 


\begin{tabular}{|c|c|c|c|c|c|c|c|}
\hline \multicolumn{8}{|c|}{ SIC check for Kansas } \\
\hline & & \multicolumn{2}{|c|}{$2006 Q 3$} & \multicolumn{2}{|c|}{ 2009Q2 } & \multicolumn{2}{|c|}{$2012 Q 1$} \\
\hline SIC & industry & frequency & percent & frequency & percent & frequency & percent \\
\hline . & missing & 0 & $0.00 \%$ & 9 & $0.00 \%$ & 1 & $0.00 \%$ \\
\hline 00 & missing & 639 & $0.04 \%$ & 117271 & $7.86 \%$ & 242598 & $16.85 \%$ \\
\hline $01-09$ & $\begin{array}{c}\text { Agriculture, } \\
\text { Forestry, and } \\
\text { Fishing }\end{array}$ & 23253 & $1.49 \%$ & 21142 & $1.42 \%$ & 17463 & $1.21 \%$ \\
\hline $10-14$ & Mining & 11822 & $0.76 \%$ & 9621 & $0.64 \%$ & 9964 & $0.69 \%$ \\
\hline $15-17$ & Construction & 83503 & $5.34 \%$ & 64397 & $4.31 \%$ & 49071 & $3.41 \%$ \\
\hline $20-39$ & Manufacturing & 215784 & $13.81 \%$ & 176416 & $11.82 \%$ & 146960 & $10.21 \%$ \\
\hline $40-49$ & \begin{tabular}{|c|} 
Transportation, \\
communications, \\
Electic, gas and \\
Sanitary \\
\end{tabular} & 88501 & $5.66 \%$ & 62360 & $4.18 \%$ & 53055 & $3.68 \%$ \\
\hline $50-51$ & Wholesale Trade & 82737 & $5.29 \%$ & 73439 & $4.92 \%$ & 64812 & $4.50 \%$ \\
\hline $52-59$ & Retail Trade & 307231 & $19.66 \%$ & 260059 & $17.42 \%$ & 224324 & $15.58 \%$ \\
\hline $60-67$ & $\begin{array}{c}\text { Finance, } \\
\text { Insurance and } \\
\text { Real estate }\end{array}$ & 77317 & $4.95 \%$ & 69316 & $4.64 \%$ & 59828 & $4.15 \%$ \\
\hline $70-89$ & Services & 588757 & $37.68 \%$ & 554190 & $37.13 \%$ & 500519 & $34.76 \%$ \\
\hline $91-99$ & $\begin{array}{c}\text { Public } \\
\text { Administration }\end{array}$ & 83010 & $5.31 \%$ & 84342 & $5.65 \%$ & 71404 & $4.96 \%$ \\
\hline
\end{tabular}

Table B.1: Kansas Frequency Check for SIC Industry Code

cases account for $16.85 \%$ of the data. As a comparison, the percentages of missing NAICS cases in Missouri data are very small and consistent over quarters. The reason for the increasing number of missing SIC records is the construction of SIC codes in Kansas data. It appears that Kansas's labor agency stopped assigning SIC codes to newly established firms in the end of 2007. As a result, they are identified as missing SIC cases in the data.

\section{B.2.2 Converting SIC to NAICS}

\section{B.2.2.1 Matching Problems}

One important difference between the SIC code and the NAICS code is that the NAICS divides industries into more detailed categories and includes some newly emerging industries. In other words, Missouri data are divided into more industry groups using the NAICS codes. In our analysis, we use the NAICS codes to identify 
industries, so we need to make sure that the firms from Missouri and Kansas are compared in the same industry category. One task for us is to precisely convert the SIC codes in Kansas data into the NAICS codes. Converting can be done primarily by using the crosswalks provided online ${ }^{1}$.

In general, the conversion process is smooth. However, we do find two problems when we translate SIC to NAICS. The first one is that the NAICS reclassifies some industry categories, which causes one four-digit SIC code to match with several different NAICS broad categories. At first, if one 4-digit SIC code corresponds to multiple NAICS broad categories, we assign this SIC code as missing. However, if these kinds of SIC codes are all excluded, the resulting conversion causes $40 \%$ of the records from Kansas border counties to be missing NAICS. In such cases, we also use 2006 Q4 ${ }^{2}$ Missouri data as a reference. since Missouri data includes both SIC and NAICS codes for many firms. This allows us to check in practice how SIC is matched with NAICS.

The other problem is that NAICS assigns new codes for some emerging industries. For example, the NAICS broad category " 55 " is for management of companies and enterprises. We cannot find any matching category in the SIC system. As a result, in our analysis, Missouri firms in this category do not have any matching cases in Kansas data. We have chosen to exclude Missouri firms with NAICS code " 55 " from the analysis. This exclusion will not bias our results for two reasons. The first reason is that records in this category are always less then $2 \%$ of the data. The other reason is that this code is for management, so minimum wages are not likely to be effective for employees in this category.

In the official crosswalk, one four-digit SIC code could be matched to different NAICS codes and these NAICSs are from different broad two-digit categories. If this is the case, we ignore this sic code if there is no way to find a primary corresponding

\footnotetext{
${ }^{1}$ The reference website is www.naics.com

${ }^{2}$ Missouri started to implement its state minimum wage in January 2007. 2006 Q4 is the last quarter before state minimum wage implementation. In order to minimize the industrial difference between the two states, we use this quarter as a reference.
} 
NAICS code. Primary means that at least $80 \%$ observations that are associated with this particular SIC code can be translated into one two-digit NAICS code. If there is a primary NAICS, we do the revision by making all cases converted to this NAICS. If not, we cannot match this SIC code with NAICS.

\section{B.2.2.2 Logic of Consistency Check}

Because of the matching problems, the first step we need to do is to check whether the NAICS code is consistent with SIC code in the data, that is, for each given employer, NAICS and SIC should link to the same industry. The logic for this consistency check is illustrated in figure B.1.

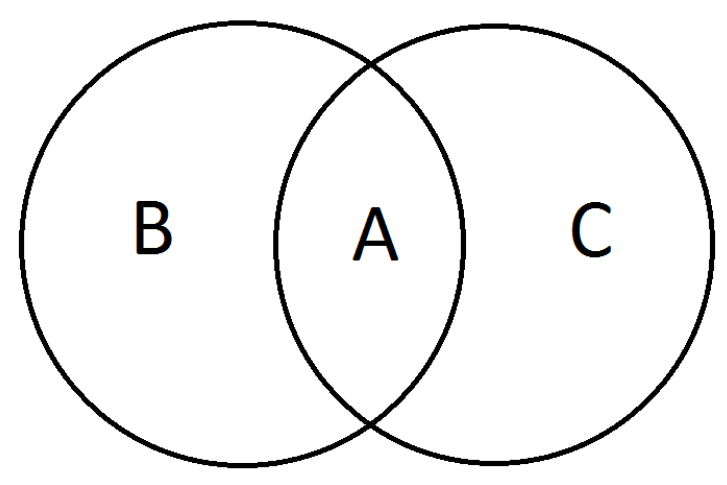

Figure B.1: Illustration of the SIC-NAICS Consistency Check

As mentioned above, we can use Missouri data to check the consistency, since Missouri data have both SIC and NAICS codes. The left circle represents the firms for which the SIC code is translated into the corresponding NAICS code, and the right one is for the firms that are actually classified in the industry by NAICS code. The intersection A means that both codes classify a firm in the same industry. B means that a case is classified as the given industry based on the SIC code, but it is not so classified by the actual NAICS. C is the opposite, it is the cases that are in 
the specified industry but are not so classified in the conversion from SIC to NAICS. We are inerested in the following two ratios:

$\frac{C}{A+B}$ : returns the false negative, which shows the cases that should be in the industry but are not so classified.

$\frac{B}{A+B}$ : indicates the false positive, which corresponds to the cases that should not be in the industry but are so classified.

This matching check is done for all broad NAICS industries using Missouri 2006 Q3 data, which includes both SIC and NAICS for most firms. In some industry, the check is done for different firm size groups.

\section{B.2.2.3 Revision Procedures}

In order to better utilize our data, instead of throwing out cases where matches were imperfect during the conversion process, we decide to revise some NAICS in the following two ways so that the false negative and false positive ratios are minimized.

First, in the official crosswalk, one four-digit SIC code could be matched to more than one NAICS code and these NAICSs were from different broad two-digit categories. If this is the case, by using 2006 Q3 Missouri data, we try to find if there is a primary corresponding NAICS code. Primary means that at least $80 \%$ observations that are associated with this particular SIC code can be translated into the same one two-digit NAICS code. If there is a primary NAICS, we do the revision by making all cases converted to this NAICS. If not, we cannot match this SIC code with NAICS and have to exclude all cases associated with this particular SIC code.

Second, we eliminate some detailed NAICS codes if one four-digit SIC code corresponds to many six-digit detailed NAICS codes, which are in different broad two-digit industries. Once some of the datailed NAICS codes are eliminated from the broad category, the rest can be correctly predicted by the crosswalk. This process is done with caution, since one problem here is that although these detailed NAICS codes 
are not the primary NAICS code for this particular SIC and account for very small percentages of the SIC observations, they may be associated with many observations in the data and are the primary NAICS for other SIC codes. If this is the case, they can not be eliminated.

\section{B.2.2.4 SIC-NAICS Revision Details ${ }^{3}$}

Firstly, if there are any inconsistencies between the official crosswalk and the constructed crosswalk based on Missouri 2006 Q3 data, we decide to follow the constructed crosswalk. Some SIC codes are revised to the following NAICS broad categories. The four-digit numbers are the SIC codes. The two-digit numbers in the parenthesis are the broad NAICS codes after revision.

2731(32); 3312(81); 3812(56); 3821(56); 2873(54); 7231(81); 5963(45); 5032(42); $8699(81) ; 5199(54)$.

Secondly, the SIC-NAICS conversion uses the primary NAICS, when the official crosswalk specifies more than one broad SIC category. As above, the four-digit numbers are the SIC codes, and the two-digit numbers in parenthesis are the broad NAICS codes after revision.

2771(32); 2819(32); 3732(33); 3721(33); 3731(33); 3769(33); 3761(33).

Thirdly, Eliminate some SIC codes that are not associated with any primary NAICS codes. Followings are the SIC codes eliminated.

$3546 ; 3961 ; 5023 ; 5074 ; 5191 ; 5143 ; 5147 ; 5441 ; 4225 ; 5194 ; 1795 ; 2448 ; 3086$; $3231 ; 7622 ; 5162 ; 3272 ; 3555 ; 3999 ; 5021 ; 5032 ; 5045 ; 5083 ; 5091 ; 5199 ; 5712 ; 5714$; $5719 ; 5731 ; 5961 ; 5992 ; 7378 ; 7629 ; 4724 ; 7389 ; 8999 ; 5039 ; 7536 ; 7549 ; 7623 ; 7631$; $7694 ; 7991 ; 1522 ; 1531 ; 2791 ; 3341 ; 3825 ; 7323 ; 8243 ; 8741$.

Lastly, Eliminate some detailed NAICS codes. Followings are the six-digits NAICS codes eliminated.

\footnotetext{
${ }^{3}$ Two associated tables are upon requests. One is the SIC-NAICS matching before revision, and the other is the SIC-NAICS matching after revision.
} 
332999; 337127; 332420; 333923; 332420; 333923; 488210; 522298; 336120; 331222; 331513; 332992; 237310; 311812; 315233; 315299; 314121; 334611; 332611; 334518; 334310; 488210; 493110; 485999; 562111; 481212; 454390; 488410; 423740; 561110; 441310; 453210; 339914; 337127; 446199; 532291; 331221; 551114. 


\section{Appendix C}

\section{Missouri Payroll-to-Revenue Ratio}

\begin{tabular}{|c|c|c|c|c|}
\hline NAICS & industry $\ln \mathrm{MO}$ & sales(\$1000) & annual payroll( $\$ 1000)$ & ratio \\
\hline 11 & Agriculture, Forestry, Fishing and Hunting(US) & $37,303,380$ & $5,551,415$ & 0.1488 \\
\hline 21 & Mining, Quarrying, and Oil and Gas Extraction & 976,540 & 161,177 & 0.1650 \\
\hline 22 & Utilities & $13,107,447$ & $1,183,543$ & 0.0903 \\
\hline 23 & Construction & $35,462,821$ & 164,362 & 0.0046 \\
\hline $31-33$ & Manufacturing & $110,907,604$ & $12,996,508$ & 0.1172 \\
\hline 42 & Wholesale Trade & $117,328,998$ & $5,801,793$ & 0.0494 \\
\hline $44-45$ & retail trade & $76,575,216$ & $7,155,282$ & 0.0934 \\
\hline $48-49$ & Transportation and Warehousing & $14,974,422$ & $3,277,280$ & 0.2189 \\
\hline 51 & Information(US) & $1,072,342,856$ & $228,836,587$ & 0.2134 \\
\hline 52 & Finance and Insurance(US) & $3,669,302,691$ & $502,416,670$ & 0.1369 \\
\hline 53 & Real Estate and Rental and Leasing & $7,186,291$ & $1,248,765$ & 0.1738 \\
\hline 54 & Professional, Scientific, and Technical Services & $19,915,650$ & $7,539,559$ & 0.3786 \\
\hline 55 & Management of Companies and Enterprises & $2,030,836$ & $4,920,613$ & 2.4229 \\
\hline 56 & ve and Support and Waste Management and Remedia & $8,622,236$ & $3,998,164$ & 0.4637 \\
\hline 61 & Educational Services & 498,859 & 161,018 & 0.3228 \\
\hline 62 & Health Care and Social Assistance & $32,886,620$ & $12,918,598$ & 0.3928 \\
\hline 71 & Arts, Entertainment, and Recreation & $3,411,405$ & $1,254,452$ & 0.3677 \\
\hline 72 & Accommodation and Food Services & $11,070,634$ & $3,109,147$ & 0.2808 \\
\hline 81 & Other Services (except Public Administration) & $6,770,667$ & $1,799,903$ & 0.2658 \\
\hline 92 & Public Administration & & & \\
\hline
\end{tabular}

The calculation is based on data from 2007 Economic Census Industry Series

data source: http://factfinder2.census.gov/faces/tableservices/jsf/pages/productview.xhtml?pid=ECN_2007_US_00A1\&prodType=table

note: Information for "Public Administration" is not reported from the same source.

Table C.1: Missouri Payroll-to-Revenue Ratio, Based on 2007 US Census 


\section{Appendix D}

\section{Discontinuous Records}

In each quarter, there are some newly emerging firms and some firms cease to exist. At the same time, some firms merge into other ones. All these situations lead to discontinuous employer identification in the data. We need to deal with the discontinuous records in both Missouri and Kansas data. In order to test what exactly happen in the data, we run several tests. In general, we decide to address discontinuous records in the following ways. We use 7 employees in a firm as the cut-off. If the firm has less than 7 employees, it is hard to decided whether the firm ceases to exist or just changes the name. If the firm has more than 7 employees and most of the employees move to another firm, it is reasonable to conclude that this firm may change the ID title or merge into another firm. We'll use the information from the "old" firm to deal with these records, not simply treating them as new emerging firms.

Table D.1 below lists all the notation used in this section. The first test is to check the distribution of ratio $N_{12} / N_{1}$, from which we can know how many employees who work in quarter 1 continue to work in the same firm in quarter 2 . If this ratio is between 0 and 0.1 , it may suggest that the firm is experiencing some change or ceases to exist in quarter 2. Our data range is from 2006 Q3 to 2012 Q1, so we check 22 quarter-pairs by industry ${ }^{1}$. The average percentage for range $0-0.1$ is around $6 \%$. This number varies by industry and by quarter. In some cases, this number is even

\footnotetext{
${ }^{1}$ All checking tables in this appendix are not included and upon request.
} 


\begin{tabular}{|c|c|}
\hline notation & meaning \\
\hline \hline$N_{1}$ & for each employer, employees in quarter 1 \\
\hline$N_{2}$ & for each employer, employees in quarter 2 \\
\hline$N_{12}$ & for each employer, employees work in both quarters \\
\hline$N_{12}^{\prime}$ & employees who do not work in this firm, but are employed in other \\
& firms in quarter 2 \\
\hline$N_{12}^{\prime \prime}$ & $N_{12}^{\prime}$ employees in the largest alternative firm in quarter 2 \\
\hline$N_{2}^{\prime}$ & all employees in the largest alternative firm in quarter 2 \\
\hline
\end{tabular}

Table D.1: Notations and Meanings for Discontinuous Records Check

higher than $10 \%$. We also observe some seasonal patterns in the data. This number is more likely to be higher during the end of the year and during the recession periods.

From the first test, we can confirm the nontrivial existence of the discontinuous cases. However, we still have no information about the specific situation for each employer. There are several possibilities to cause the ratio $N_{12} / N_{1}$ to be low. The first possibility is that the firm is closed. All employees have to find jobs in other companies. The second possibility is that the firm may change the title or switch business to another industry. This situation causes the change of employer id code, which is shown as discontinuous cases in the data. However, most employees still work in the same firm. The last possibility is merging. Many employees move together from this firm to another firm. The next test is designed to distinguish between these possibilities for each alternative firm. Here, our analysis focuses only on the firms within the 0-0.1 $N_{12} / N_{1}$ ratio range. For each employer, $N_{1}-N_{12}$ is the complement of $N_{12}$ in $N_{1}$, which includes the employees who do not work in this firm any more. Then, we check whether these employees are still being employed in quarter 2 in other firms by finding the intersection of $N_{1}-N_{12}$ and $N_{2}:\left(N_{1}-N_{12}\right) \cap N_{2}=N_{12}^{\prime}$. These employees are sorted by the employer ids of the alternative firms. $N_{12}$ " is the $N_{12}^{\prime}$ employees who work in the firm with the most workers from a given firm in quarter 2. We check the distribution of ratio $N_{12} " / N_{1}$. If this ratio is high, that is in the range (0.7-1), it means that most employees from the old firm still work together 
in one alternative firm, which suggests the possibility that the firm may change the employer id code or merge. Small firms are more likely to have these changes. So we pay particular attention to the small firms by checking the distribution of ratio $N_{12} " / N_{1}$ by different firm $\operatorname{sizes}\left(N_{1}\right)$. Except for the firms with only one employee, the percentage of ratio range $0.7-1$ is from $0.0 \%$ to $11.5 \%$. The most common ones are from $5 \%$ to $6 \%$. These results confirm that some firms may just change employer id codes or merge into other firms. This percentage exhibits seasonal pattern as well. It is relatively high during the end of the year.

The next test can help us to know whether the firm changes the id code or merges. What we do is to find the total number of employees in the firm with the most workers from a given firm of $N_{12}^{\prime}$ employees, and it is labeled as $N_{2}^{\prime}$. For each $N_{1}$ employer, these is a corresponding largest alternative employer $N_{2}^{\prime}$. Then, we check the distribution of ratio $N_{12}$ " $/ N_{2}^{\prime}$. This ratio tells us what proportion of employees in this firm is from the discontinued firm. For a given discontinued employer, if the ratio $N_{12} " / N_{1}$ is high but this ratio $N_{12} " / N_{2}^{\prime}$ is low, it suggests that this firm may be taken over by another firm. If both ratios are high, the situation may be the same firm changes employer id code.

By testing the above possibilities, we can check whether a firm exists the market or merges into other firms. If it is a firm changes title or merges into other ones, we will track firm information from new name firm or firm that the old one merged into, so that we can get continuous records for the employees in these firms.

In Missouri data, two variables can be used to identify employers. One is called "empid", which is from UI-employee record. The other is "FEIN" number, which is the federal tax ID from IRS. When one employer starts a new business, the "empid" code is changed but the "FEIN" code remains the same. The above test results are obtained by using "empid" code. We then reproduce the results using "FEIN" code. There are no significant difference between two sets of results. The only difference is 
that less than $1 \%$ of the data are missing the FEIN code. We have to exclude these records from this analysis. In addition, we use "empid" as the employer identifier in the analysis. 


\section{Appendix E}

\section{Restrictions Based on Missing}

\section{Counties and Industry Codes}

\section{Conversion for Firm-Level Analysis}

This appendix summarizes the general selection rules for the firm level analysis. The selection rules are based on two checks based on Missouri data. Our first concern is the Missouri firms that are missing counties codes. Our second concern is that the number of cases where the translation from SIC to NAICS is not successful. We examine both industries and firm sizes ${ }^{1}$. The firm level ananlysis will in general follow the rules below and the results are presented in table E.1.

For each firm size group within each broad industry, we select industries and firm sizes, such that :

1. more than $80 \%$ of the observations are associated with valid county codes.

2. less than $10 \%$ of the observations fall in the "false positive" and "false negative" categories

Table E.1presents tabulations on which our selection was based. Categories indi-

\footnotetext{
${ }^{1}$ Results for these two checks are not included and are available upon request.
} 


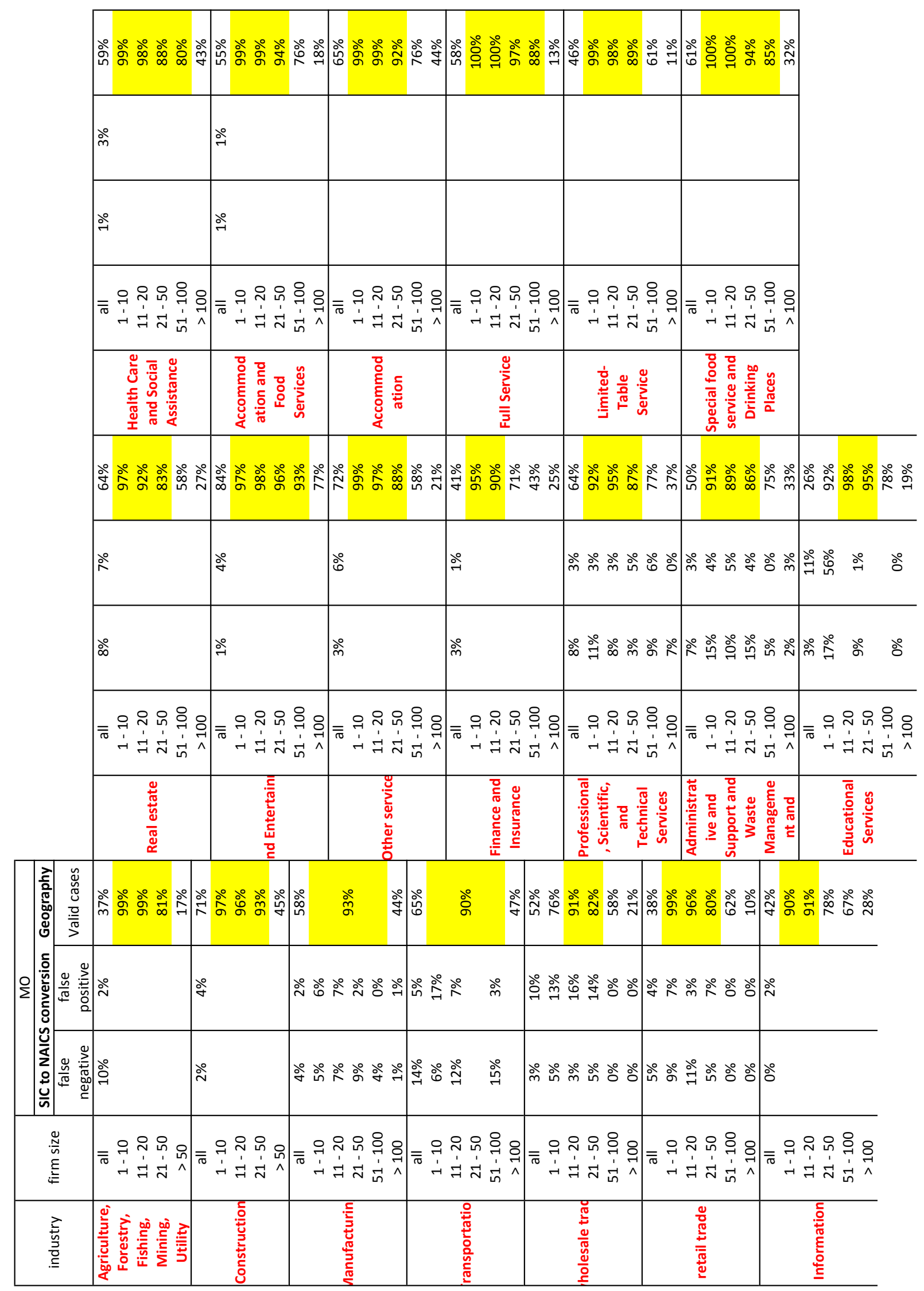


cated by shadings are those that meet our selection criteria. The selection summary is shown in table E.2.

\begin{tabular}{|c|c|}
\hline Industry & Firm Size in the Analysis \\
\hline Agriculture, Forestry, Fishing, Mining, Utility & - \\
\hline Construction & $1-50$ \\
\hline Manufacturing & $1-100$ \\
\hline Transportation & - \\
\hline Wholesale trade & - \\
\hline Retail trade & $1-50$ \\
\hline Selective Industry Combined & $1-20$ \\
Information & $1-50$ \\
Real Estate & $1-100$ \\
Art and Entertainment & $1-50$ \\
Other service & $1-20$ \\
Finance and Insurance & $1-50$ \\
Educational Services & $11-50$ \\
Professional, Scientific and Technical Services & $1-100$ \\
Health Care and Social Assistance & - \\
Administrative and Support and Waste & \\
Management and Remediation Services & \\
\hline Accommodation and Food Services & \\
\hline
\end{tabular}

Table E.2: Summary of the Restriction Rule 


\section{Appendix F}

\section{Bumps in Kansas Border}

\section{Employment Level Plot}

Figure 1a shows that for all firms in Missouri and Kansas, the employment levels follow similar patterns. However, once we limit data to border firms, the plot of Kansas border firms shows several oddities. In general, the bumps are due to the coding on the original Kansas files being inconsistent from one quarter to the next. The problem is shown in the following figures. Figure F.1 and F.2 are the employment level plots of the six Kansas city area counties in Kansas, shown separately. One can notice that all the employment levels follow similar patterns except for Wyandotte county, which exhibits similar bumps as the the plot of all Kansas border firms. So the bumps are solely caused by the coding for Wyandotte county.

In Kansas data, there are two firm identifiers. One is "fedid" number. For multiple location firms, the parent firm and all the subordinate establishments are assigned the same fedid number. The other identifier is "serial" number. This is the number assigned to each establishment. As a result, fedid can identify firms with multiple locations. Those bumps appear to be caused by some multi-location firms switching primary locations, so that their records jump in and out of the border counties. When 


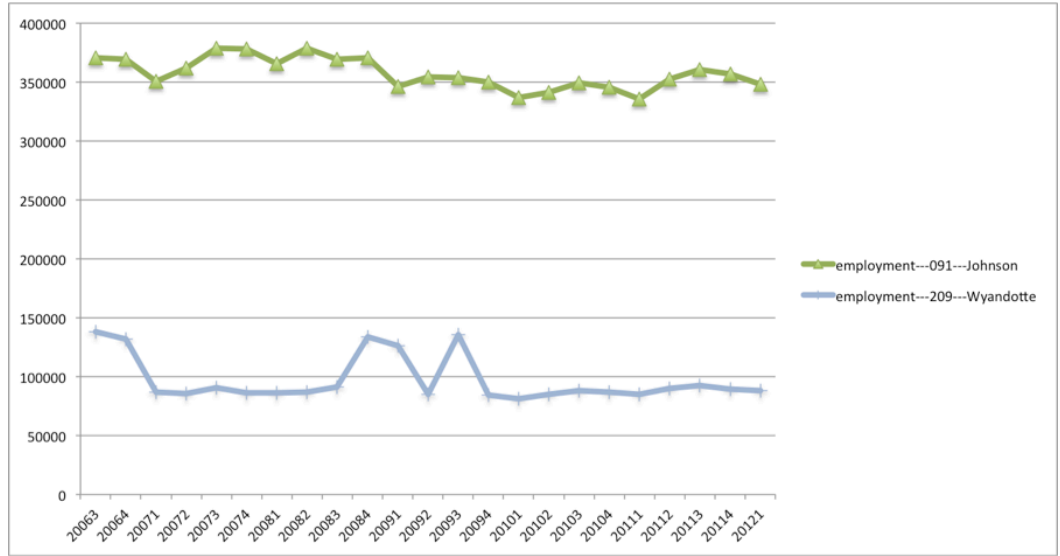

Figure F.1: Employment Level Plot of Johnson and Wyandotte in Kansas

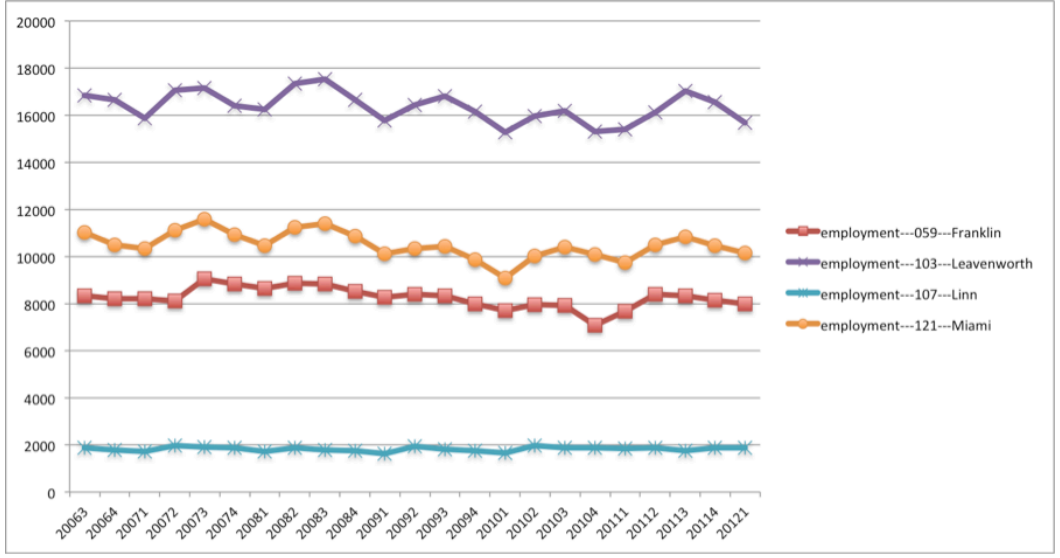

Figure F.2: Employment Level Plot of Leavenworth, Miami, Linn and Franklin

we use "fedid" as the firm identifier and limit Kansas border firms to single location firms, each "fedid" only corresponds to one unique county measure. All bumps disappear, and it is shown in Figure F.3. 


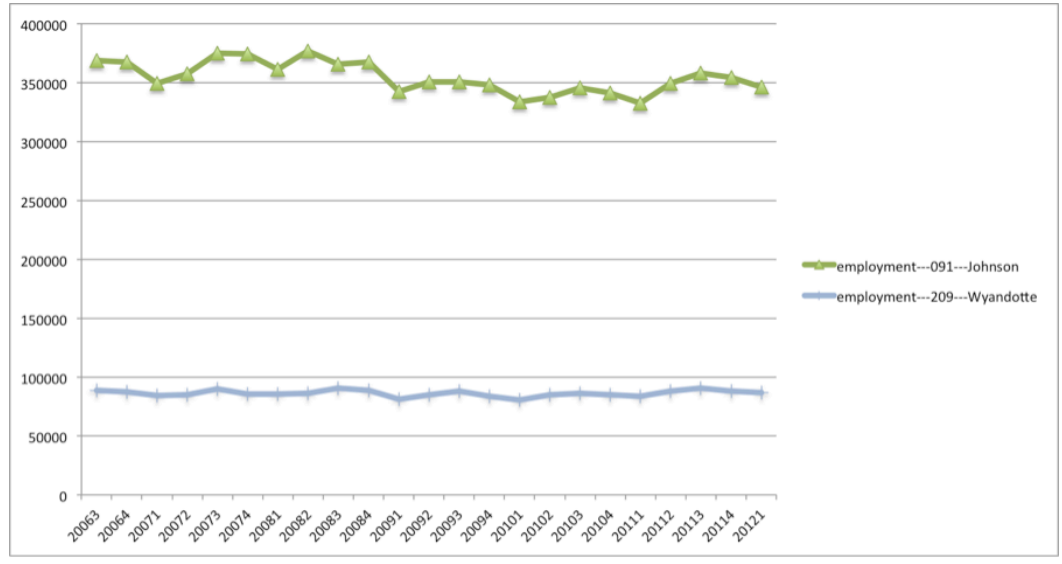

Figure F.3: Employment Level Plot of Johnson and Wyandotte after Limiting to No-Multi Location Firms 


\section{Appendix G}

\section{Procedures to Construct Data for DID Analysis}

This appendix lists the detailed procedures to select Missouri and Kansas data for the DID analysis.

\section{G.1 Missouri Part}

1. Calculate estimated annual revenue for each firm. In order to apply the $\$ 500,000$ exemption rule, we need to estimate each firm's revenue in previous years. First, firms' annual payrolls from 2005 to 2012 are calculated by summing four quarters' payroll earnings. Then, we use the industry average payroll-to-revenue ratios to calculate the estimated annual revenue for each firm. The ratios are based on the 2007 economic census data ${ }^{1}$.

2. Several dummies are added to the data. The first dummy is for construction, which equals 1 if a firm is in construction industry. The next dummy is for excluded firms. It is equal to 1 if a firm's NAICS code is missing, or a firm is in the management industry, with NAICS code 55, or a firm is in public administrative service industry,

\footnotetext{
${ }^{1}$ See appendix $\mathrm{C}$
} 
with NAICS code 92, or a firm with NAICS 99, meaning unknown industry. Another dummy is for exempted firms. It is equal to 1 if a firm is not in construction or excluded industries and has a past year estimated revenue less than $\$ 500,000$. Next is a dummy for minimum wage covered firms. This dummy equals 1 if a firm is not in construction or excluding industries and has a past year estimated revenue greater than $\$ 500,000$. The last dummy is for new firms, which equals 1 if a firm does not have any record in previous four quarters and is not in excluding industries or construction. After adding these dummies, a check is done to make sure that all dummies sum to one for each firm, so that categories are exclusive.

3. Calculate each firm's total employment by simply counting the number of employees in each firm.

4. Find the firms that existed before 2007 Q4. Since after 2007 Q4, new Kansas firms were assigned 0000 SIC code, there is no way to identify the industries for these firms. In order to make Missouri firms comparable to Kansas firms, the analysis is limited to the firms that existed before 2007 Q4. In other words, our analysis is limited to firms that exist from 2006Q3 to 2007Q4. The analysis uses their information up to 2012 Q1.

5. Select data. First, firms are limited to border counties (013025037047049 095107165 177). Second, firms are limited to minimum wage covered firms, ie, firms are either in the construction industry or in firms with more than $\$ 500,000$ prior year estimated revenue. As noted above, the analysis is limited to the firms that existed before 2007Q4.

6. Separate results for each broad industries ${ }^{2}$.

7. DID for two quarters: The analysis is limited to firms that existed in the first quarter of the two.

\footnotetext{
${ }^{2}$ See Table E.2 as a reference.
} 


\section{G.2 Kansas Part}

Other than the previous seven steps, Kansas data require two more steps.

1.Convert SIC to NAICS based on official crosswalk and revision.

2. Find the firms that have multiple locations or change locations over quarters and exclude them from the analysis.

\section{G.3 Another Set of DID Results}

At first, the $\$ 500,000$ Missouri minimum wage threshold is strictly applied. Then, it is relaxed to $\$ 400,000$, which is $20 \%$ lower than the original one. By doing this, more

firms are included in the analysis, and we can check whether the results differ or not. 
Appendix $\mathrm{H}$

Estimation Results for the DID

Robustness Check 


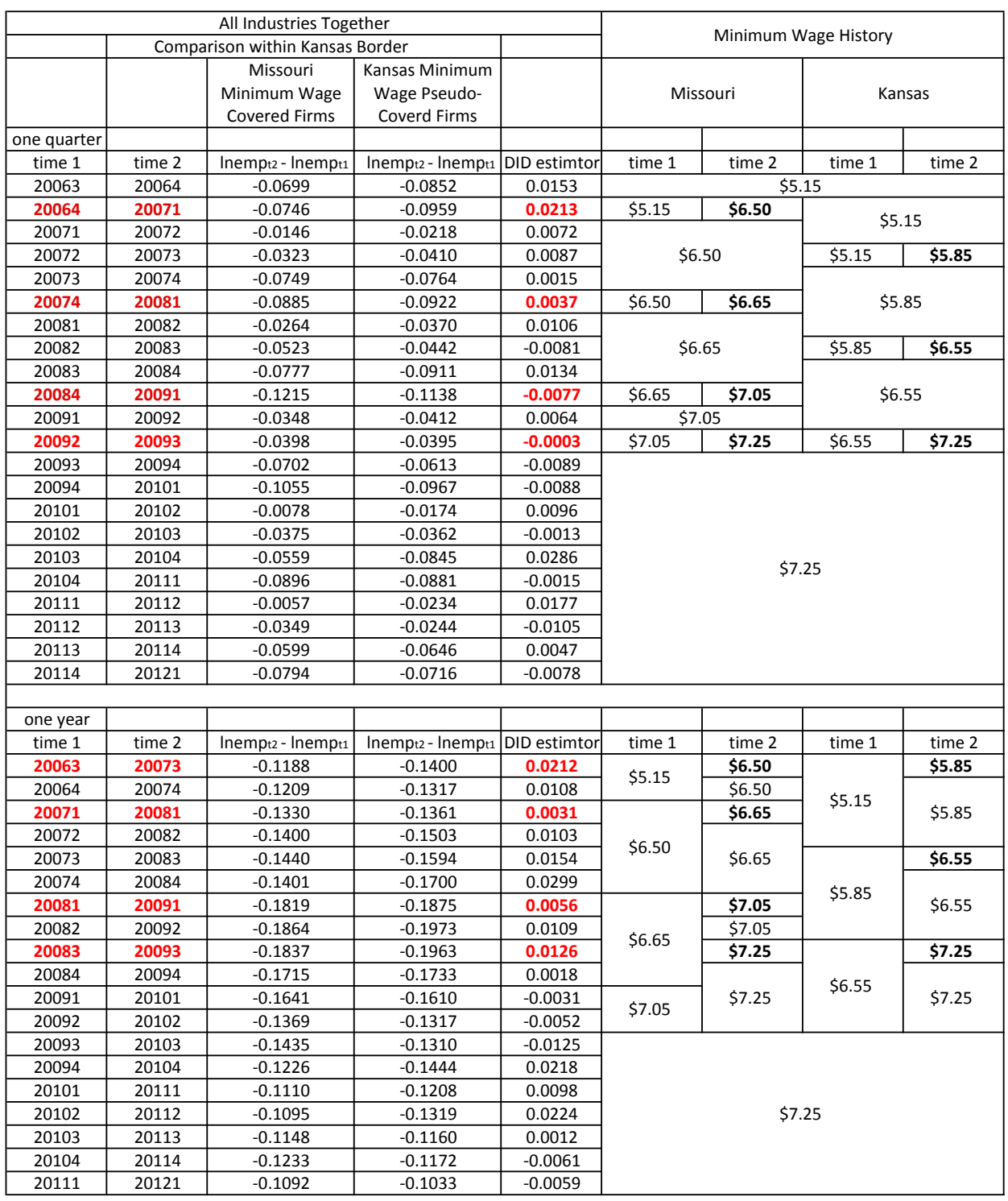

Table H.1: Single Wave DID Estimations for the Entire Panel Sample with $\$ 400,000$ as the Threshold 


\begin{tabular}{|c|c|c|c|c|c|c|c|c|}
\hline \multicolumn{5}{|c|}{ Food and Accomodation, NAICS:72, 1 - 50 Employees } & \multirow{2}{*}{\multicolumn{4}{|c|}{ Minimum Wage History }} \\
\hline & & & & & & \\
\hline & & $\begin{array}{c}\text { Missouri } \\
\text { Minimum Wage } \\
\text { Covered Firms }\end{array}$ & $\begin{array}{l}\text { Kansas Minimum } \\
\text { Wage Pseudo- } \\
\text { Coverd Firms }\end{array}$ & & \multicolumn{2}{|c|}{ Missouri } & \multicolumn{2}{|c|}{ Kansas } \\
\hline time 1 & time 2 & Inempt2 - Inempt1 & Inempt 2 - Inempt 1 & DID estimtor & time 1 & time 2 & time 1 & time 2 \\
\hline 20063 & 20064 & -0.1144 & -0.1100 & -0.0044 & \multicolumn{4}{|c|}{$\$ 5.15$} \\
\hline 20064 & 20071 & -0.1121 & -0.0967 & -0.0154 & $\$ 5.15$ & $\$ 6.50$ & \multirow{2}{*}{\multicolumn{2}{|c|}{$\$ 5.15$}} \\
\hline 20071 & 20072 & -0.0707 & -0.1155 & 0.0448 & \multirow{3}{*}{\multicolumn{2}{|c|}{$\$ 6.50$}} & & \\
\hline 20072 & 20073 & -0.0854 & -0.0889 & 0.0035 & & & $\$ 5.15$ & $\$ 5.85$ \\
\hline 20073 & 20074 & -0.1252 & -0.1653 & 0.0401 & & & \multirow{3}{*}{\multicolumn{2}{|c|}{$\$ 5.85$}} \\
\hline 20074 & 20081 & -0.1068 & -0.2105 & 0.1037 & $\$ 6.50$ & $\$ 6.65$ & & \\
\hline 20081 & 20082 & -0.0596 & -0.0980 & 0.0384 & \multirow{3}{*}{\multicolumn{2}{|c|}{$\$ 6.65$}} & & \\
\hline 20082 & 20083 & -0.1189 & -0.0877 & -0.0312 & & & $\$ 5.85$ & $\$ 6.55$ \\
\hline 20083 & 20084 & -0.1363 & -0.1740 & 0.0377 & & & \multirow{3}{*}{\multicolumn{2}{|c|}{$\$ 6.55$}} \\
\hline 20084 & 20091 & -0.1444 & -0.1570 & 0.0126 & $\$ 6.65$ & $\$ 7.05$ & & \\
\hline 20091 & 20092 & -0.0527 & -0.0754 & 0.0227 & \multicolumn{2}{|c|}{$\$ 7.05$} & & \\
\hline 20092 & 20093 & -0.0639 & -0.0660 & 0.0021 & $\$ 7.05$ & $\$ 7.25$ & $\$ 6.55$ & $\$ 7.25$ \\
\hline 20093 & 20094 & -0.1369 & -0.1425 & 0.0056 & \multirow{10}{*}{\multicolumn{4}{|c|}{$\$ 7.25$}} \\
\hline 20094 & 20101 & -0.1162 & -0.1312 & 0.0150 & & & & \\
\hline 20101 & 20102 & -0.0582 & -0.0585 & 0.0003 & & & & \\
\hline 20102 & 20103 & -0.0766 & -0.0693 & -0.0073 & & & & \\
\hline 20103 & 20104 & -0.1026 & -0.1295 & 0.0269 & & & & \\
\hline 20104 & 20111 & -0.1214 & -0.0809 & -0.0405 & & & & \\
\hline 20111 & 20112 & -0.0844 & -0.0609 & -0.0235 & & & & \\
\hline 20112 & 20113 & -0.0241 & -0.0869 & 0.0628 & & & & \\
\hline 20113 & 20114 & -0.1203 & -0.1331 & 0.0128 & & & & \\
\hline 20114 & 20121 & -0.1128 & -0.0763 & -0.0365 & & & & \\
\hline \multicolumn{9}{|l|}{ one year } \\
\hline time 1 & time 2 & Inempt 2 - Inemp $p_{11}$ & Inemp $p_{\mathrm{t} 2}-$ Inemp $\mathrm{t}_{\mathrm{t}}$ & DID estimtor & time 1 & time 2 & time 1 & time 2 \\
\hline 20063 & 20073 & -0.2115 & -0.1519 & -0.0596 & \multirow{2}{*}{$\$ 5.15$} & $\$ 6.50$ & \multirow{4}{*}{$\$ 5.15$} & $\$ 5.85$ \\
\hline 20064 & 20074 & -0.2117 & -0.2142 & 0.0025 & & $\$ 6.50$ & & \\
\hline 20071 & 20081 & -0.1762 & -0.3096 & 0.1334 & \multirow{4}{*}{$\$ 6.50$} & $\$ 6.65$ & & $\$ 5.85$ \\
\hline 20072 & 20082 & -0.1650 & -0.2815 & 0.1165 & & \multirow{3}{*}{$\$ 6.65$} & & \\
\hline 20073 & 20083 & -0.1949 & -0.2673 & 0.0724 & & & \multirow{4}{*}{$\$ 5.85$} & $\$ 6.55$ \\
\hline 20074 & 20084 & -0.2018 & -0.2884 & 0.0866 & & & & \\
\hline 20081 & 20091 & -0.2563 & -0.2685 & 0.0122 & \multirow{4}{*}{$\$ 6.65$} & $\$ 7.05$ & & $\$ 6.55$ \\
\hline 20082 & 20092 & -0.2756 & -0.2396 & -0.0360 & & $\$ 7.05$ & & \\
\hline 20083 & 20093 & -0.2537 & -0.2610 & 0.0073 & & $\$ 7.25$ & \multirow{4}{*}{$\$ 6.55$} & $\$ 7.25$ \\
\hline 20084 & 20094 & -0.2218 & -0.2453 & 0.0235 & & & & \\
\hline 20091 & 20101 & -0.2040 & -0.2154 & 0.0114 & & $\$ 7.25$ & & $\$ 7.25$ \\
\hline 20092 & 20102 & -0.2120 & -0.2219 & 0.0099 & $\$ 7.05$ & & & \\
\hline 20093 & 20103 & -0.2425 & -0.2053 & -0.0372 & & & & \\
\hline 20094 & 20104 & -0.2062 & -0.2199 & 0.0137 & & & & \\
\hline 20101 & 20111 & -0.1772 & -0.1971 & 0.0199 & & & & \\
\hline 20102 & 20112 & -0.1835 & -0.2130 & 0.0295 & & & & \\
\hline 20103 & 20113 & -0.1889 & -0.1997 & 0.0108 & & & & \\
\hline 20104 & 20114 & -0.2164 & -0.1553 & -0.0611 & & & & \\
\hline 20111 & 20121 & -0.2211 & -0.1588 & -0.0623 & & & & \\
\hline
\end{tabular}

Table H.2: Single Wave DID Estimations for the Food and Accomodation Industry with 1 to 50 Employees and with $\$ 400,000$ as the Threshold 


\begin{tabular}{|c|c|c|c|c|c|c|c|c|}
\hline \multicolumn{5}{|c|}{ Retail Trade, NAICS: 44 - 45, 1 - 50 Employees } & \multirow{2}{*}{\multicolumn{4}{|c|}{ Minimum Wage History }} \\
\hline & \multicolumn{3}{|c|}{ Comparison within Kansas Border } & & & & & \\
\hline & & $\begin{array}{c}\text { Missouri } \\
\text { Minimum Wage } \\
\text { Covered Firms }\end{array}$ & $\begin{array}{l}\text { Kansas Minimum } \\
\text { Wage Pseudo- } \\
\text { Coverd Firms }\end{array}$ & & \multicolumn{2}{|c|}{ Missouri } & \multicolumn{2}{|c|}{ Kansas } \\
\hline time 1 & time 2 & Inempt2 - Inempt 1 & Inempt2 - Inemp $p_{1}$ & DID estimtor & time 1 & time 2 & time 1 & time 2 \\
\hline 20063 & 20064 & -0.0525 & -0.0763 & 0.0238 & \multicolumn{4}{|c|}{$\$ 5.15$} \\
\hline 20064 & 20071 & -0.0586 & -0.0837 & 0.0251 & $\$ 5.15$ & $\$ 6.50$ & \multirow{2}{*}{\multicolumn{2}{|c|}{$\$ 5.15$}} \\
\hline 20071 & 20072 & -0.0185 & -0.0612 & 0.0427 & \multirow{3}{*}{\multicolumn{2}{|c|}{$\$ 6.50$}} & & \\
\hline 20072 & 20073 & -0.0286 & -0.0383 & 0.0097 & & & $\$ 5.15$ & $\$ 5.85$ \\
\hline 20073 & 20074 & -0.0704 & -0.0837 & 0.0133 & & & \multirow{3}{*}{\multicolumn{2}{|c|}{$\$ 5.85$}} \\
\hline 20074 & 20081 & -0.0688 & -0.1082 & 0.0394 & $\$ 6.50$ & $\$ 6.65$ & & \\
\hline 20081 & 20082 & -0.0510 & -0.0485 & -0.0025 & \multirow{3}{*}{\multicolumn{2}{|c|}{$\$ 6.65$}} & & \\
\hline 20082 & 20083 & -0.0554 & -0.0371 & -0.0183 & & & $\$ 5.85$ & $\$ 6.55$ \\
\hline 20083 & 20084 & -0.0827 & -0.0816 & -0.0011 & & & \multirow{3}{*}{\multicolumn{2}{|c|}{$\$ 6.55$}} \\
\hline 20084 & 20091 & -0.1303 & -0.1216 & -0.0087 & $\$ 6.65$ & $\$ 7.05$ & & \\
\hline 20091 & 20092 & -0.0089 & -0.0300 & 0.0211 & \multicolumn{2}{|c|}{$\$ 7.05$} & & \\
\hline 20092 & 20093 & -0.0497 & -0.0296 & -0.0201 & $\$ 7.05$ & $\$ 7.25$ & $\$ 6.55$ & $\$ 7.25$ \\
\hline 20093 & 20094 & -0.0446 & -0.0437 & -0.0009 & \multirow{10}{*}{\multicolumn{4}{|c|}{$\$ 7.25$}} \\
\hline 20094 & 20101 & -0.1006 & -0.0948 & -0.0058 & & & & \\
\hline 20101 & 20102 & 0.0058 & -0.0269 & 0.0327 & & & & \\
\hline 20102 & 20103 & -0.0229 & -0.0421 & 0.0192 & & & & \\
\hline 20103 & 20104 & -0.0490 & -0.0744 & 0.0254 & & & & \\
\hline 20104 & 20111 & -0.0761 & -0.1018 & 0.0257 & & & & \\
\hline 20111 & 20112 & -0.0117 & -0.0255 & 0.0138 & & & & \\
\hline 20112 & 20113 & -0.0331 & -0.0282 & -0.0049 & & & & \\
\hline 20113 & 20114 & -0.0766 & -0.0479 & -0.0287 & & & & \\
\hline 20114 & 20121 & -0.0528 & -0.0611 & 0.0083 & & & & \\
\hline \multicolumn{9}{|l|}{ one year } \\
\hline time 1 & time 2 & Inempt2- Inempt 1 & Inempt2 - Inempt 1 & DID estimtor & time 1 & time 2 & time 1 & time 2 \\
\hline 20063 & 20073 & -0.1001 & -0.1466 & 0.0465 & \multirow{2}{*}{$\$ 5.15$} & $\$ 6.50$ & \multirow{4}{*}{$\$ 5.15$} & $\$ 5.85$ \\
\hline 20064 & 20074 & -0.1043 & -0.1259 & 0.0216 & & $\$ 6.50$ & & \\
\hline 20071 & 20081 & -0.1257 & -0.1299 & 0.0042 & \multirow{4}{*}{$\$ 6.50$} & $\$ 6.65$ & & $\$ 5.85$ \\
\hline 20072 & 20082 & -0.1548 & -0.1379 & -0.0169 & & \multirow{3}{*}{$\$ 6.65$} & & \\
\hline 20073 & 20083 & -0.1691 & -0.1411 & -0.0280 & & & \multirow{4}{*}{$\$ 5.85$} & $\$ 6.55$ \\
\hline 20074 & 20084 & -0.1713 & -0.1616 & -0.0097 & & & & \\
\hline 20081 & 20091 & -0.2388 & -0.2007 & -0.0381 & \multirow{4}{*}{$\$ 6.65$} & $\$ 7.05$ & & $\$ 6.55$ \\
\hline 20082 & 20092 & -0.2081 & -0.1965 & -0.0116 & & $\$ 7.05$ & & \\
\hline 20083 & 20093 & -0.2139 & -0.1908 & -0.0231 & & $\$ 7.25$ & \multirow{4}{*}{$\$ 6.55$} & $\$ 7.25$ \\
\hline 20084 & 20094 & -0.1828 & -0.1613 & -0.0215 & & & & \\
\hline 20091 & 20101 & -0.1297 & -0.1309 & 0.0012 & 5705 & $\$ 7.25$ & & $\$ 7.25$ \\
\hline 20092 & 20102 & -0.1177 & -0.1123 & -0.0054 & $\$ 1.05$ & & & \\
\hline 20093 & 20103 & -0.1065 & -0.1461 & 0.0396 & & & & \\
\hline 20094 & 20104 & -0.1136 & -0.1510 & 0.0374 & & & & \\
\hline 20101 & 20111 & -0.1021 & -0.1209 & 0.0188 & & & & \\
\hline 20102 & 20112 & -0.1082 & -0.1337 & 0.0255 & & & & \\
\hline 20103 & 20113 & -0.1200 & -0.1241 & 0.0041 & & & & \\
\hline 20104 & 20114 & -0.1310 & -0.1286 & -0.0024 & & & & \\
\hline 20111 & 20121 & -0.1055 & -0.0834 & -0.0221 & & & & \\
\hline
\end{tabular}

Table H.3: Single Wave DID Estimations for the Retail Trade Industry with 1 to 50 Employees with $\$ 400,000$ as the Threshold 


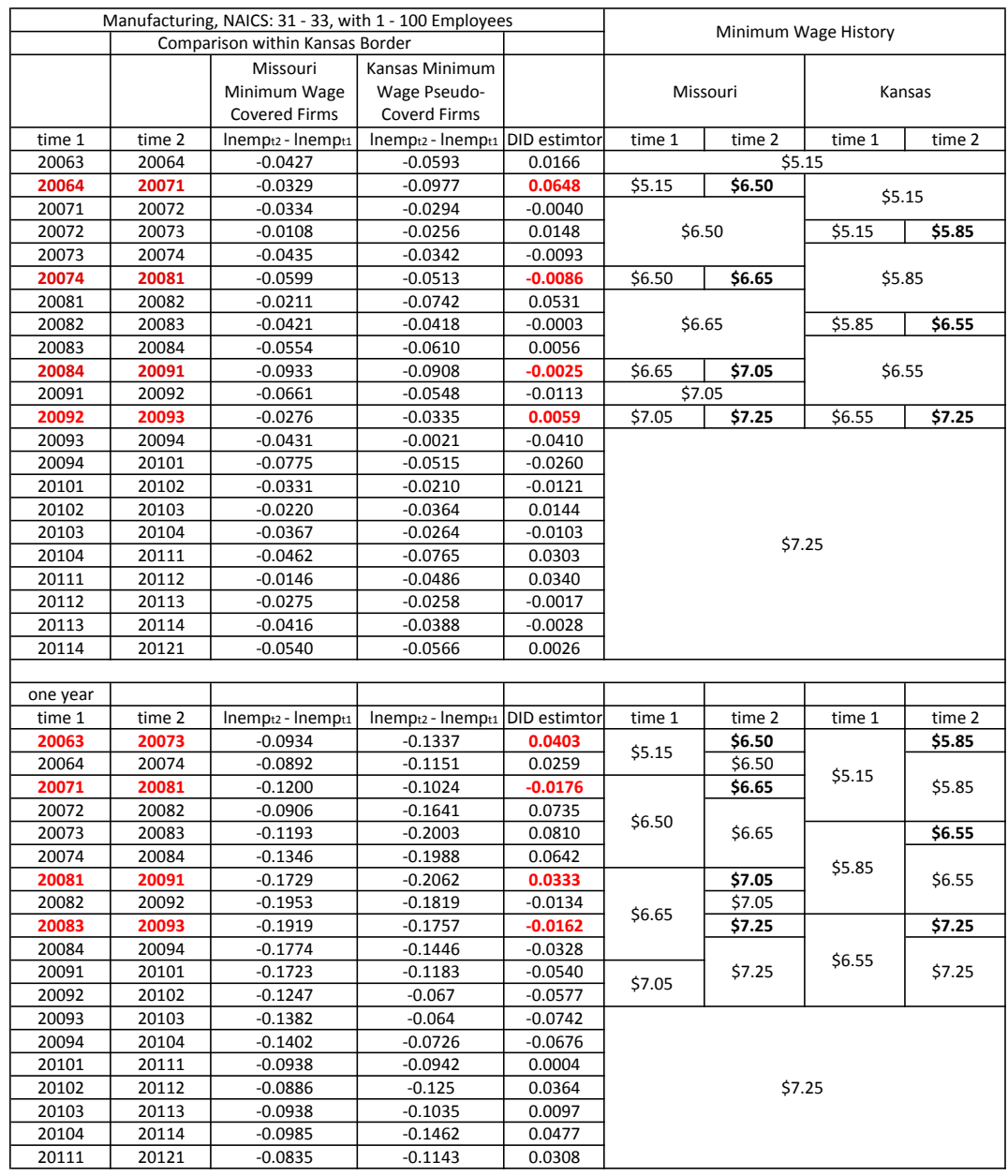

Table H.4: Single Wave DID Estimations for the Manufactoring Industry with 1 to 100 Employees with $\$ 400,000$ as the Threshold 


\begin{tabular}{|c|c|c|c|c|c|c|c|c|}
\hline \multicolumn{5}{|c|}{ Selective Industies Combined } & \multirow{2}{*}{\multicolumn{4}{|c|}{ Minimum Wage History }} \\
\hline & \multicolumn{3}{|c|}{ Comparison within Kansas Border } & & & & & \\
\hline & & $\begin{array}{c}\text { Missouri } \\
\text { Minimum Wage } \\
\text { Covered Firms }\end{array}$ & $\begin{array}{l}\text { Kansas Minimum } \\
\text { Wage Pseudo- } \\
\text { Coverd Firms }\end{array}$ & & \multicolumn{2}{|c|}{ Missouri } & \multicolumn{2}{|c|}{ Kansas } \\
\hline time 1 & time 2 & Inempt2-Inempt1 & Inempt2 - Inemp $\mathrm{t}_{1}$ & DID estimtor & time 1 & time 2 & time 1 & time 2 \\
\hline 20063 & 20064 & -0.0609 & -0.0687 & 0.0078 & \multicolumn{4}{|c|}{$\$ 5.15$} \\
\hline 20064 & 20071 & -0.0679 & -0.0893 & 0.0214 & $\$ 5.15$ & $\$ 6.50$ & \multirow{2}{*}{\multicolumn{2}{|c|}{$\$ 5.15$}} \\
\hline 20071 & 20072 & -0.0029 & -0.0048 & 0.0019 & \multirow{3}{*}{\multicolumn{2}{|c|}{$\$ 6.50$}} & & \\
\hline 20072 & 20073 & -0.0262 & -0.0291 & 0.0029 & & & $\$ 5.15$ & $\$ 5.85$ \\
\hline 20073 & 20074 & -0.0619 & -0.0607 & -0.0012 & & & \multirow{3}{*}{\multicolumn{2}{|c|}{$\$ 5.85$}} \\
\hline 20074 & 20081 & -0.0691 & -0.0557 & -0.0134 & $\$ 6.50$ & $\$ 6.65$ & & \\
\hline 20081 & 20082 & -0.0172 & -0.0243 & 0.0071 & \multirow{3}{*}{\multicolumn{2}{|c|}{$\$ 6.65$}} & & \\
\hline 20082 & 20083 & -0.0353 & -0.0296 & -0.0057 & & & $\$ 5.85$ & $\$ 6.55$ \\
\hline 20083 & 20084 & -0.0575 & -0.0736 & 0.0161 & & & \multirow{3}{*}{\multicolumn{2}{|c|}{$\$ 6.55$}} \\
\hline 20084 & 20091 & -0.0914 & -0.0866 & -0.0048 & $\$ 6.65$ & $\$ 7.05$ & & \\
\hline 20091 & 20092 & -0.0300 & -0.0257 & -0.0043 & \multicolumn{2}{|c|}{$\$ 7.05$} & & \\
\hline 20092 & 20093 & -0.0335 & -0.0313 & -0.0022 & $\$ 7.05$ & $\$ 7.25$ & $\$ 6.55$ & $\$ 7.25$ \\
\hline 20093 & 20094 & -0.0562 & -0.0519 & -0.0043 & \multirow{10}{*}{\multicolumn{4}{|c|}{$\$ 7.25$}} \\
\hline 20094 & 20101 & -0.0842 & -0.0789 & -0.0053 & & & & \\
\hline 20101 & 20102 & -0.0118 & -0.0149 & 0.0031 & & & & \\
\hline 20102 & 20103 & -0.0415 & -0.0257 & -0.0158 & & & & \\
\hline 20103 & 20104 & -0.0432 & -0.0823 & 0.0391 & & & & \\
\hline 20104 & 20111 & -0.0802 & -0.0774 & -0.0028 & & & & \\
\hline 20111 & 20112 & 0.0058 & -0.0052 & 0.0110 & & & & \\
\hline 20112 & 20113 & -0.0440 & -0.0134 & -0.0306 & & & & \\
\hline 20113 & 20114 & -0.0464 & -0.0585 & 0.0121 & & & & \\
\hline 20114 & 20121 & -0.0768 & -0.0680 & -0.0088 & & & & \\
\hline \multicolumn{9}{|l|}{ one year } \\
\hline time 1 & time 2 & Inempt2- Inempt 1 & Inempt2 - Inempt 1 & DID estimtor & time 1 & time 2 & time 1 & time 2 \\
\hline 20063 & 20073 & -0.0945 & -0.1192 & 0.0247 & \multirow{2}{*}{$\$ 5.15$} & $\$ 6.50$ & \multirow{4}{*}{$\$ 5.15$} & $\$ 5.85$ \\
\hline 20064 & 20074 & -0.0906 & -0.1168 & 0.0262 & & $\$ 6.50$ & & \\
\hline 20071 & 20081 & -0.0941 & -0.0942 & 0.0001 & \multirow{4}{*}{$\$ 6.50$} & $\$ 6.65$ & & $\$ 5.85$ \\
\hline 20072 & 20082 & -0.1060 & -0.1040 & -0.0020 & & \multirow{3}{*}{$\$ 6.65$} & & \\
\hline 20073 & 20083 & -0.0986 & -0.1098 & 0.0112 & & & \multirow{4}{*}{$\$ 5.85$} & $\$ 6.55$ \\
\hline 20074 & 20084 & -0.0867 & -0.1157 & 0.0290 & & & & \\
\hline 20081 & 20091 & -0.1218 & -0.1470 & 0.0252 & \multirow{4}{*}{$\$ 6.65$} & $\$ 7.05$ & & $\$ 6.55$ \\
\hline 20082 & 20092 & -0.1303 & -0.1540 & 0.0237 & & $\$ 7.05$ & & \\
\hline 20083 & 20093 & -0.1323 & -0.1568 & 0.0245 & & $\$ 7.25$ & \multirow{4}{*}{$\$ 6.55$} & $\$ 7.25$ \\
\hline 20084 & 20094 & -0.1303 & -0.1385 & 0.0082 & & & & \\
\hline 20091 & 20101 & -0.1359 & -0.1348 & -0.0011 & 5705 & $\$ 7.25$ & & $\$ 7.25$ \\
\hline 20092 & 20102 & -0.1240 & -0.1211 & -0.0029 & $\$ 1.05$ & & & \\
\hline 20093 & 20103 & -0.1355 & -0.1134 & -0.0221 & & & & \\
\hline 20094 & 20104 & -0.1050 & -0.1359 & 0.0309 & & & & \\
\hline 20101 & 20111 & -0.1060 & -0.1108 & 0.0048 & & & & \\
\hline 20102 & 20112 & -0.0932 & -0.1074 & 0.0142 & & & & \\
\hline 20103 & 20113 & -0.0991 & -0.0925 & -0.0066 & & & & \\
\hline 20104 & 20114 & -0.1128 & -0.0993 & -0.0135 & & & & \\
\hline 20111 & 20121 & -0.1040 & -0.0941 & -0.0099 & & & & \\
\hline
\end{tabular}

Table H.5: Single Wave DID Estimations for the "Selected Industies Combined" category (Finance, Information and Other Service) with $\$ 400,000$ as the Threshold 


\section{Appendix I}

\section{Procedures to Construct}

\section{Multi-Period and Multi-Group Firm-Level Panel Data}

In general, the procedures are similar to the steps described in Appendix G, since both analysis are performed at the firm level.

\section{I.1 Missouri Part}

1. Estimate annual revenue for each firm.

2. Add dummies .

3. Find the firms that existed before 2007 Q4 for both states, and the entire analysis is limited to these firms only.

4. Calculate each firm's total employment by counting number of employees in the firm.

5. Select data: in border counties; in construction industry or covered by Missouri minimum wage.

6. Further subset based on the relevant industries and firm sizes. 
6. Separate firms into four groups: For firms that exist at the beginning of quarter 2006 Q3, they are divided into three groups based on their initial firm sizes in this quarter. The first group includes firms with 1 - 10 employees. The next group includes firms with 11 - 20 employees. The third group includes firms with more than 20 employees. The firms that did not exist at the 2006Q3 form the last group.

7. Add Missouri minimum wage and Missouri county unemployment rates

\section{I.2 Kansas Part}

Other than above steps,

1. Convert SIC to NAICS based on official crosswalk and revisions

2. Excluding multiple location firms from the analysis

\section{I.3 Final Data Set}

The final multi-period and multi-group panel data is constructed by combining Missouri and Kansas parts and create a variable to cluster the observations within state and every quarter. 
Appendix J

\section{Regression Results When D4 Group is Omitted}


Estimation Results

\begin{tabular}{|c|c|c|c|c|c|}
\hline \multirow[t]{2}{*}{ Variables and Controls } & \multicolumn{5}{|c|}{ Missouri and Kansas Border Firms } \\
\hline & $(1)$ & $(2)$ & (3) & (4) & (5) \\
\hline \multirow[t]{2}{*}{$\mathrm{D} 1 * \operatorname{lnmw}$} & -0.378 & 0.147 & 0.169 & -0.181 & 0.578 \\
\hline & $(0.043)$ & $(0.055)$ & $(0.055)$ & $(0.038)$ & $(0.075)$ \\
\hline \multirow[t]{2}{*}{$\mathrm{D} 2 * \operatorname{lnmw}$} & -0.731 & -0.194 & -0.279 & -0.528 & 0.144 \\
\hline & $(0.071)$ & $(0.035)$ & $(0.039)$ & $(0.064)$ & $(0.050)$ \\
\hline \multirow[t]{2}{*}{$\mathrm{D} 3 * \operatorname{lnmw}$} & -0.810 & -0.272 & -0.384 & -0.607 & 0.033 \\
\hline & $(0.072)$ & $(0.045)$ & $(0.049)$ & $(0.068)$ & $(0.054)$ \\
\hline \multirow{2}{*}{ overall minimum wage effects } & -0.687 & -0.153 & -0.226 & -0.486 & 0.046 \\
\hline & $(0.004)$ & $(0.004)$ & $(0.004)$ & $(0.004)$ & $(0.004)$ \\
\hline \multicolumn{6}{|l|}{ controls } \\
\hline firm & yes & yes & yes & yes & yes \\
\hline firm size & yes & yes & yes & yes & yes \\
\hline time & no & yes & yes & no & yes \\
\hline time*industry & no & no & yes & no & no \\
\hline \multirow[t]{2}{*}{ county unemployment } & no & no & no & -0.019 & no \\
\hline & & & & $(0.0001)$ & \\
\hline industry-Inmw interaction & no & no & no & no & yes \\
\hline \multirow[t]{2}{*}{ ind1*Inmw } & - & - & - & - & -0.765 \\
\hline & - & - & - & - & $(0.047)$ \\
\hline \multirow[t]{2}{*}{ ind $2 * \operatorname{lnm} w$} & - & - & - & - & -0.411 \\
\hline & - & - & - & - & $(0.035)$ \\
\hline \multirow[t]{2}{*}{ ind $3 * \operatorname{lnmw}$} & - & - & - & - & -0.384 \\
\hline & - & - & - & - & $(0.035)$ \\
\hline \multirow[t]{2}{*}{ ind $4 * \operatorname{lnmw}$} & - & - & - & - & -0.190 \\
\hline & - & - & - & - & $(0.033)$ \\
\hline
\end{tabular}

Description

\begin{tabular}{|c|c|c|c|c|}
\hline & observation & $\begin{array}{c}\text { total } \\
\text { employment }\end{array}$ & $\begin{array}{c}\text { average } \\
\text { employment }\end{array}$ & $\begin{array}{l}\text { perentage } \\
\text { rate of } \\
\text { employment }\end{array}$ \\
\hline D1: small size firms group & 164,519 & 871,951 & 5.3 & $24.18 \%$ \\
\hline D2: medium size firms group & 59,413 & 825,841 & 13.9 & $22.91 \%$ \\
\hline D3: largel size firms group & 58,697 & $1,907,653$ & 32.5 & $52.91 \%$ \\
\hline total & 282,629 & $3,605,444$ & - & $100.00 \%$ \\
\hline
\end{tabular}

Table J.1: Estimation Results for Missouri and Kansas Border Firms When D4 Group is Omitted 


\section{Retail Trade}

Missouri and Kansas Border Firms in Retail Trade with 1 - 50 Employees

\begin{tabular}{|c|c|c|c|}
\hline & $(1)$ & $(2)$ & $(3)$ \\
\hline & $-\mathbf{0 . 2 9 4}$ & $\mathbf{0 . 2 5 7}$ & $-\mathbf{0 . 0 8 8}$ \\
\hline D1*Inmw & $(0.040)$ & $(0.060)$ & $(0.032)$ \\
\hline & $-\mathbf{0 . 6 9 5}$ & $-\mathbf{0 . 1 3 7}$ & $-\mathbf{0 . 4 8 5}$ \\
\hline & $(0.072)$ & $(0.048)$ & $(0.066)$ \\
\hline D2*Inmw & $-\mathbf{0 . 9 7 4}$ & $-\mathbf{0 . 4 2 7}$ & -0.771 \\
\hline & $(0.079)$ & $(0.049)$ & $(0.070)$ \\
\hline D3*Inmw & $-\mathbf{0 . 6 9 0}$ & $-\mathbf{0 . 1 3 8}$ & $-\mathbf{0 . 4 8 4}$ \\
\hline & $(0.005)$ & $(0.005)$ & $(0.005)$ \\
\hline & & & \\
\hline overall minimum wage effect & yes & yes & yes \\
\hline controls & yes & yes & yes \\
\hline firm & no & yes & no \\
\hline firm size & no & no & $-\mathbf{0 . 0 1 9}$ \\
\hline county unemployment & & & $(0.002)$ \\
\hline
\end{tabular}

\begin{tabular}{|c|c|c|c|c|}
\hline & observation & $\begin{array}{c}\text { total } \\
\text { employment }\end{array}$ & $\begin{array}{c}\text { average } \\
\text { employment }\end{array}$ & $\begin{array}{l}\text { perentage } \\
\text { rate of } \\
\text { employment }\end{array}$ \\
\hline D1: small size firms group & 24,545 & 139,907 & 5.7 & $30.35 \%$ \\
\hline D2: medium size firms group & 9,698 & 128,983 & 13.3 & $27.98 \%$ \\
\hline D3: large size firms group & 6,937 & 192,155 & 27.7 & $41.68 \%$ \\
\hline total & 41,180 & 461,045 & - & $100.00 \%$ \\
\hline
\end{tabular}

Table J.2: Estimation Results for the Retail Trade Industry When D4 Group is Omitted 
Food and Accomodation

Missouri and Kansas Border Firms in Food and Accomodation with 1 - 50 Employees

\begin{tabular}{|c|c|c|c|}
\hline & $(1)$ & $(2)$ & $(3)$ \\
\hline & 0.020 & $\mathbf{0 . 4 7 6}$ & $\mathbf{0 . 2 0 3}$ \\
\hline D1*Inmw & $(0.100)$ & $(0.129)$ & $(0.097)$ \\
\hline & -0.182 & $\mathbf{0 . 2 5 4}$ & 0.002 \\
\hline D2*Inmw & $(0.059)$ & $(0.065)$ & $(0.077)$ \\
\hline & -0.549 & -0.104 & -0.365 \\
\hline D3*Inmw & $(0.074)$ & $(0.048)$ & $(0.080)$ \\
\hline & -0.473 & -0.029 & -0.289 \\
\hline overall minimum wage effect & $(0.006)$ & $(0.006)$ & $(0.006)$ \\
\hline & & & \\
\hline controls & yes & yes & yes \\
\hline firm & yes & yes & yes \\
\hline firm size & no & yes & no \\
\hline time & no & no & -0.018 \\
\hline county unemployment & & & $(0.004)$ \\
\hline
\end{tabular}

panel b:

\begin{tabular}{|c|c|c|c|c|}
\hline & observation & $\begin{array}{c}\text { total } \\
\text { employment }\end{array}$ & $\begin{array}{c}\text { average } \\
\text { employment }\end{array}$ & $\begin{array}{l}\text { perentage } \\
\text { rate of } \\
\text { employment }\end{array}$ \\
\hline D1: small size firms group & 1,163 & 13,375 & 11.5 & $4.10 \%$ \\
\hline D2: medium size firms group & 2,821 & 46,829 & 16.6 & $14.35 \%$ \\
\hline D3: large size firms group & 8,477 & 266,178 & 31.4 & $81.55 \%$ \\
\hline total & 12,461 & 326,381 & - & $55.08 \%$ \\
\hline
\end{tabular}

Table J.3: Estimation Results for the Food and Accomodation Industry When D4 Group is Omitted 


\section{Construction}

Missouri and Kansas Border Firms in Construction with 1 - 50 Employees

\begin{tabular}{|c|c|c|c|}
\hline & $(1)$ & $(2)$ & $(3)$ \\
\hline & -0.686 & 0.190 & -0.343 \\
\hline$D^{*} \operatorname{lnmw}$ & $(0.077)$ & $(0.064)$ & $(0.068)$ \\
\hline $\mathrm{D}^{*} \operatorname{lnmw}$ & -1.525 & -0.616 & -1.167 \\
\hline & $(0.139)$ & $(0.049)$ & $(0.124)$ \\
\hline $\mathrm{D}^{*} \operatorname{lnmw}$ & -1.542 & $-\mathbf{0 . 6 2 4}$ & $-\mathbf{1 . 1 8 2}$ \\
\hline & $(0.128)$ & $(0.079)$ & $(0.122)$ \\
\hline overall minimum wage effect & -1.227 & -0.326 & -0.873 \\
\hline & $(0.004)$ & $(0.004)$ & $(0.004)$ \\
\hline controls & & & \\
\hline firm & yes & yes & yes \\
\hline firm size & yes & yes & yes \\
\hline time & no & yes & no \\
\hline county unemployment & no & no & -0.033 \\
\hline & & & $(0.005)$ \\
\hline
\end{tabular}

\begin{tabular}{|c|c|c|c|c|}
\hline & observation & $\begin{array}{c}\text { total } \\
\text { employment }\end{array}$ & $\begin{array}{c}\text { average } \\
\text { employment }\end{array}$ & $\begin{array}{l}\text { perentage } \\
\text { rate of } \\
\text { employment }\end{array}$ \\
\hline D1: small size firms group & 55,532 & 216,575 & 3.9 & $36.34 \%$ \\
\hline D2: medium size firms group & 11,699 & 143,898 & 12.3 & $24.15 \%$ \\
\hline D3: large size firms group & 9,455 & 235,430 & 24.9 & $39.51 \%$ \\
\hline total & 76,686 & 595,902 & - & $100.00 \%$ \\
\hline
\end{tabular}

Table J.4: Estimation Results for the Construction Industry When D4 Group is Omitted 


\section{Manufacturing}

Missouri and Kansas Border Firms in Manufacturing with 1 - 100 Employees

\begin{tabular}{|c|c|c|c|}
\hline & (1) & (2) & (3) \\
\hline \multirow[t]{2}{*}{$\mathrm{D} 1 * \operatorname{lnmw}$} & -0.426 & 0.342 & -0.119 \\
\hline & $(0.052)$ & $(0.061)$ & $(0.048)$ \\
\hline \multirow[t]{2}{*}{ D2*Inmw } & -0.722 & 0.069 & -0.401 \\
\hline & $(0.083)$ & $(0.051)$ & $(0.067)$ \\
\hline \multirow[t]{2}{*}{ D3*Inmw } & -0.890 & -0.105 & -0.579 \\
\hline & $(0.083)$ & $(0.058)$ & $(0.078)$ \\
\hline \multirow[t]{2}{*}{ overall minimum wage effect } & -0.806 & -0.023 & -0.494 \\
\hline & $(0.003)$ & $(0.003)$ & $(0.003)$ \\
\hline \multicolumn{4}{|l|}{ controls } \\
\hline firm & yes & yes & yes \\
\hline firm size & yes & yes & yes \\
\hline time & no & yes & no \\
\hline \multirow[t]{2}{*}{ county unemployment } & no & no & -0.030 \\
\hline & & & $(0.003)$ \\
\hline
\end{tabular}

\begin{tabular}{|c|c|c|c|c|}
\hline & observation & $\begin{array}{c}\text { total } \\
\text { employment }\end{array}$ & $\begin{array}{c}\text { average } \\
\text { employment }\end{array}$ & $\begin{array}{l}\text { perentage } \\
\text { rate of } \\
\text { employment }\end{array}$ \\
\hline D1: small size firms group & 11,189 & 62,658 & 5.6 & $12.28 \%$ \\
\hline D2: medium size firms group & 5,808 & 80,731 & 13.9 & $15.83 \%$ \\
\hline D3: large size firms group & 9,146 & 366,755 & 40.1 & $71.89 \%$ \\
\hline total & 26,143 & 510,144 & - & $100.00 \%$ \\
\hline
\end{tabular}

Table J.5: Estimation Results for the Manufacturing Industry When D4 Group is Omitted 
Selected Industries Combined (information and Other Services)

Missouri and Kansas Border Firms in "Selected Industries Combined" Category

\begin{tabular}{|c|c|c|c|}
\hline & $(1)$ & $(2)$ & $(3)$ \\
\hline & -0.132 & 0.046 & -0.064 \\
\hline D1*Inmw & $(0.030)$ & $(0.056)$ & $(0.028)$ \\
\hline & -0.465 & -0.286 & $-\mathbf{0 . 3 9 5}$ \\
\hline & $(0.055)$ & $(0.043)$ & $(0.051)$ \\
\hline D2*Inmw ${ }^{*} \operatorname{lnmw}$ & $-\mathbf{0 . 5 3 4}$ & $-\mathbf{0 . 3 5 3}$ & $-\mathbf{0 . 4 6 4}$ \\
\hline & $(0.056)$ & $(0.046)$ & $(0.054)$ \\
\hline & $-\mathbf{0 . 4 1 4}$ & $-\mathbf{0 . 2 3 4}$ & $-\mathbf{0 . 3 4 4}$ \\
\hline overall minimum wage effect & $(0.005)$ & $(0.005)$ & $(0.005)$ \\
\hline & & & \\
\hline controls & yes & yes & yes \\
\hline firm & yes & yes & yes \\
\hline firm size & no & yes & no \\
\hline time & no & no & $-\mathbf{0 . 0 0 7}$ \\
\hline county unemployment & & & $(0.002)$ \\
\hline
\end{tabular}

\begin{tabular}{|c|c|c|c|c|}
\hline & observation & $\begin{array}{c}\text { total } \\
\text { employment }\end{array}$ & $\begin{array}{c}\text { average } \\
\text { employment }\end{array}$ & $\begin{array}{l}\text { perentage } \\
\text { rate of } \\
\text { employment }\end{array}$ \\
\hline D1: small size firms group & 72,090 & 439,749 & 6.1 & $25.64 \%$ \\
\hline D2: medium size firms group & 29,387 & 426,112 & 14.5 & $24.85 \%$ \\
\hline D3: large size firms group & 24,682 & 849,061 & 34.4 & $49.51 \%$ \\
\hline total & 126,159 & $1,714,921$ & - & $100.00 \%$ \\
\hline
\end{tabular}

Table J.6: Estimation Results for the "Selected Industries Combined" Category When D4 Group is Omitted 


\section{Appendix K}

\section{Procedures to Construct}

\section{Multi-Period and Multi-Group Individual-Level Panel Data}

In order to investigate how minimum wage affects individual employment possibilites, we need to track each individual's employment status in both Missouri and Kansas. First, we limit the individuals to the border area in the beginning quarter 2006 Q3. Then, we find whether they are still being employed and whether they are employed in Missouri or Kansas. Here, for all the following quarters, the employment status is based on the information in the entire Missouri and Kansas data, not limited to border areas as in the previous analysis. The construction steps are described as follows ${ }^{1}$ :

1. 2006Q3 data:

1.1 For Kansas part, we limit the sample to individuals to who are from firms with no multi-locations.

1.2 Divide individuals into different groups based on their hourly wage rate proxied

\footnotetext{
${ }^{1}$ These steps summarize the procedures to contruct the panel data for the analysis in both section 4.6 and 4.7 .
} 
by quarterly earnings.

First, we estimate hourly wage rate for each individual. On average, people work 43 hours per week. So the hourly wage rate is estimated as total quarterly earning divided by 516 hours.

Then, we can divide people into different groups:

A. people with hourly wage rate greater than $\$ 15$.

B. individual's hourly wage rate is from $\$ 7.25$ to $\$ 15$.

C. individual's hourly wage rate is from $\$ 4.55$ to $\$ 7.25$.

D. individual's hourly wage rate is from $\$ 1.65$ to $\$ 4.55$.

E. people with hourly wage rate $\$ 1.65$.

1.3 It is common that one people have multiple jobs. If an individual has multiple jobs in different industries or firms, his industry is determined by the firm where he earned the highest earning.

\subsection{Select relevant industries}

1.5 Exclude individuals with jobs in both Missouri and Kansas in 2006Q32 ${ }^{2}$.

1.6 Find all the distinct SSN in the above data set

2. Track the above individuals' employment status in all the following quarters in both Missouri and Kansas. By doing so, we can get 22 records with variables: ssn, employment status in Missouri, employment status in Kansas. Then, all the records are appended with 2006Q3 data from step 1

3. Create $23^{*} 2$ dummies based on state ${ }^{*}$ quarters. Coded 1 if an individual is employed in the corresponding quarter and in the corresponding state, zero otherwise.

4. Merge the group dummies we get from step 1.2 into the data.

5. Merge the employment status dummies to form the dependent varibles. For the analysis in section 4.6, the dependent variable is the employment status, which equals one if an individual is being employed, no matter where the job location is.

\footnotetext{
${ }^{2}$ However, if an individual has jobs in both states in any following quarters, he is treated as being employed in that quarter. This rule only applies to the beginning quarter 2006 Q3.
} 
For the analysis in section 4.7 , the dependent variables are the employment status in either Missouri or Kansas.

6. Add a cluster variable to cluster the data by state and year-quarter.

7. Add quarterly minimum wage into the data. To be specific, if an individual is employed in Missouri in 2006Q3, he is assigned the Missouri minimum wages for all the records. Otherwise, he is assigned federal minimum wages.

8. Add minimum wage and hourly wage group interaction terms 


\section{Bibliography}

Aaronson, Daniel, Eric French, and James MacDonald, "The Minimum Wage, Restaurant Prices, and Labor Market Structure," Federal Reserve Bank of Chicago Working Paper, 2007.

Addison, John T., Mckinley L. Blackburn, and Chad D. Cot, "The Effect of Minimum Wages on labour Market Outcomes: County-Level Estimates from the Restaurant-and-Bar Sector," British Journal of Industrial Relation, September 2012, $50(3), 412-435$.

Alatas, Vivi and Lisa Cameron, "The Impact of Minimum Wages on Employment in a Low Income Country: An Evaluation using the Difference-in-Differences Approach," World Bank Policy Research Working Paper, 2003, 2985.

Allegretto, Sylvia A., Arindrajit Dube, and Michael Reich, "Do Minimum Wages Really Reduce Teen Employment? Accounting for Heterogeneity and Selectivity in State Panel Data," Industrial Relations, 2011, 50 (2), 205-240.

Antonova, Stefka, , and Mihnea Tudoreanu, "The Effects of a Raised Minimum Wage on Employment: Differences across States and Social Groups," Issues in Political Economy, 2009, 19, 69-89.

Ashenfelter, Orally C, Henry Farer, and Michael R. Ransom, "Modern Models of Monopsony in Labor Markets: A Brief Survey," Journal of Labor Economics, 2010, 28 (4), 203-210. 
Baker, Michael, Dwayne Benjamin, and Shuchita Stanger, "The High and Lows of the Minimum Wage Effect: A Time Series-Cross Section Study of the Canadian Law," Journal of Labor Economics, 1999, 17, 318-350.

Bazen, Stephen and Julie Le Gallo, "The Differential Impact of Federal and State Minimum Wages on Teenage Employment," working paper, 2009.

Bertrand, Marianne, Esther Duffle, and Sendhil Mullainathan, "How Much Should We Trust Differences-In-Differences Estimates?," The Quarterly Journal of Economics, February 2004.

Brown, Charles, Curtis Gilroy, and Andrew Kohen, "The Effect of the Minimum Wage on Employment and Unemployment," Journal of Economic Literature, 1982, 20, 487-528.

Burdett, Kenneth and Dale T. Mortensen, "Equilibrium Wage Differentials and Employer Size," Northwestern University Working Paper No., 1989, 860 (October).

Burkhauser, Richard V., Kenneth A. Couch, and David C. Wittenburg, "A Reassessment of the New Economics of the Minimum Wage," Journal of Labor Economics, 2000, 18 (4), 653-681.

Campolieti, Michele, Morley Gunderson, and Chris Riddell, "Minimum Wage Impacts from a Prespecified Research Design: Canada 1981-1997," Industrial Relations, April 2006, 45 (2), 195-216.

Card, David and Alan B Krueger, Myth and Measurement: The New Economics of the Minimum Wage, Princeton University Press, 1995.

— and David C. Wittenburg, "Minimum Wages and Employment: A Case Study of the Fast-Food Industry in New Jersey and Pennsylvania: Reply," The American Economic Review, 2000, 90, 1397-1420. 
_, Lawrence Katz, and Alan B. Krueger, "Comment on David Neumark and William Wascher, ?Employment Effects of Minimum and Subminimum Wages: Panel Data on State Minimum Wage Laws'," Industrial and Labor Relations Review, 1994, 48, 487-496.

Cardoso, Ana Rute, "The long-run impact of youth minimum wages on workers' careers," 2011.

Couch, Kenneth A. and David C. Wittenburg, "The Response of Hours of Work to Increases in the Minimum Wage," Southern Economic Journal, 2001, 68 (1), 171-177.

David, Salas J.M. Ian Neumark and William Wascher, "Revisiting the Minimum Wage-Employment Debate: Throwing Out the Baby with the Bathwater?," NBER Working Paper 18681, 2013.

Deere, Donald, Kevin M. Murphy, and Finis Welch, "Reexamining Methods of Estimating Minimum Wage Effects: Employment and the 1990?1991 Minimum Wage Hike," American Economic Association Papers and Proceedings, 1995, 85, 232-237.

Donald, Stephen G. and Kevin Lang, "Inference with difference-in-differences and other panel data," Review of Economics and Statistics, 2007, 89 (2), 221-233.

Dube, Arindrajit, Suresh nidu, and Michael Reich, "The Economic Effects of a Citywide Minimum Wage," Industrial and Labor Relations Review, 2007, 60 (4).

_, T. William Lester, and Michael Reich, "Minimum Wage Effects Across State Borders: Estimates Using Contiguous Counties," The Review of Economics and Statistics, November 2010, 92 (4), 945-964. 
Giuliano, Laura, "Minimum Wage Effects on Employment, Substitution, and the Teenage Labor Supply: Evidence from Personnel Data," Journal of Labor Economics, January 2013, 31 (1), 155-194.

Katz, Lawrence F. and Alan B. Krueger, "The Effect of the Minimum Wage on the Fast Food Industry," Industrial and Labor Relations Review, October 1992, 46 (1), 6-21.

Lee, Wang-Sheng and Sandy Suardi, "Minimum Wages and Employment: Reconsidering the Use of a Time-Series Approach as an Evaluation Tool," British Journal of Industrial Relations, 2011, 49, 375-401.

Macpherson, David A., "The Effects of the Proposed Missouri Minimum Wage Increase," Employment Policies Institute Policy Study, 2006.

Meer, Jonathan and Jeremy West, "Effects of the Minimum Wage on Employment Dynamics," NBER Working Paper No. 19262, 2013.

Mincer, Jacob, "Unemployment Effects of Minimum Wages," The University of Chicago Press, 1976, 84 (4), 87-104.

Neumark, David, "The Economic Effects of Minimum Wages. What Might Missouri Expect From Passage of Proposition B?," Show-Me Institute, Policy Study, 2006, (2).

- and Olena Nizalova, "Minimum Wage Effects in the Longer Run," The Journal of Human Resources, 2007, 42 (2).

_ and William Wascher, "Employment Effects of Minimum Wages and Subminimum Wages: Panel Data on State Minimum Wage Laws," Industrial and Labor Relations Review, 1992, 46, 55-81. 
_ and _ , "Minimum wages and employment: A case study of the fast-food industry in New Jersey and Pennsylvania: Comment," The American Economic Review, 2000, 90, 1362-1396.

_ and _, "Minimum Wages and Employment," Foundations and Trends in Microeconomics, 2007, 3 (1), 1-182.

Orazem, Peter F. and J. Peter Mattila, "Minimum Wage Effects on Hours, Employment and Number of Firms: The Iowa Case," Journal of Labor Research, 2002, $23(1), 3-23$.

Orrenius, Pia M. and Madeline Zavodny, "The Effect of Minimum Wages on Immigrants? Employment and Earnings," Discussion paper, No. 3499., 2008.

Pedace, Roberto and Stephanie Rohn, "The Impact of Minimum Wages on Unemployment Duration: Estimating the Effects Using the Displaced Worker Survey," Industrial Relations, 2011, 50 (1).

Powers, Elizabeth T., "The Impact of Minimum-Wage Increases: Evidence from Fast-food Establishments in Illinois and Indiana," Journal of Labor Research, 2009, 30 (4), 365-394.

Sabia, Joseph J., "The Effects of Minimum Wage Increases on Retail Employment and Hours: New Evidence from Monthly CPS Data," Journal of Labor Research, Mar 2009, 30 (1), 75-97.

Sabia, Joseph J, "Identifying Minimum Wage Effects: New Evidence from Monthly CPS Data," Industrial Relations, 2009, 48 (2).

- and Richard V. Burkhauser, "The Employment and Distributional Effects of Minimum Wage Increases: A Case Study of the State of New York," Employment Policy Institutes, 2008. 
_ and _ , "Minimum Wages and Poverty: Will a $\$ 9.50$ Federal Minimum Wage Really Help the Working Poor?," Southern Economic Journal,, 2010, 76 (3), 592623.

${ }_{-}, \ldots$, and Benjamin Hansen, "Are the Effects of Minimum Wage Increases Always Small? New Evidence from a Case Study of New York State," Industrial and Labor Relations Review, 2012, 65 (2), 350-376.

Schmitt, John, "Why Does the Minimum Wage Have No Discernible Effect on Employment?," Center for Economic and Policy Research reports, Sepetember 2013.

Singell, Larry D. and James R. Terborg, "Employment Effects of Two Northwest Minimum Wage Initiatives," Economic Inquiry, 2007, 45 (1), 40-55.

Stigler, George J, "The Economics of Minimum Wage Legislation," American Economic Review, June 1946, 36, 358-365.

Thompson, Jeffrey P., "Using Local Labor Market Data to Re-examine the Employment Effects of the Minimum Wage," Industrial and Labor Relations Reviews, 2009, 62 (3).

Troske, Kenneth R. and Aaron Yelowitz, "The Impact of Missouri's Proposed \$6.50 Minimum Wage on the Labor Market," Show-Me Institute Policy Study, 2006, 3.

Zavodny, Madeline, "Why Minimum Wage Hikes May Not Reduce Employment," Federal Reserve Bank of Atlanta, Economic Review, 1998, 20, 18-28.

_ , "The Effect of the Minimum Wage on Employment and Hours," Labour Economics, November 2000, 7 (6), 729-750. 


\section{VITA}

Yandi Liu was born on January 13th 1985 in city of Tianjin, China. She graduated with a Bachelor of Finance from Nankai University, Tianjin in 2007. She came to University of Missouri in 2008 for pursuing the Doctor of Philosophy degree in Economics. Since then, she worked as a teaching assistant in Economics department. In 2011, she started the research regarding the minimum wages under the direction of Dr. Peter Mueser. She will graduate in May, 2015. 